\title{
Performance Indicators
}

\author{
Third Quarter CY-1991
}

\section{Lawrence Berkeley Laboratory}

\author{
January 1, 1992
}

\section{DISCLAIMER}

\begin{abstract}
This report was prepared as an account of work sponsored by an agency of the United States Government. Neither the United States Government nor any agency thereof, nor any of their employees, makes any warranty, express or implied, or assumes any legal liability or responsibility for the accuracy, completeness, or usefulness of any information, apparatus, product, or process disclosed, or represents that its use would not infringe privately owned rights. Reference herein to any specific commercial product, process, or service by trade name, trademark, manufacturer, or otherwise does not necessarily constitute or imply its endorsement, recommendation, or favoring by the United States Government or any agency thereof. The views and opinions of authors expressed herein do not necessarily state or reflect those of the United States Government or any agency thereof.
\end{abstract}




\section{CONTENTS}

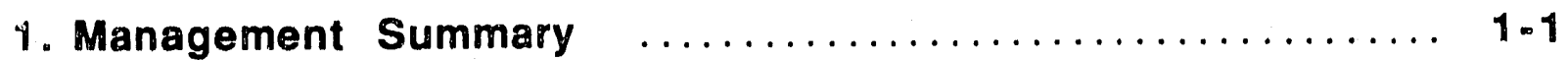

1.1 Overview

1.2 Performance Initiatives

1.3 Good Practices

2. Performance Indicator Summary Charts $\ldots \ldots \ldots \ldots \ldots \ldots \ldots \ldots$ 2-1

\section{Appendices}

A1. Summary by Performance Indicator

A2. Performance Indlcator Charts

1.0 Personnel Safety

PI 1.1 Page 1

2.0 Operational Incidents

PI 2.1 Page 1

3.0 Environmental Releases

(Normal Operations)

PI 3.1 Page 1

4.0 Management

PI 4.1 Paqe 1

A3. Performance Indicator Definitions

A4. Root Cause Narratives 


\section{Management Summarx}

\subsection{Overview}

This Performance Indicator Report represents a compllation of data for the third quarter of calendar year 1991 (i.e., July 1 through Sepiember 30, 1991) for the following Lawrence Berkeley Laboratory (LBL) facilities:
(1) Bevalac
(2) 88-Inch Cyclotron
(3) Materials Sciences Division

Since this is only the third report generated, the data presented - three points on each chart - is not sufficient to make a conclusive trend analysis or qualitative evaluation regarding the performances of the above facilities.

In some cases trends are becoming recognizable. As data is accumulated in the next period a more definite description of performance can be presented.

\subsection{Performance Initiatives}

LBL will have a permanent employee assigned responsibility for this report in place prior to the submittal of the fourth quarter data report on March 1, 1992.

The present computer program being utilized for the Performance Indicator Report is being evaluated and refined as necessary to provide a product that will be useful to LBL and DOE operations.

Data acquisition and entry procedures will also be reviewed for effectiveness.

\subsection{Good Practices}

Increased emphasis on preventive and periodic maintenance is essential to reduce backlogs and ensure operational effectiveness.

The necessity to develop, implement, and comply with established procedures is evident.

Originating and maintaining adequate facility and utility drawings and related documentation is essential to safe construction and modification activities.

Training and certification of personnel on a periodic Lasis needs to be provided even for the most experienced individuals. 
2. Performance Indicator Summary Char's

\section{Performance Indicator Summary Charts}

The following charts provide a summary of the performance indicator data provided for the Third Quarter of Calendar Year 1991. More detailed data on each performance indicator is provided in Appendix 2 of this report.

\subsection{Personnel Safety}

\subsection{Collective Radiation Dose}

The total external whole-body dose (deep and shallow) ieceived by all facility personnel (including subcontractors anci visitors) as measured by the primary dosimeter, i.e., thermoluminescent dosimeter (TLD), or film badge. Exposure measured by direct reading dosimeters should be included only for those pericds or situations when more accurate data are not available. Collective radiation dose is reported in units of person-rem.

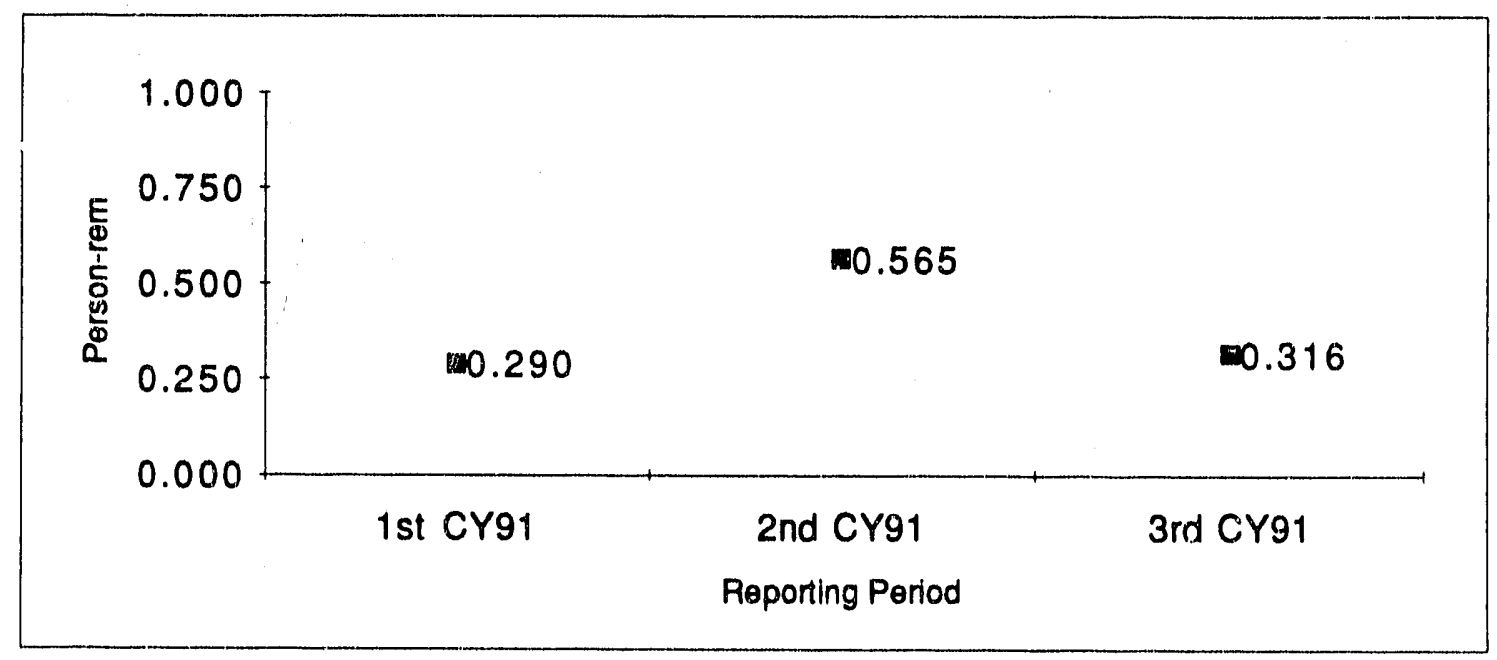

Collective radiation doses remain well below permitted levels. 
2. Performance Indicator Summary Charts

\subsection{Skin Contaminations.}

The total number of confirmed skin and personal clothing contaminations for all facility personnel, including subcontractors and visitors. Skin or clothing contamination due to radioactive noble gases or naturally occurring radon gas are not included.

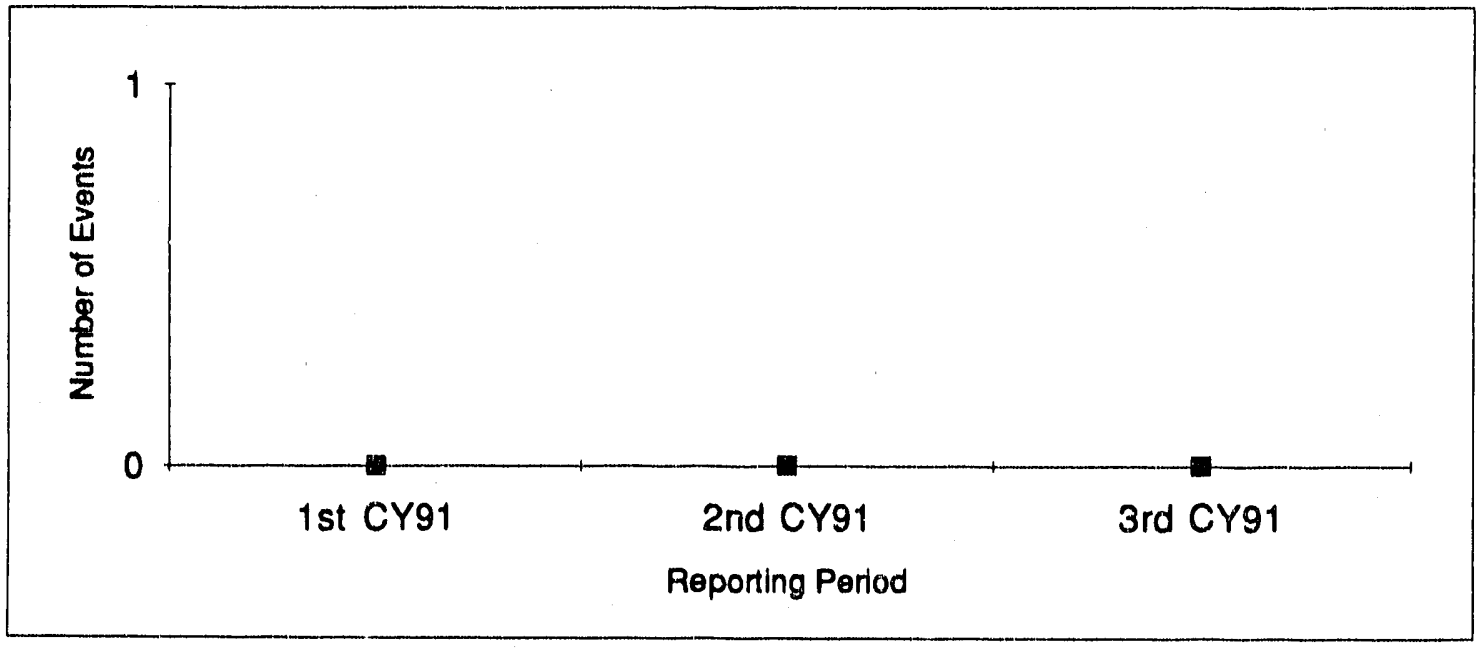

There have beer. no skin contamination incidents to date.

\section{1,3 Internal Contaminations}

The total number of confirmed intakes of radioactive material for all facility personnel, including subcontractors and visitors, occuring during the reporting period.

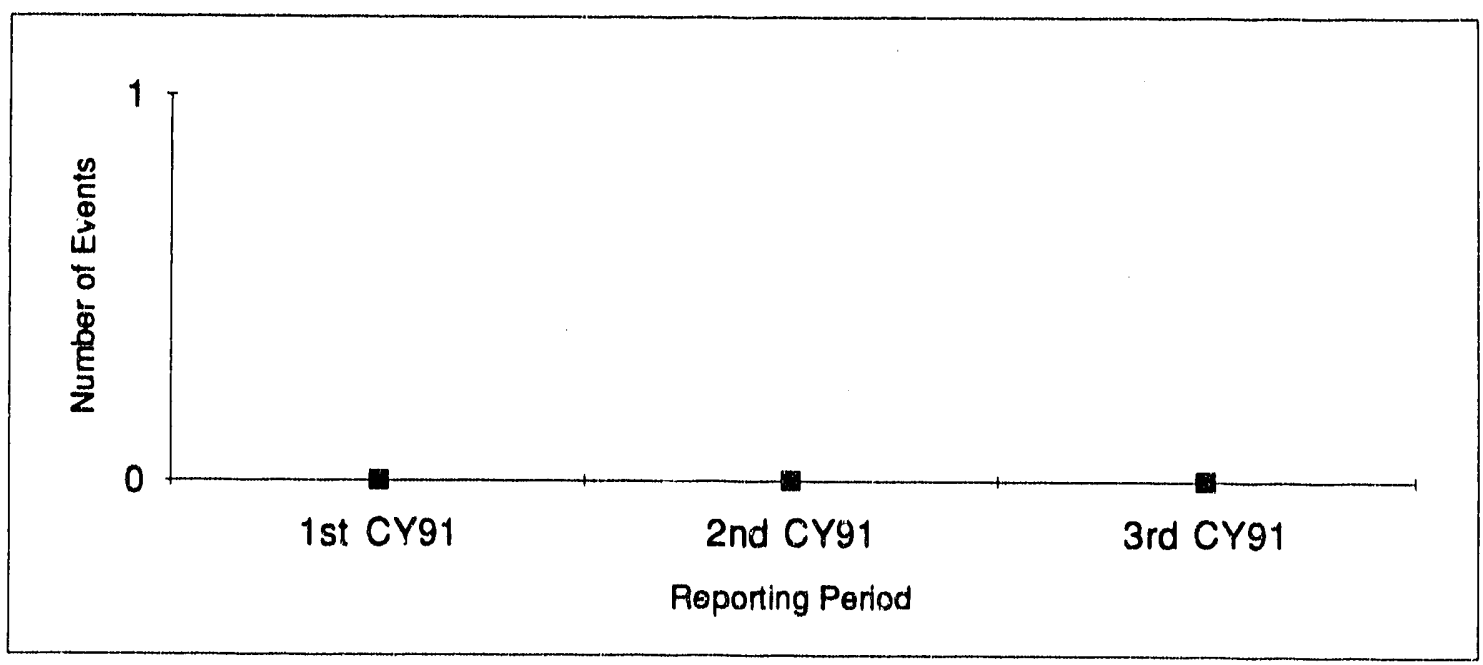

There have been no internal contaminations to date. 


\subsection{Radioactive or Hazardous Material Overexposures}

The number of reportable occurrences resulting from a personnel exposure (for all facility personnel, including subcontractors and visitors) to radioactive or hazardous materials in excess of limits established in DOE Orders.

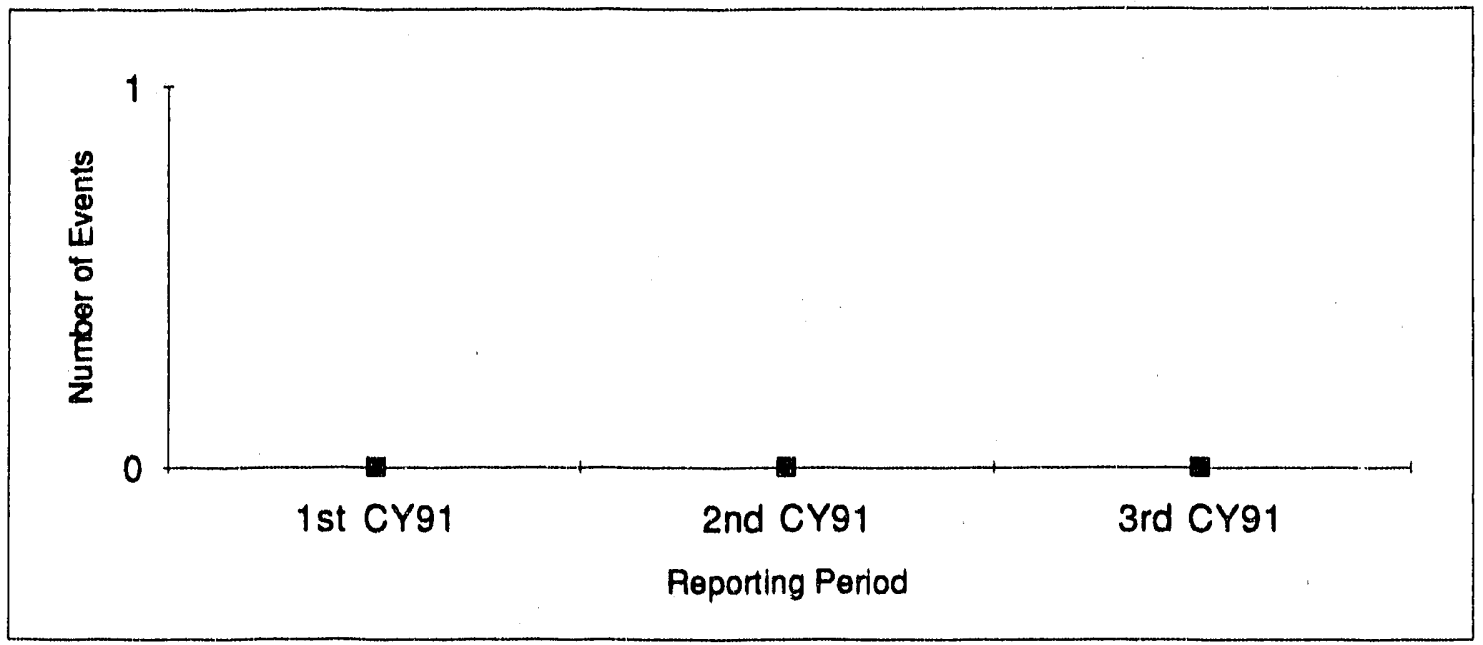

There have been no overexposures to radioactive or hazardous materials to date.

\subsection{Lost Work Day Cases (Lost Time Accident Rate)}

Number of incidents for all facility personnel involving days away from work per 100 personyears $(200,000$ person-hours) worked.

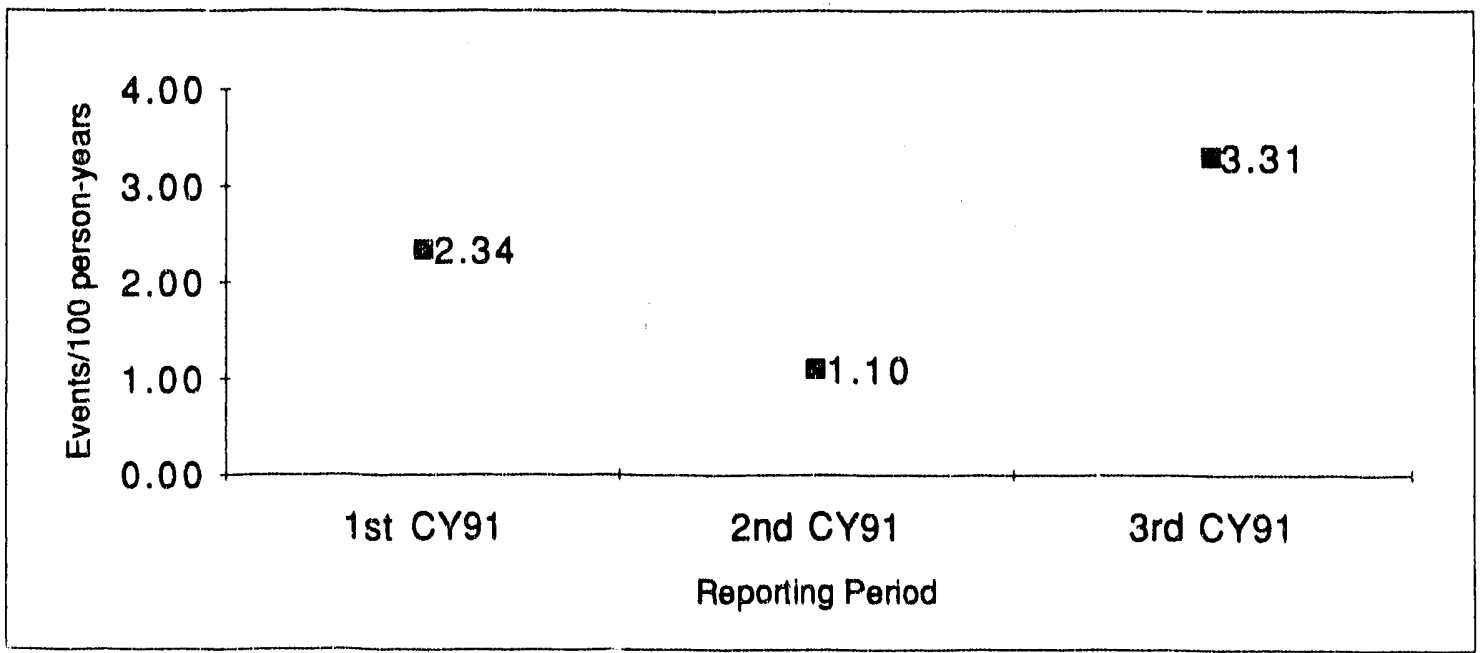

Although at a three quarter high, the lost time accident rate remains acceptable for the calendar year. 
2. Performance Indicator Summary Charts

\subsection{Recordable Injuries/llinesses Rate}

Total number of injuries or illness instances resulting from on-the-job activities that are recordabie in accordance with OSHA Standards, per 100 person-years (200,000 personhours) worked.

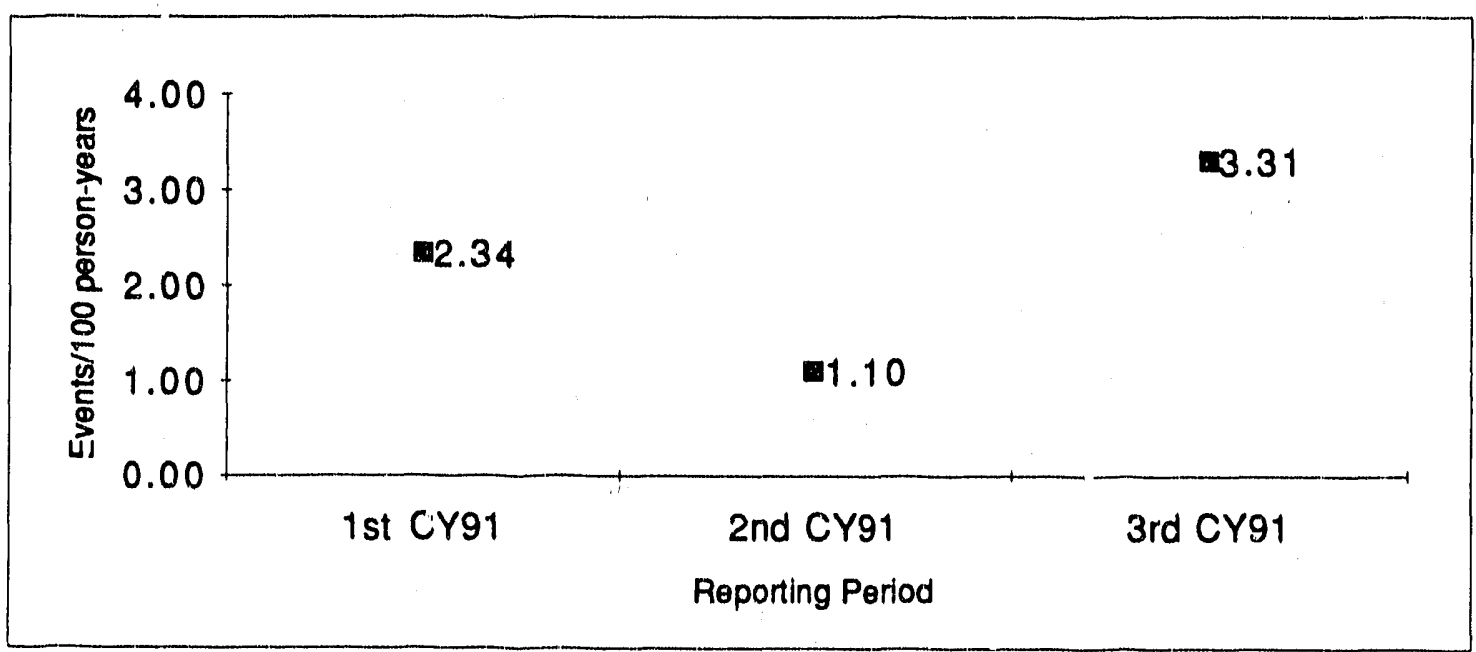

Although at a three quarter high, the recordable injuries/ilinesses rate remains acceptable for the calendar year. 
2. Performance Indicator Sunimary Charts

\subsection{Operational Incidents}

\subsection{Environmental Incidents}

The nurnber of reportable occurrences, both on-site and off-site, involving an inadvertent radioactive or hazardous material spill or release.

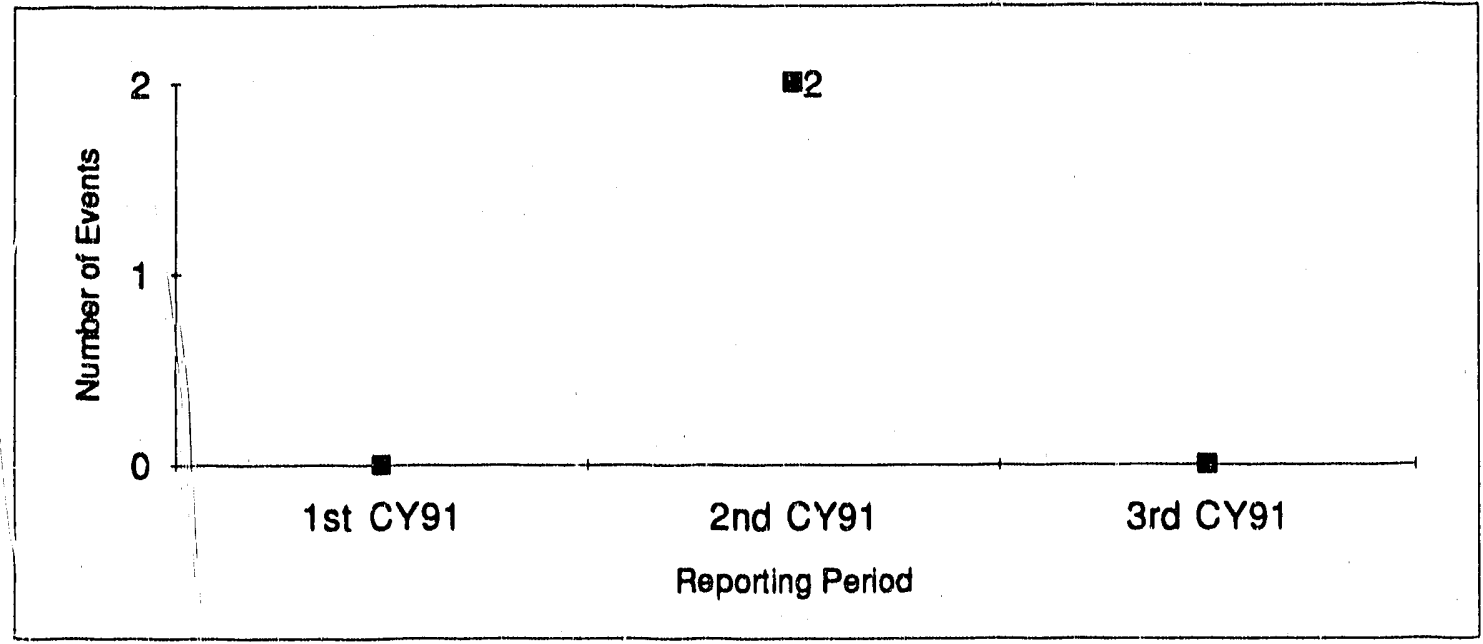

To date, only two minor environmental incidents have occurred at LBL's facilities this calendar year. Both of these occurred in the second quarter of 1991.

\subsection{Unplanned Safety Function Actuations}

The number of unplanned actuations of any safety function or facility safety systems that occur when an actuation setpoint for a safety fuction is reached or when a spurious or inadvertent signal is generated, and major equipment is actuated or demanded. Unplanned means that the actuation was not part of a planned test or evolution.

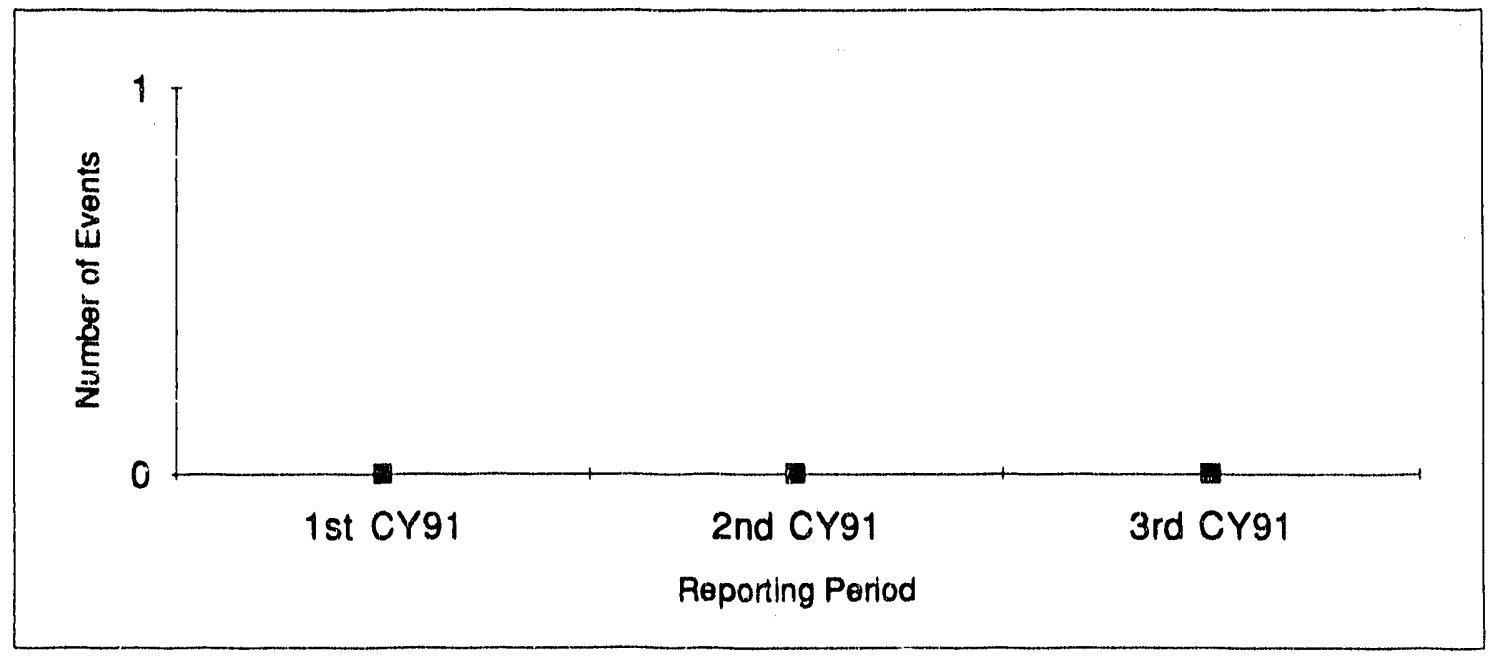

There have been no unplanned safety function actuations during CY-1991. 
2. Performance Indicator Summary Charts

\subsection{Violations of Operatina Procedures}

The number of instances where a failure of personnel to follow operating procedures resulted in a reportable occurrence.

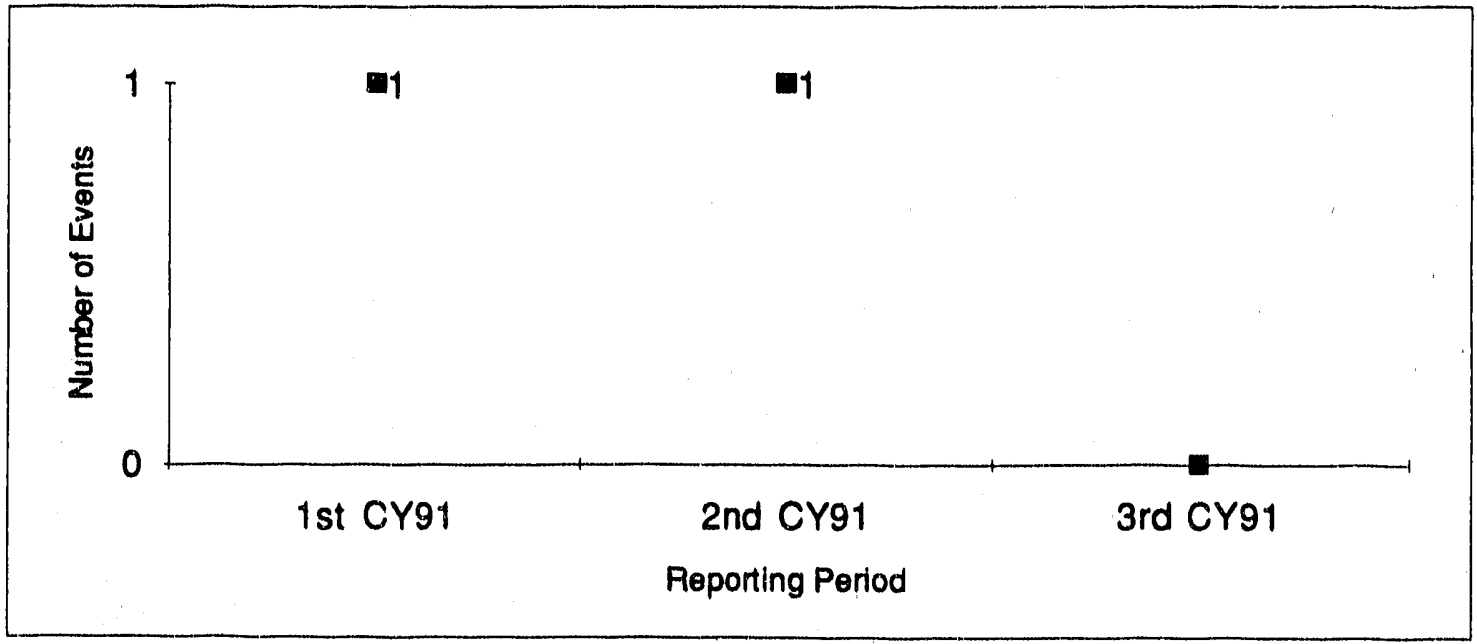

After having one violation of operating procedures in each of the first two quarters, there were none in the current reporting period.

\subsection{QSHA Violations}

The total number of items of noncompliance with OSHA standards.

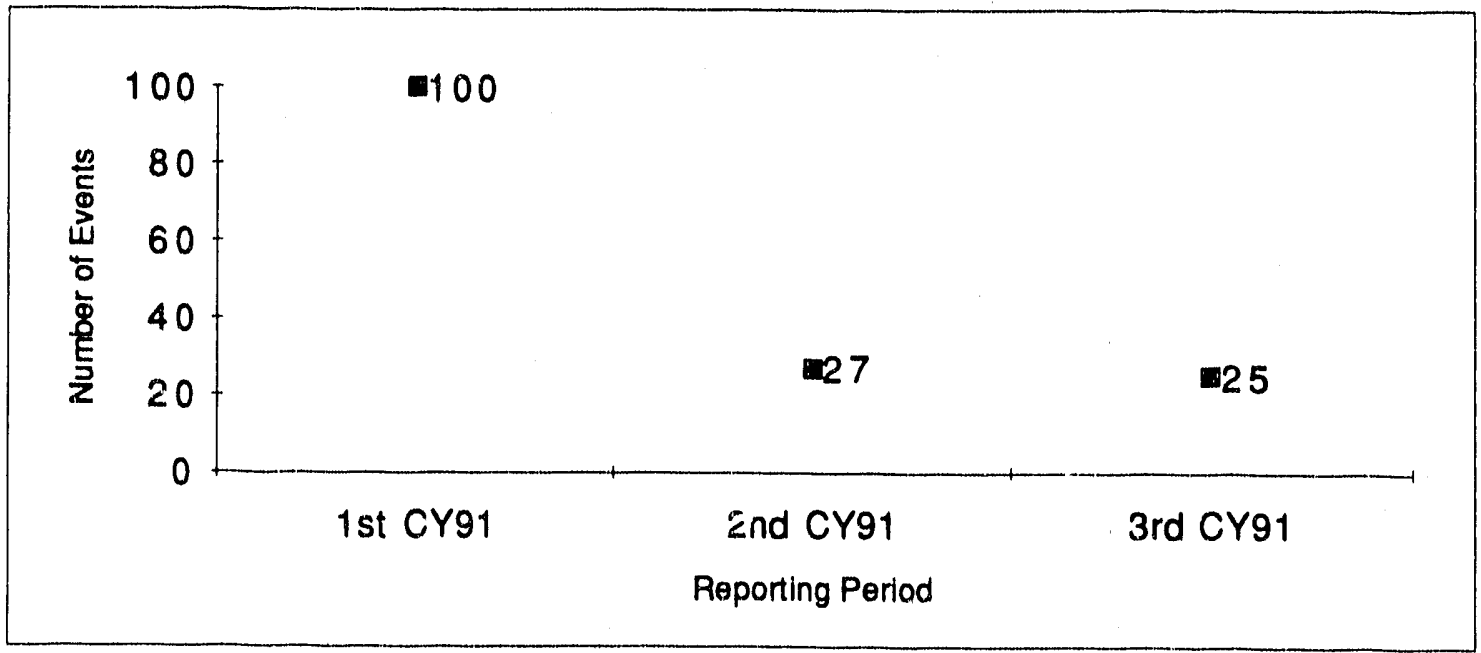

The number of OSHA violations continues to be much lower than in the first quarter, although still greater than desirable. 
2. Performance Indicator Summary Charts

\subsection{Unplanned Shutdowns}

The number of unscheduled shutdowns of a facility, process or operation.

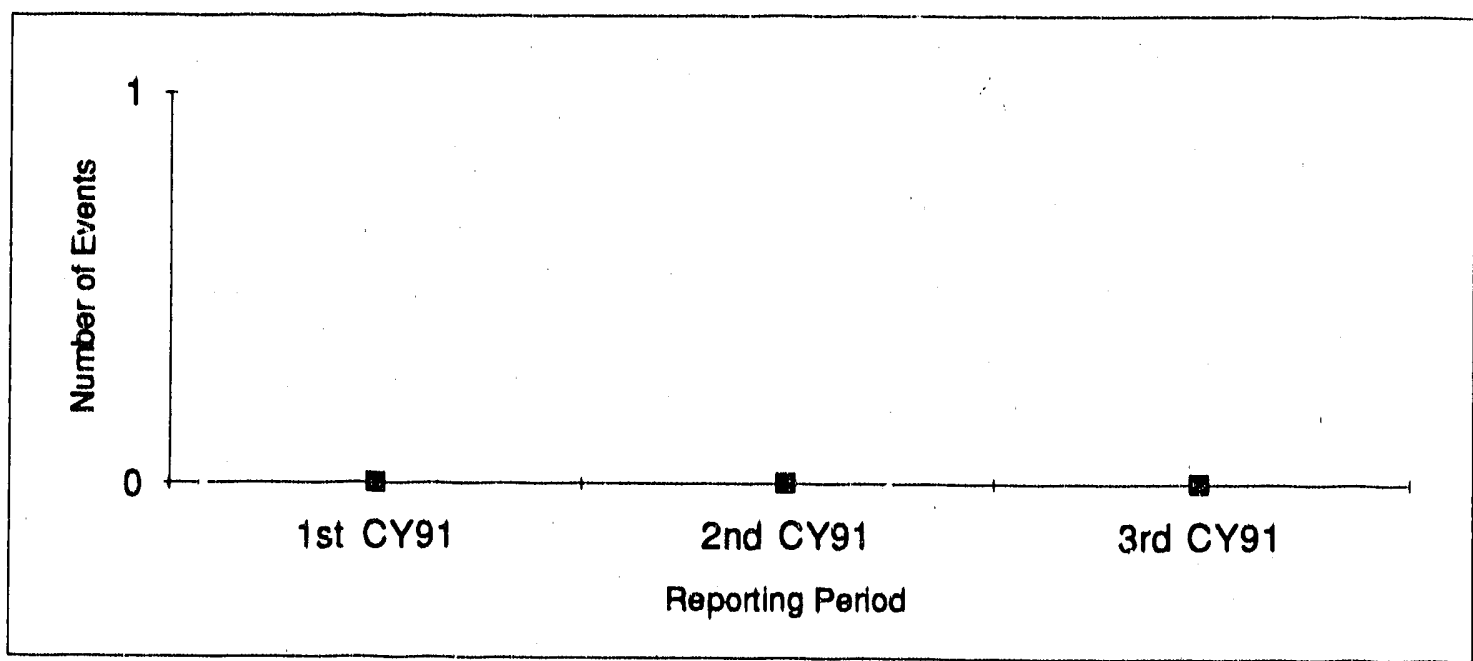

There have been no unplanned shutdowns to date for CY-1991.

\section{1 Emeroency and Unusual Occurrences}

The number of Emergency and Unusual Occurrences reported in accordance with DOE Order 5000.3A, "Occurrence Reporting and Processing of Operations Information."

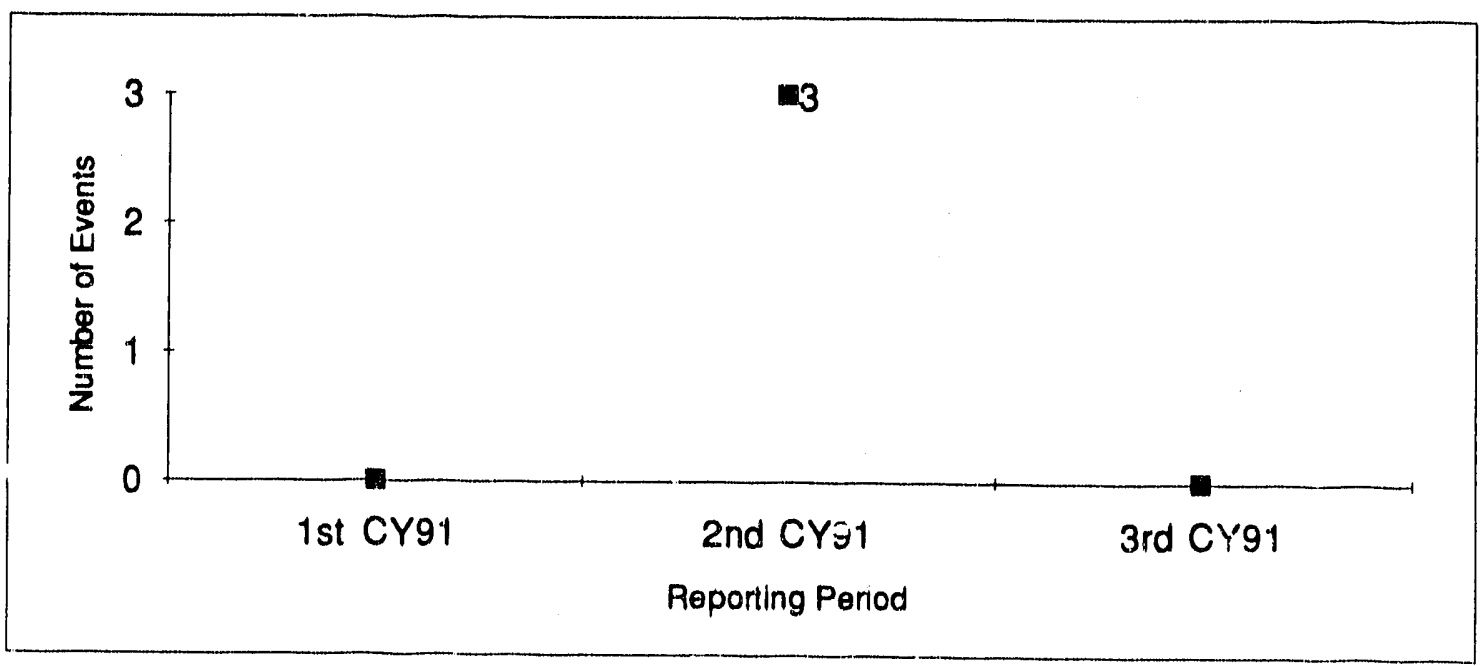

Despite having three unusual occurrences in the second quarter, there were none in the current reporting period. 
2. Performance Indicator Summary Charts

\subsection{Environmental Releases (Normal Operations)}

\subsubsection{Radionuclide Effluent Releases (Airborne)}

Airborne releases to the environment, as measured at the point of release, for the following radionuclides: plutonium, uranium, nobel gases, particulates (including radiocesiums and radiostrontium, and activation products), radioiodine, tritium, and other actinides.

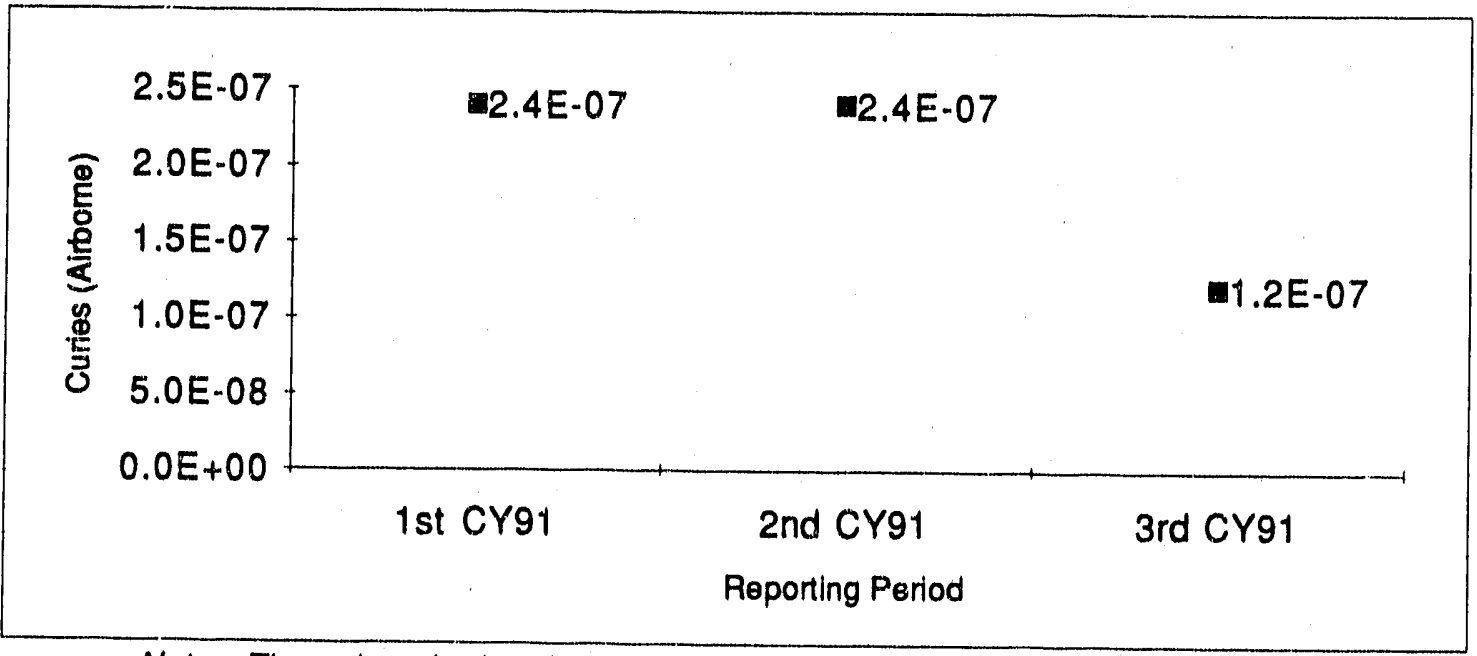

Note: The values in the chart depict upper bounds on the amounts released.

The amounts of airborne radionuclide effluent releases remains negligible.

\subsubsection{Radionuclide Effluent Releases (Llquid)}

Liquid releases to the environment, as measured at the point of release, for the following radionuclides: plutonium, uranium, nobel gases, particulates (including radiocesiums and radiostrontium, and activation products), radioiodine, tritium, and other actinides.

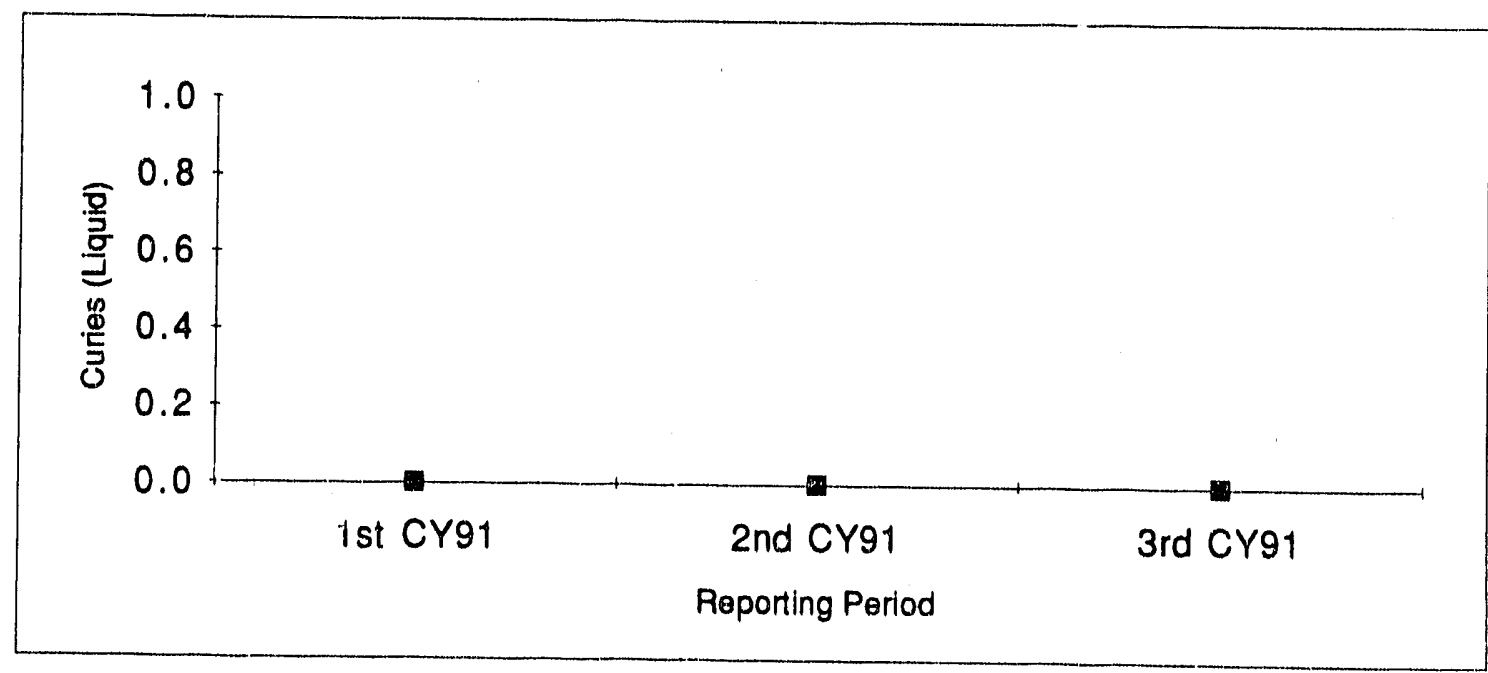

There have been no liquid radionuclide effluent releases to date. 


\subsubsection{Hazardous Substance/Regulated Pollutant Effluent Release (Alrborne)}

The amount of "permitted" airtorne non-radioactive releases. All hazardous substances and regulated pollutanis that are listed in permits (e.g., Clean Air Act or NPDES permits) or otherwise reported to regulators (e.g., through SARA Title III, Section 313 reporting requirements) are included. Data shall be cumulative over the reporting period and reported in units of pounds.

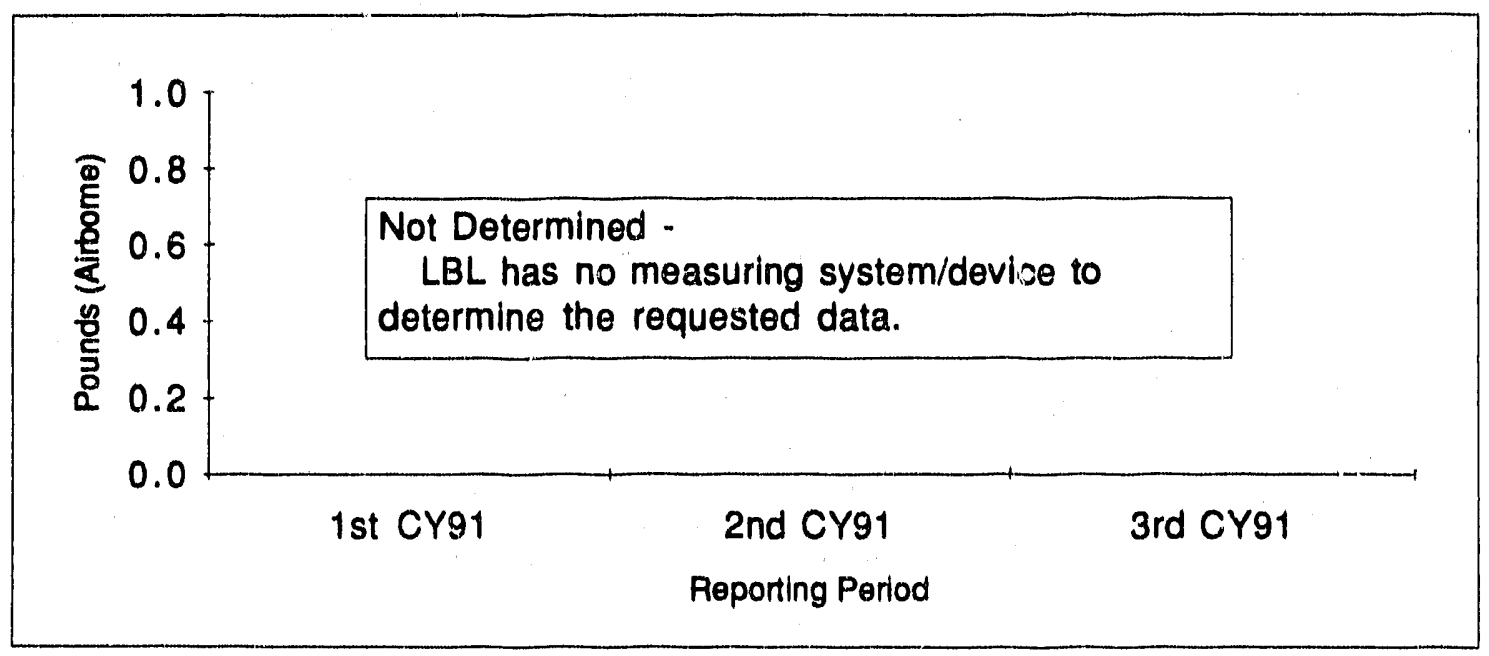

\subsubsection{Hazardous Substance/Requlated Pollutant Effluent Releases (Liquid)}

The amount of "permitted" liquid non-radioactive releases. (Seo 3.2.1 for included substances). Data shall be cumulative over the reporting period and reported in units of gallons.

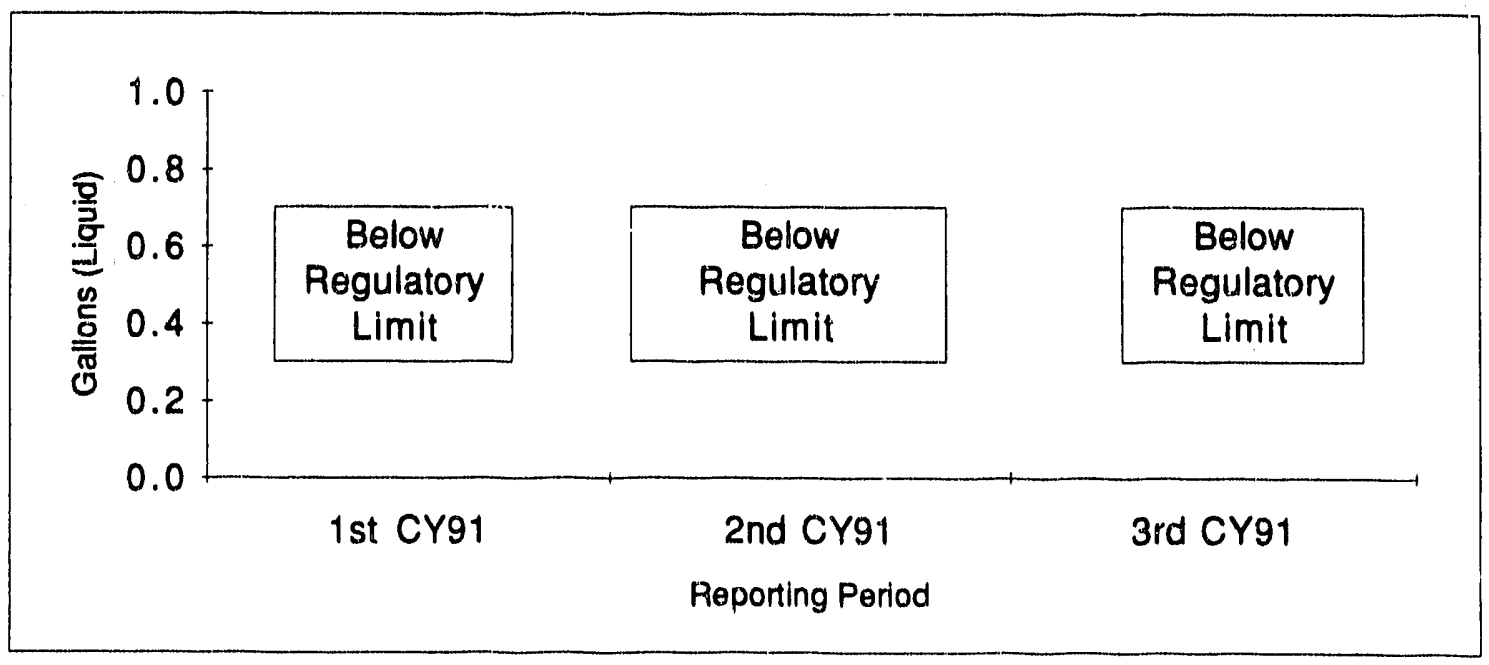

To date, the amounts of liquid hazardous substances and/or regulated pollutants released have been below regulatory limits. 


\section{Performance Indicator Summary Charts}

\subsection{Management}

\subsection{0pen DOE Audit Issues}

The total number of findings, ircluding concerns and recommendations requiring corrective actions, by oversight assessments and line program self-assessments for which contractor corrective actions have not been compleied at the time of the report.

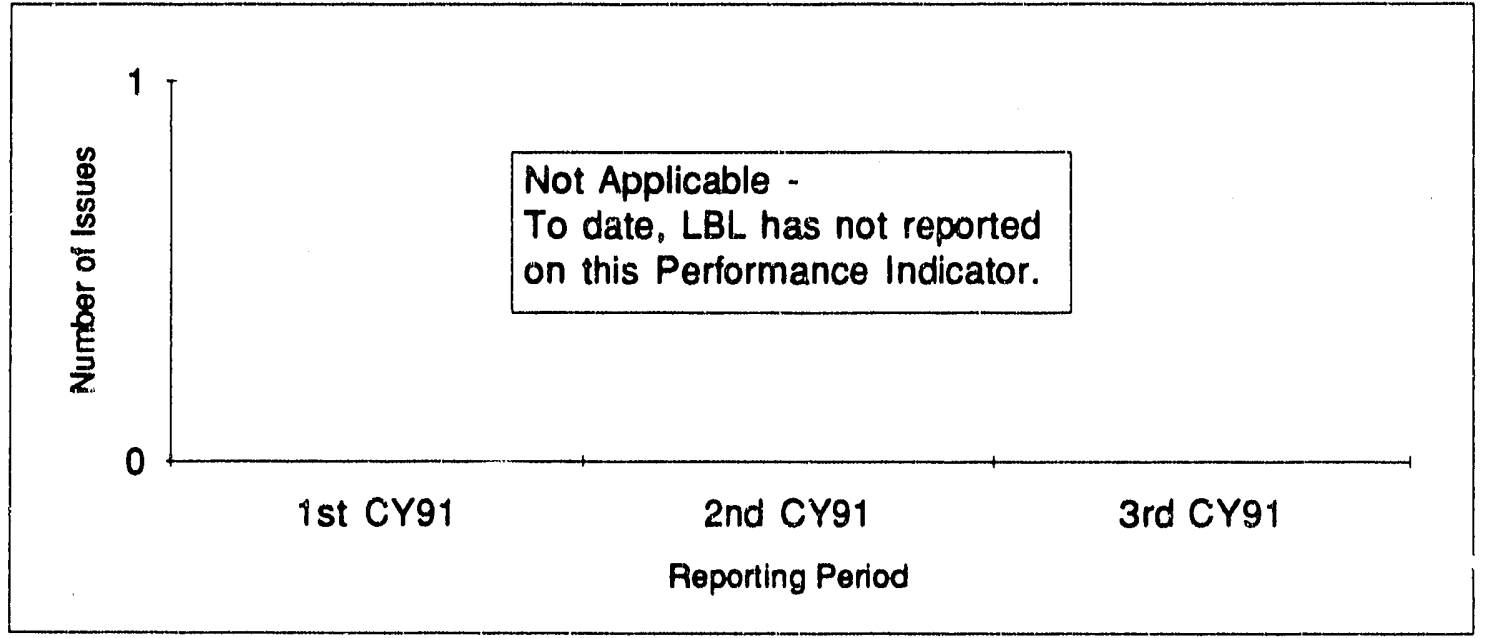

\subsection{0pen External Oraanization Recommendations}

The total number of recommendations by external organizations, such as the Advisory Committee on Nuclear Facility Safety, the Defense Nuclear Facility Safery Board, the National Academy of Sciences, etc., directed to specific contractors or their facility operations, for which contractor corrective actions have not been completed at the time of the report.

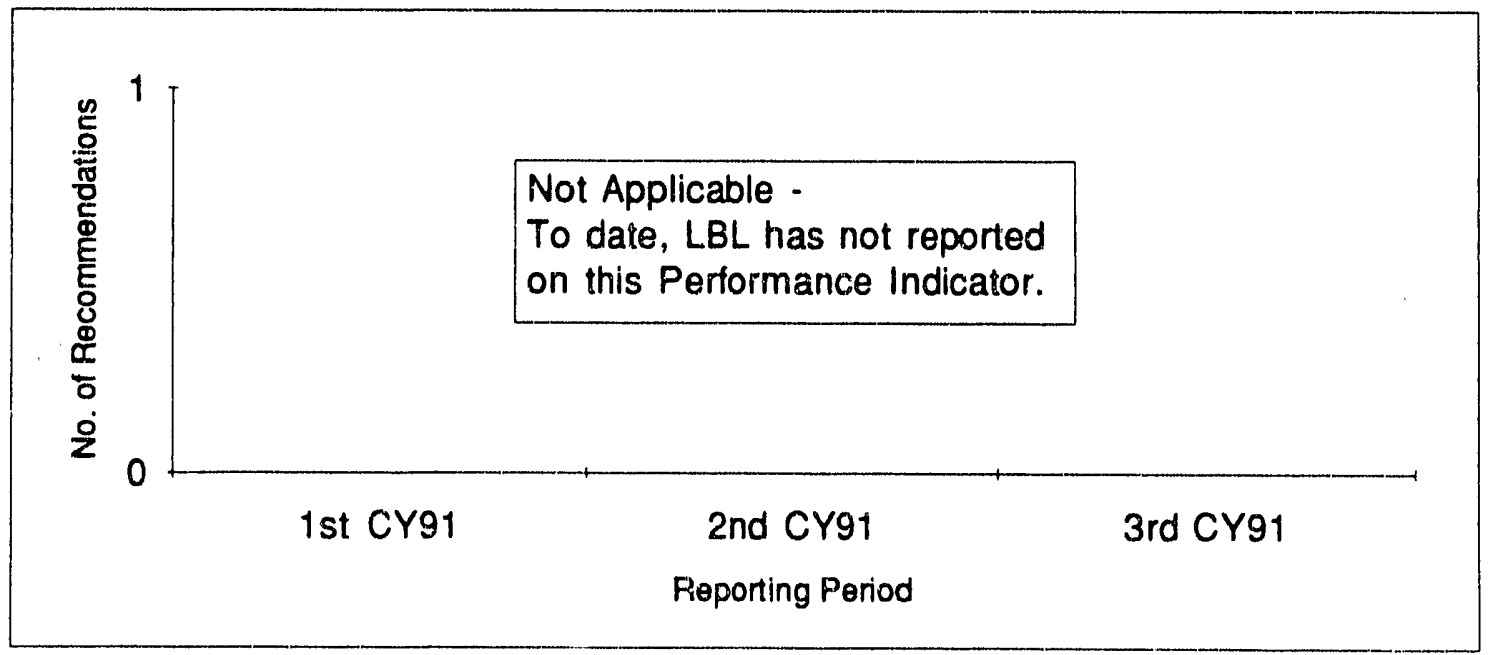


2. Performance Indicator Summary Charts

\subsection{Occurrence Reports with Open Corrective Actions}

The number of Final Occurrence Reports for which all corrective actions have not been completed at the time of the report.

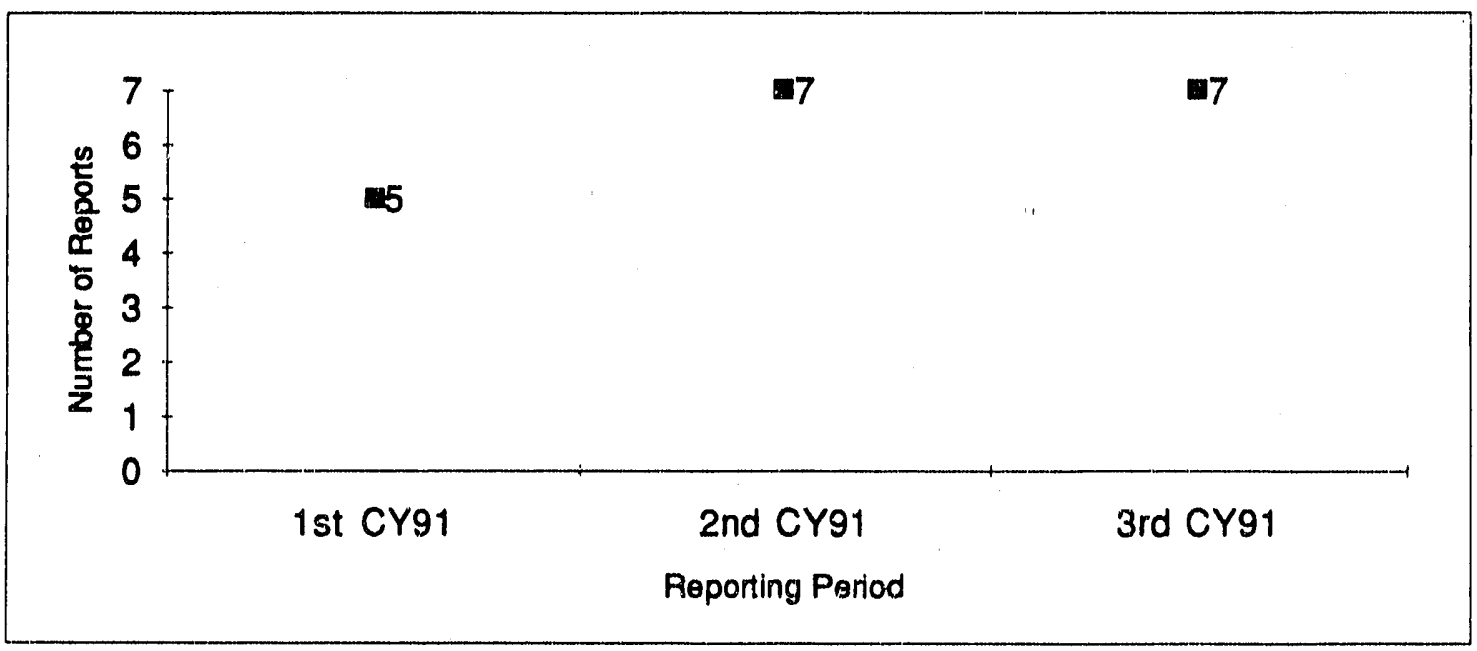

The number of Final Occurrence Reports with open corrective actions has remained relatively constant over the three reporting quarters.

\subsection{Corrective Maintenance Backlog}

The persentage of open corrective maintenance work requests, including those requiring facility or process shutdown, that are greater than three months old at the end of the reporting period. Corrective mainienance may include minor modifications if performed under a corrective maintenance work request.

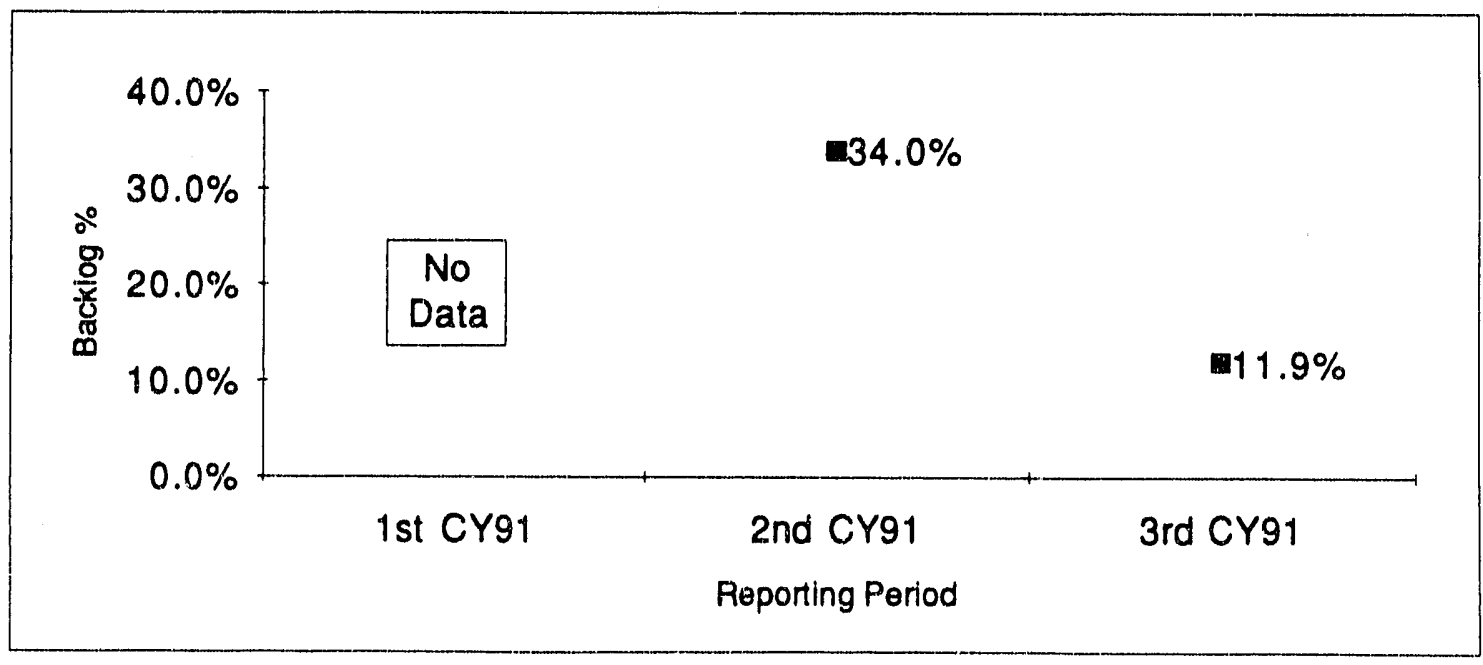

The corrective maintenance backlog was considerably reduced from the second to the third quarter. 


\section{Performance Indicator Summary Charts}

\subsection{Preventive Maintenance Overdue}

The percentage of preventive mairitenarice items that were not completed within the originally scheduled interval.

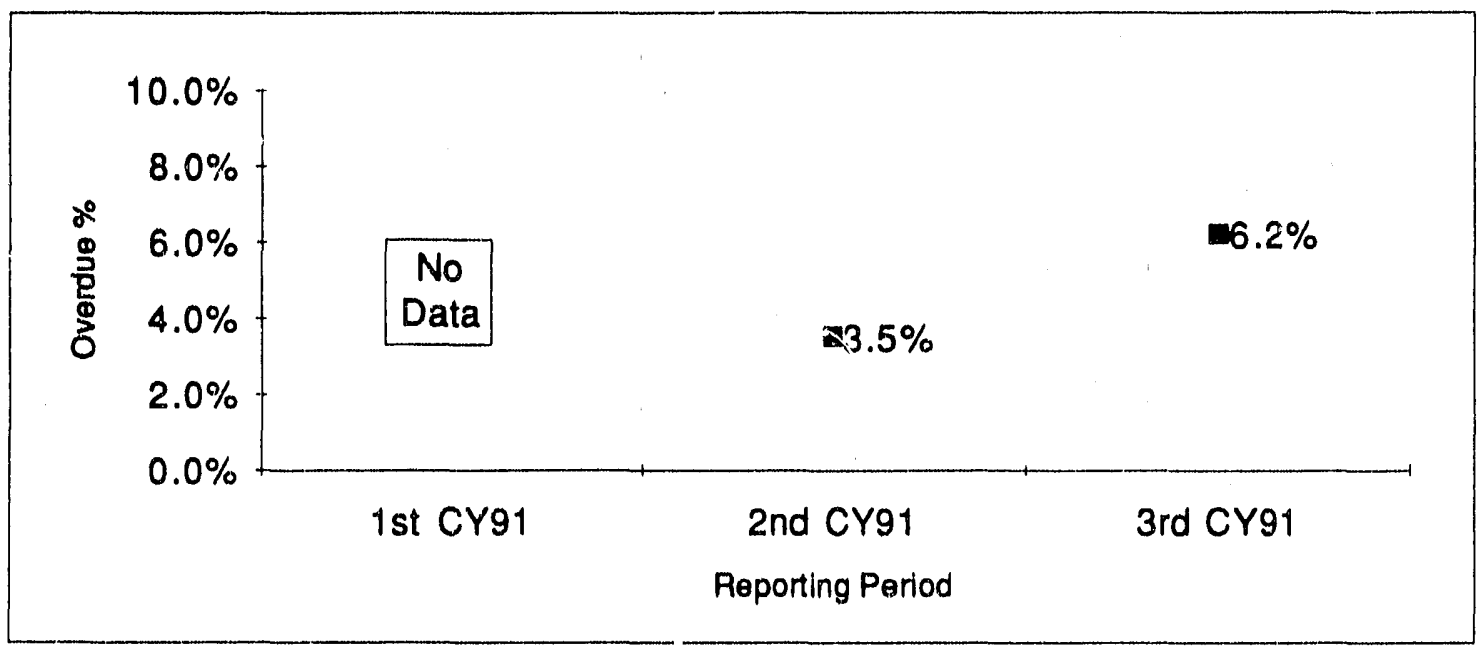

Although the percentage of preventive maintenance overdue rose from the second to the third quarter, the percent overdue remains relatively low.

\subsection{Substance Abuse Incidents}

The number of reportable occurrences involving personnel use, possession or involvement of/with controlled substances, e.g., drugs, alcohol, etc.

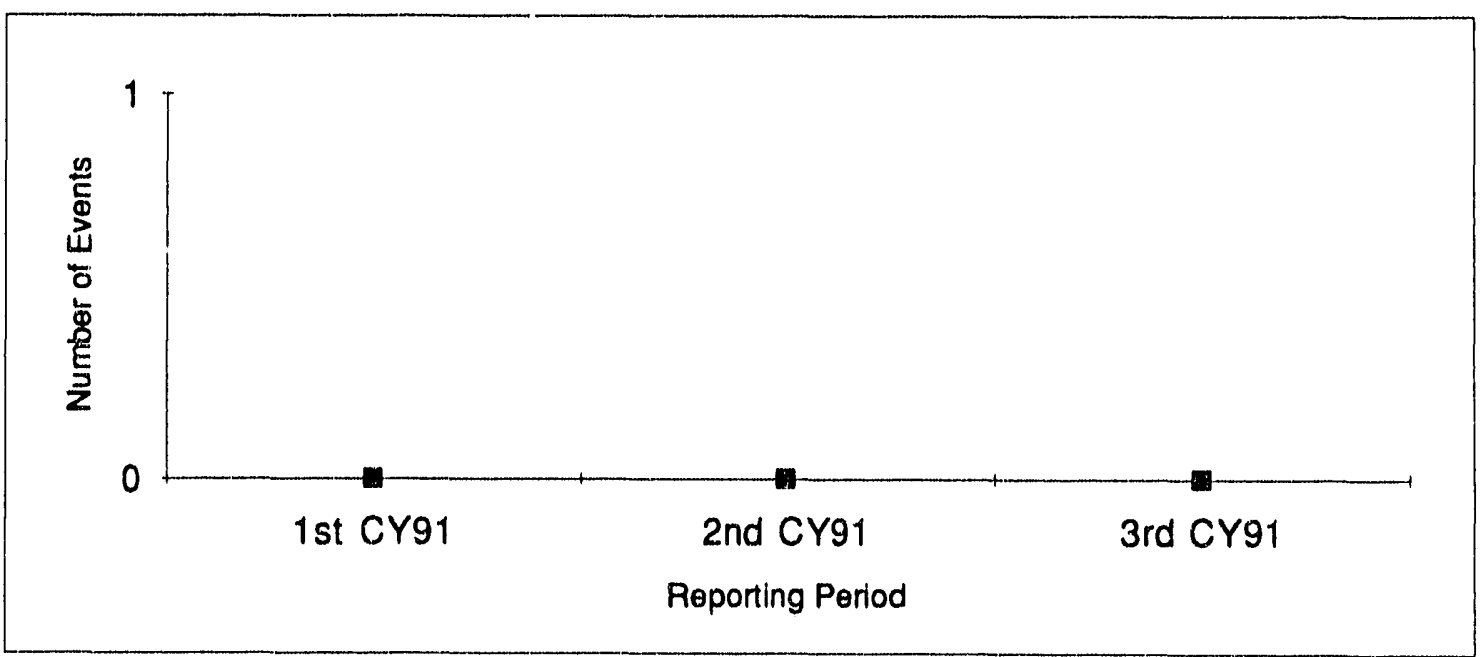

There have been no substance abuse incidents to date. 
2. Performance Indicator Summary Charts

\subsubsection{Solid Low Level Radioactive Waste - Generated}

The total volume, in cubic feet, of solid low level radioactive waste generated during the reporting period.

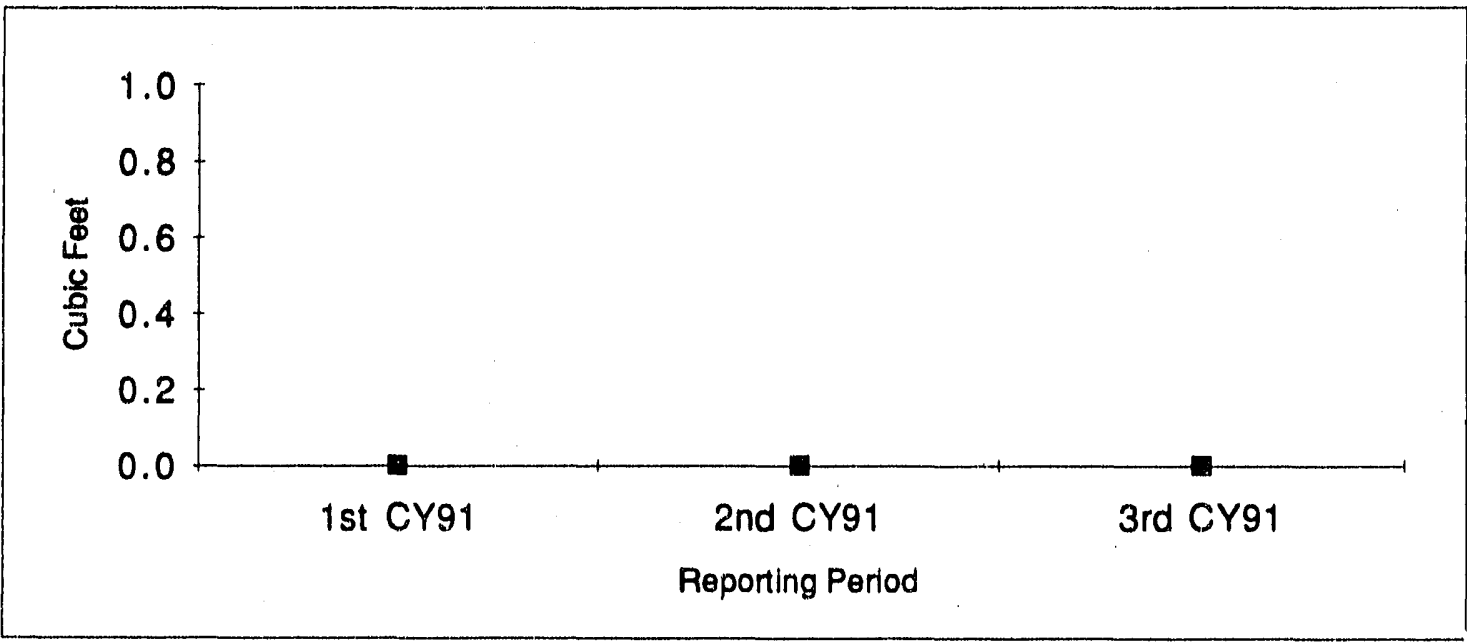

There has been no radioactive waste generated to date for CY-1991.

\subsubsection{Solid Low Level Radioactive Waste - Ready to Ship}

The total volume, in cubis feet, of the final form (pending shipment) of solid low level radioactive waste generated during the reporting period.

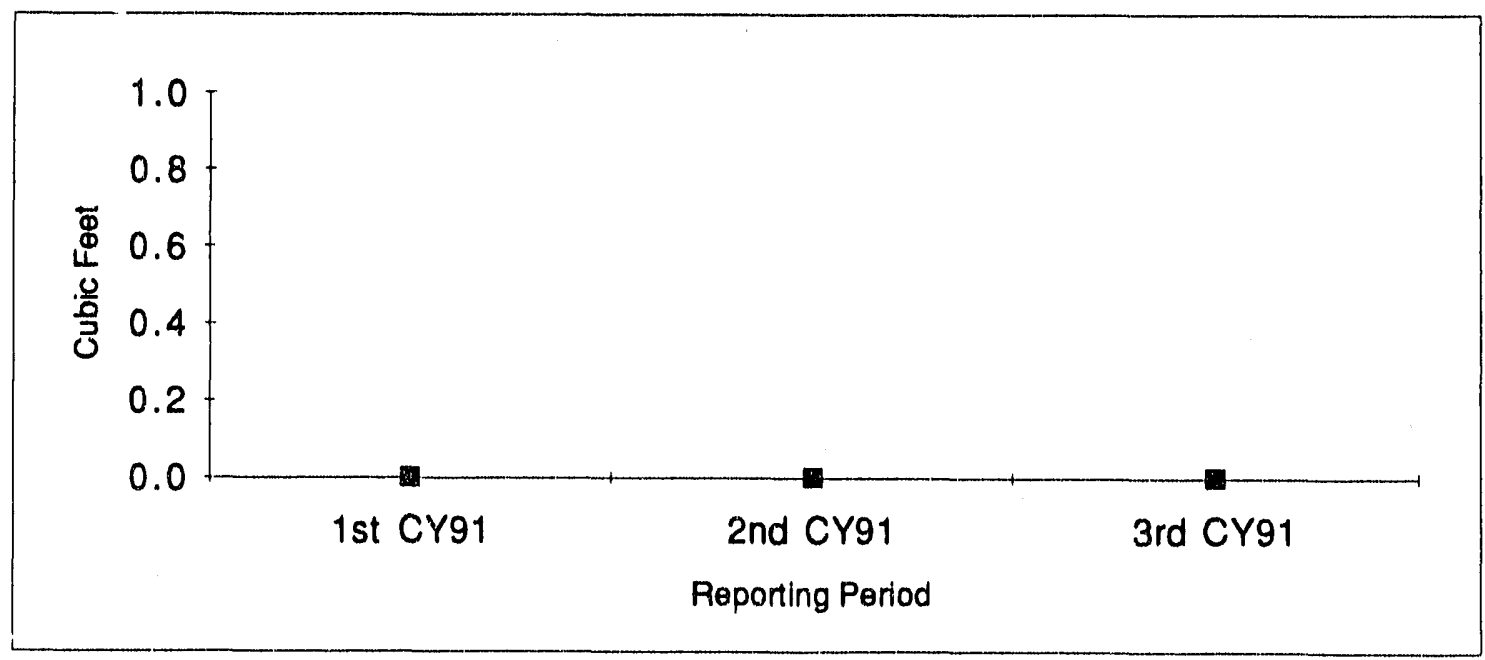

There has been no radioactive waste generated (hence, prepared to ship) during CY-1991. 
2. Performance Indicator Summary Charts

\subsubsection{Solid Low Level Radloactive Waste - Shipped}

The total volume, in cubic feet, of solid low level radioactive waste shipped during the reporting period.

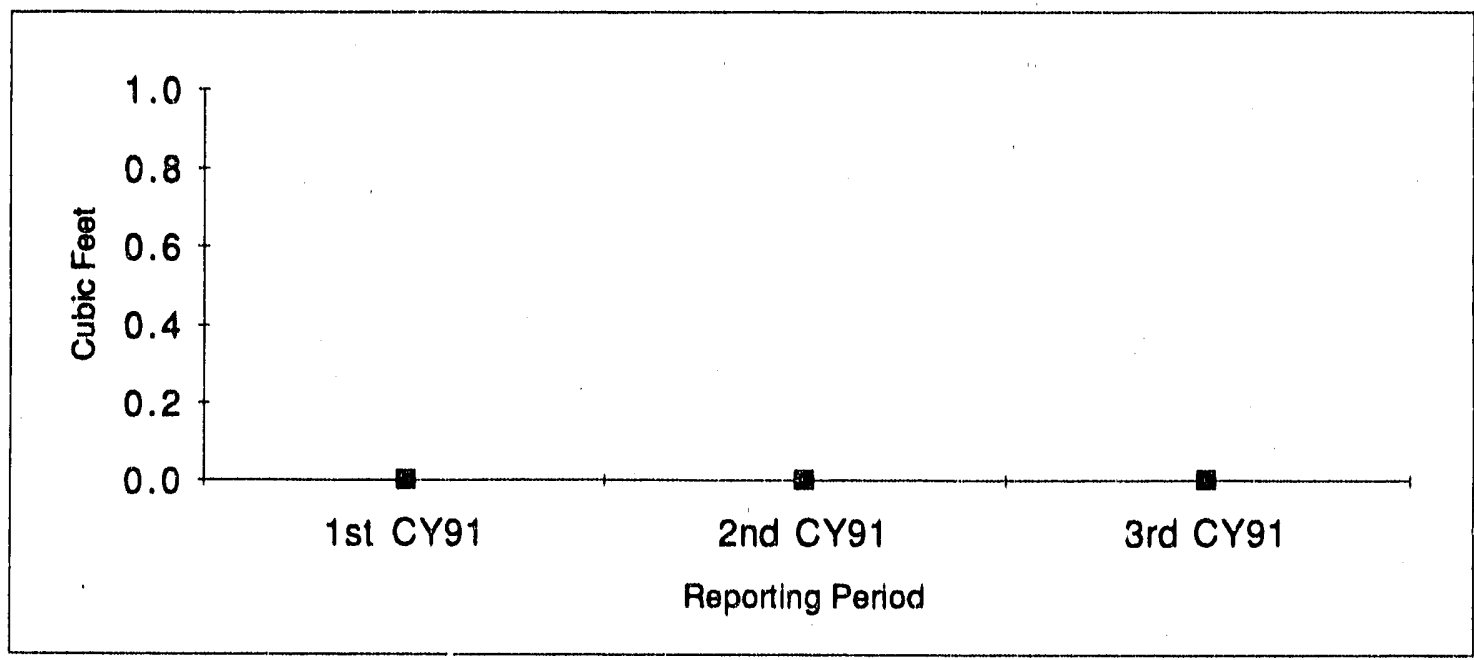

There has been no radioactive waste generated (hence, shipped) to date.

\subsubsection{Solid Low Level Hazardous Waste - Generated}

The total volume, in cubic feet, of solid hazardous waste generated during the reporting period.

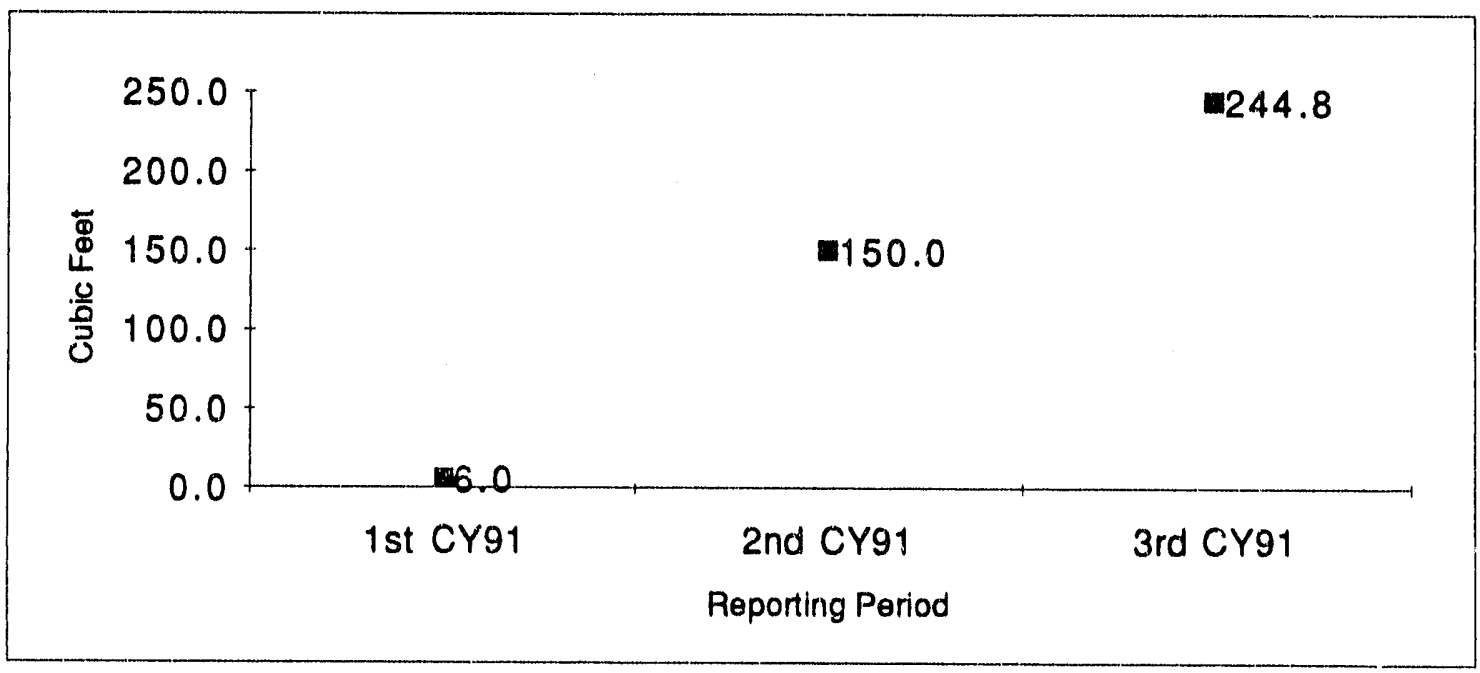

The amount of low-level hazardous waste generated has risen steadily over the past three quarters. 


\subsubsection{Solld Low Level Hazardous Waste - Ready to Shle}

The total volume, in cubic feet, of the final form (pending shipment) of hazardous waste generated during the reporting period.

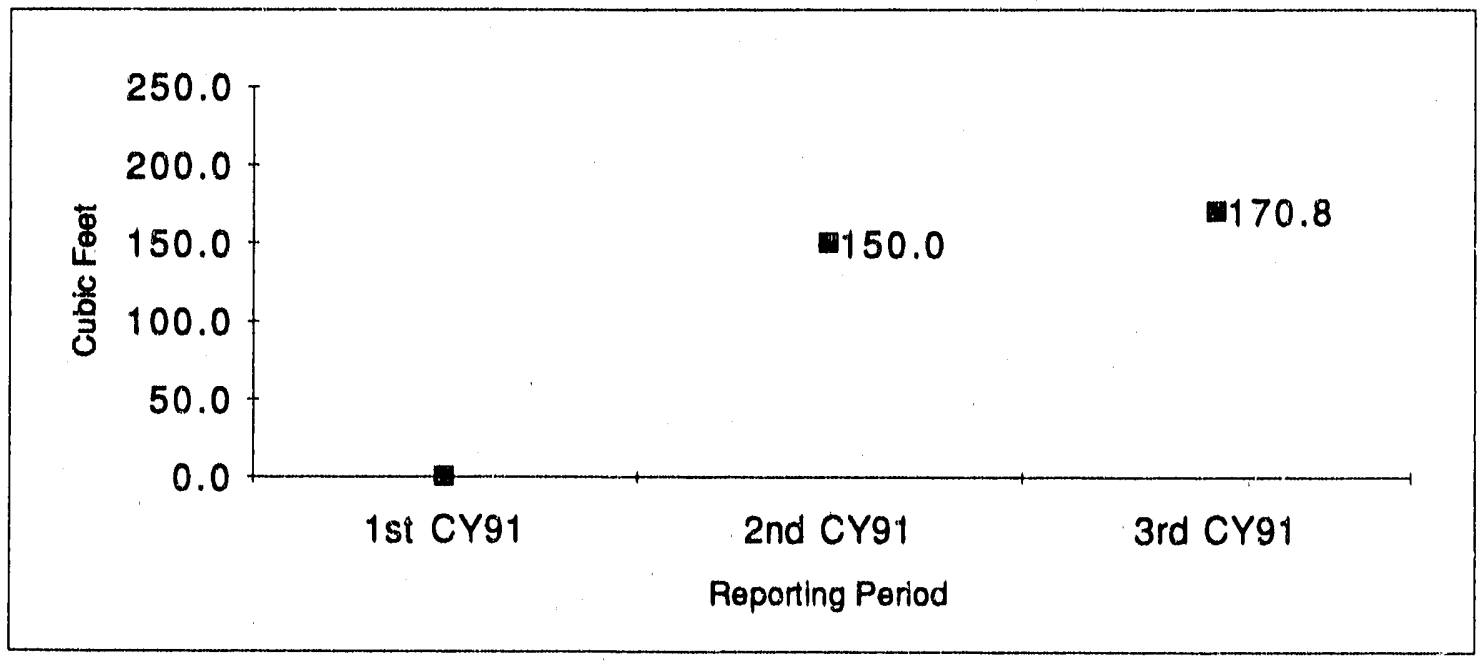

Pending shipments are slightly up over the last quarter.

\subsubsection{Sollid Low Level Hazardous Waste - Shipped}

The total volume, in cubic feet, of hazardous waste shipped during the reporting period.

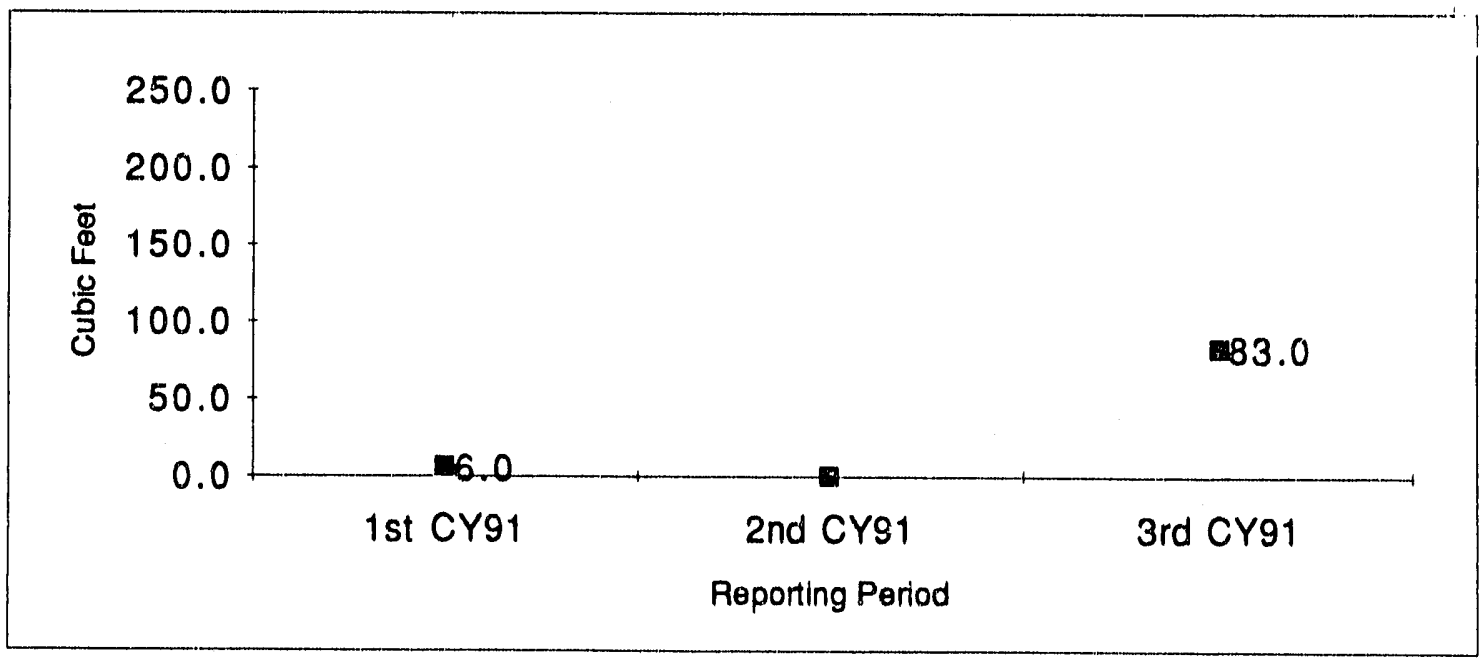

Shipments of hazardous waste were resumed during the third quarter of CY-1991. 


\subsubsection{Solld Low Level Mixed Waste - Generated}

The total volume, in cubic feet, of mixed waste generated during the reporting period.

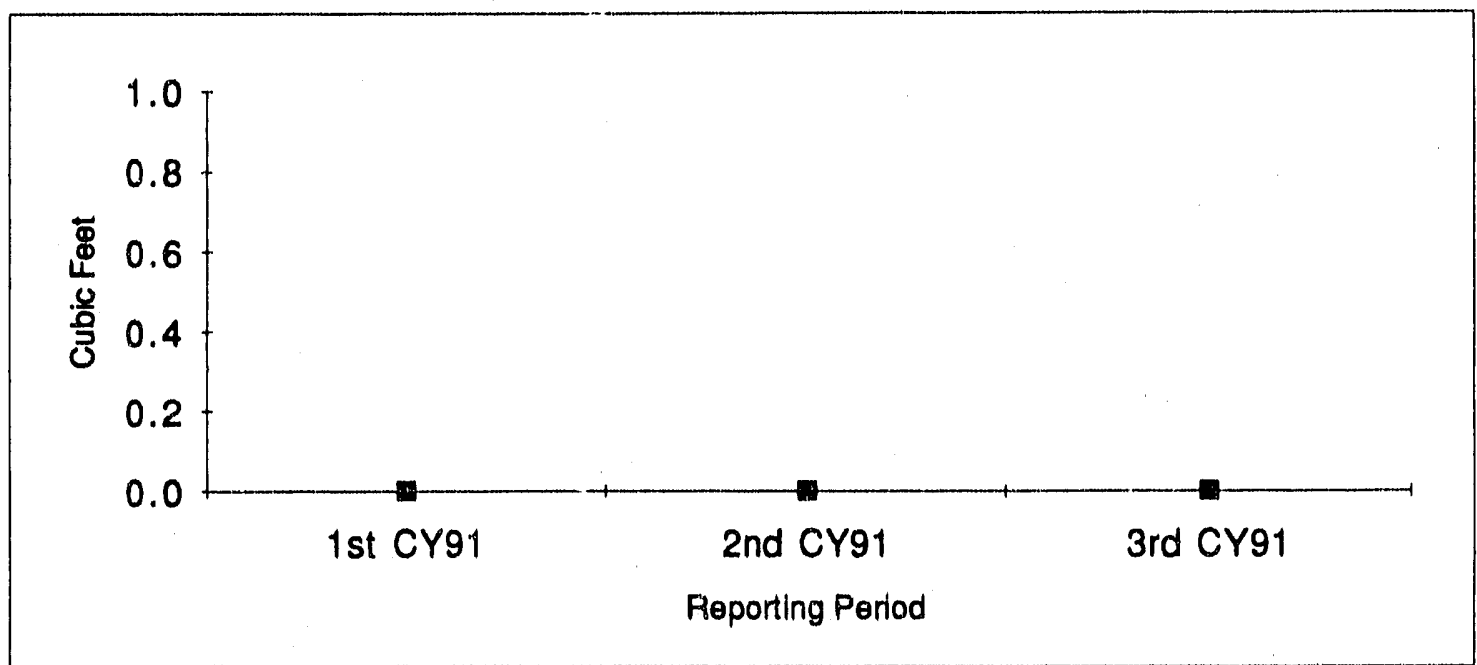

There has been no mixed waste generated to date for CY-1991.

\subsubsection{Solld Low Level Mixed Waste - Ready to Ship}

The total volume, in cubic feet, of the final form (pending shipment) of mixed waste generated during the reporting period.

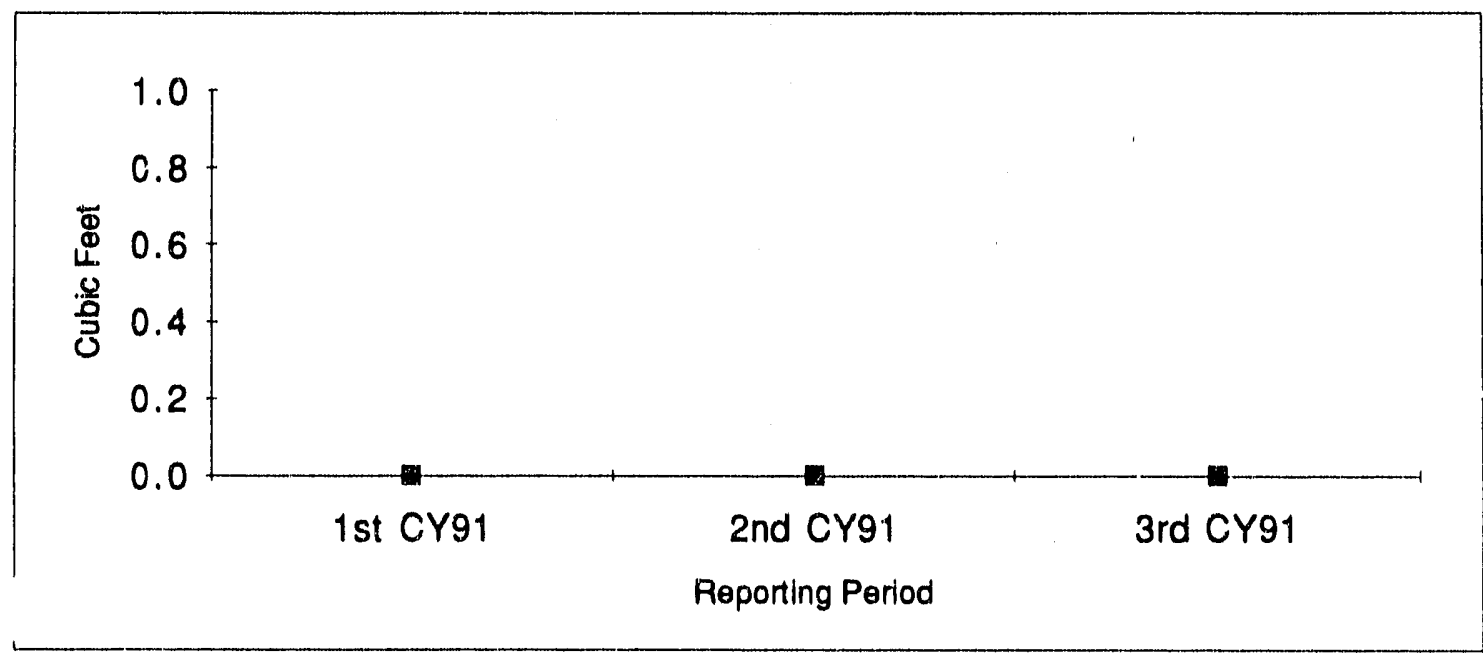

There has been no mixed waste generated (hence, prepared to ship) for the calendar year. 


\section{Performance Indicator Summary Charts}

\subsubsection{Solld Low Level Mixed Waste - Shlpped}

The total volume, in cubic feet, of mixed waste shipped during the reporting period.

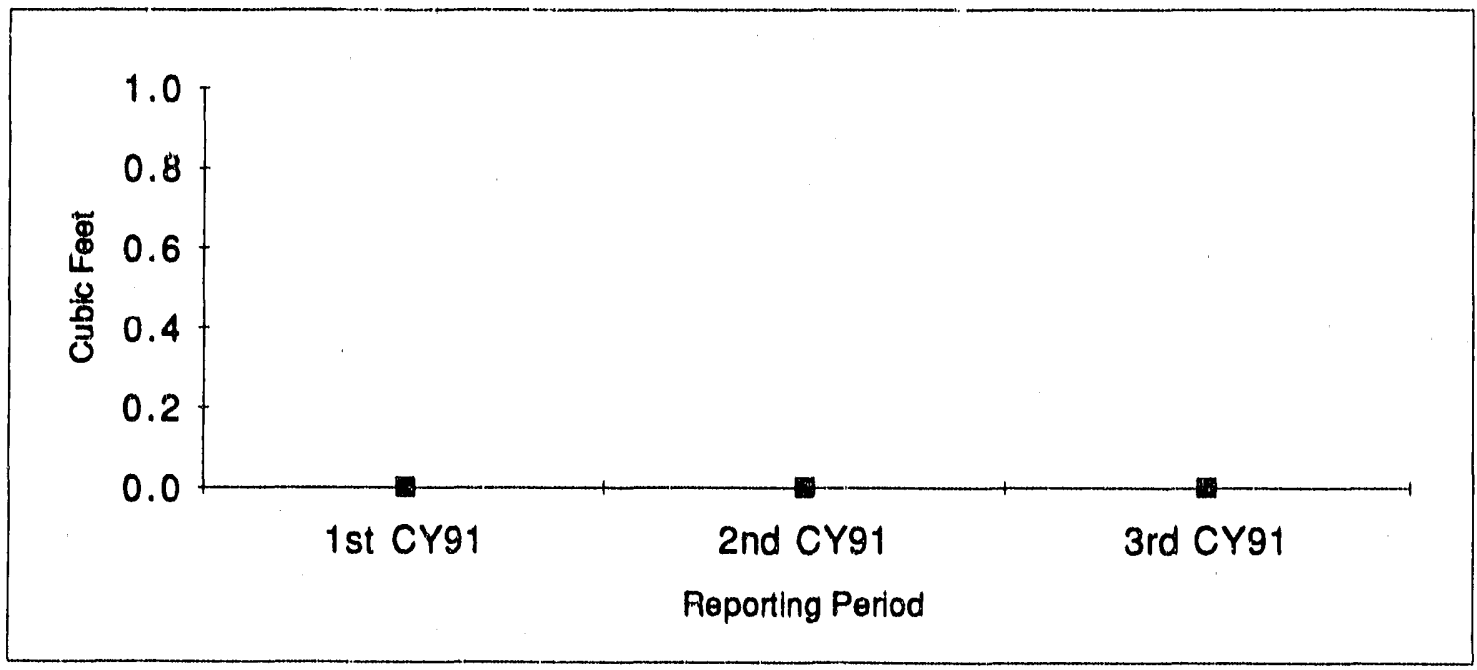

There has been no mixed waste generated (hence, shipped) to date for CY-1991. 


\section{APPENDIX 1: Summary By Performance Indicater}

The following summary is based on an evaluation of the performance indicators for the third quarter of CY-1991. Due to the limited nature of the data, further conclusions concerning DOE performance in the areas of interest should be reserved until additional information is provided by the organizations responsible for the work. A more definitive depiction of performance will become avallable in future reports as historical performance indicator data are accumulated to establish performance trends.

\subsection{Personnel Safety}

\subsection{Collective Radiation Dose}

Collective radiation dose remains well within permitted levels.

\section{Skin Contaminations}

Zero contaminations for the three documanted periods.

\subsection{Internal Contaminations}

No confirmed intakes of radioactive material for facility personnel.

\subsection{Radioactive or Hazardous Material Overexposures}

No radioactive or hazardous material overexposures for the three quarters recorded.

\subsection{Lost Work Dar Cases (Lost Time Accident Rate)}

Lost work day incidents are at a three quarter high for CY-1991, but the year-to-date rate is still acceptable.

\subsection{Recordable Injuries and IIInesses Rate}

Recordable injury and/or illness incidents are at a three quarter high, but the year-to-date rate for the calendar year is still acceptable.

\subsection{Operational Incidents}

\subsection{Environmental Incidents}

None in the current reporting period. Two to date for CY-1991.

\subsection{Unolanned Safety Function Actuations}

None to date during the calendar year.

\subsection{Violations of Operating Procedures}

None in the current reporting period. Two to date for CY-1991. 


\subsection{OSHA Violations}

The number of OSHA violations is much lower than in the first quarter of CY-1991, but it is still greater than desired.

\subsection{Unplanned Shutdowns}

None to date for CY-1991.

\subsection{Emergencles and Unusual Occurrences}

None in the current reporting period. Three to date.

\subsection{Environmental Releases (Normal Operations) \\ 3.1 Radionuclide Effluent Releases \\ 3.1.1 Alrborne:}

The airborne radionuclide effluent releases have been negligible to date.

\subsubsection{Liquid:}

None to date during CY-1991.

\subsection{Hezardous Substance/Requlated Pollutant Effluent Releases \\ 3.2.1 Alrborne:}

Not determined. LBL has no measuring system/device to determine the requested data.

\subsubsection{Liquld:}

The liquid hazardous substance/regulated pollutant effluent releases have been below regulatory limits to date this year.

\subsection{Manacoement}

\subsection{Open DOE Audit Issues}

Not reported to date. Awaiting DOE guidance.

\subsection{Open External Oraanization Recommendations}

Not reported to date. Awaiting DOE guidance.

\subsection{Occurrence Reports with Open Corrective Actions}

Remains moderate at seven for the current reporting period.

\subsection{Corrective Maintenance Backlog}

Down to $11.9 \%$ in the current reporting period from $34.0 \%$ in the second quarter. 


\subsection{Preventive Maintenance Overdue}

Up to $6.2 \%$ in the current reporting period from $3.5 \%$ in the second quarter.

\subsection{Substance Abuse Incidents}

None to date for CY-1991.

\subsection{Volume of Solld Waste Generated}

\subsubsection{Low-Level Radloactlye Waste}

There has been no low-level radloactive waste generated during the current year.

\subsubsection{Low-Level Hazardous Waste}

\subsubsection{Generated}

The amount of low-level mixed generated is the largest to date for CY-1991, 244.8 cubio feet. The amount generated has been increasing steadlly over the last three quarters.

\subsubsection{Pending Shipment}

The amount of low-level mixed waste pending shipment has inoreased slightly since the last quarter.

\subsubsection{Shipped}

The shipment of low-level mixed waste has resumed in the third quarter.

\subsubsection{Lew-Level Mixed Waste}

There has been no low-level mixed waste gerierated during the curreint calendar year. 


\section{Collective Radiation Dose}

The total external whole-body dose (deep and shallow) received by all facility personnel (including subcontractors and visitors) as measured by the primary dosimeter, i.e., thermoluminescent dosimeter (TLD), or film badge. Exposure measured by direct reading dosimeters should be included only for those periods or situations when more accurate data are not available. Collective radiation dose is reported in units of person-rem.

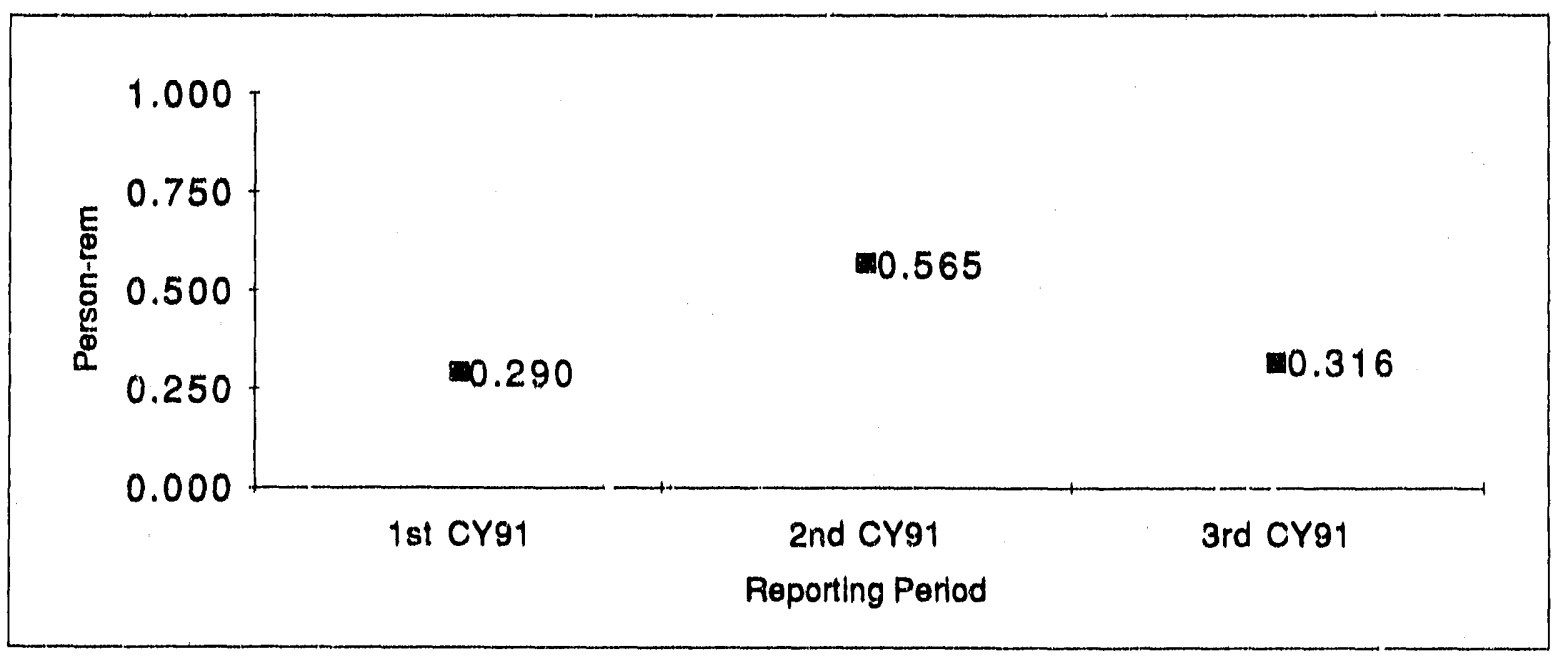

All three reporting quarters have had collective radiation doses well below permitted levels.

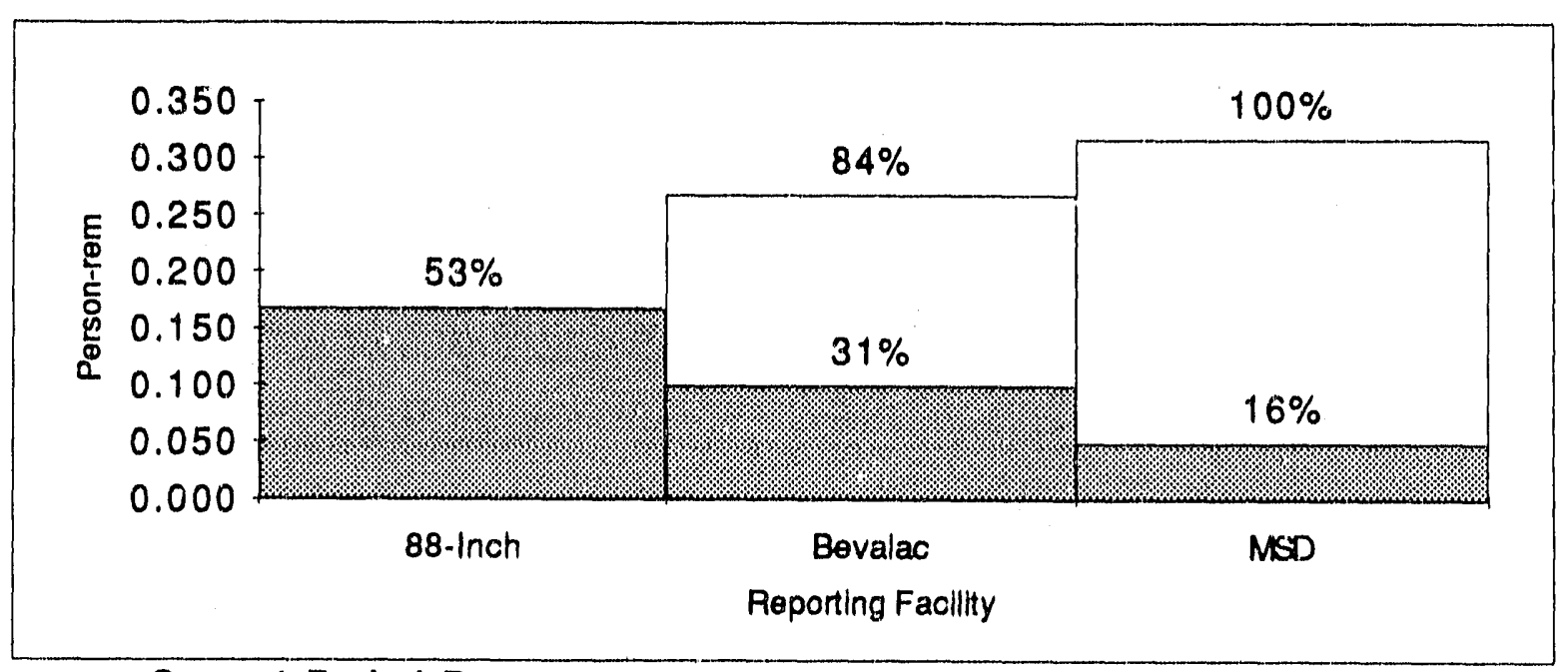

\section{Current Period Data}

P| 1.1 


\section{Materials Sciences Division}

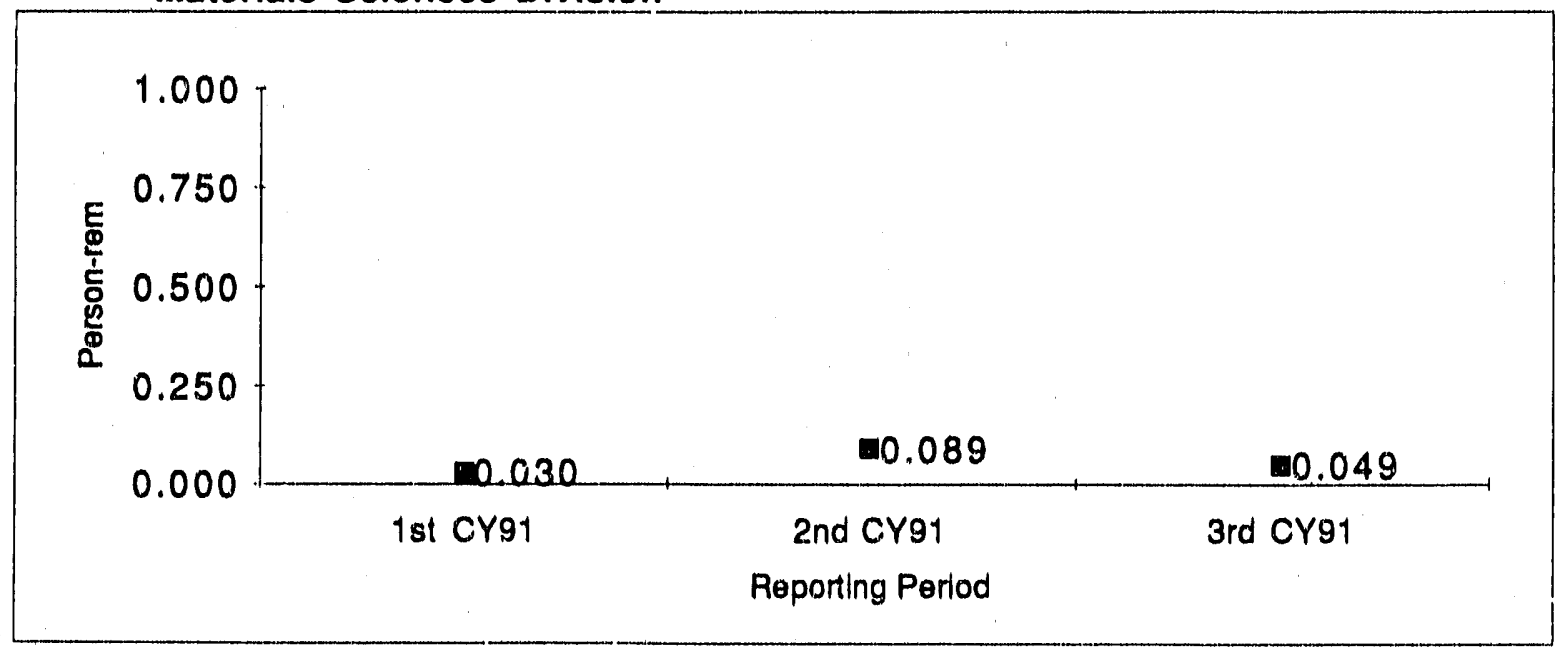

Well below permitted levels.

Bevalac

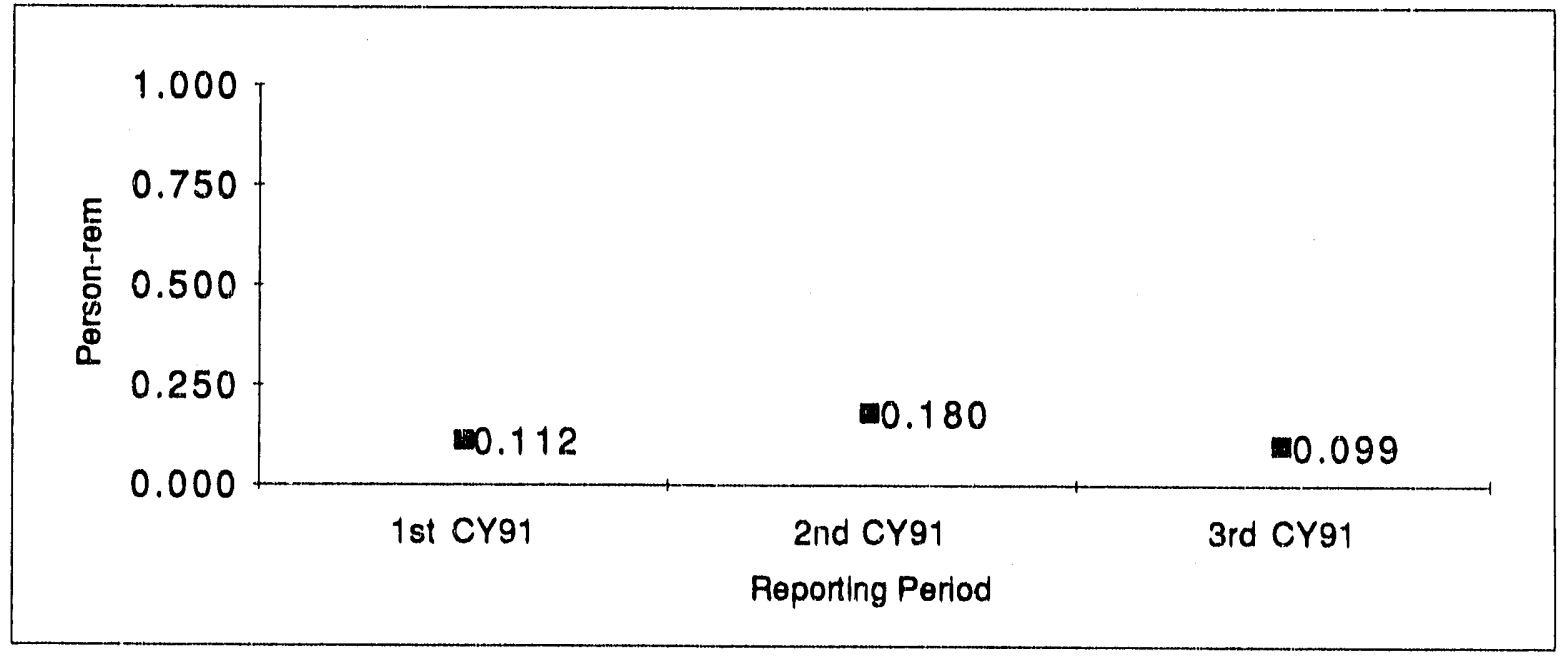

Well below permitted leveis.

PI 1.1 


\section{8-Inch Cyclotron}

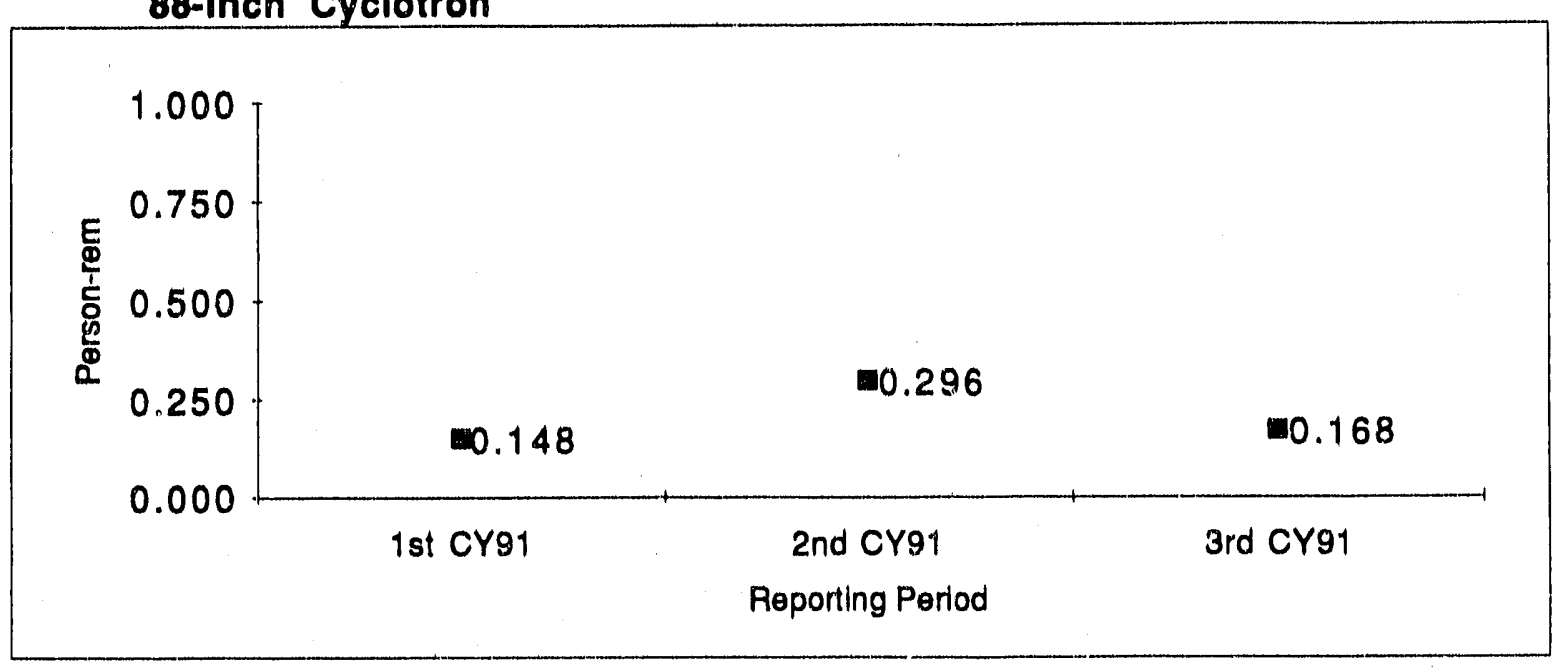

Well below permitted levels.

PI 1.1 


\subsection{Skin Contaminations}

The total number of confirmed skin and personal clothing contaminations for all facility personnel, including subcontractors and visitors. Skin or clothing contamination due to radioactive noble gases or naturally occurring radon gas are not included.

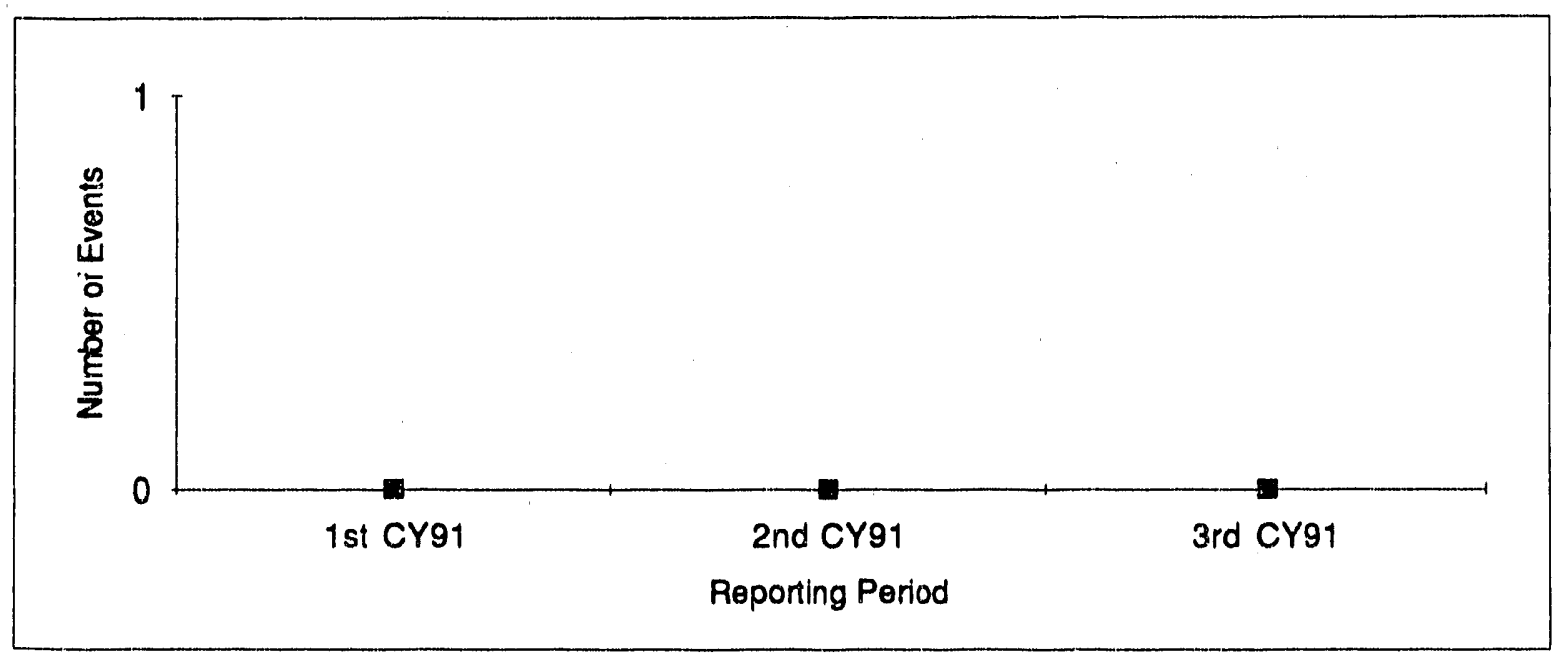

There has not been an incident of skin contamination at LBL in the past three quarters.

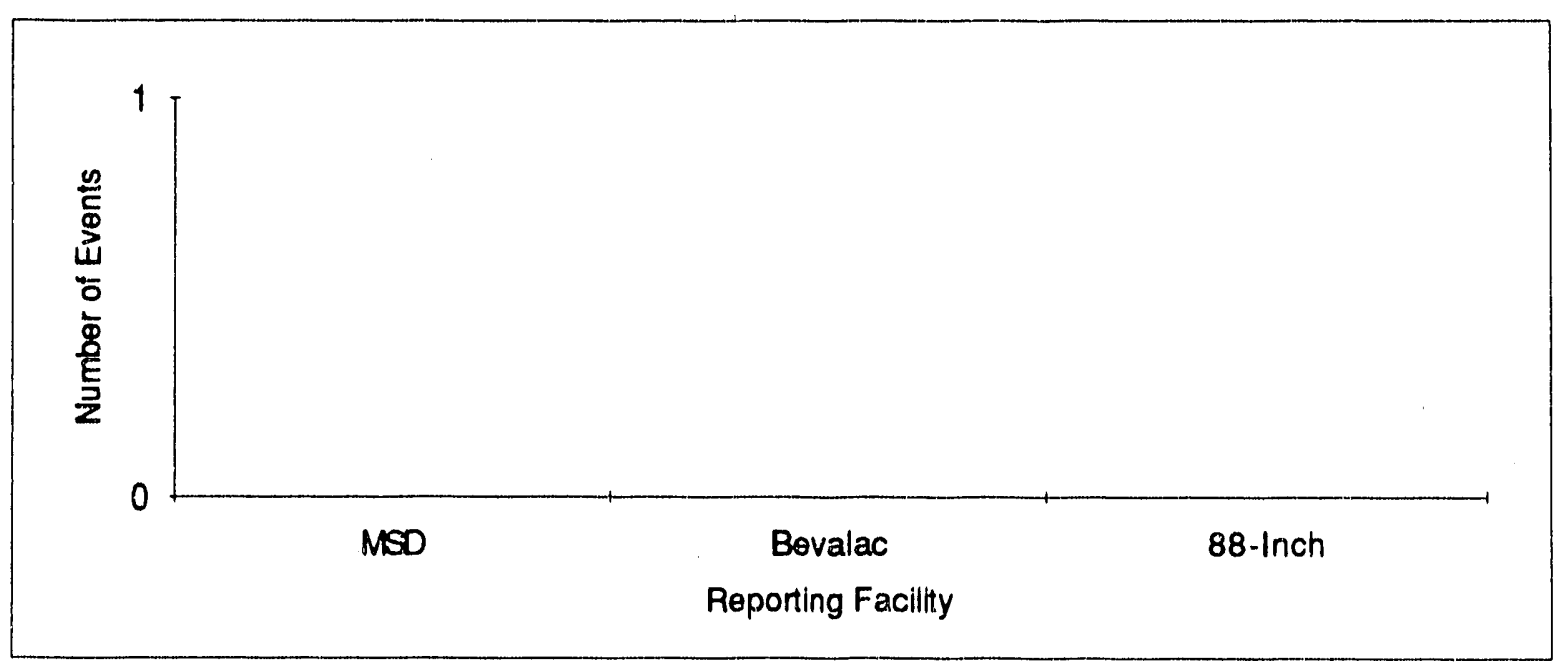

Current Period Data

No incidents of skin contamination.

PI 1.2 


\section{Root Cause of Occurrences}

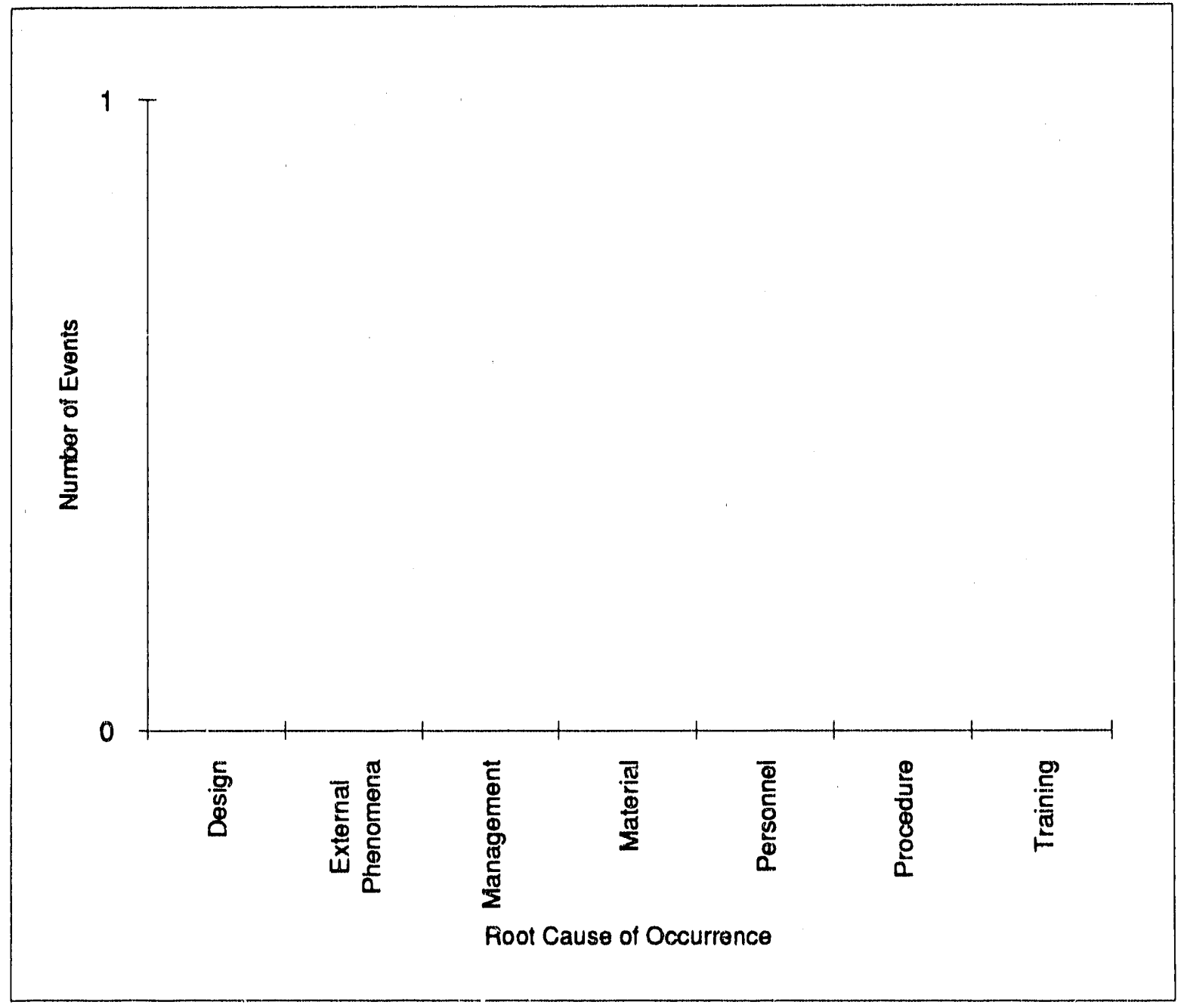

There has not been an incident of skin contamination at LBL in the past three quarters.

P) 1.2 


\section{Materials Sciences Division}

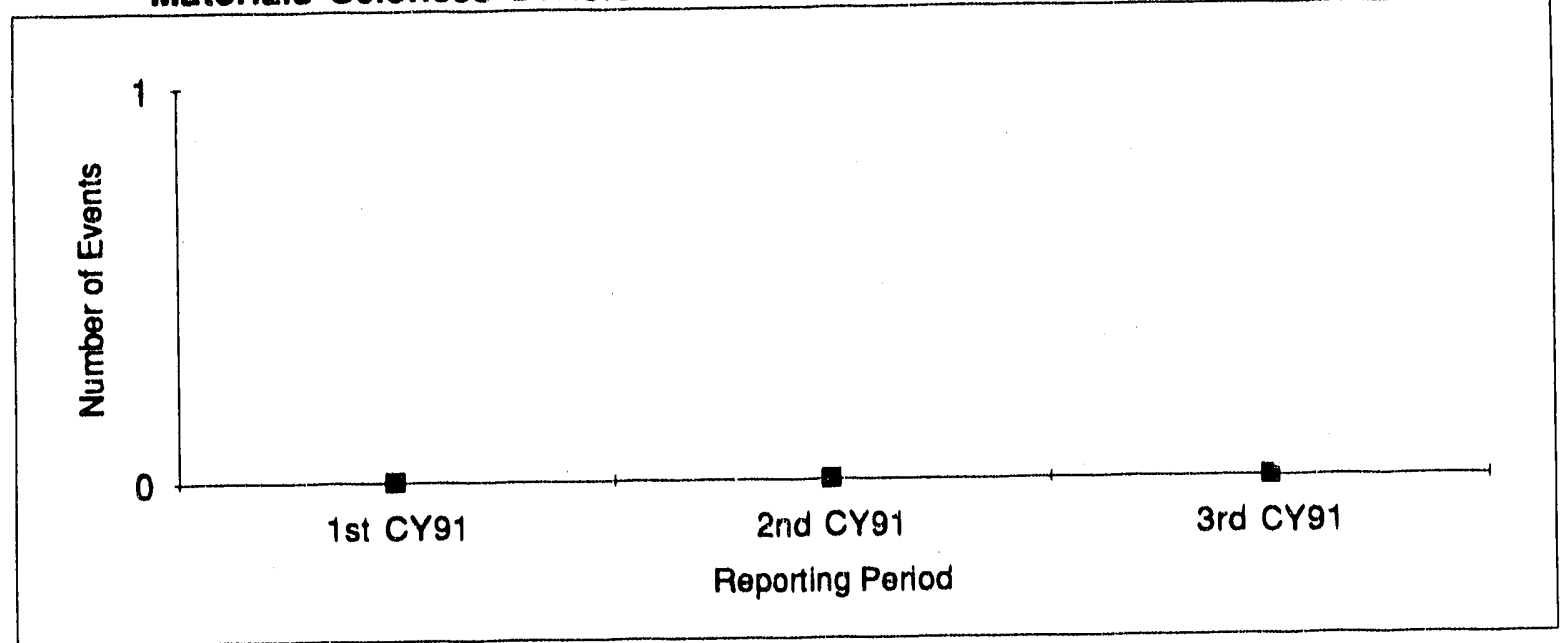

No incidents of skin contamination.

\section{Bevalac}

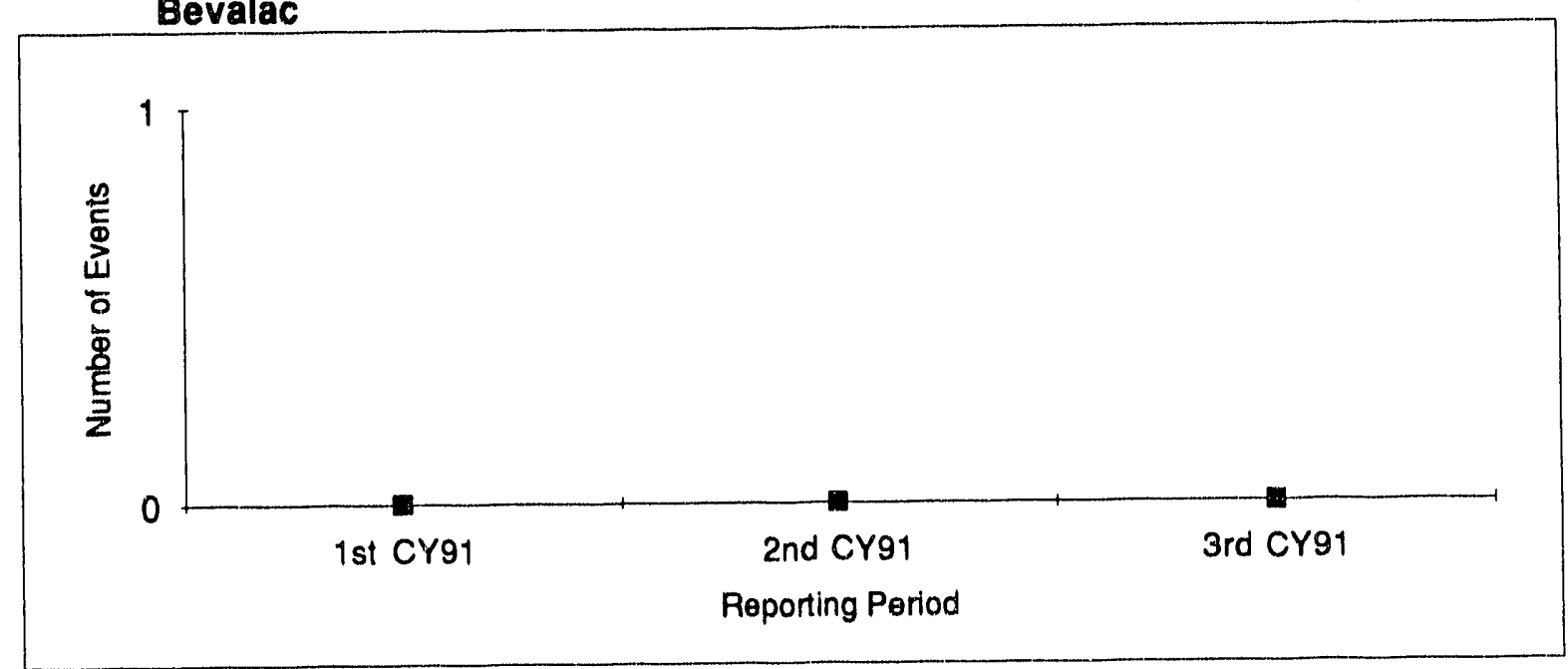

No incidents of skin contamination.

PI 1.2 


\section{8-Inch Cyclotron}

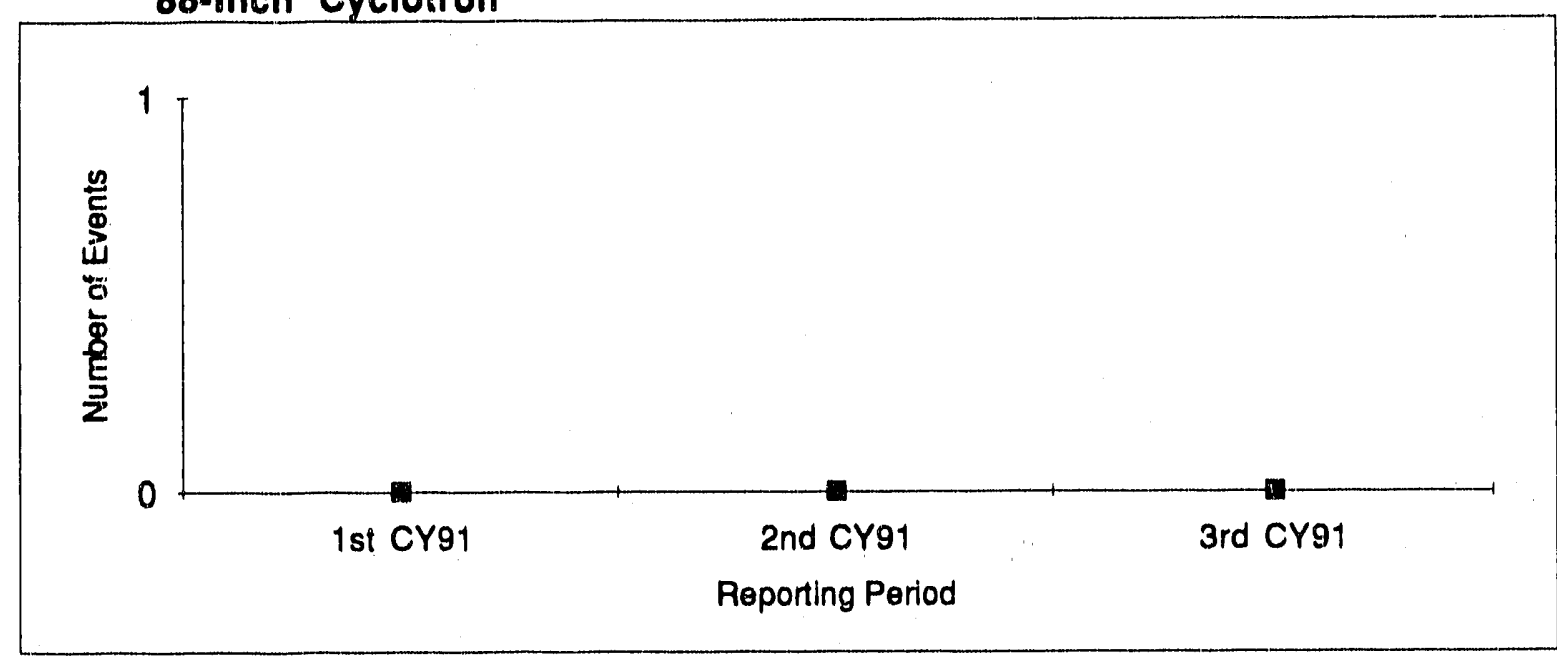

No incidents of skin contamination.

P| 1.2 


\subsection{Internal Contaminations}

The total number of confirmed intakes of radioactive material for all facility personnel, including subcontractors and visitors, occuring during the reporting period.

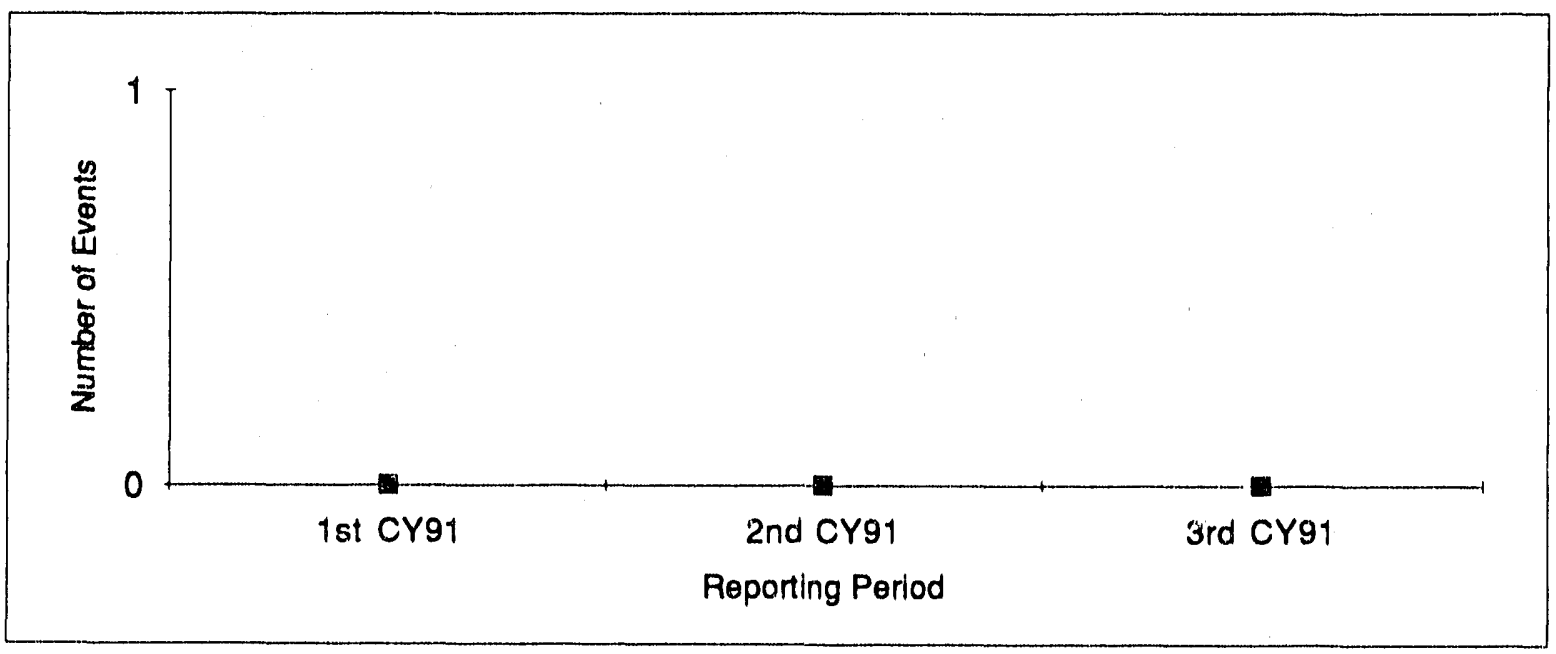

There has not been an incident of internal contamination at LBL in the past three quarters.

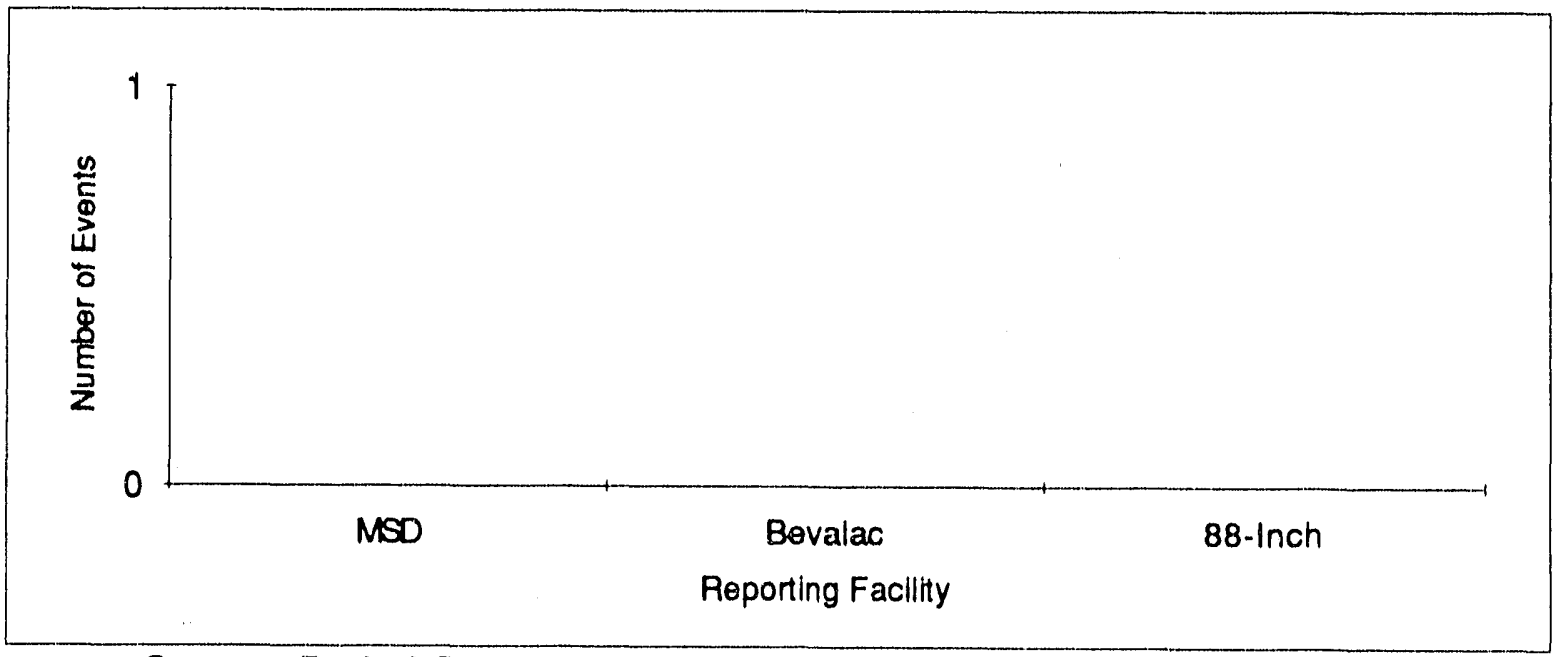

\section{Current Period Data}

No iricidents of internal contamination. 


\section{Root Cause of Occurrences}

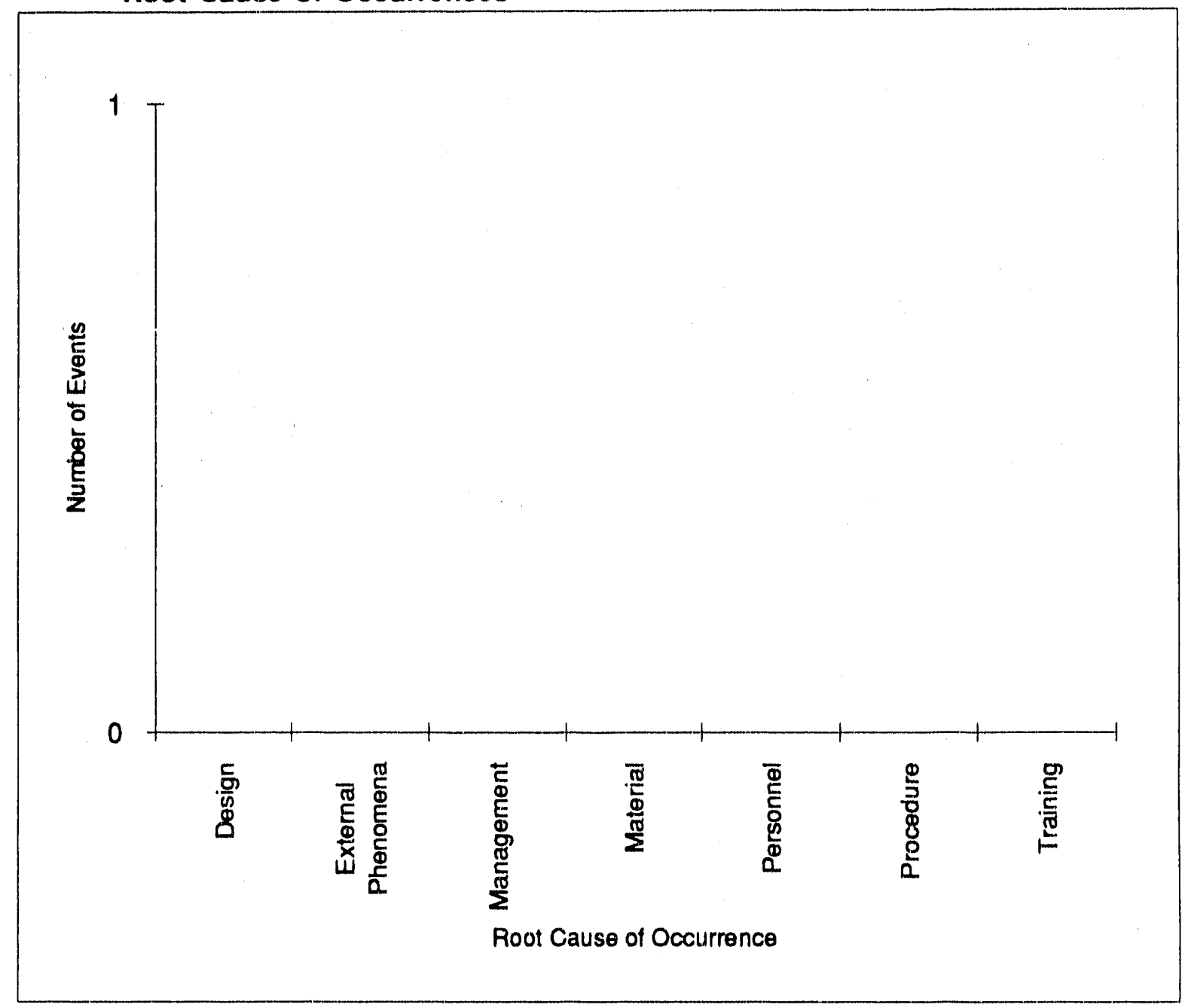

There has not been an incident of internal contamination at $L B L$ in the three quarters of calendar year 1991.

PI 1.3 
Materials Sciences Division

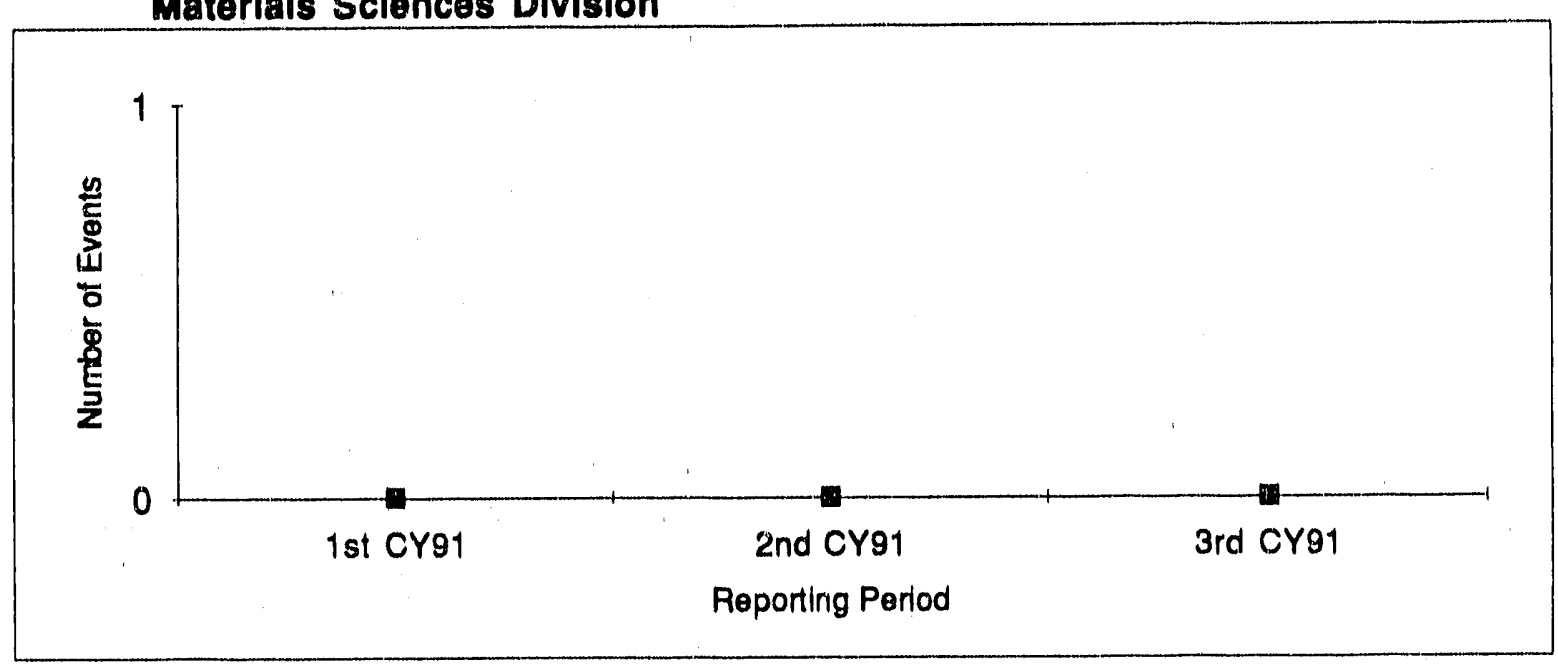

No incidents of internal contamination.

Bevalac

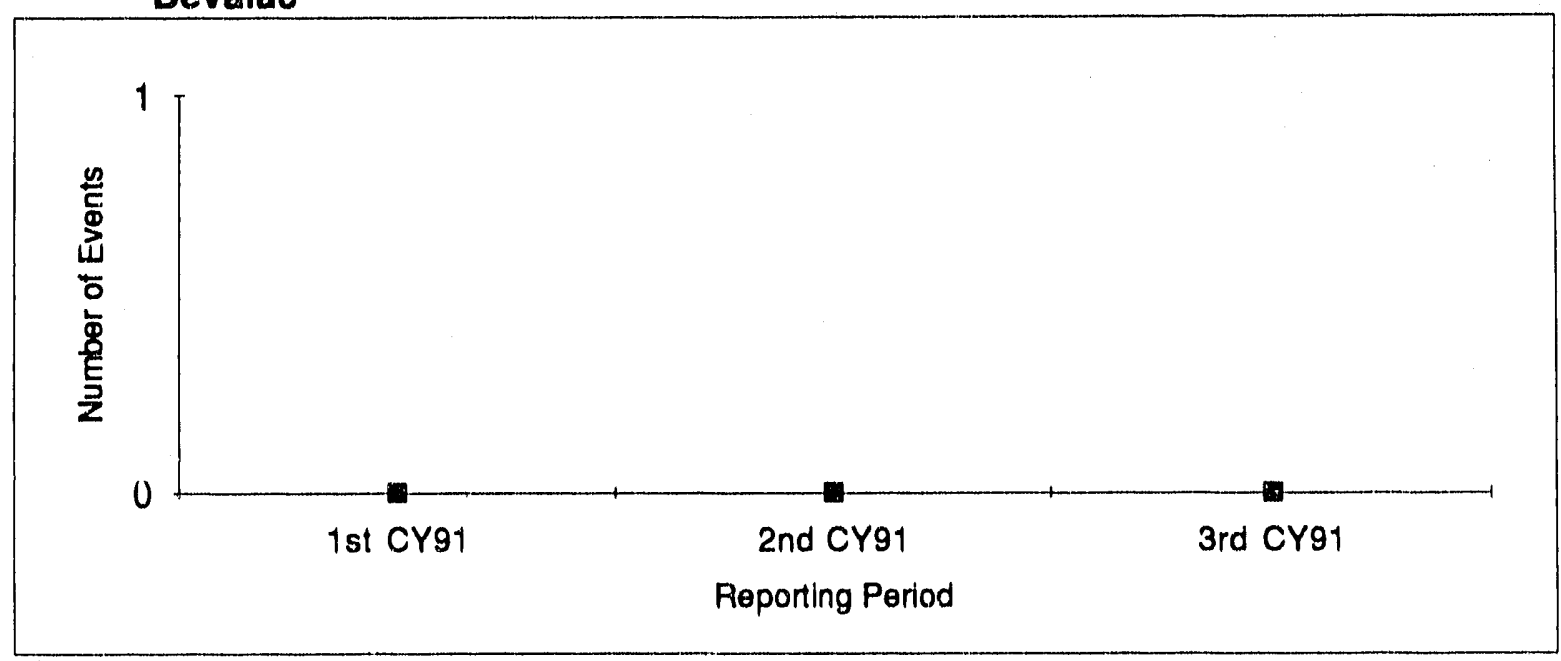

No incidents of internal contamination.

PI 1.3 


\section{8-Inch Cyclotron}

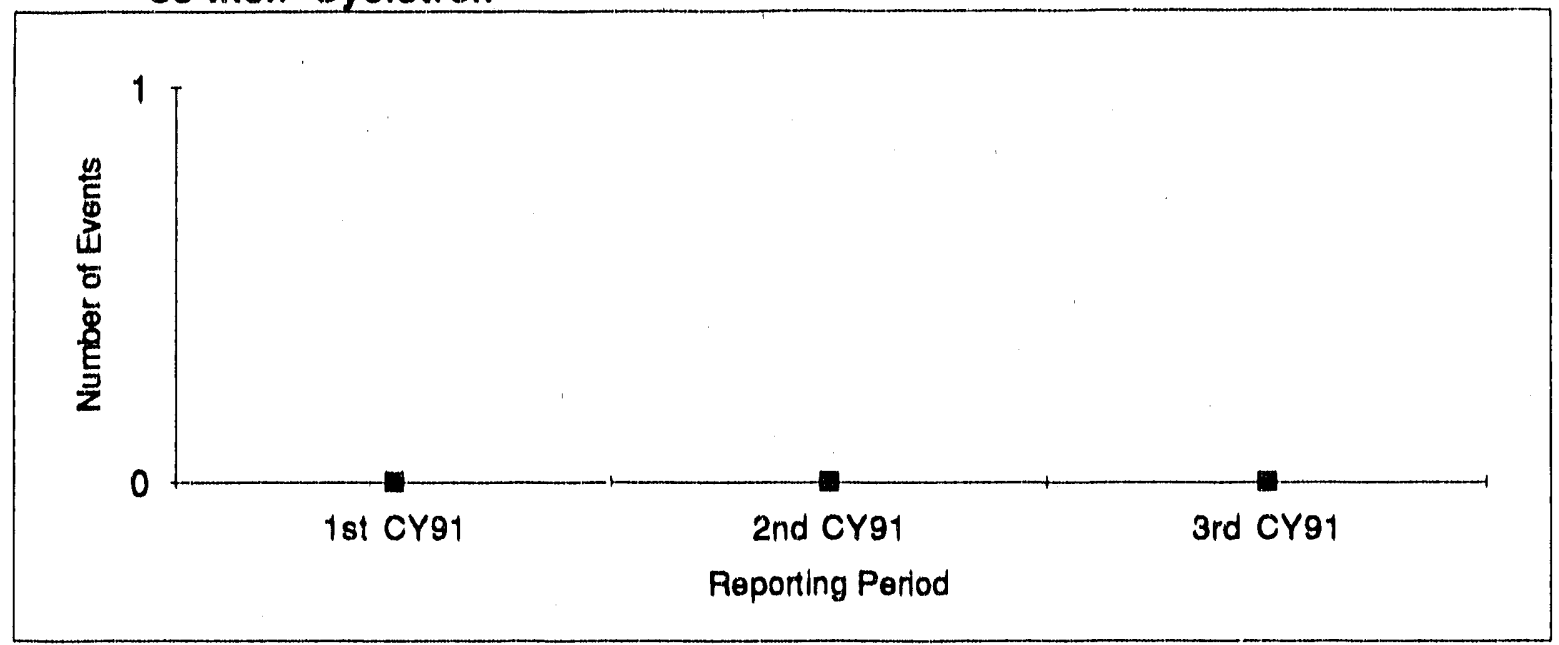

No incidents of internal contamination. 


\subsection{Radioactlve or Hazardous Material Overexposures}

The number of reportable occurrences resulting trom a personnel oxposure (for all facllity personnel, including subcontractors and visitors) to radioactive or hazardous materials in excess of limits established in DOE Orders.

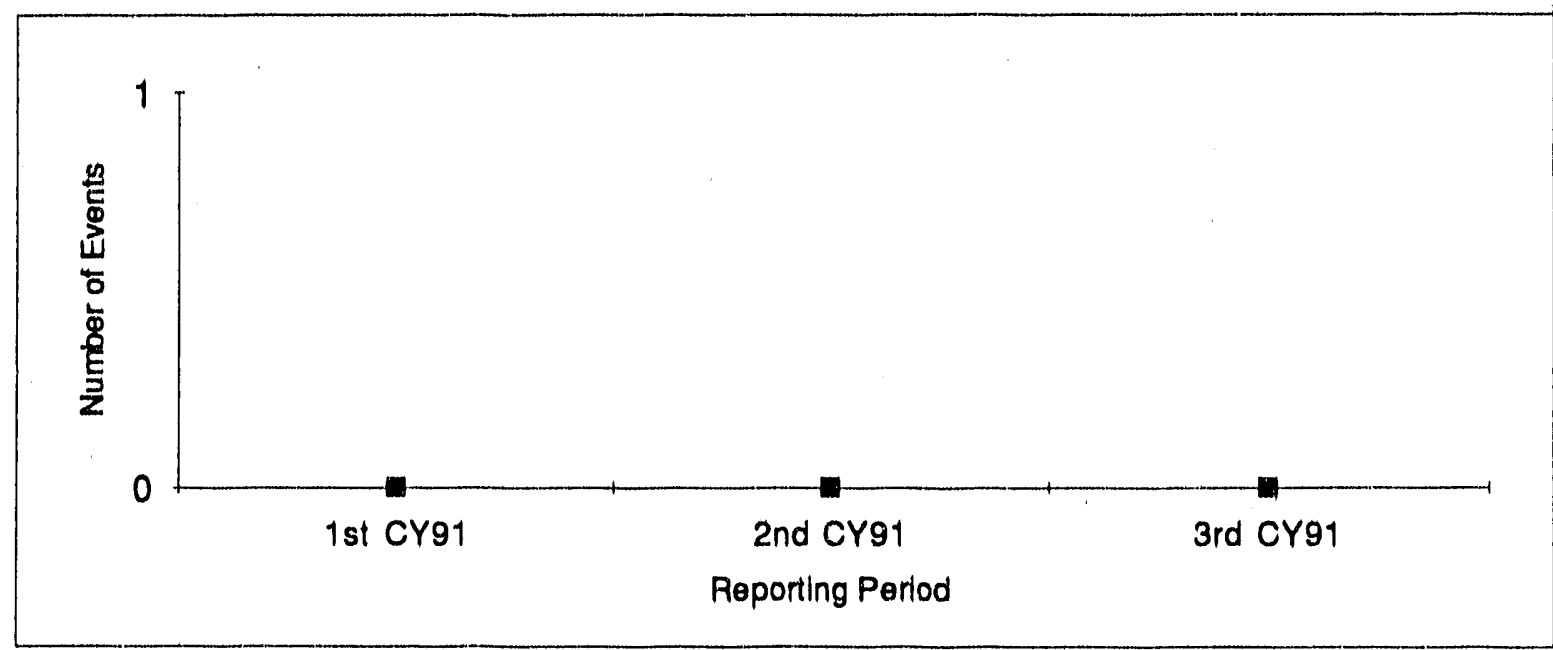

There have been no incidents of overexposure to radioactive or hazardous materials at $L B L$ in the past three quarters. (The incident reported for the second quarter in the previous report occurred in 1990).

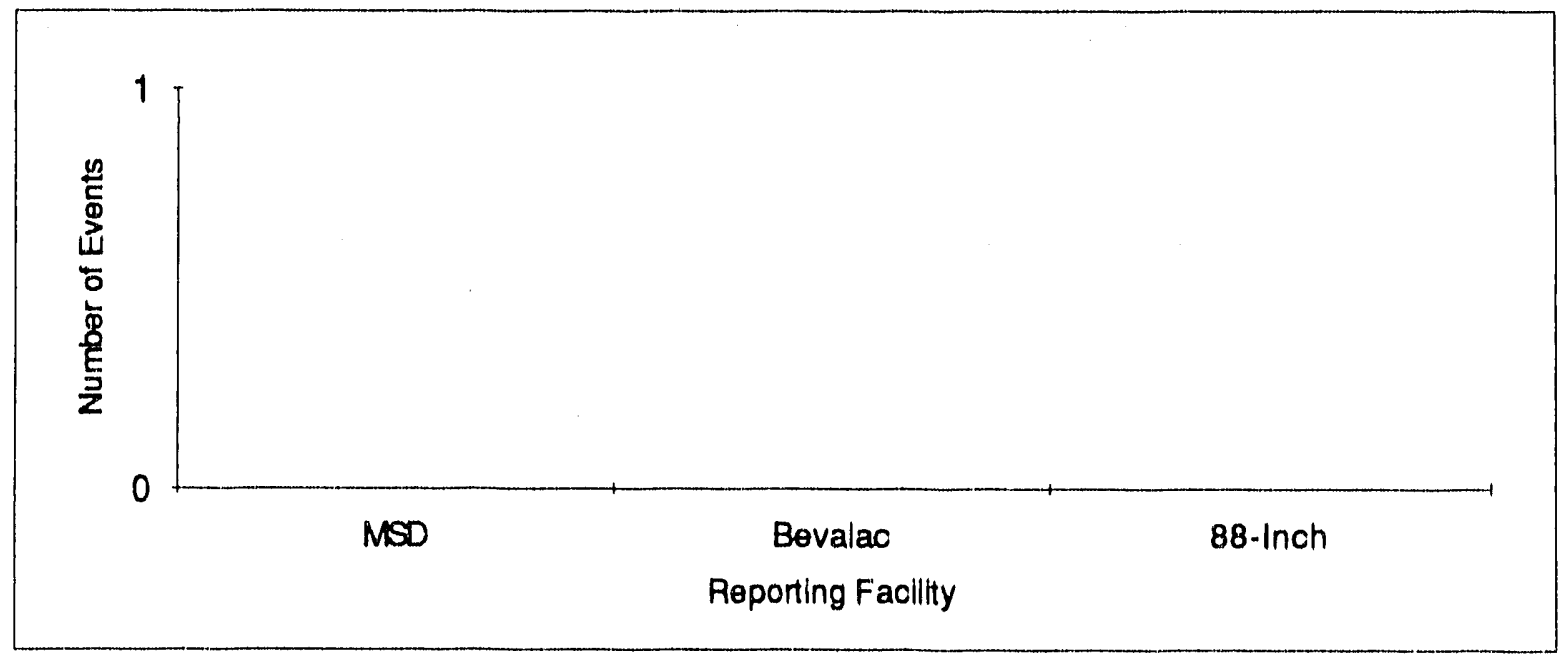

\section{Current Period Data}

No incidents of overexposure to elther radioastive or hazardous materials.

PI 1.4 
Root Cause of Occurrences
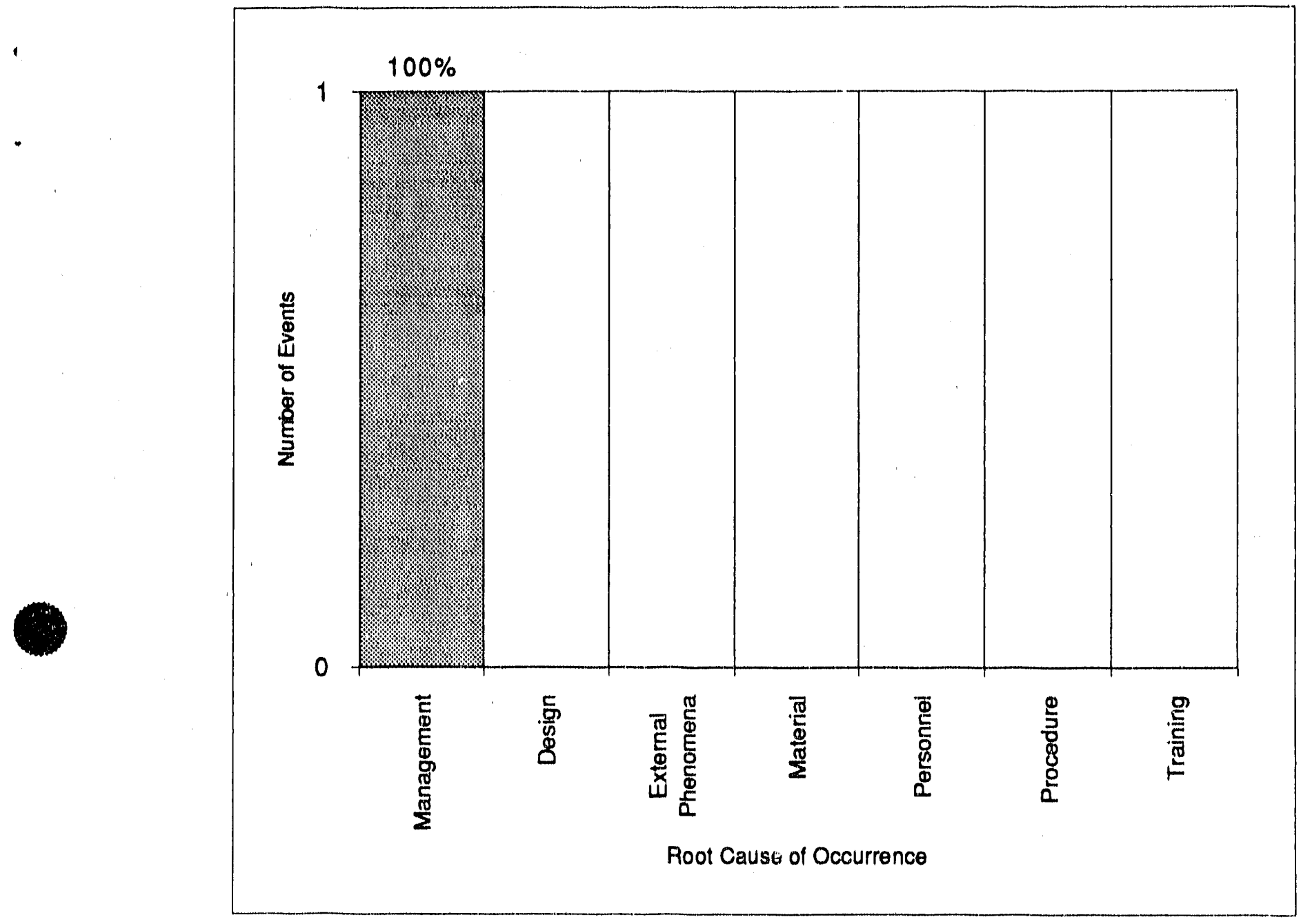

Although there have been no overexposures to radioactive or hazardous materials at LBL in the PI reporting quarters (1st - 3rd qtrs, CY-1991), there was an overexposure (LBL-90-28-51-8) in 1990 which had Management as it root cause. 


\section{Materials Sciences Division}

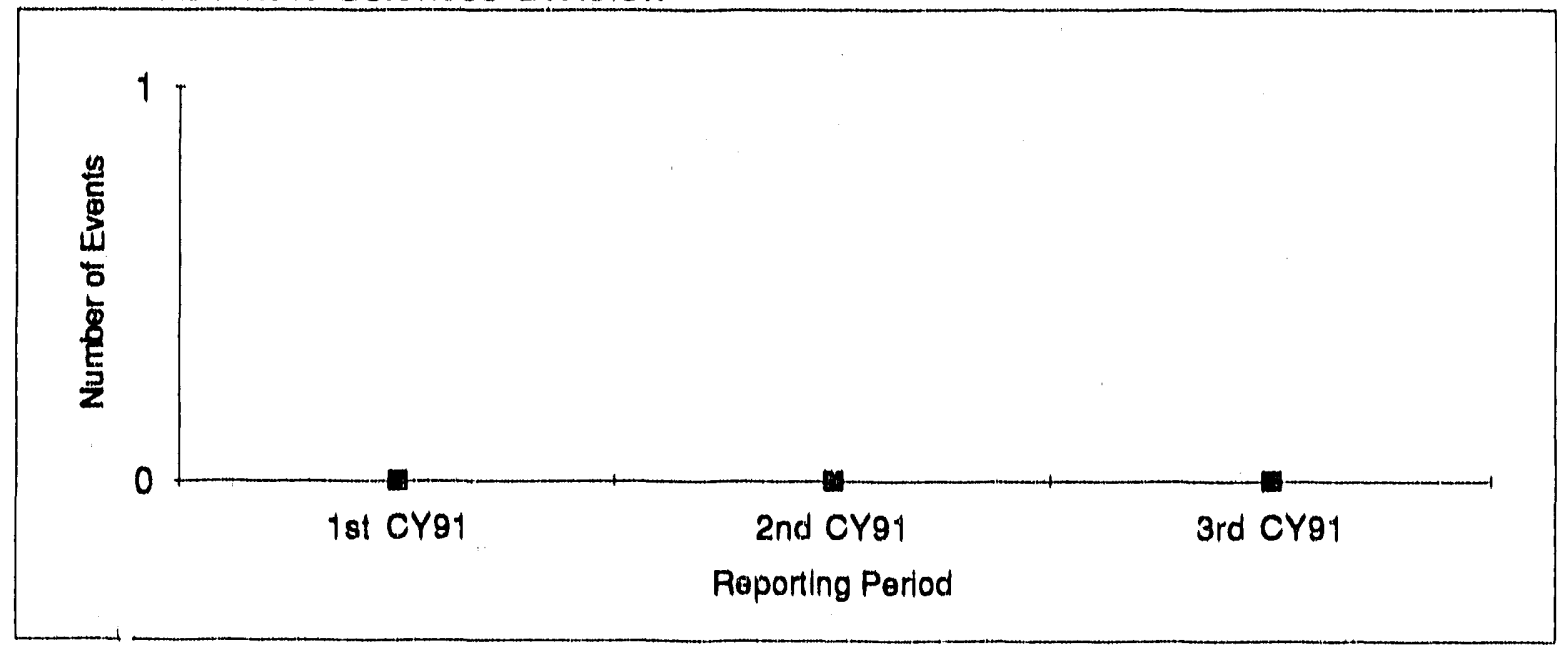

No incidents of overexposure to elther radioactive or hazardous materials.

\section{Bevalac}

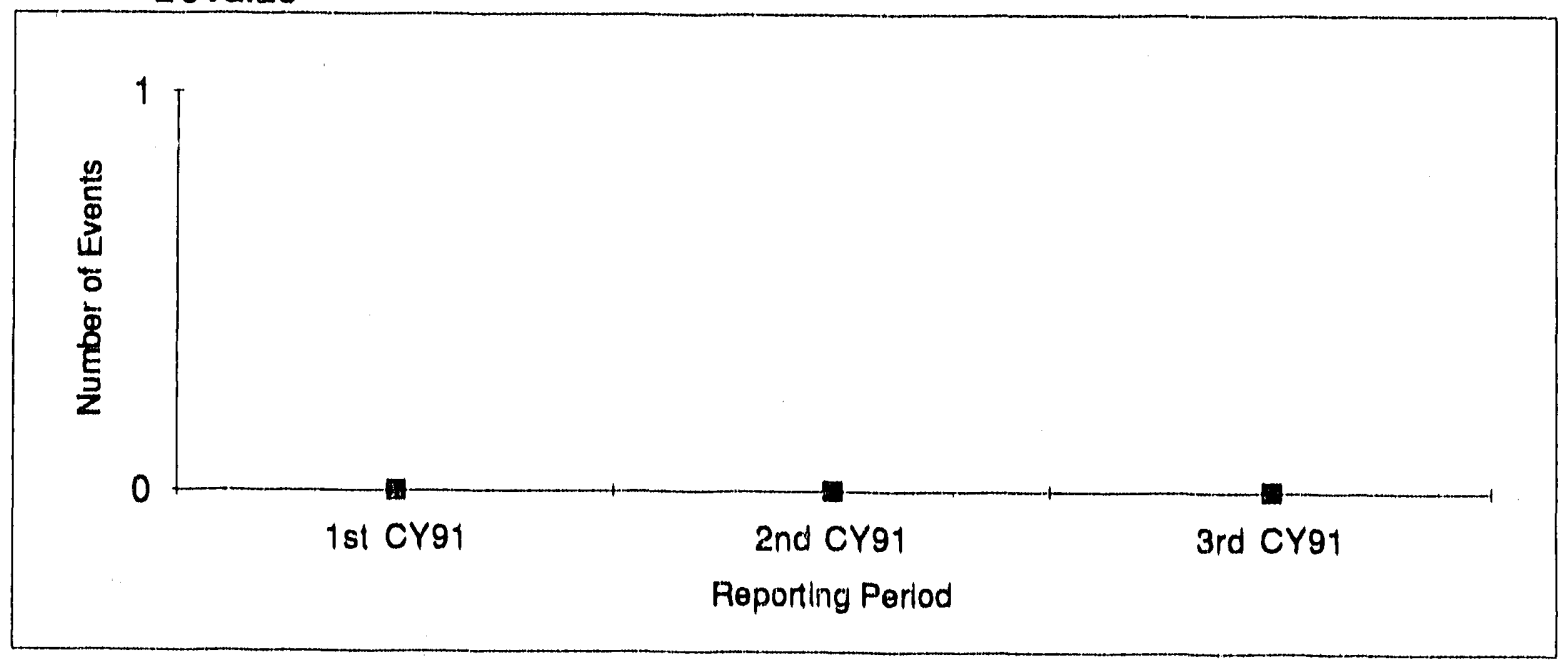

Although one second quarter overexposure was reported in the previous report, this incident took place, in fact, in 1990 and should not have been included. To date, there have been no incidents of overexposure to elther radioactive or hazardous materials at the Bevalac facillity for the reporting periods. 


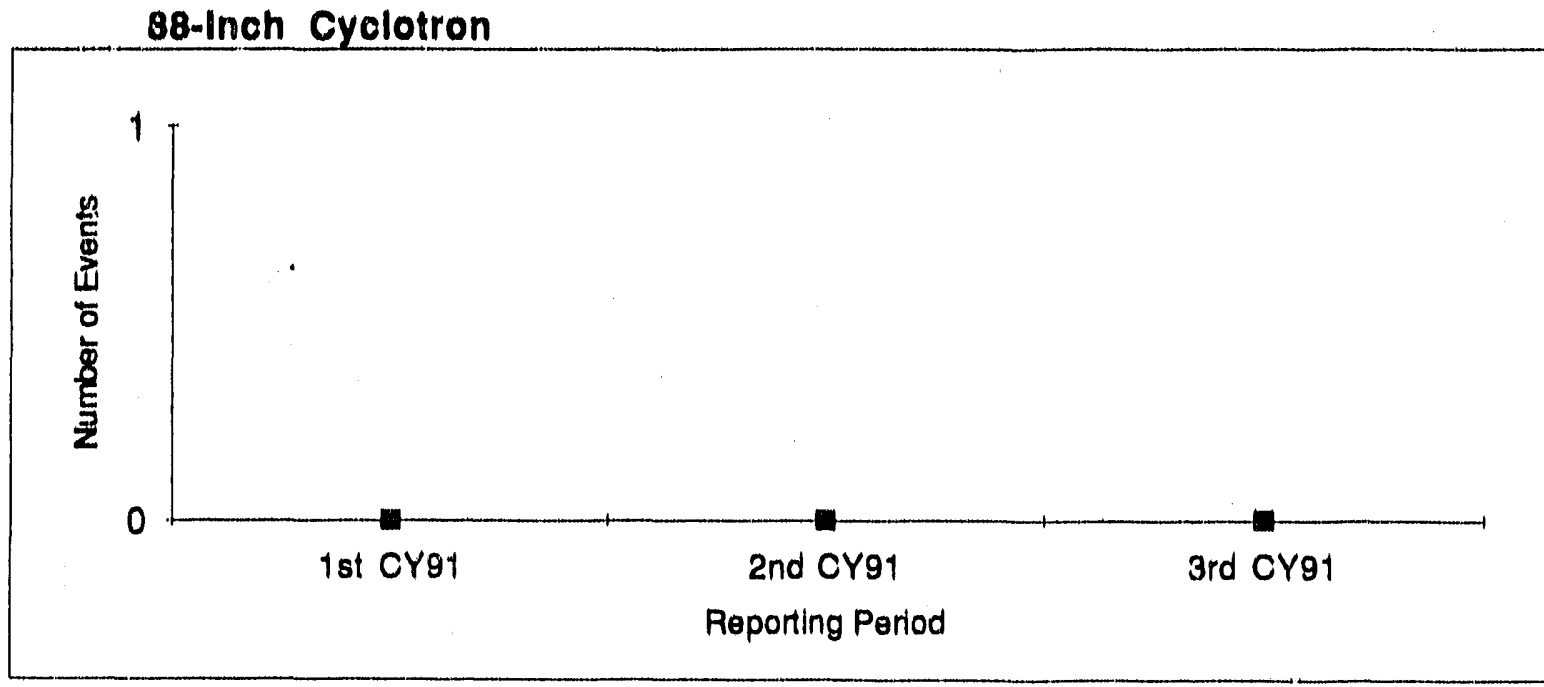

No incldents of overexposure to elther radioactive or hazardous materials. 


\subsection{Lost Work Day Cases (Lost Time Accident Rate)}

Number of incidents for all facillty personnel involving days awati from work per 100 personyears (200,000 person-hours) worked.

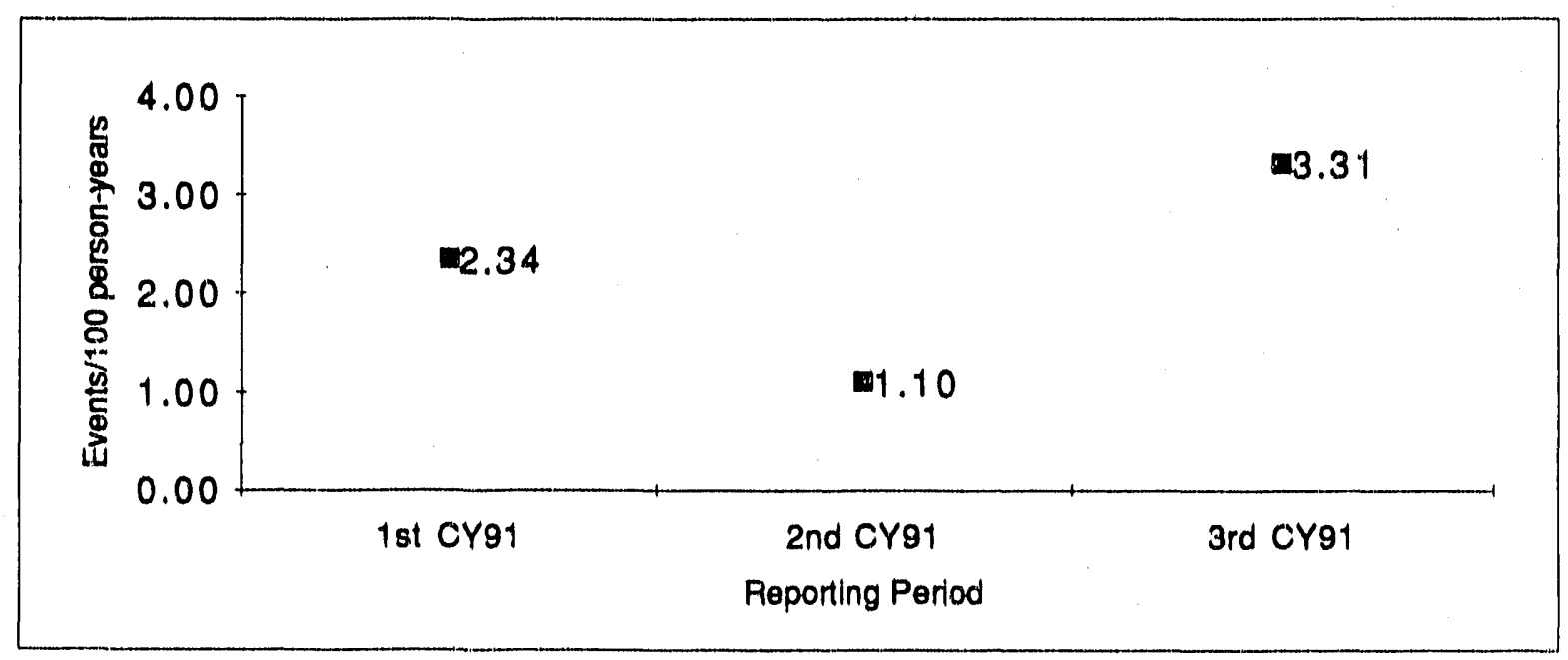

Because there has not been a large deviation in the number of hours worked at the three LBL facilities, the trend for rates also reflects the trend for number of lost work day cases for the first three quarters of 1991 (2, 1, and 3, respectively, per quarter.)

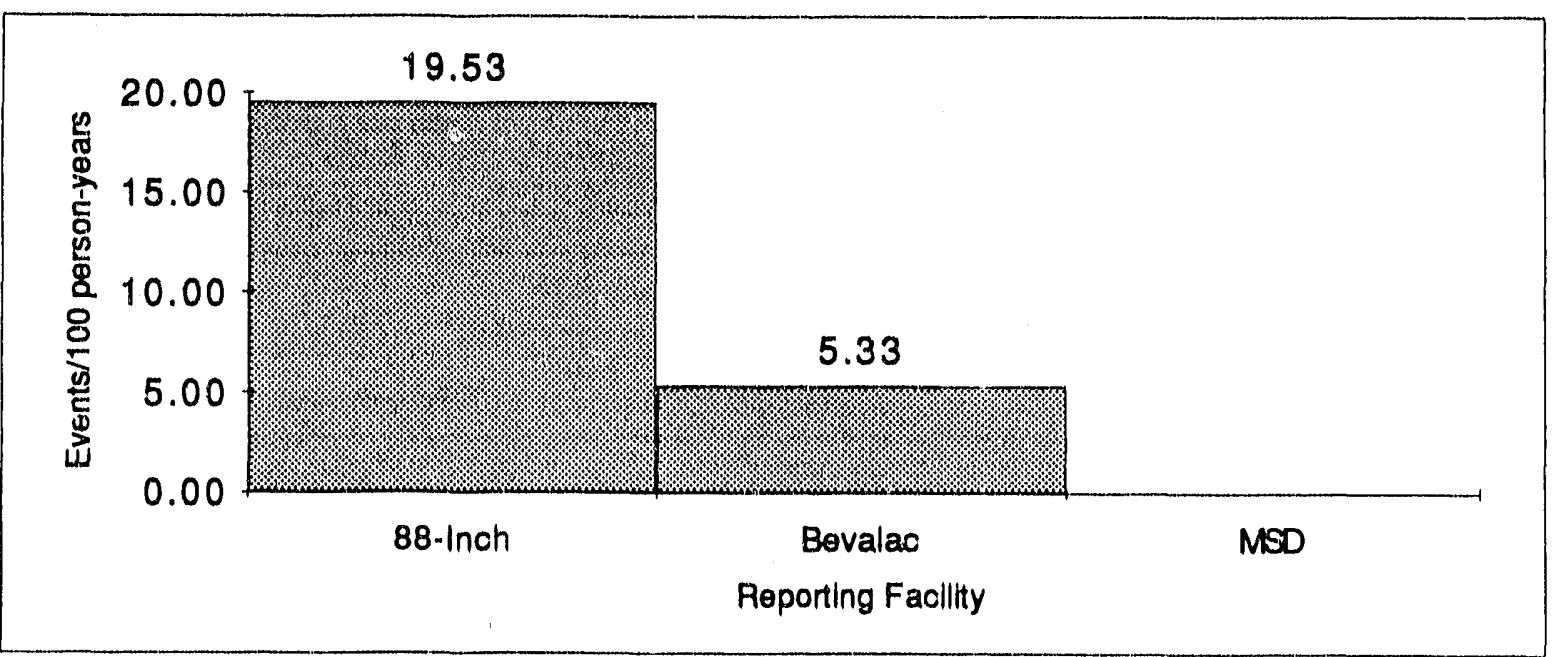

\section{Current Period Data}

Note: Because the sum of the facility rates does not accurately reflect the overall LBL rate, the individual facility rates are given here.

The seemingly large rate for the 88 -Inch facility is due in part to the low number of personnel at the facility (approx. 22). There was, in fact, only one (1) event at the 88 Inch facility in the third quarter. 
Materlals Sciences Divlsion

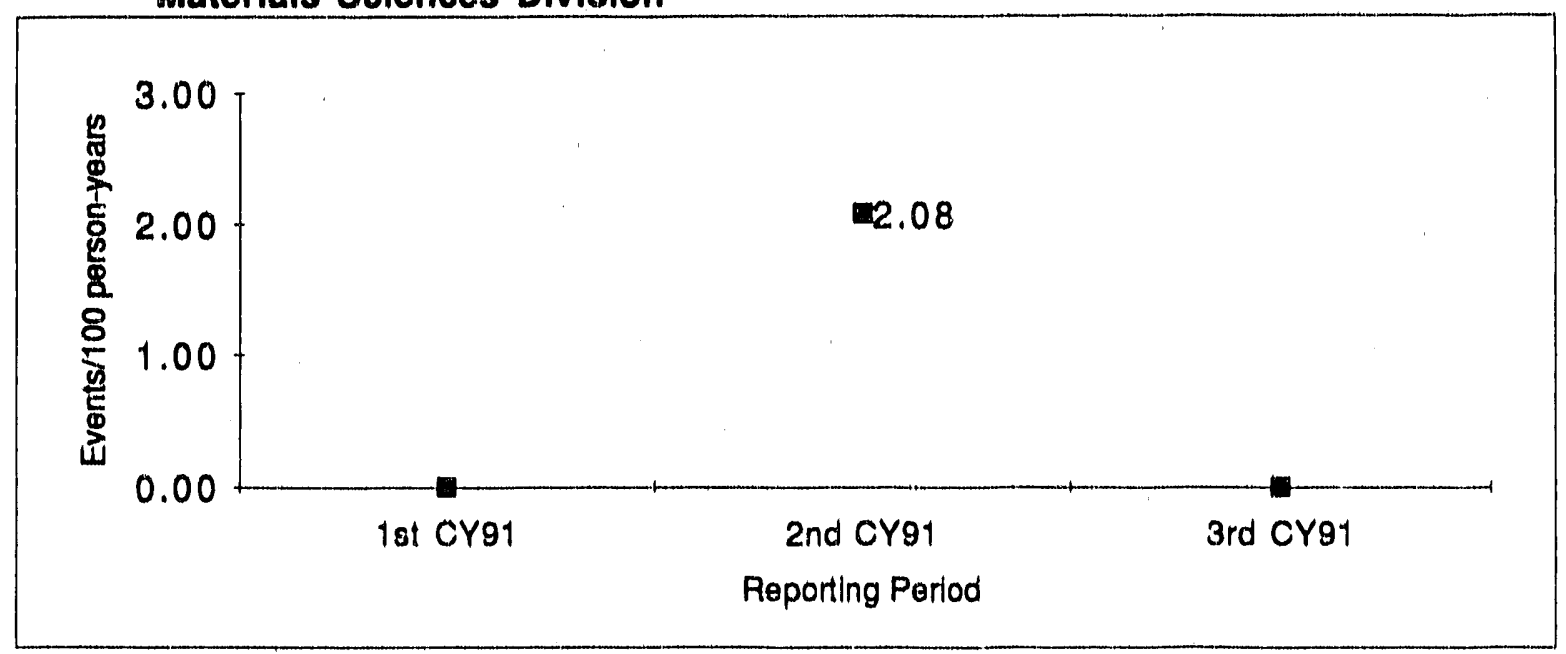

The above rates reflect one (1) incident in the second quarter, and none in elther the first or third. The Materials Sciences Division has approximately 200 personnel.

\section{Bevalac}

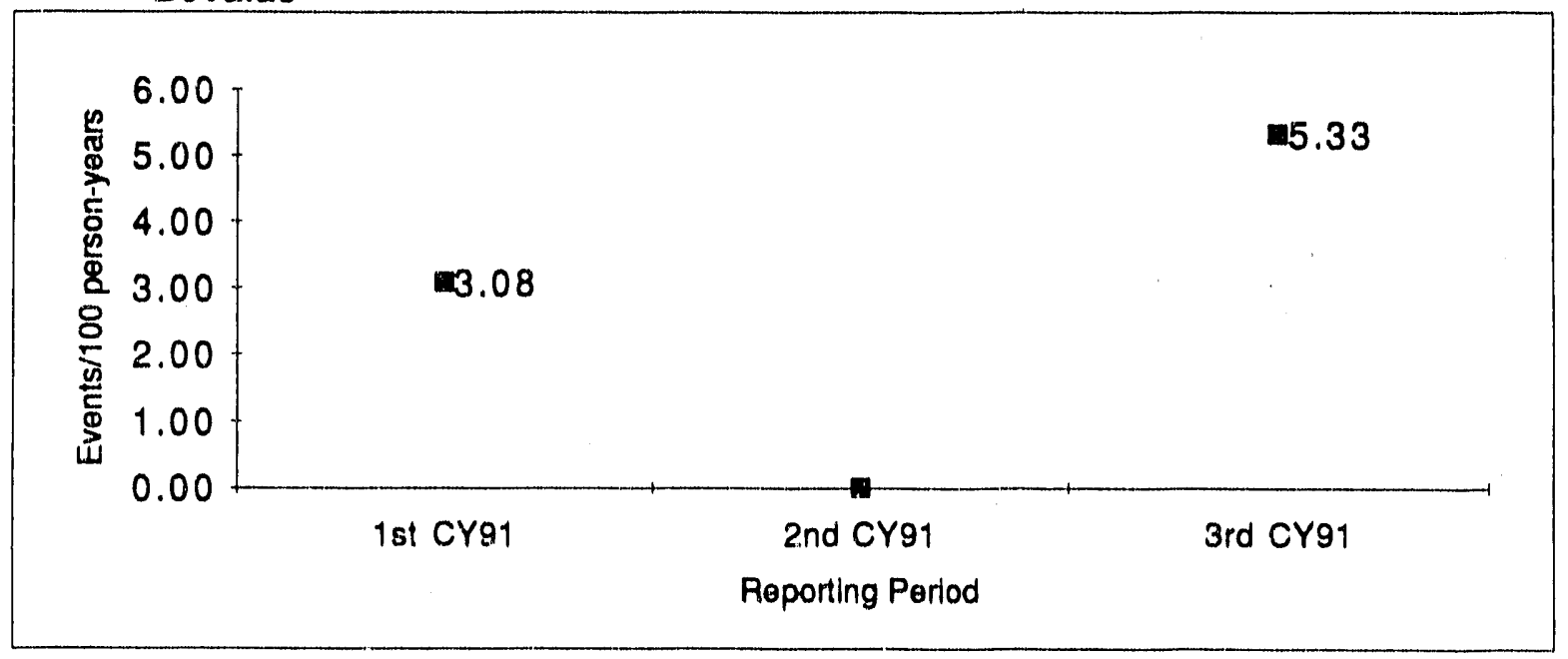

The above rates reflect one (1) incident in the first quarter, none in the second, and two (2) in the third. The Bevalac facility has approximately 150 personnel.

PI 1.5 


\section{8-Inch Cyclotron}

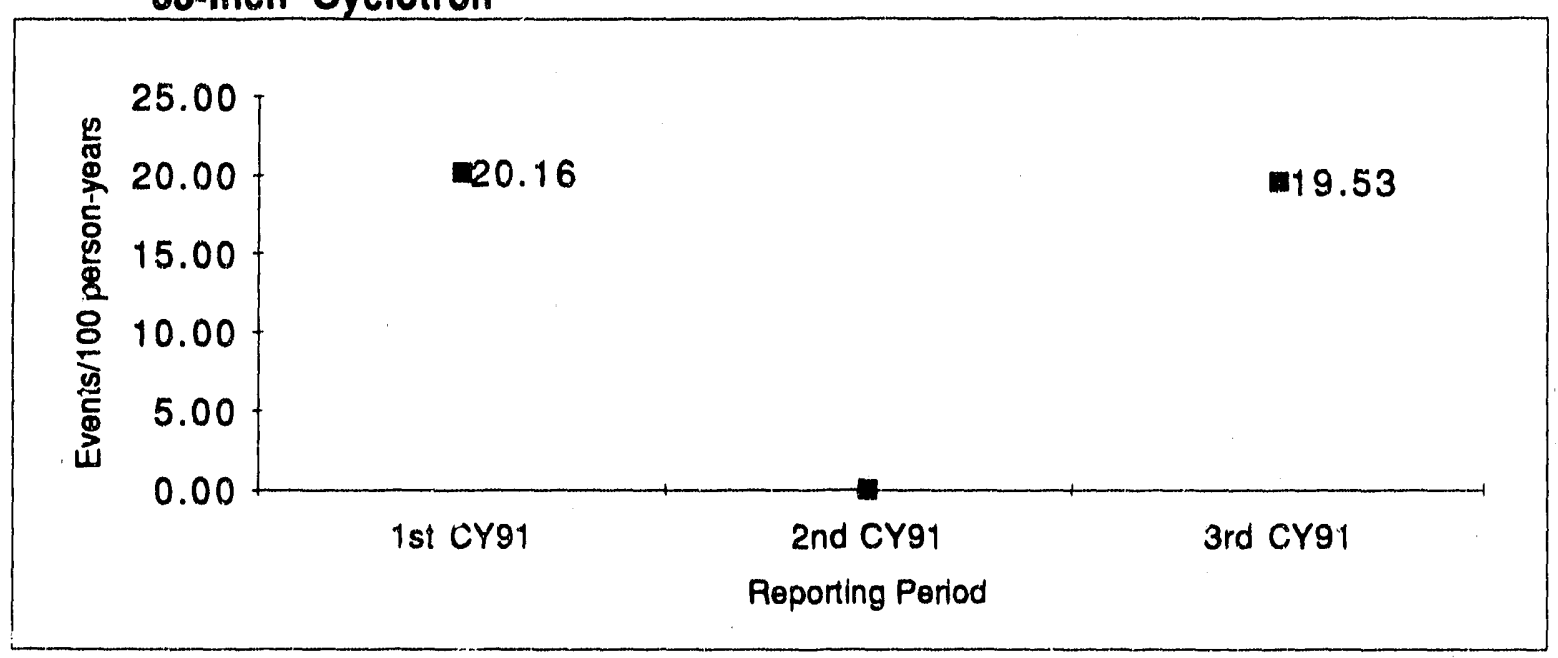

The above rates reflect one (1) incident in both the first and third quarters, and none in the second. The associated high rates are due partially to the low employee population at the 88-Inch facility (approximately 22). 


\subsection{Recordable Injuries/llinesses Rate}

Total number of injuries or illness instances resulting from on-the-job activities that are recordable in accordance with OSHA Standards, per 100 person-years (200,000 person-hours) worked.

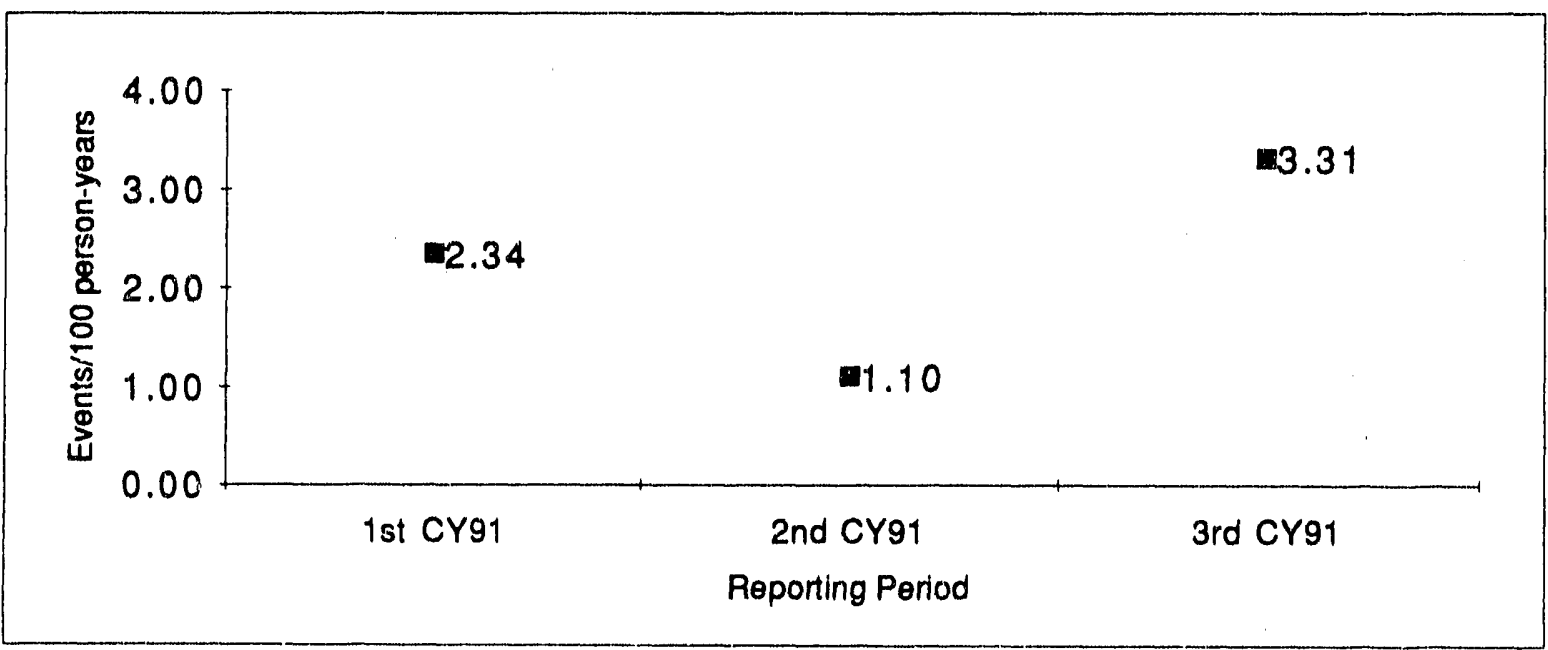

Because there has not been a large deviation in the number of hours worked at the three LBL facilities, the rate trend reflects the trend associated with the recordable injuries/illnesses for the first three quarters of $1991(2,1$, and 3 , respectively, per quarter.)

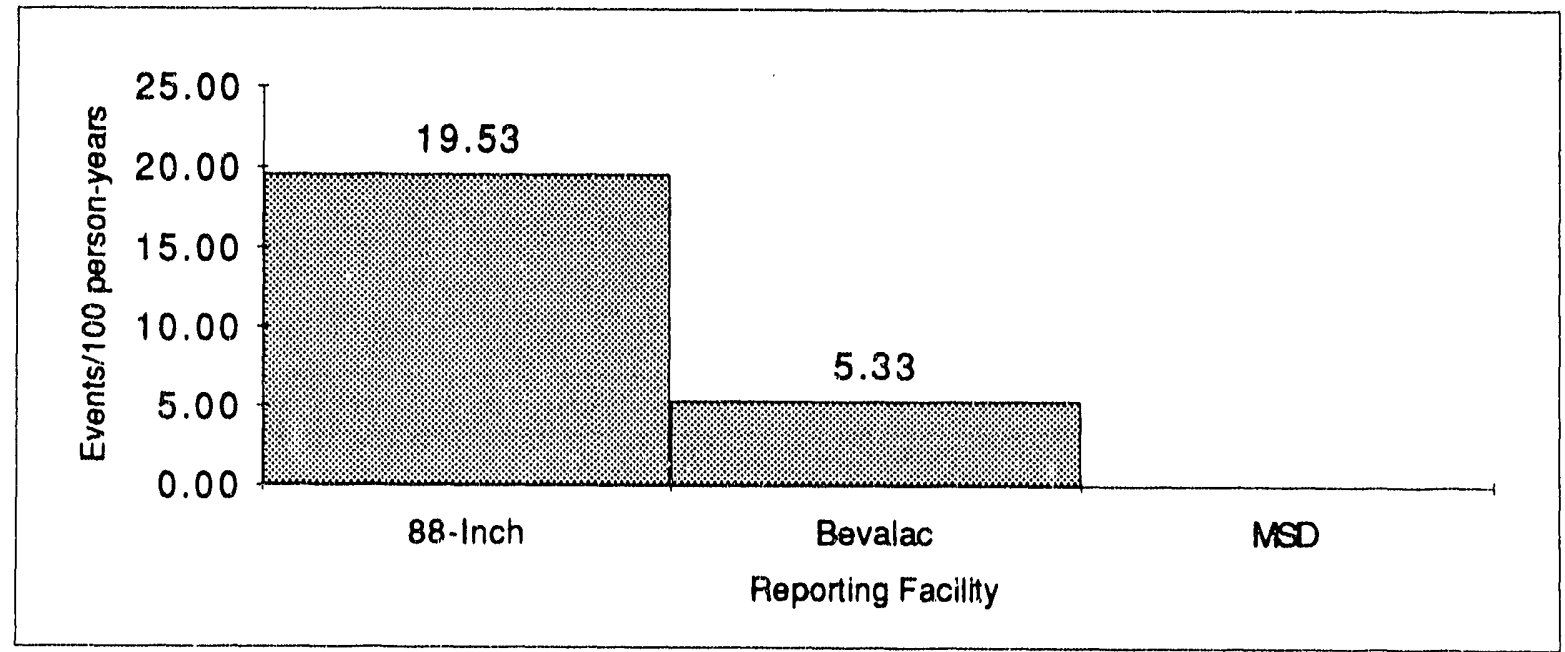

\section{Current Period Data}

Note: Because the sum of the pacility rates does not accurately reflect the overall LBL rate, the individual facility rates are given here.

The seemingly large rate for the 88 -Inch facility is due primarily to the low number of personnel at the facility (approx. 22). 


\section{Materials Sciences Division}

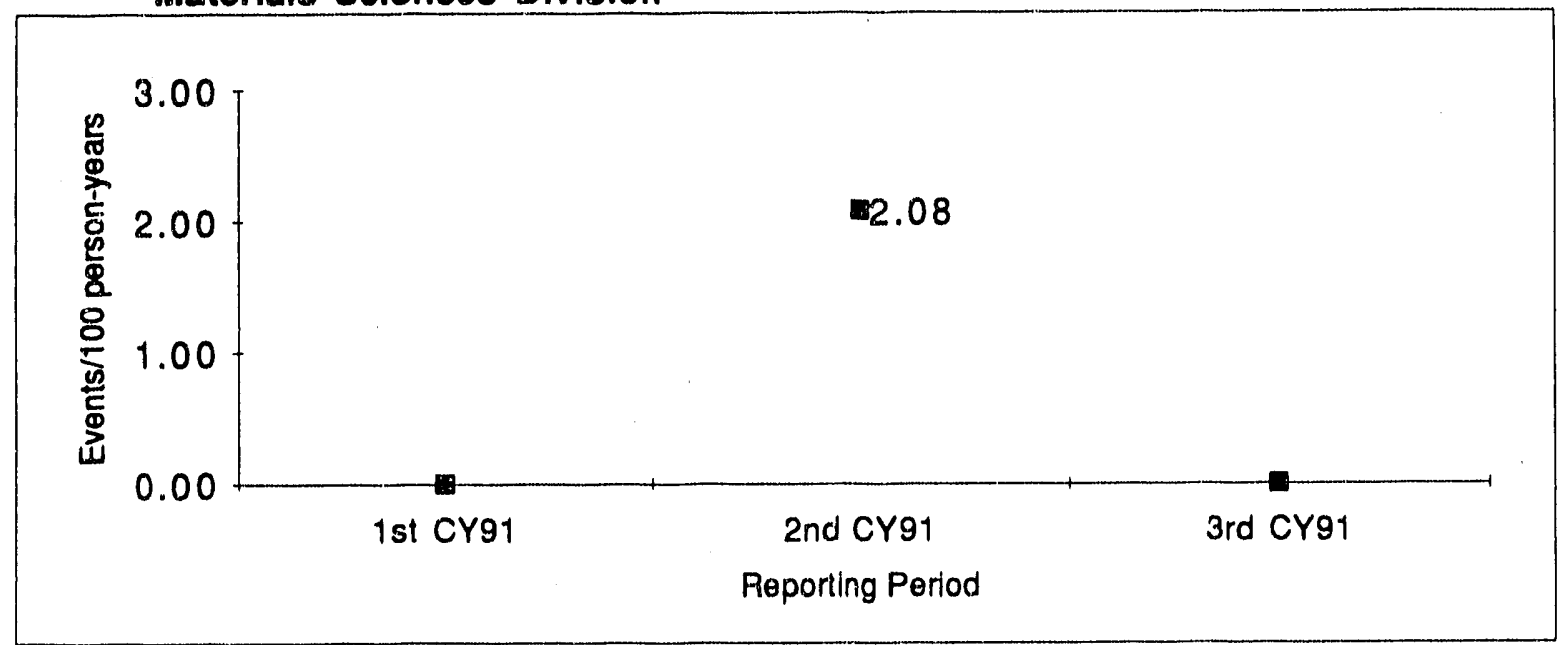

The above rates reflect one (1) incident in the second quarter, and none in either the first or third. The Materials Sciences Division has approximately 200 personnel.

\section{Bevalac}

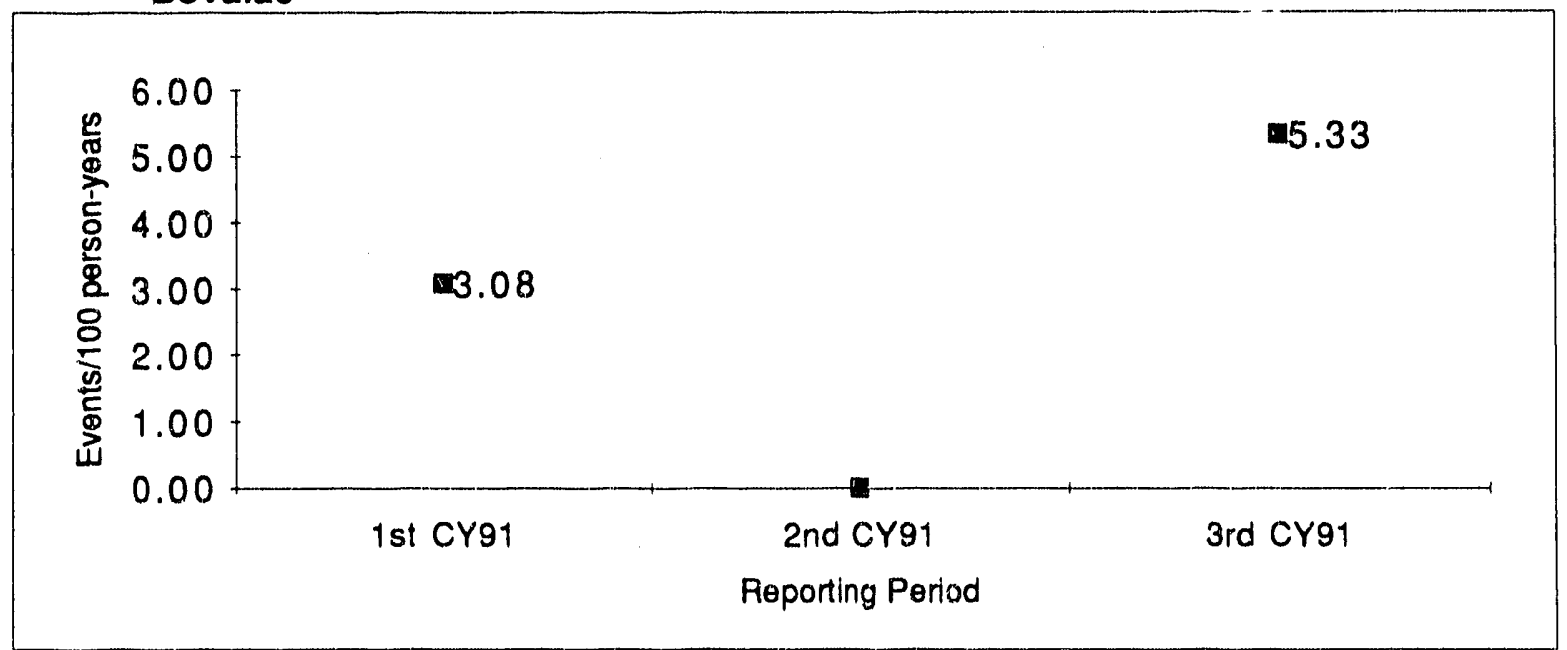

The above rates reflect one (1) incident in the first quarter, none in the second, and two (2) in the third. The Bevalac facility has approximately 150 personnel.

PI 1.6 


\section{8-Inch Cyclotron}

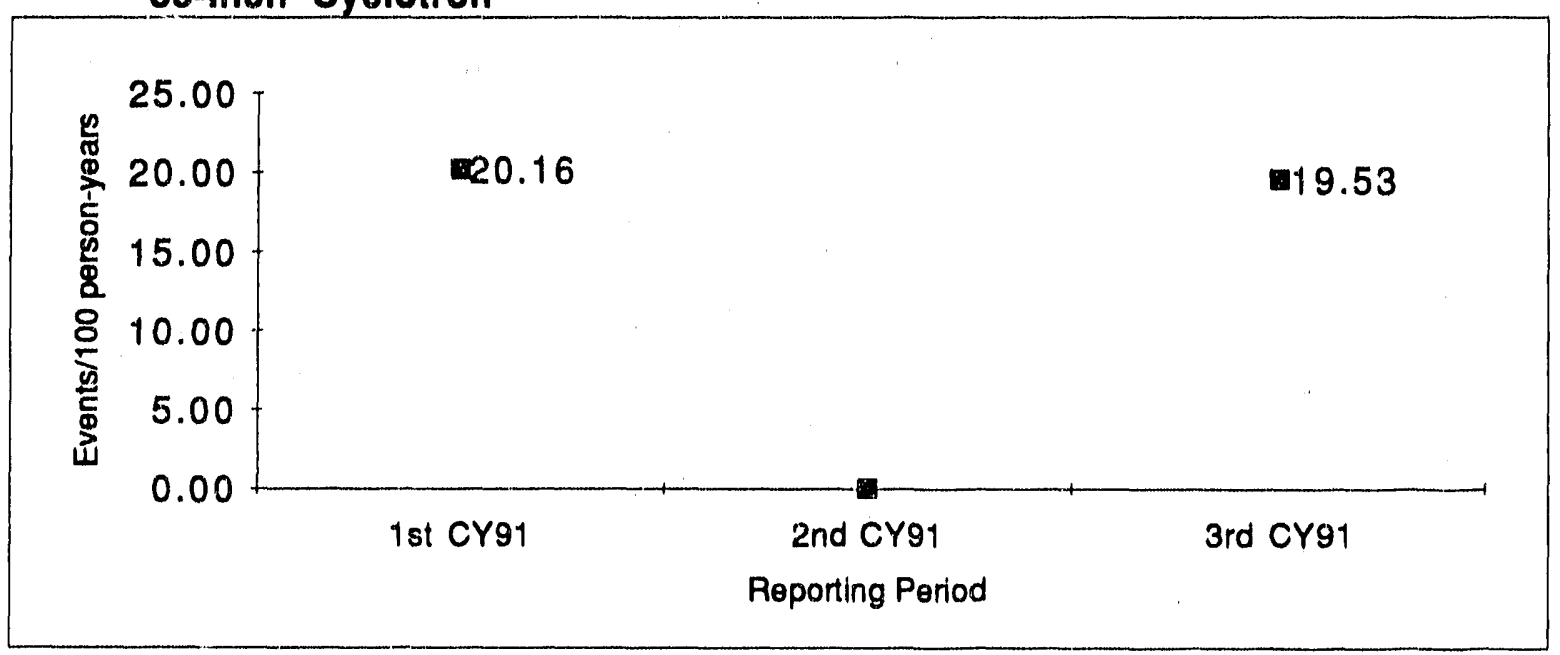

The above rates reflect one (1) incident in both the first and third quarters, and none in the second. The seemingly large magnitude of the rates is due to the low employee population at the 88-Inch facility (approximately 22). 


\subsection{Environmental incidents}

The number of reportable occurrences, both on-site and off-site, involving an inadvertent radisactive or hazardous matarial spill or release.

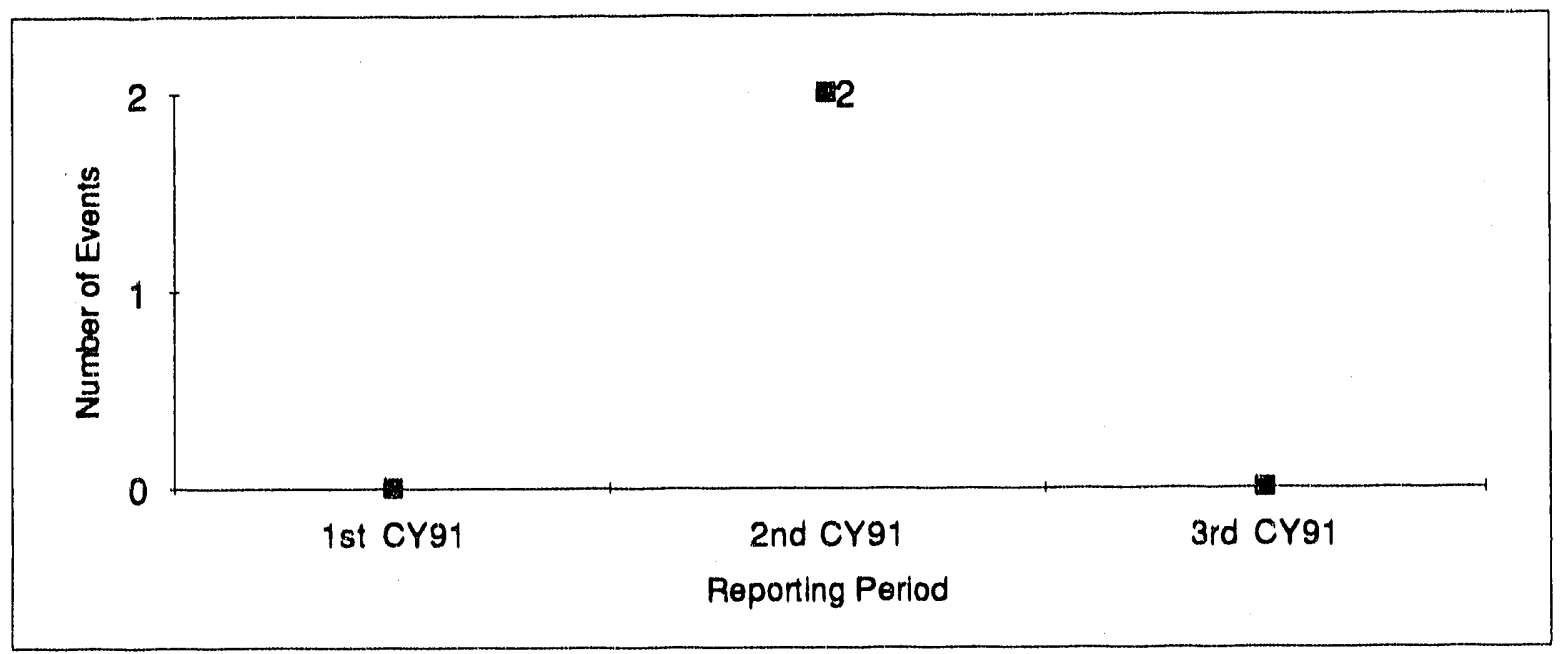

In the second quarter report, the number of environmental incidents was given as three. In fact, one of these incidents occurred in 1990 and should not have been included.

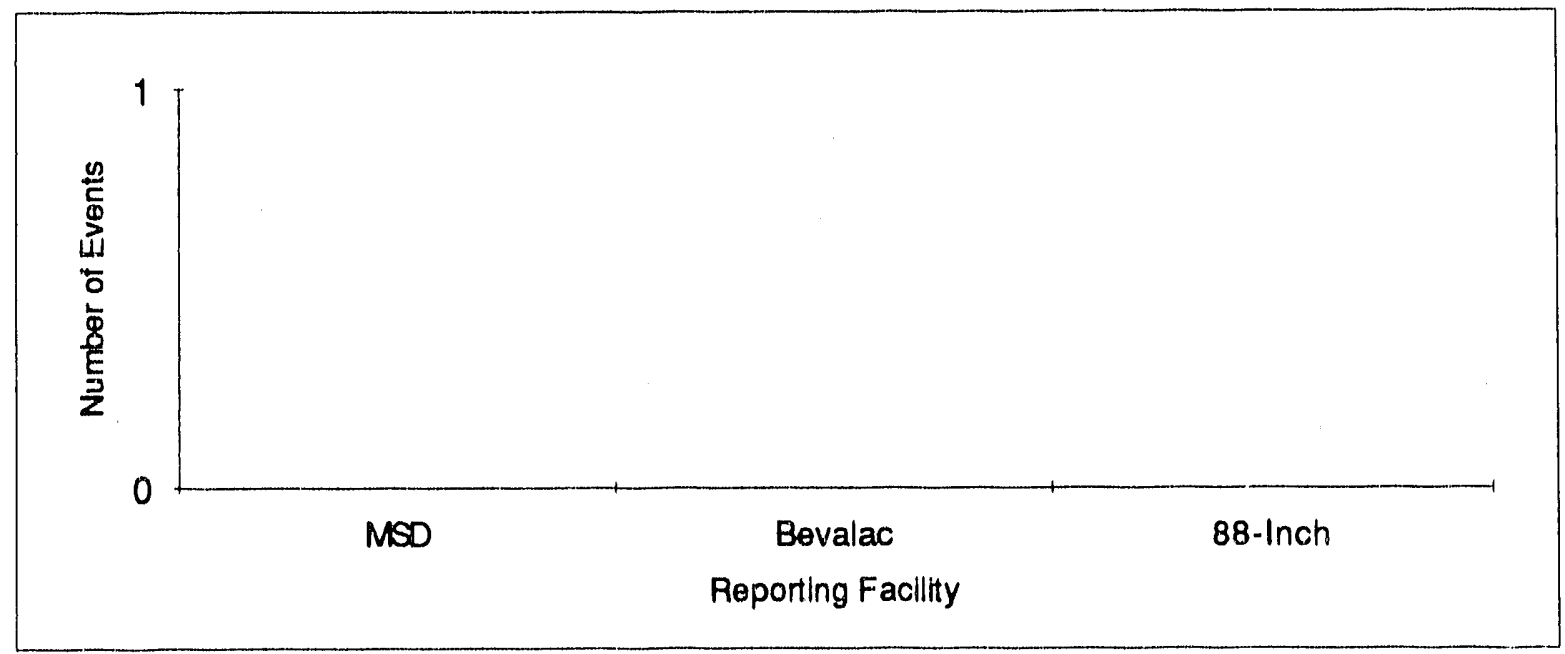

\section{Current Period Data}

There were no environmental incidents in the current reporting period. 
Root Cause of Occurrences

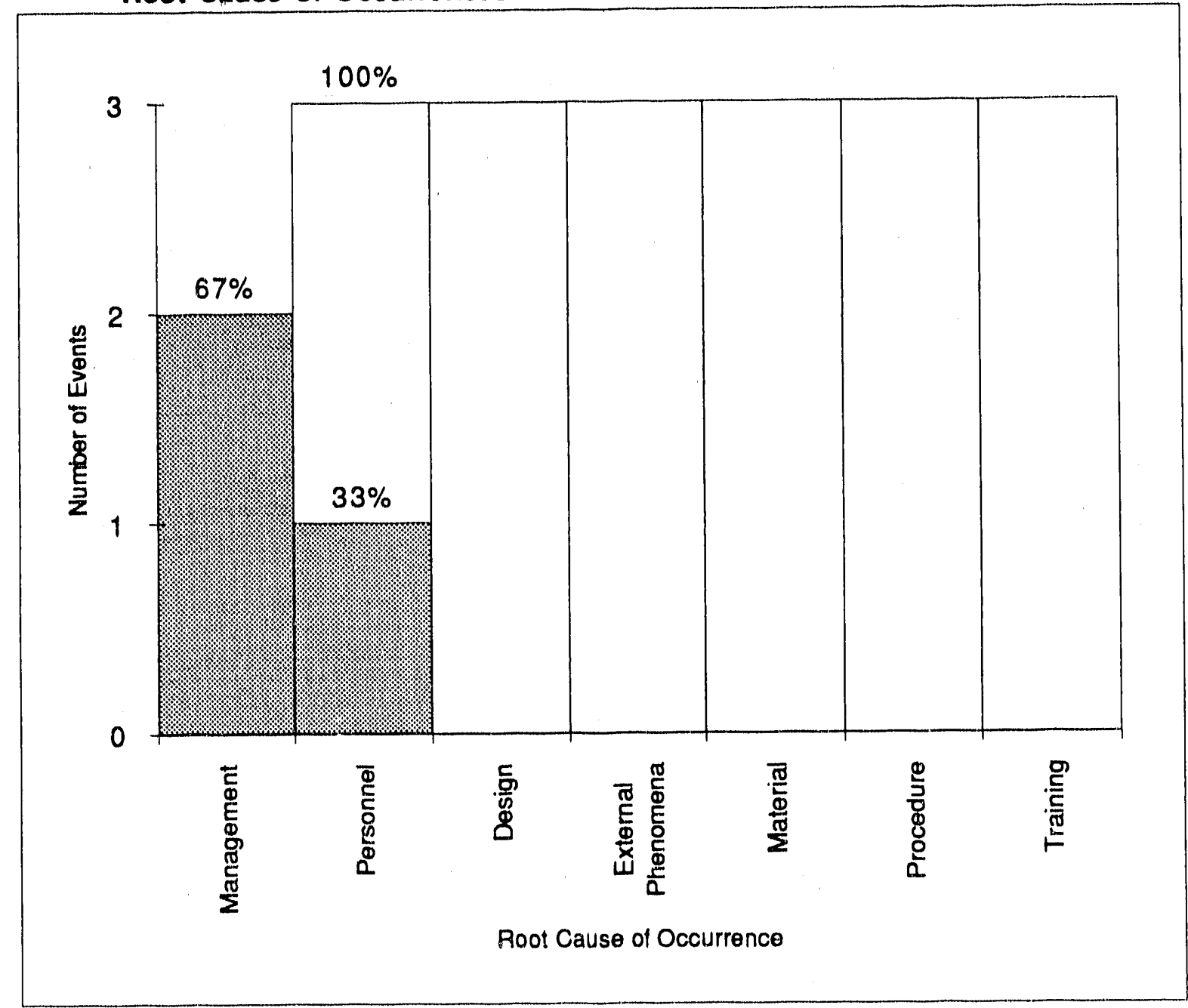

The above chart tracks the cumulative root causes of occurrence data. To date, there have been two (2) management causes and one (1) personnel cause of environmental incidents.

PI 2.1 


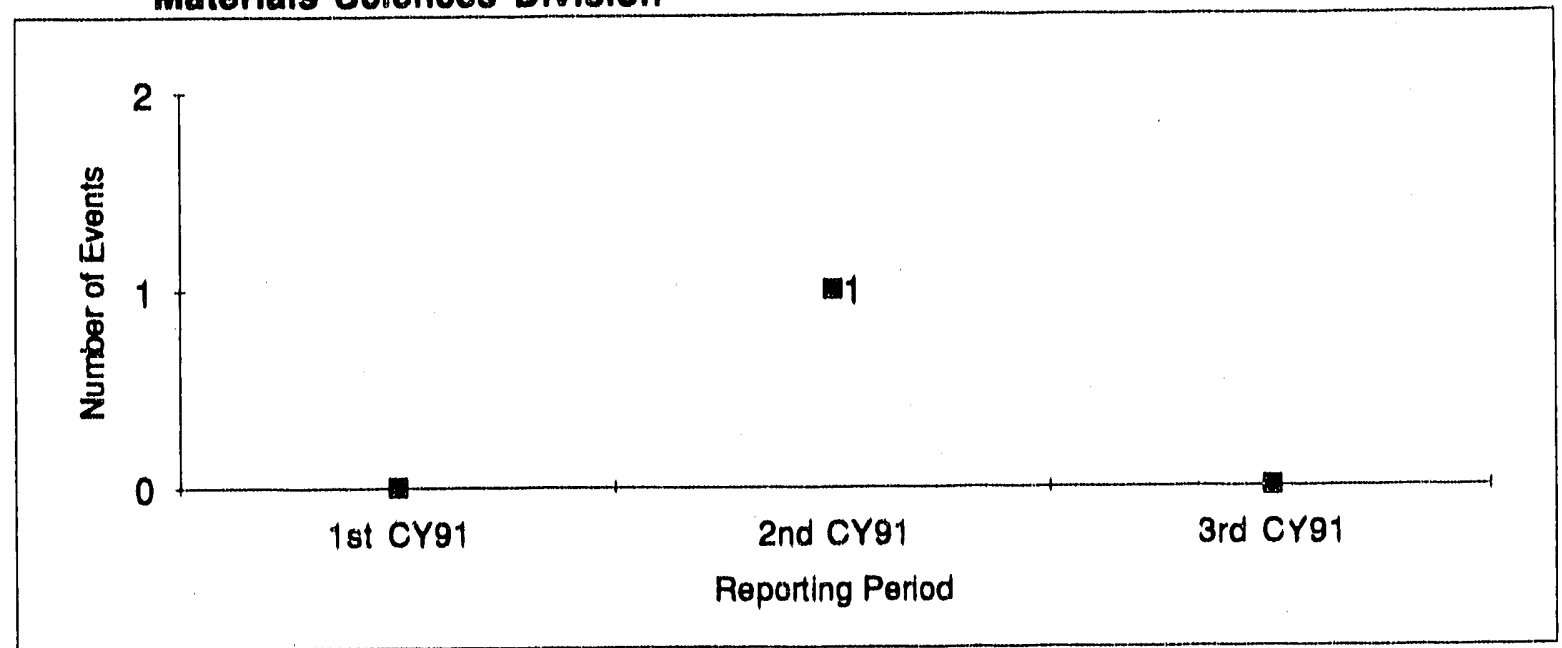

The above second quarter incident is reported in OR SAN-LBL-MSD-1991-1001.

\section{Bevalac}

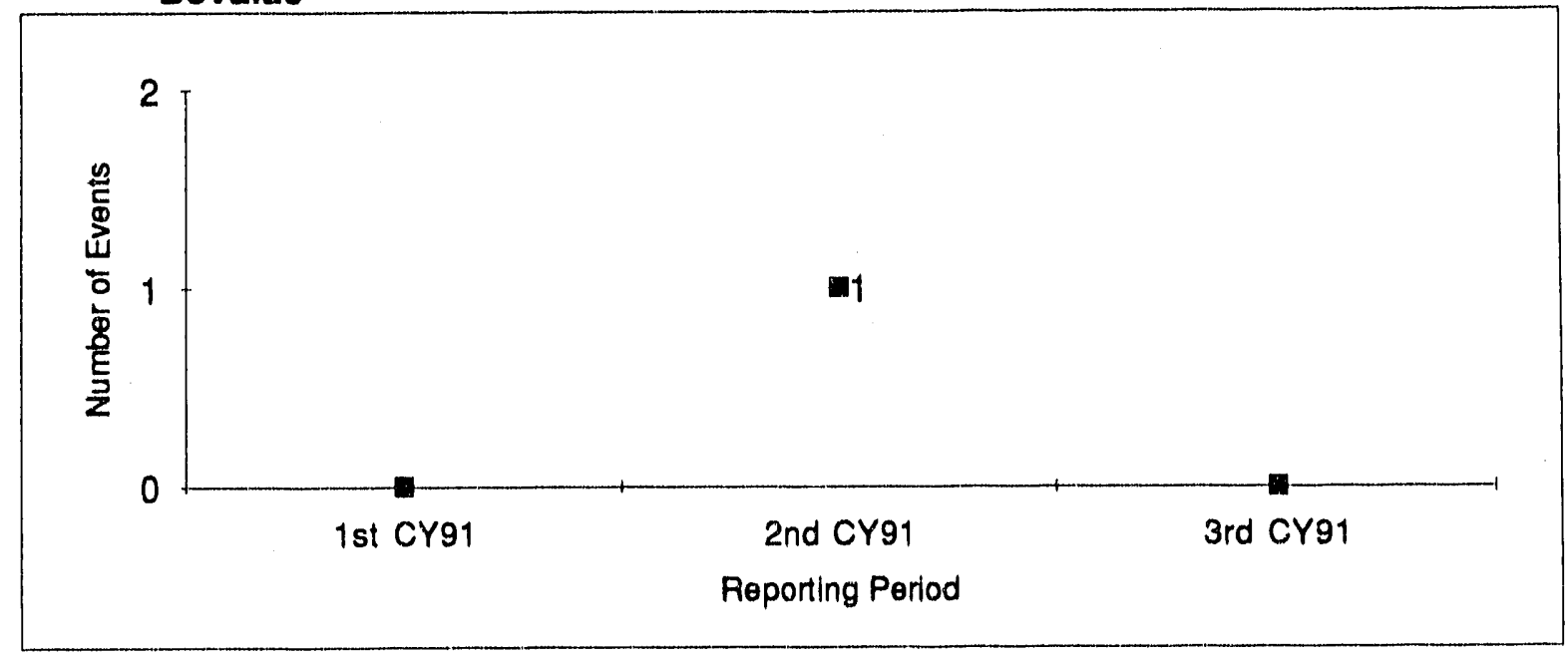

Although originally reported as two (2) second quarter incidents in the previous report, the OR SAN-LBL-AFRD-1990-0007 was included in error. Only one (1) incident (SAN$L B L-A F R D-1991-1001$ ) actually occurred in the second quarter. 


\section{8-Inch Cyclotron}

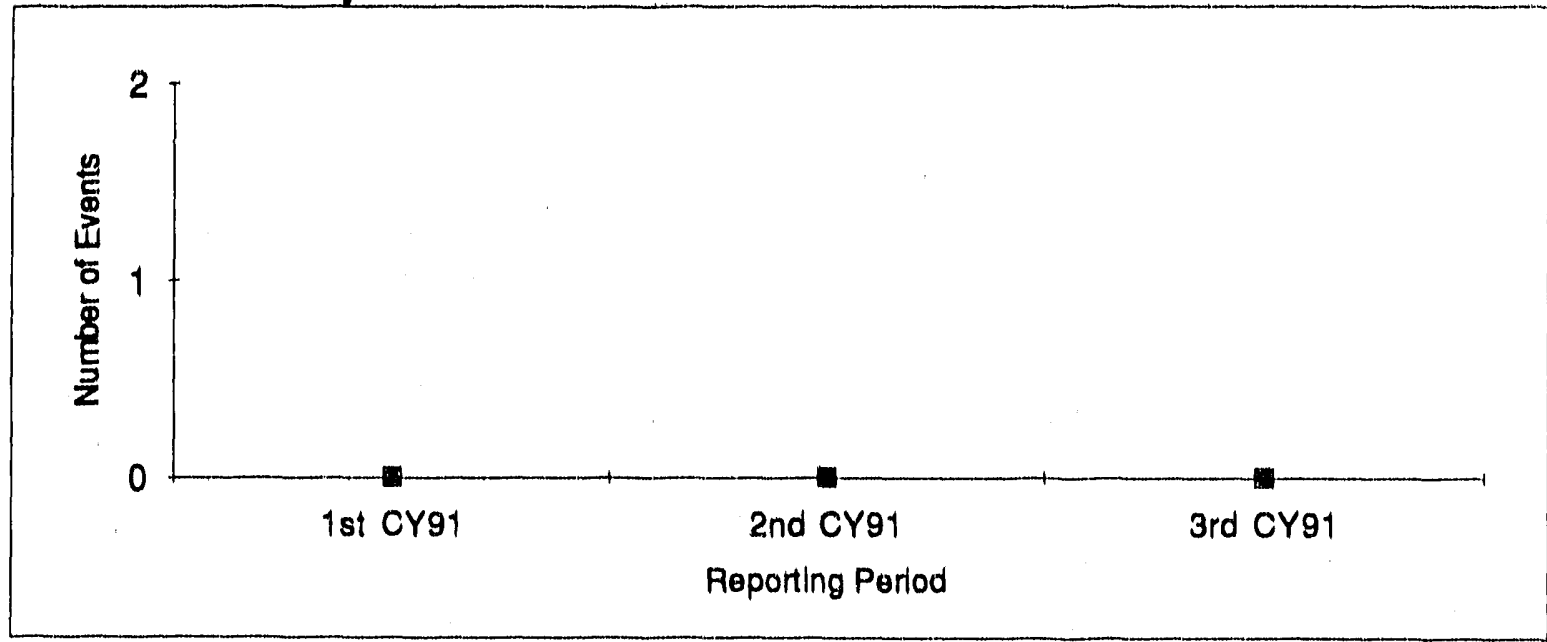

There have not been any environmental incidents at the 88 -Inch facility in the past three quarters. 


\subsection{Unplanned Safety Function Actuations}

The number of unplanned actuations of any safety function or facility safety systems that occur when an aotuation setpoint for a salety fuction is reached or when a spurious or inadvertent signal is generated, and major equipment is actuated or demanded. Unplanned means that the actuation was not part of a planned test or evolution.

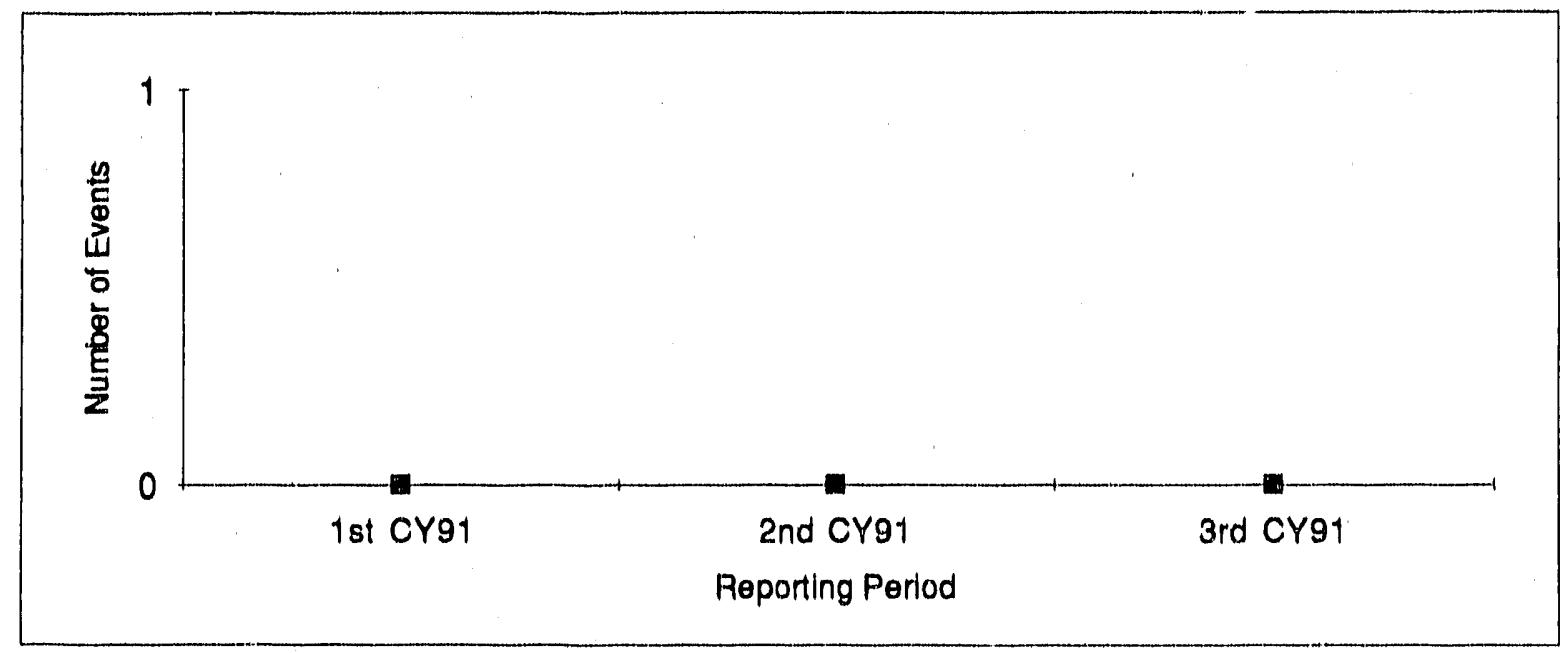

There have been no unplanned safety function acutations at LBL in the past three quarters.

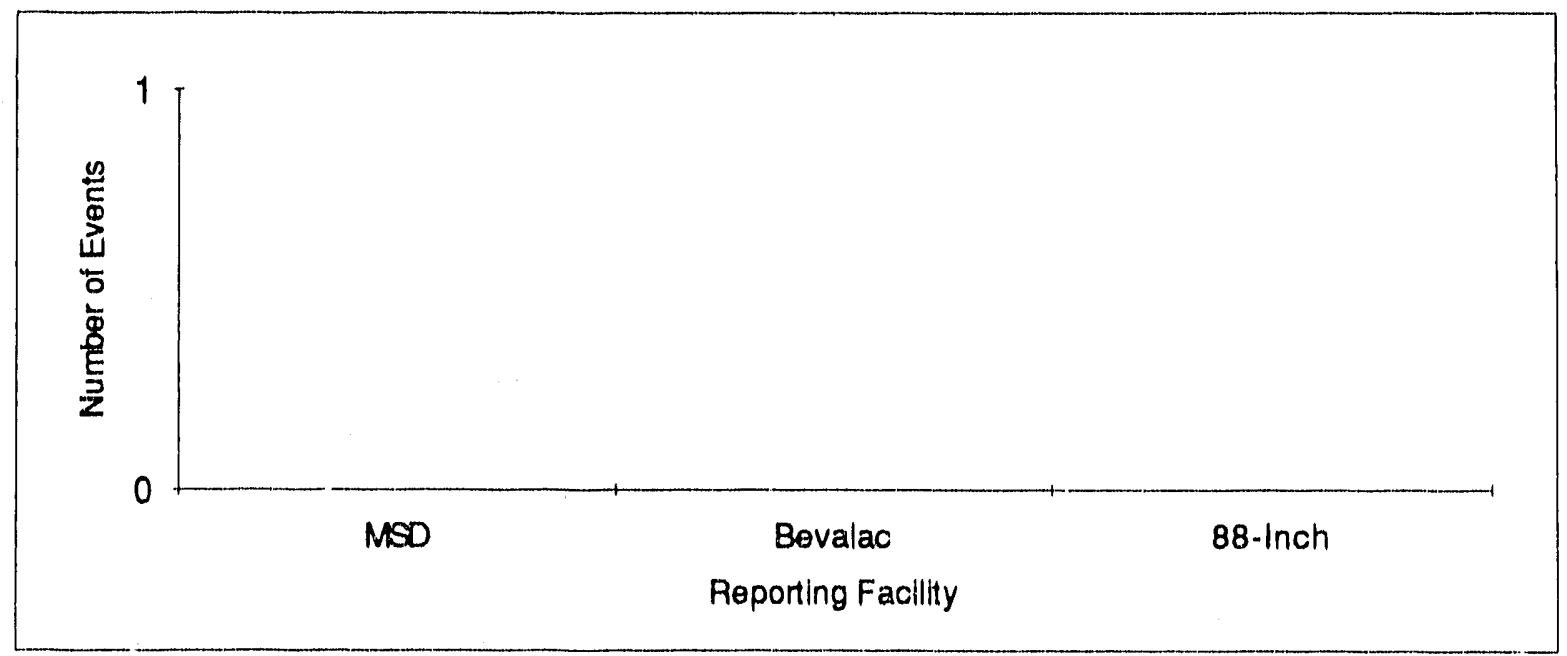

\section{Current Period Data}

There were no unplanned safety function acutations in the present reporting period.

P| 2.2 


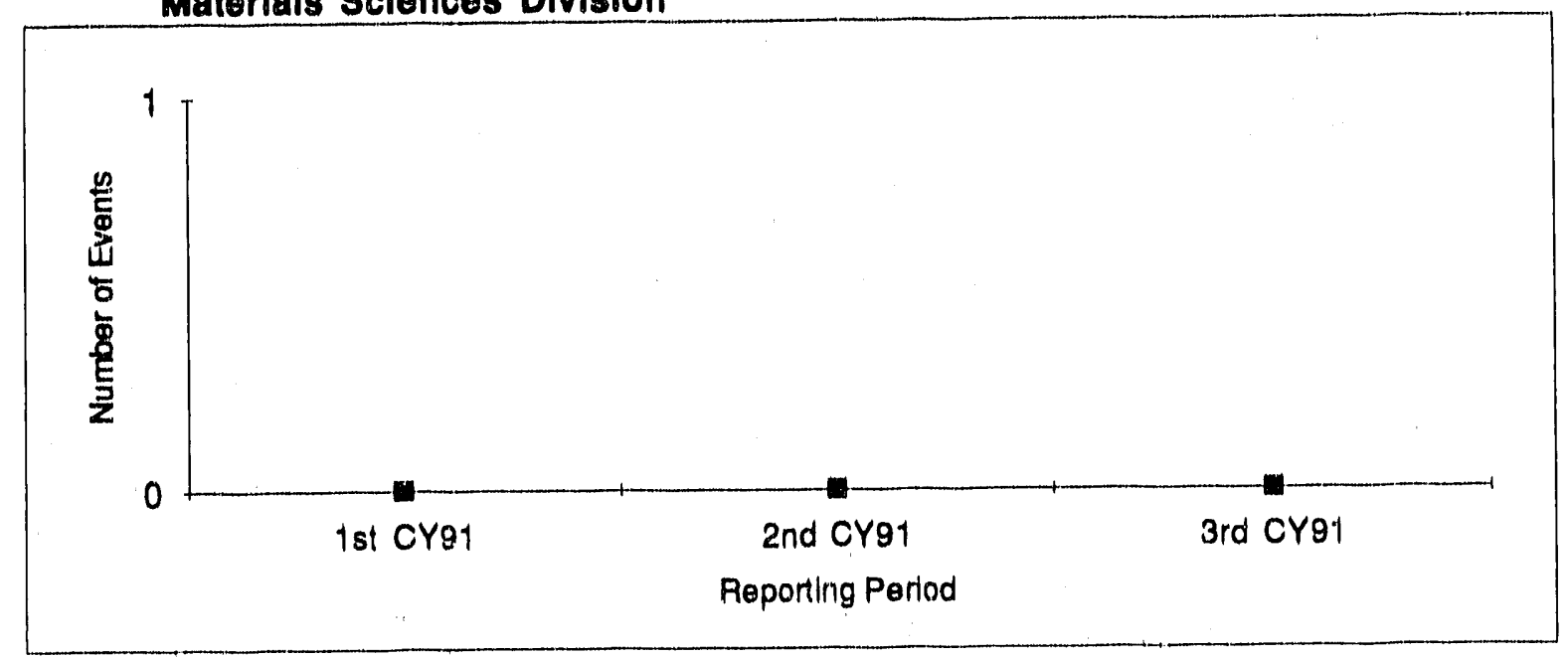

No unplanned safety function actuations.

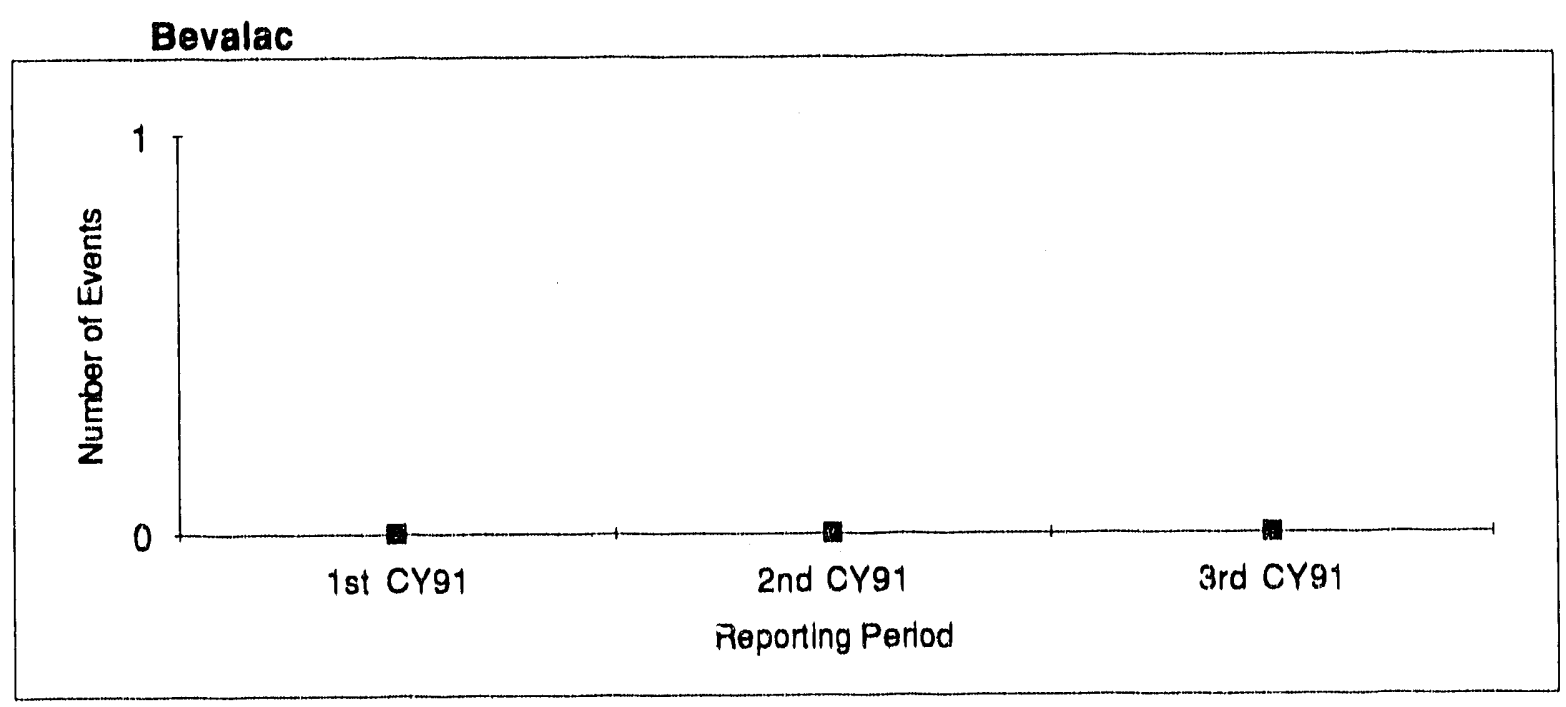

No unplanned safety function actuations.

PI 2.2 


\section{8-Inch Cyclotron}

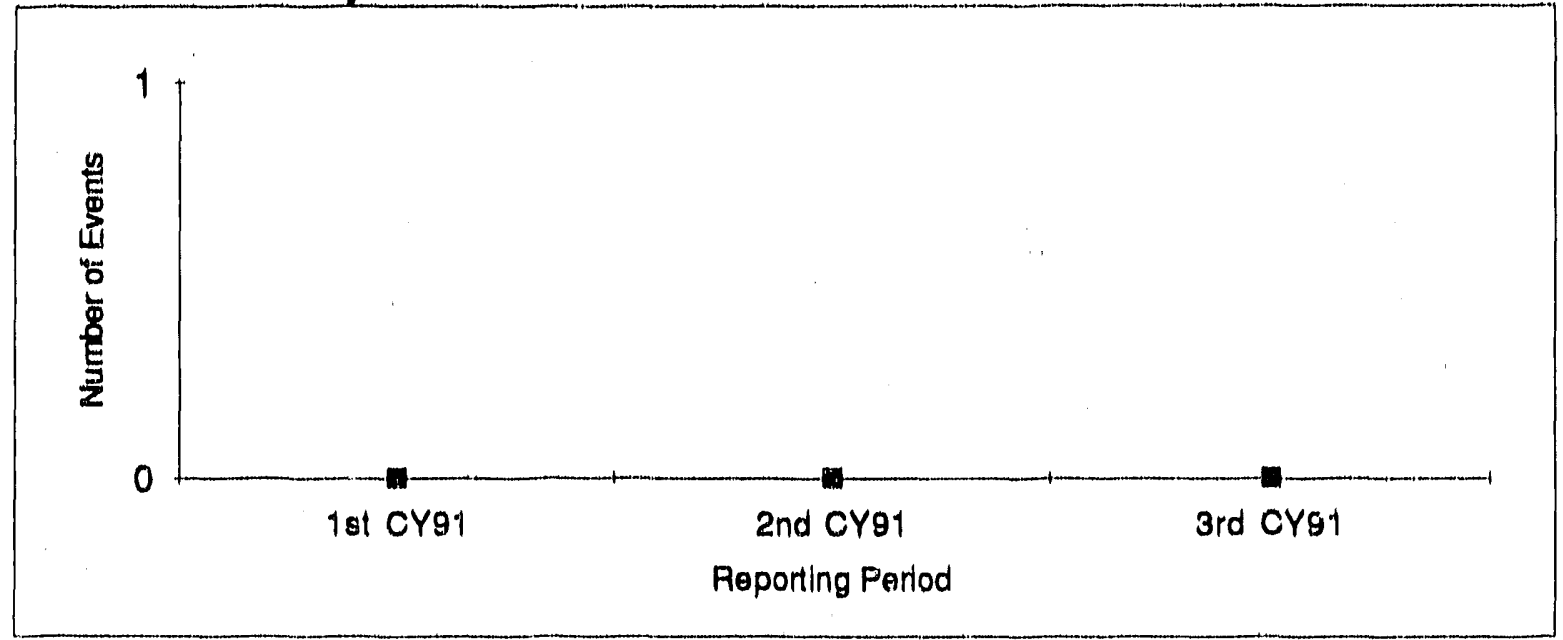

No unplanned safety function actuations.

$P \mid 2.2$ 


\subsection{Vlolations of Operating Procedures.}

The number of instances where a fallure of personnel to follow operating procedures resulted in a reportable occurrence.

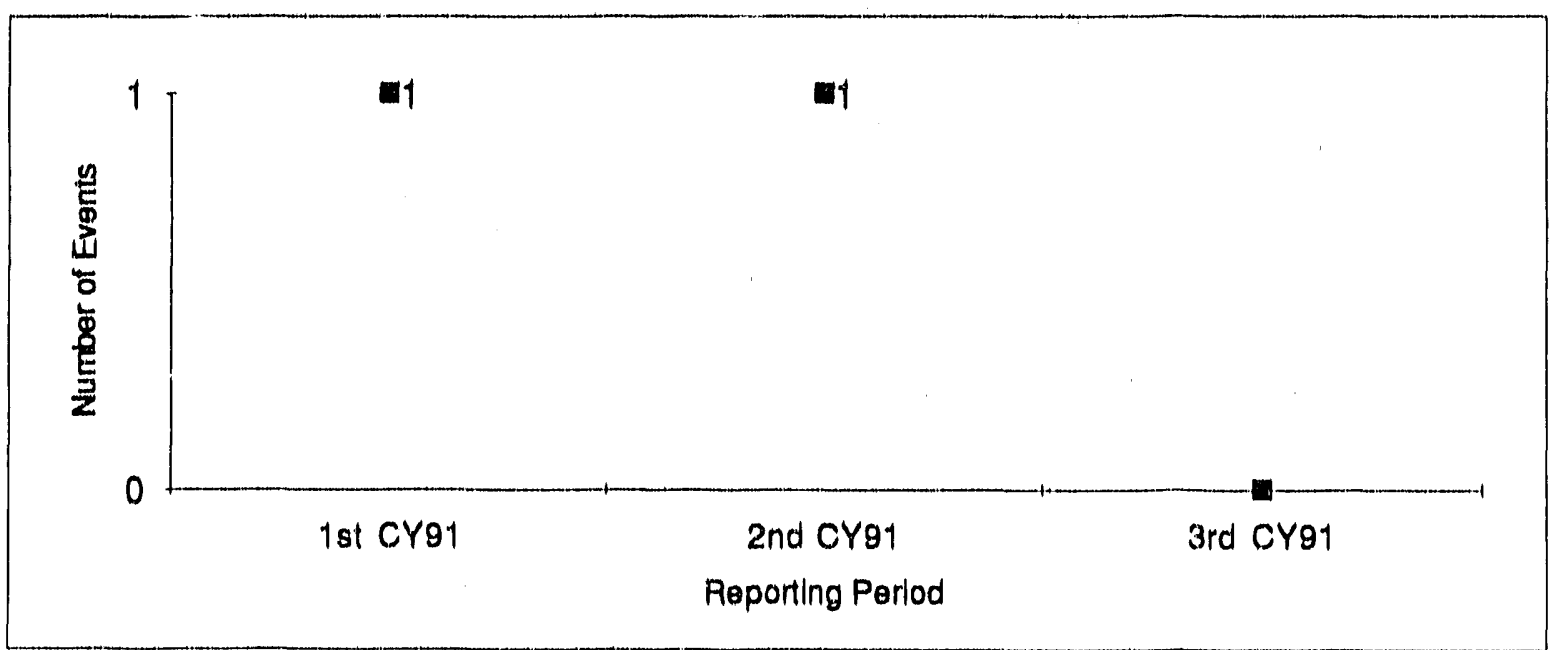

The violation in the first quarter has not been included in a PI report to date. (See MSD facility chart below). Also, in the previous PI report, it was stated that there were two violations of operating procedures in the second quarter. One of these occurred in 1990 and should not have been included. (See Bevalao faollty chart below).

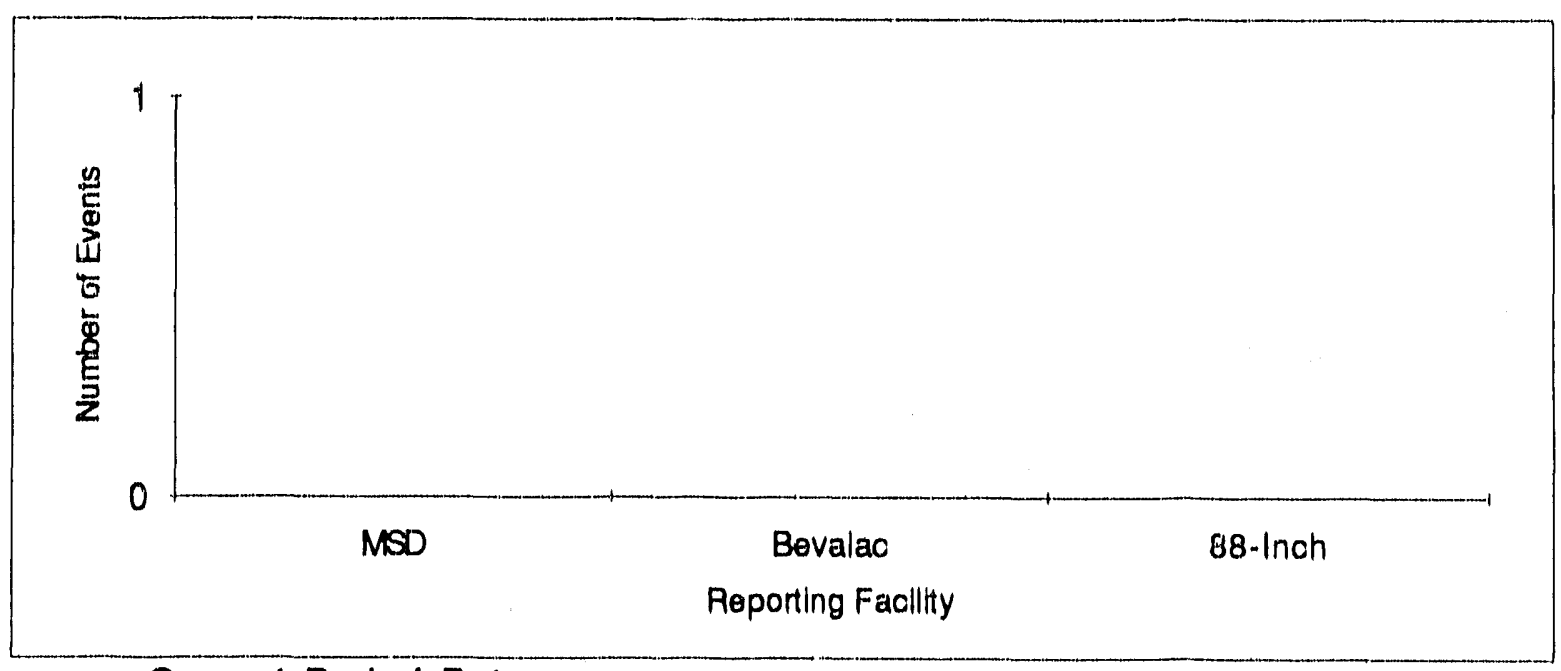

Current Perlod Data

There were no violations of operating procedures in the current reporting period.

P| 2.3 
Root Cause of Occurrences

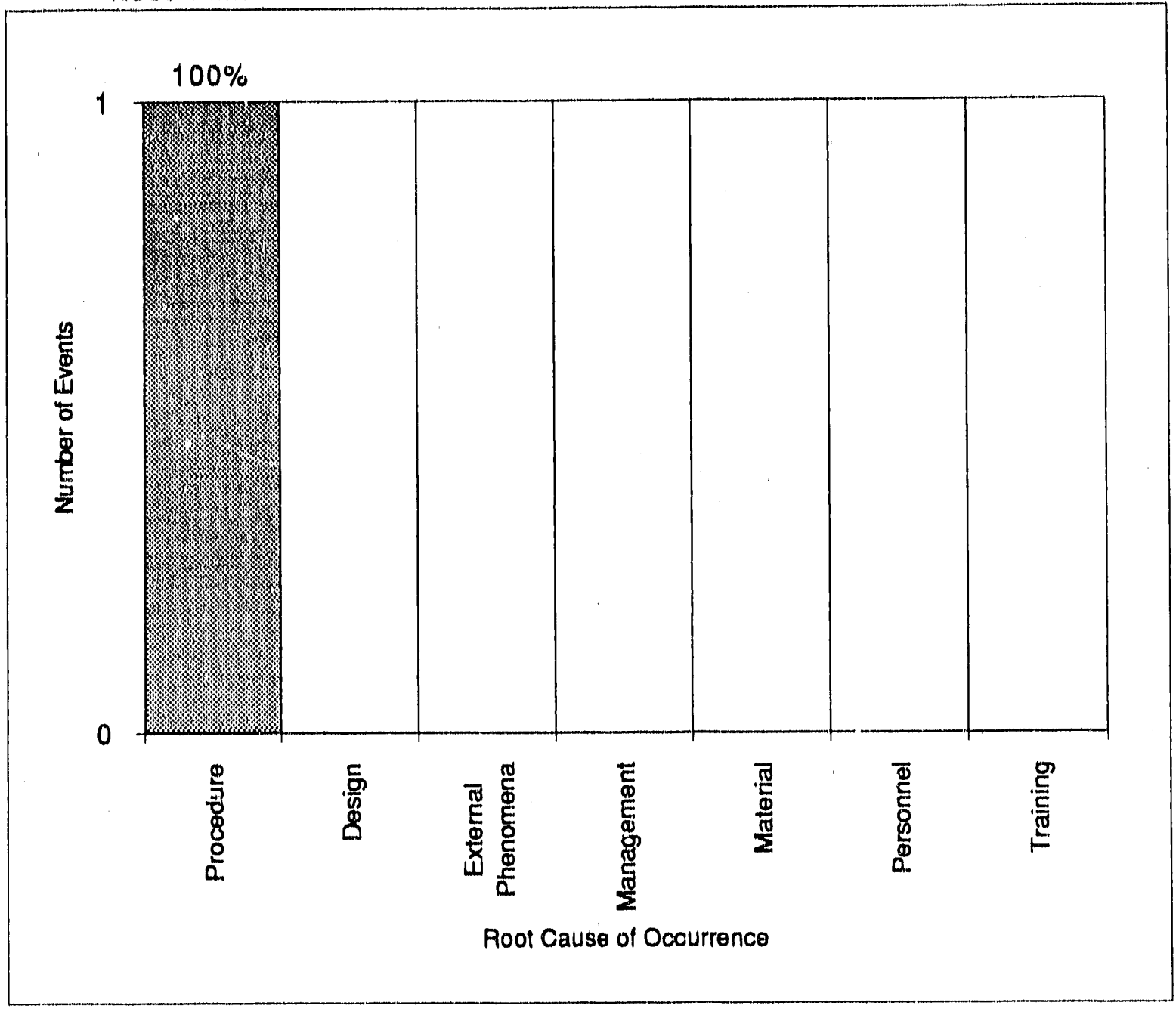

The first quarter violation of operating procedures (SAN-LBL.MSD-1991-1002) had Procedure as its root cause. The cause of the other violation (SAN-LBL-NSD-1991. 1001, second quarter) has yet to be determined.

PI 2.3 
Materials Sciences Division

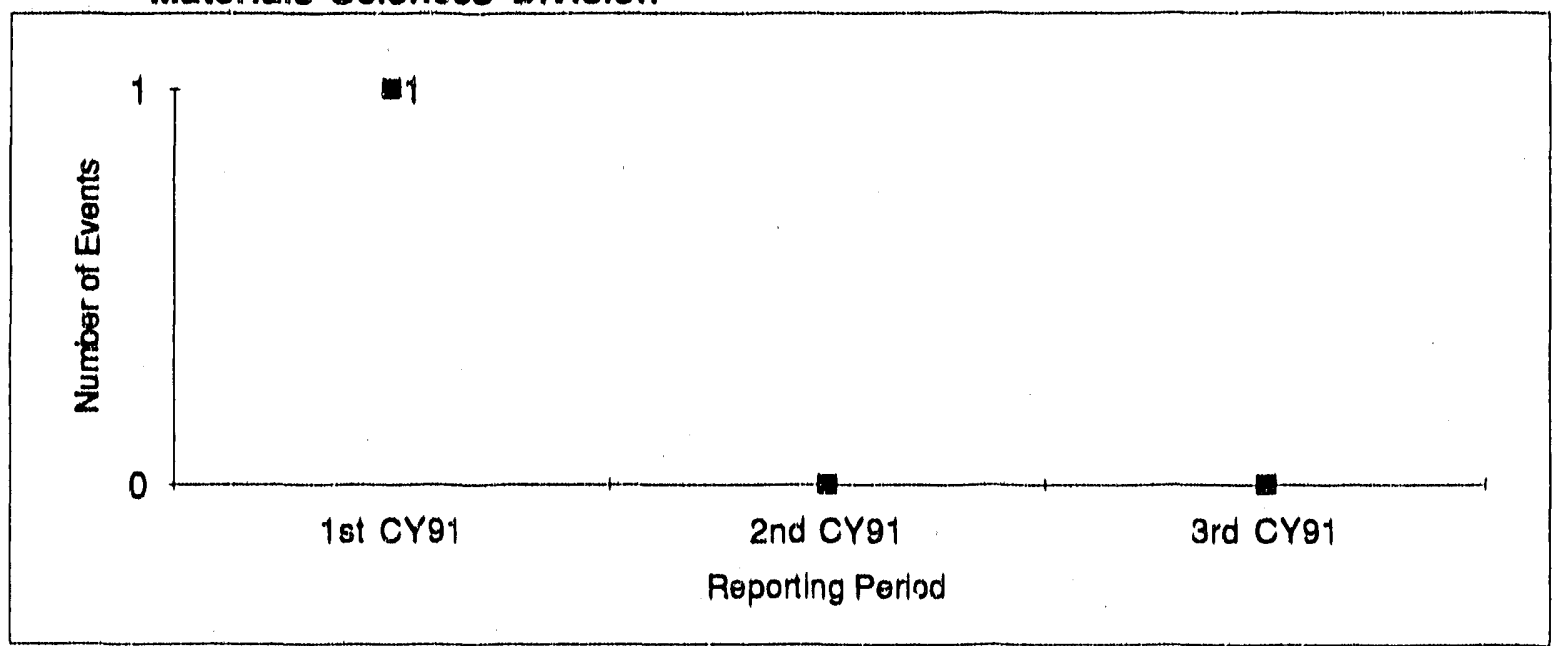

Although not reported in the previous two Performance Indicator reports, nor indicated on any errata sheet to date, there was in fact one (1) violation of operating procedures at the Material Solence Division in the first quarter (OR SAN-LBL-MSD-1991-1002)

\section{Bevalac}

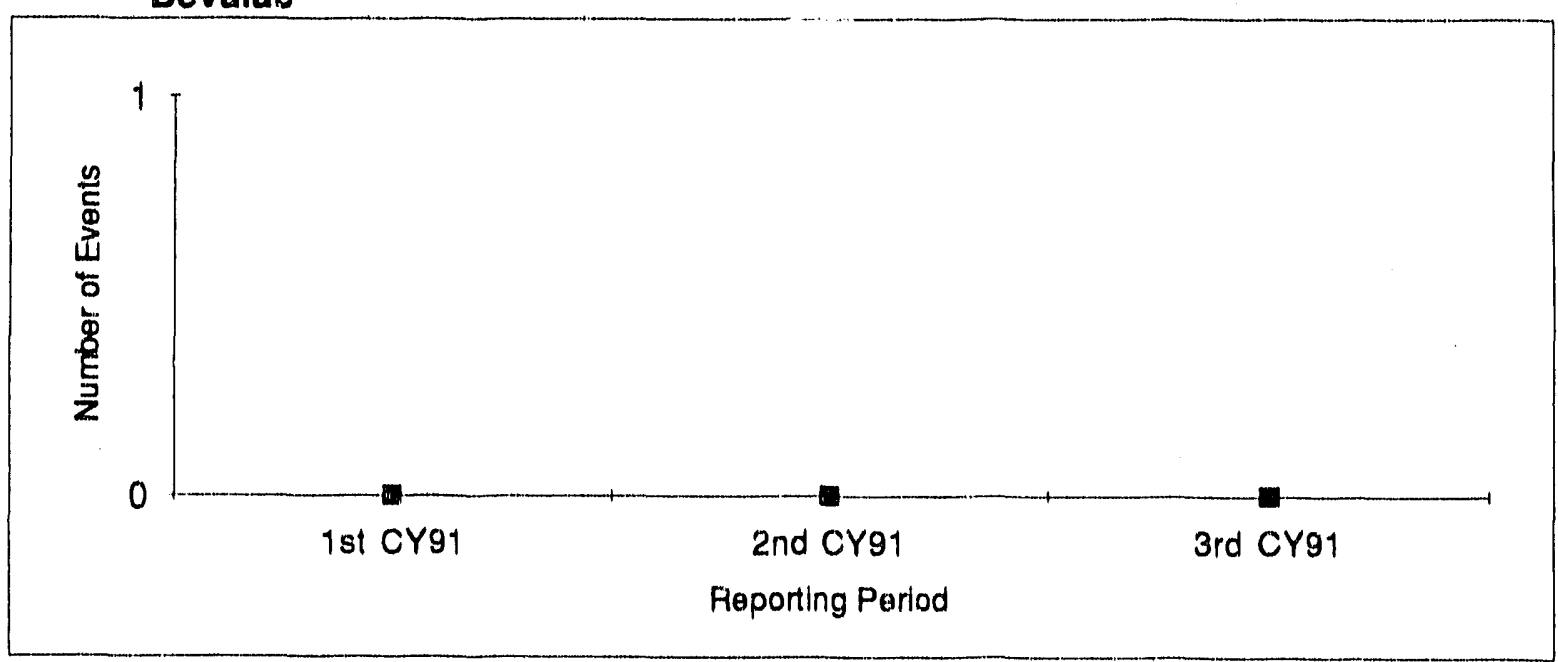

The violation reported for the second quarter in the previous report occurred, in fact, in 1990 and should not have been included. There have been no violations of operating procedures at the Bevalac facility to date. 


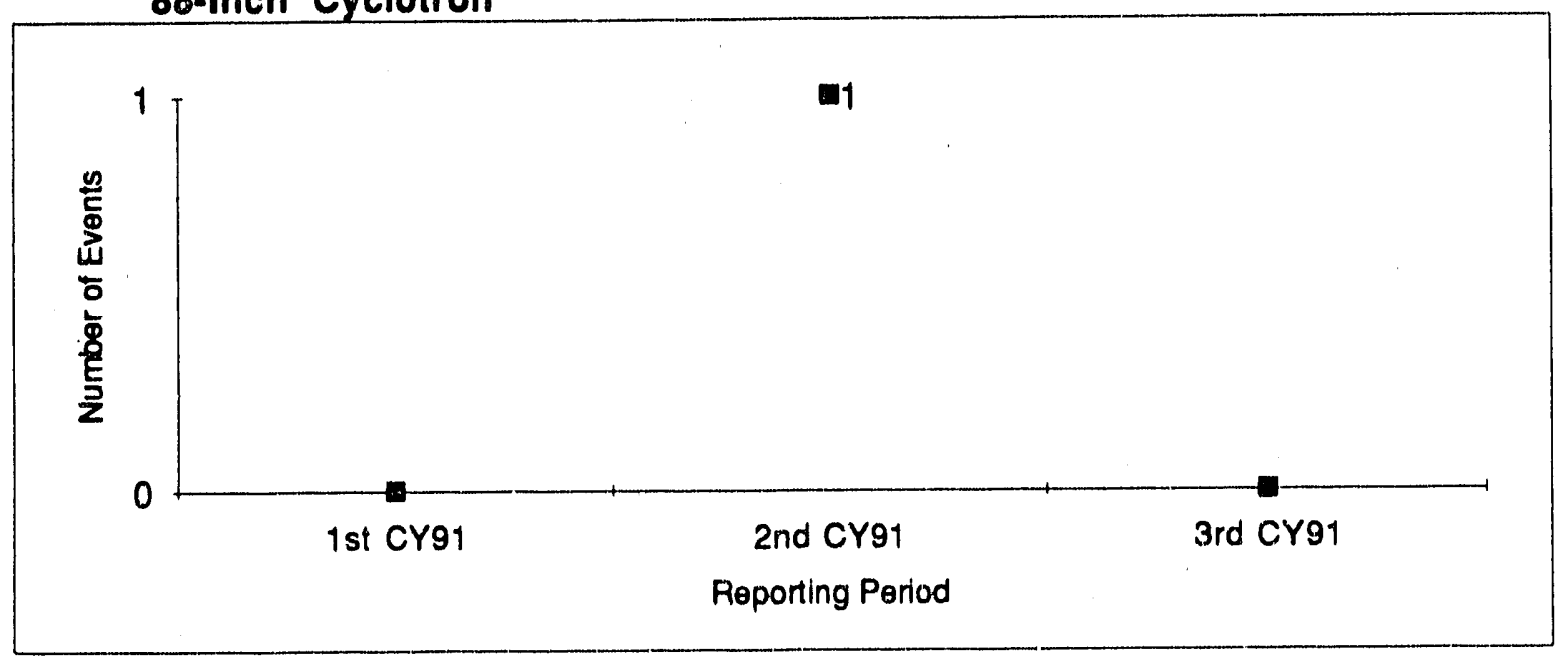

The one violation which has occurred at the 88 -Inch Cyclotron facility (in the second quarter) was reported in OR SAN-LBL-NSD-1991-1001.

PI 2.3 


\subsection{OSHA Violations}

The total number of items of noncompliance with OSHA standards.

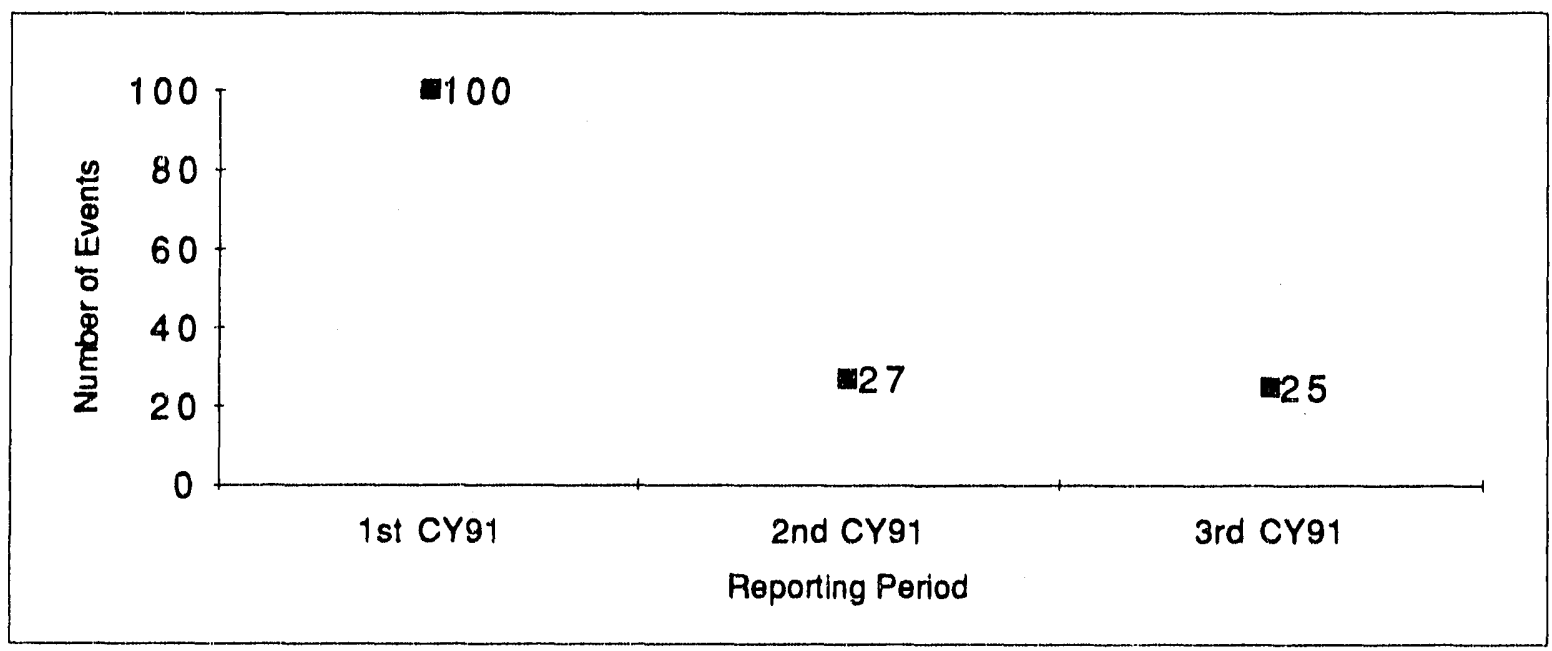

The substantially lower values over the past two quarters are due to the reduction of violations at the Bevalac facility. (See the facility charts below).

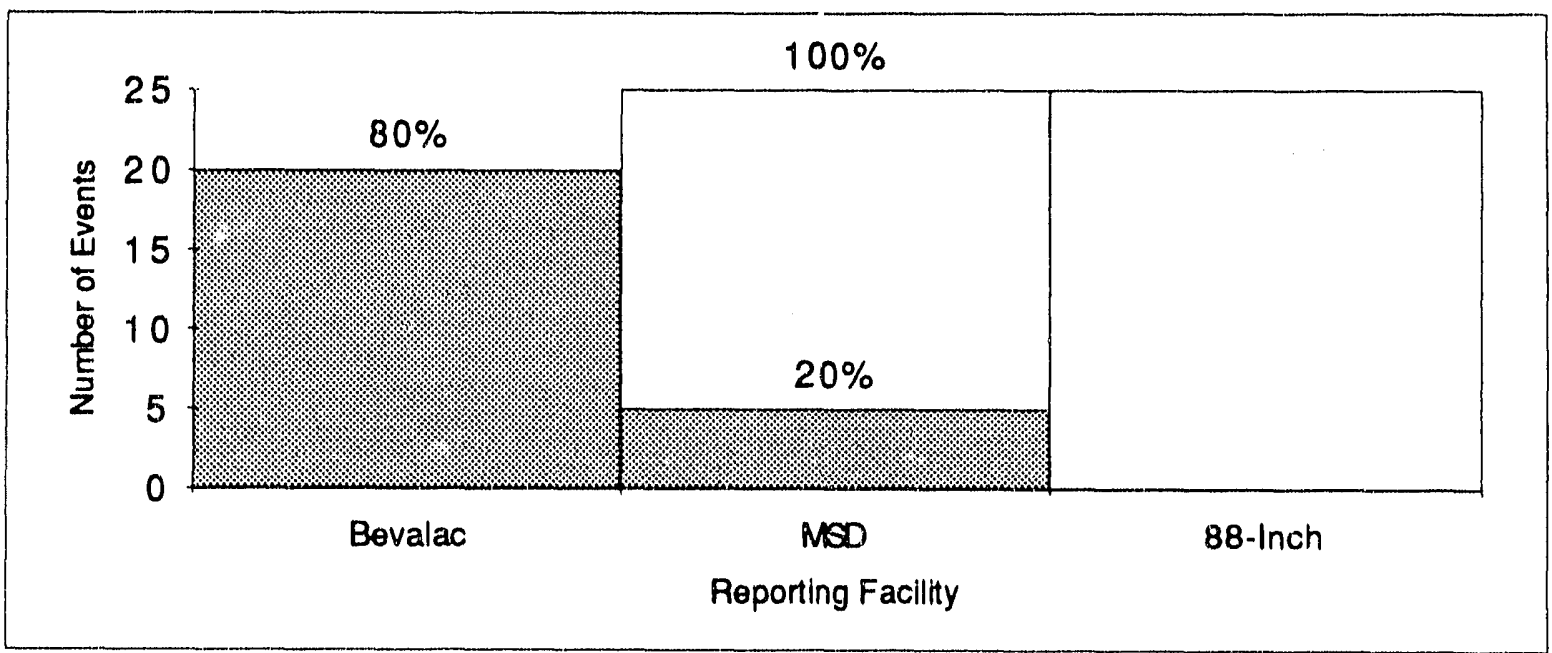

\section{Current Period Data}

Despite the Bevalac facility having a second successive quarter of reduced OSHA violations (see the Bevalac facility chart below), it again has the most of the three LBL facilities by far. 
Materials Sciences Division

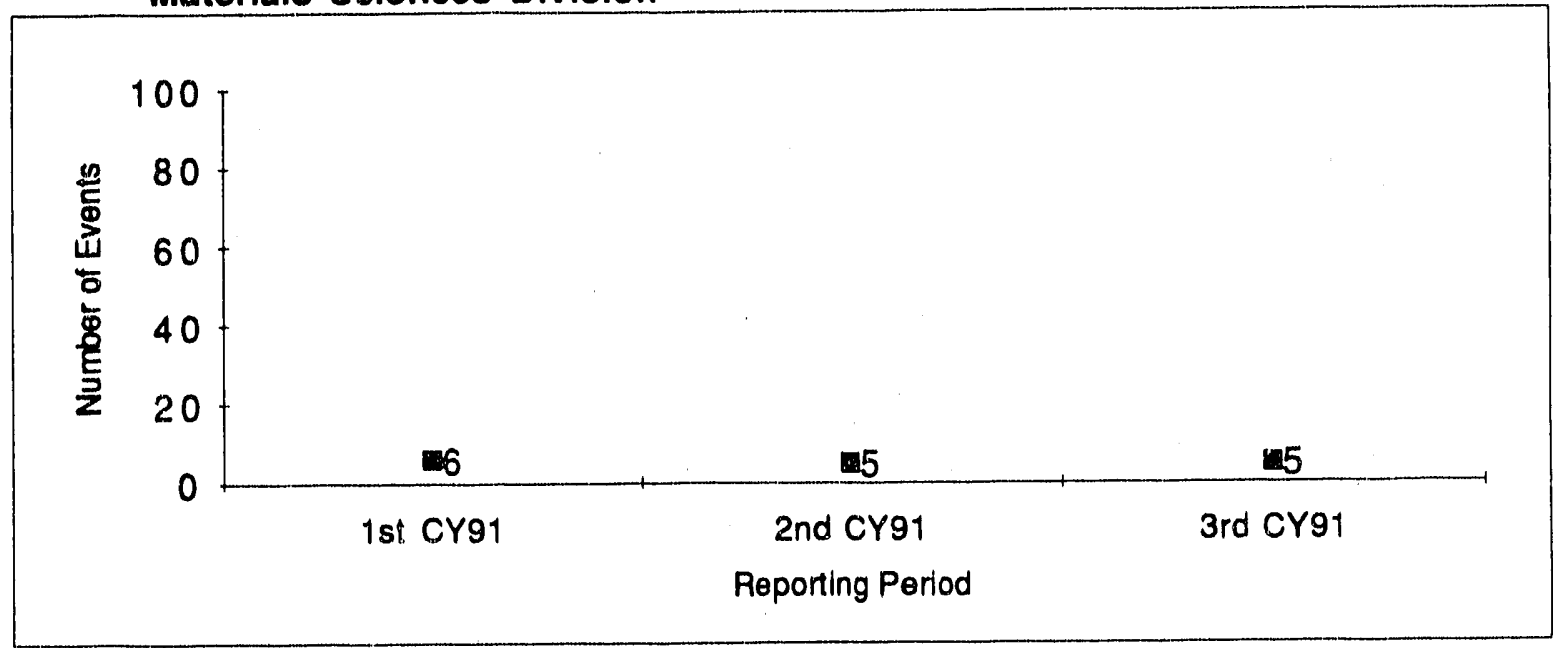

The number of OSHA violations in the Materials Sciences Division has remained relatively constant over the last three quarters.

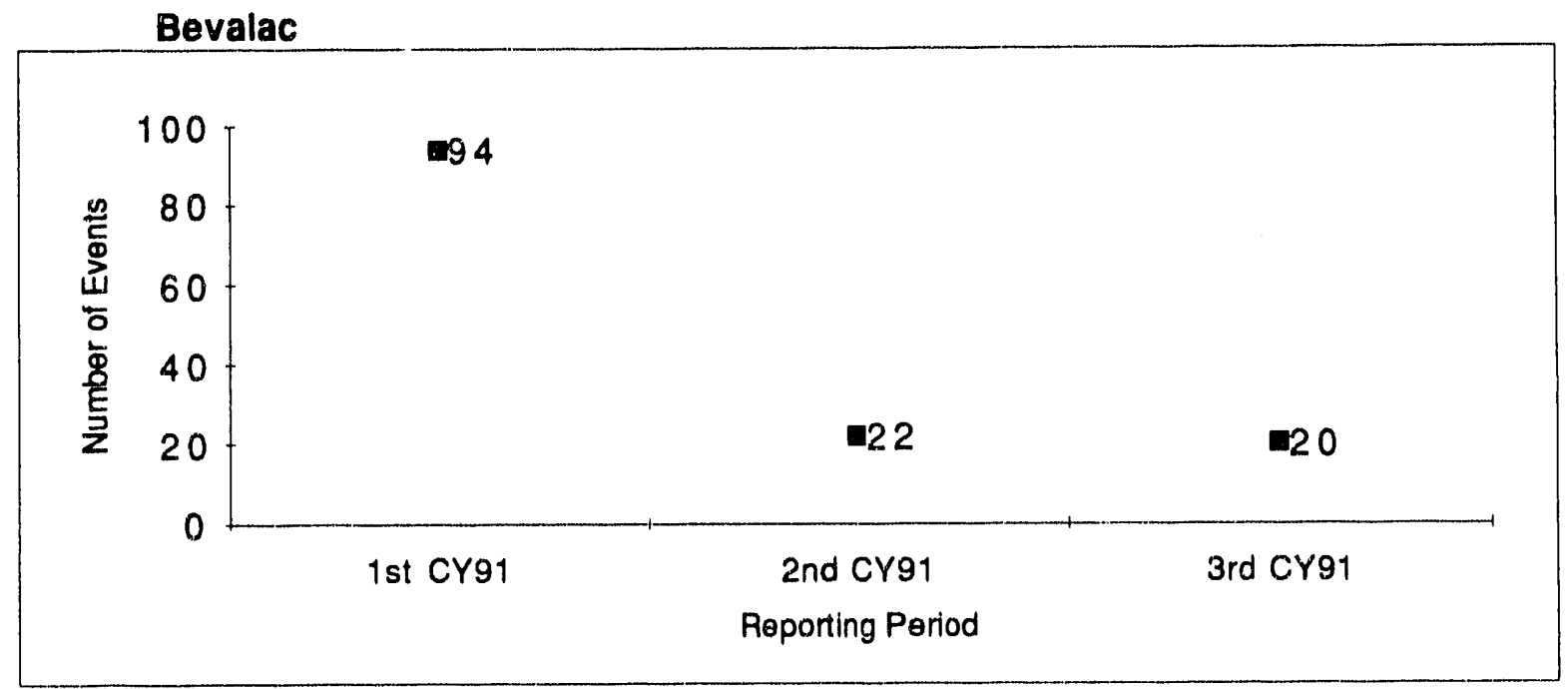

The Bevalac facility had a second successive quarter of reduced OSHA violations. 


\section{8-Inch Cyclotron}

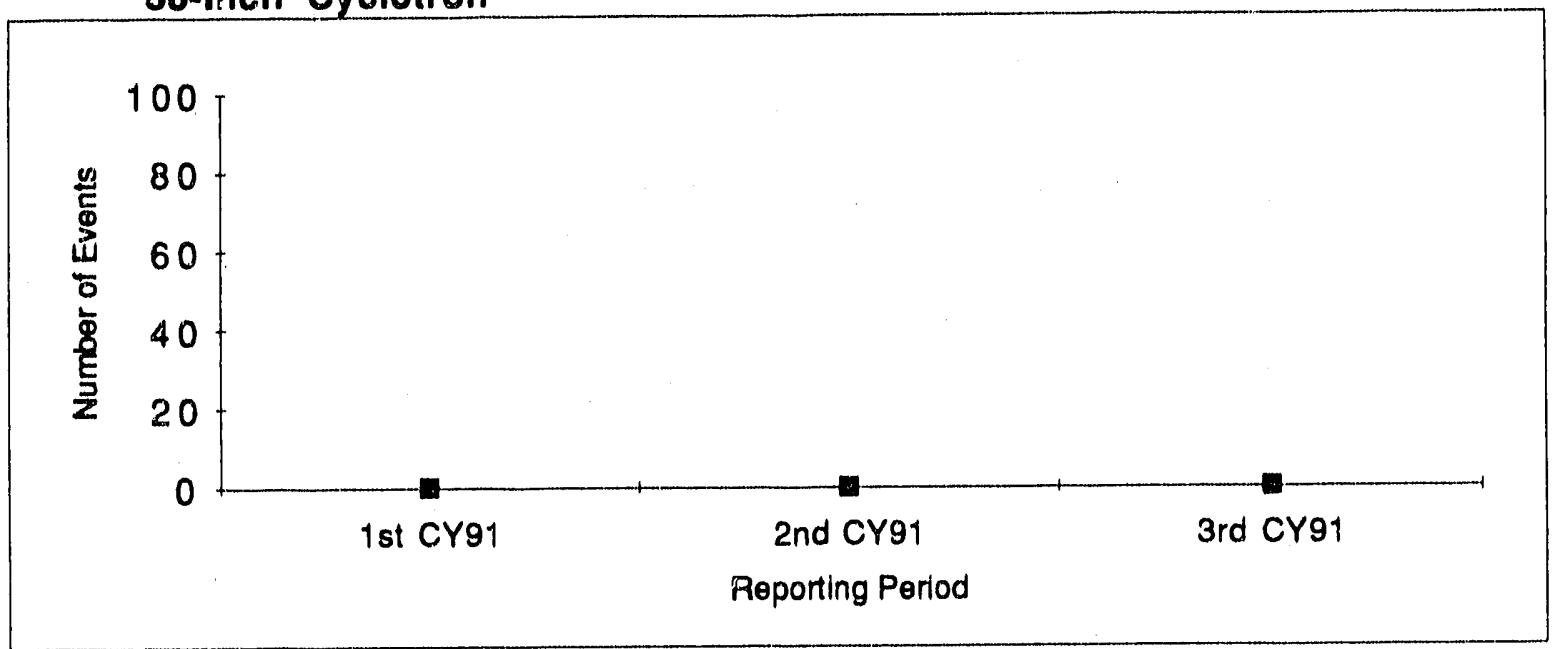

No OSHA violations to date.

PI 2.4 


\subsection{Unplanned Shutdowns}

The number of unscheduled shutdowns of a facillty, process or operation.

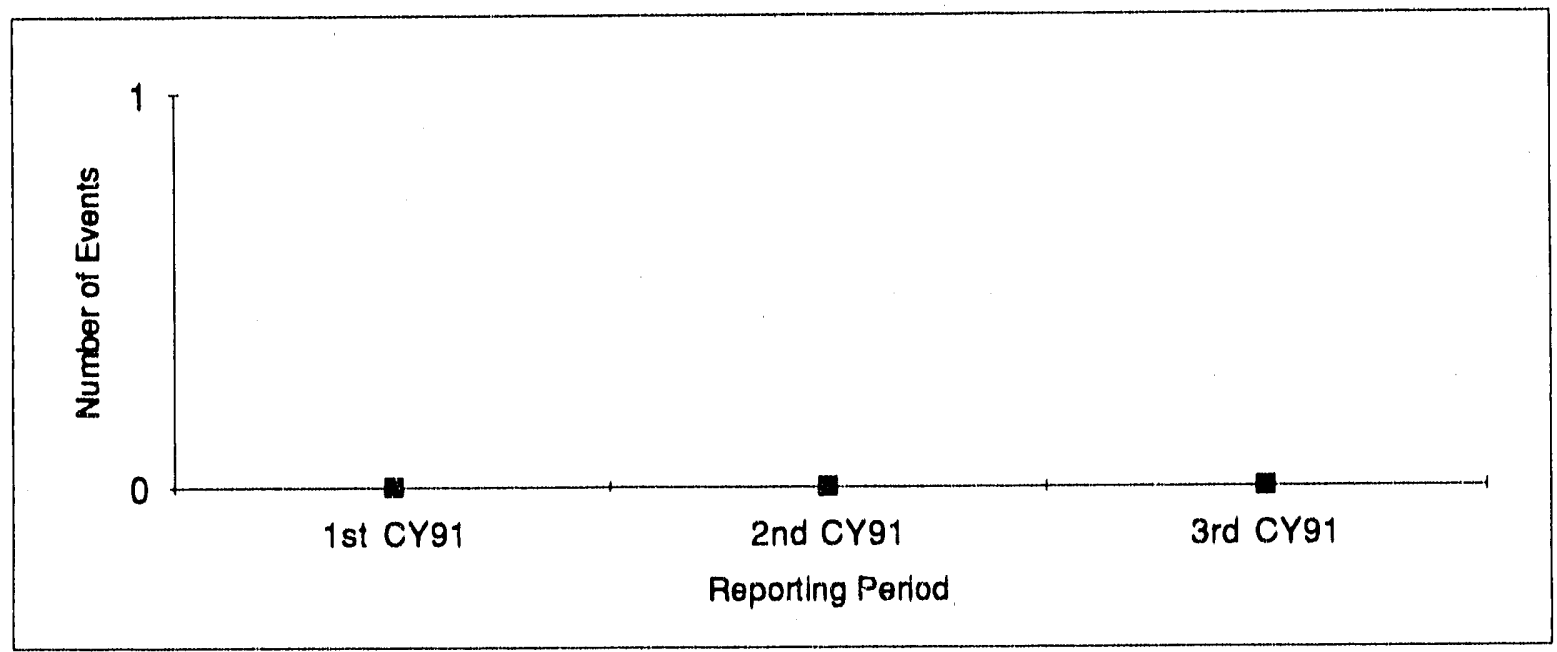

No unplanned shutdowns to date.

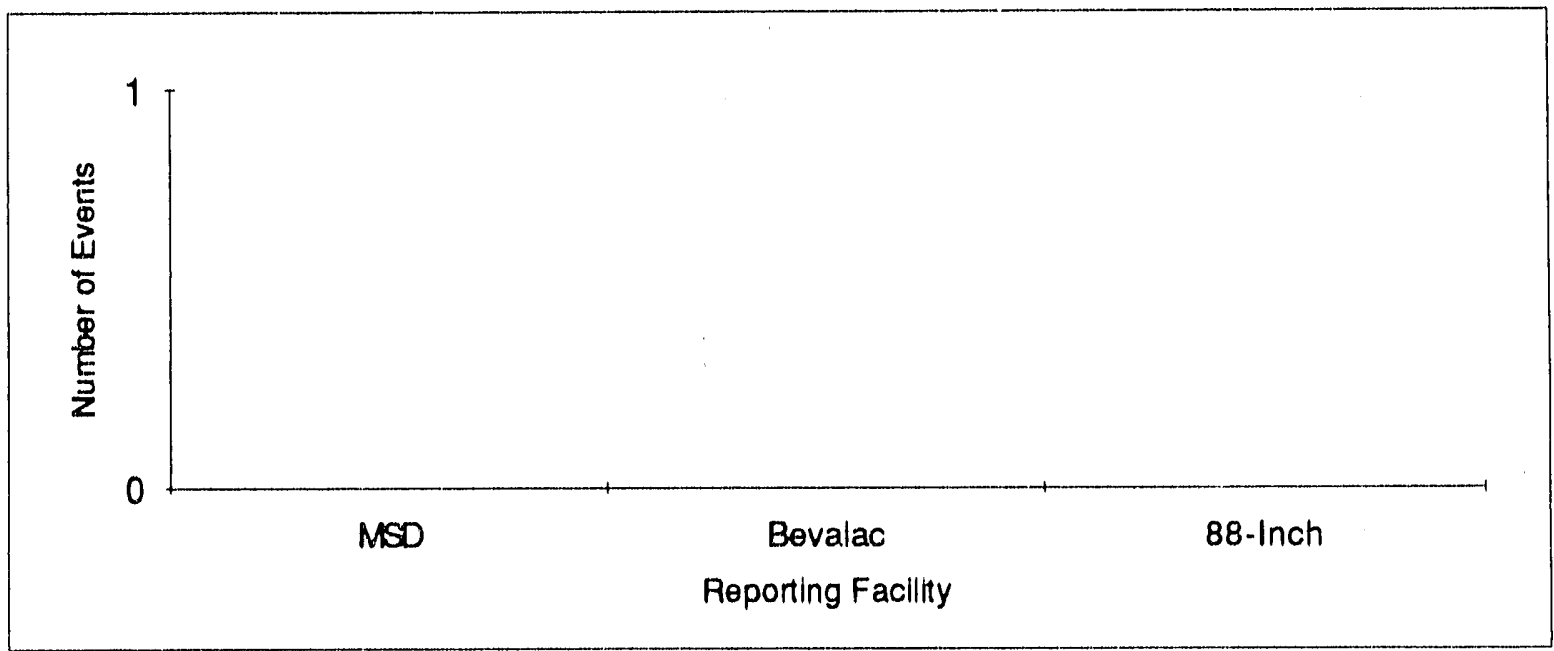

\section{Current Period Data}

No unplanned shutdowns in the current reporting period. 
Root Cause of Occurrences

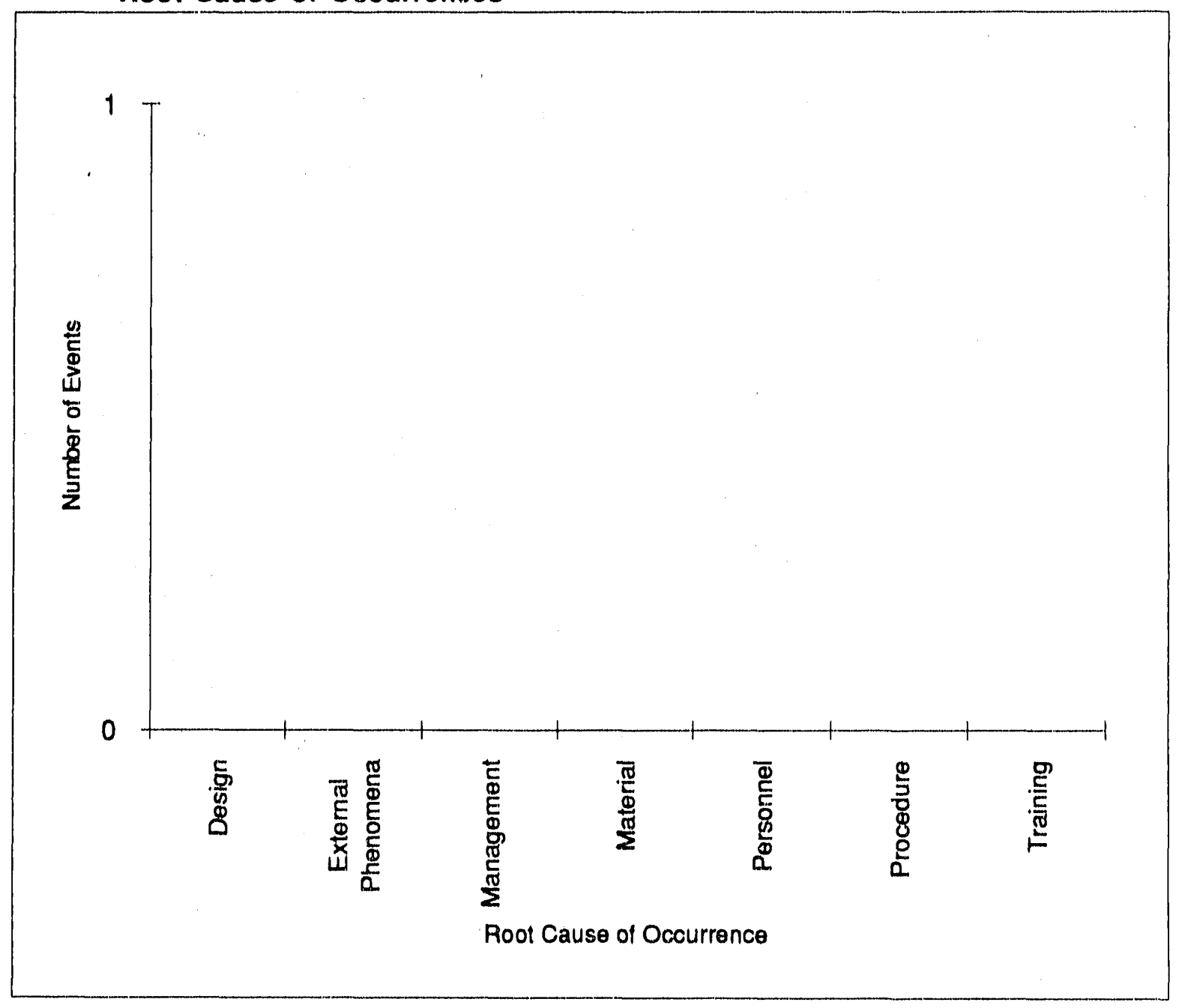

No unplanned shutdowns to date. 


\section{Materials Sciences Division}

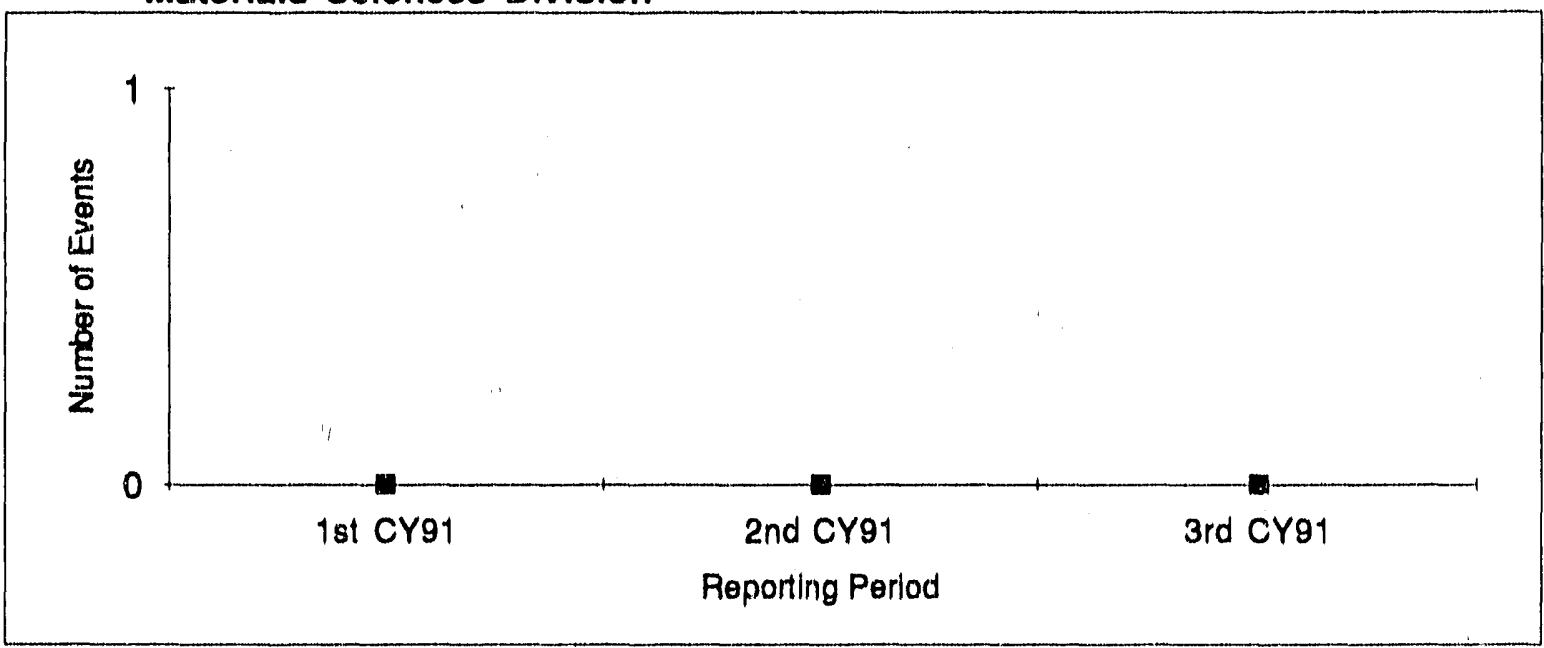

No unplanned shutdowns to date.

Bevalac

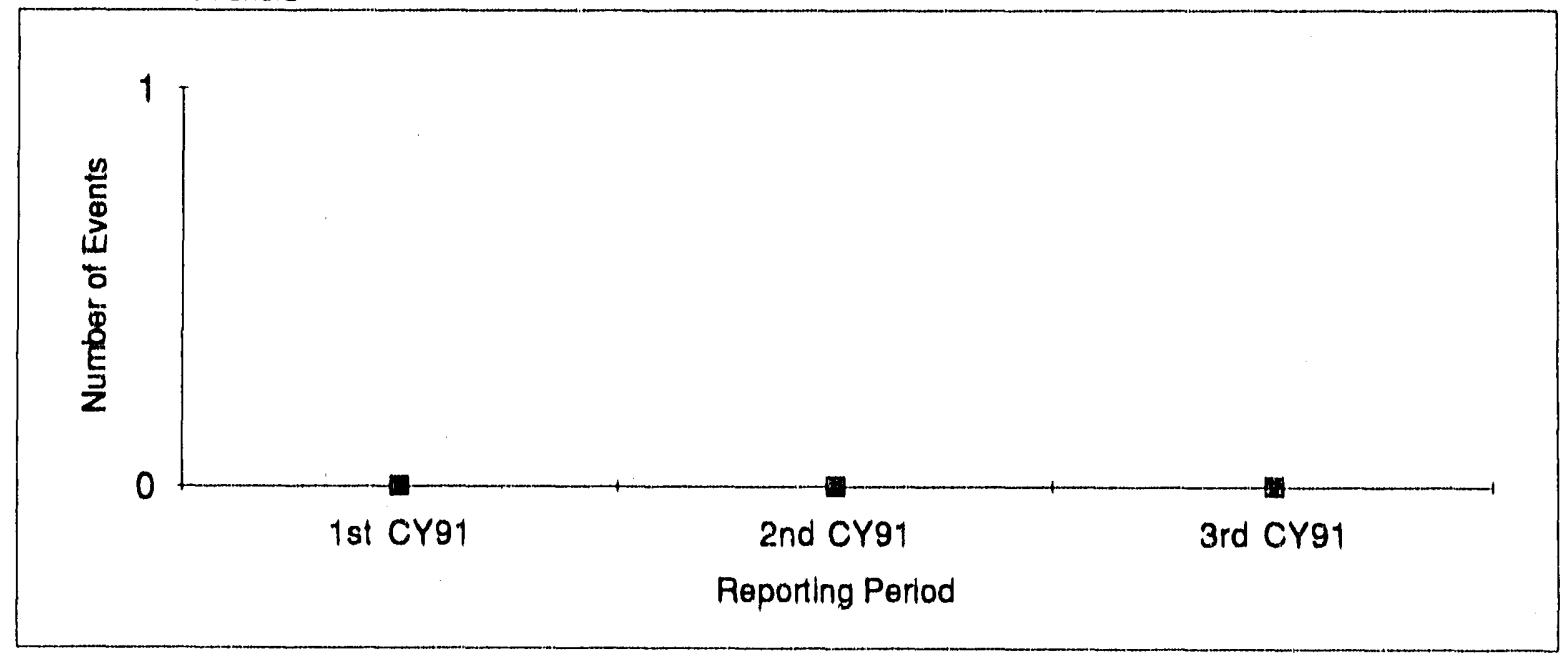

No unplanned shutdowns to date.

PI 2.5 


\section{8-Inch Cyclotron}

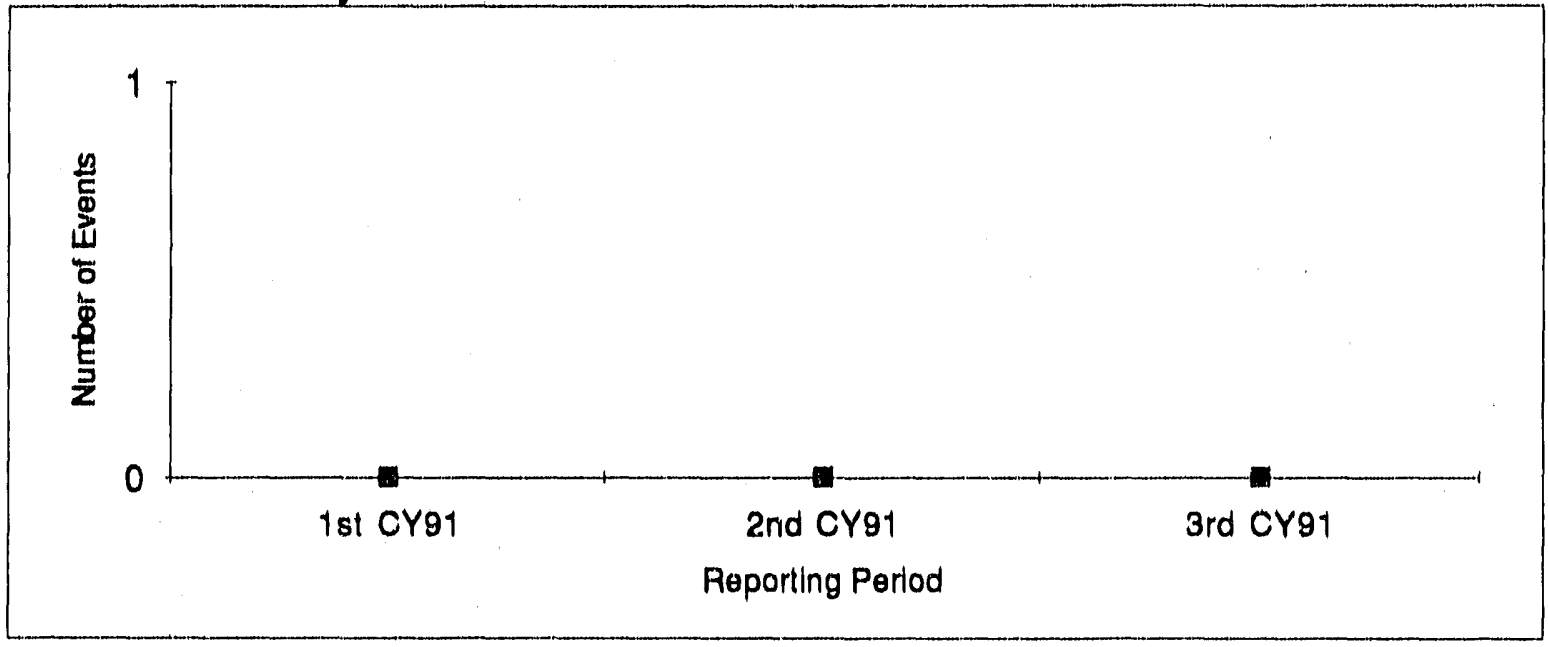

No unplanned shutdowns to date.

P| 2.5 


\subsection{Emergency and Unusual Occurrences.}

The number of Emergency and Unusual Occurrences reported in accordance with DOE Order 5000.3A, "Occurrence Reporting and Processing of Operations Information."

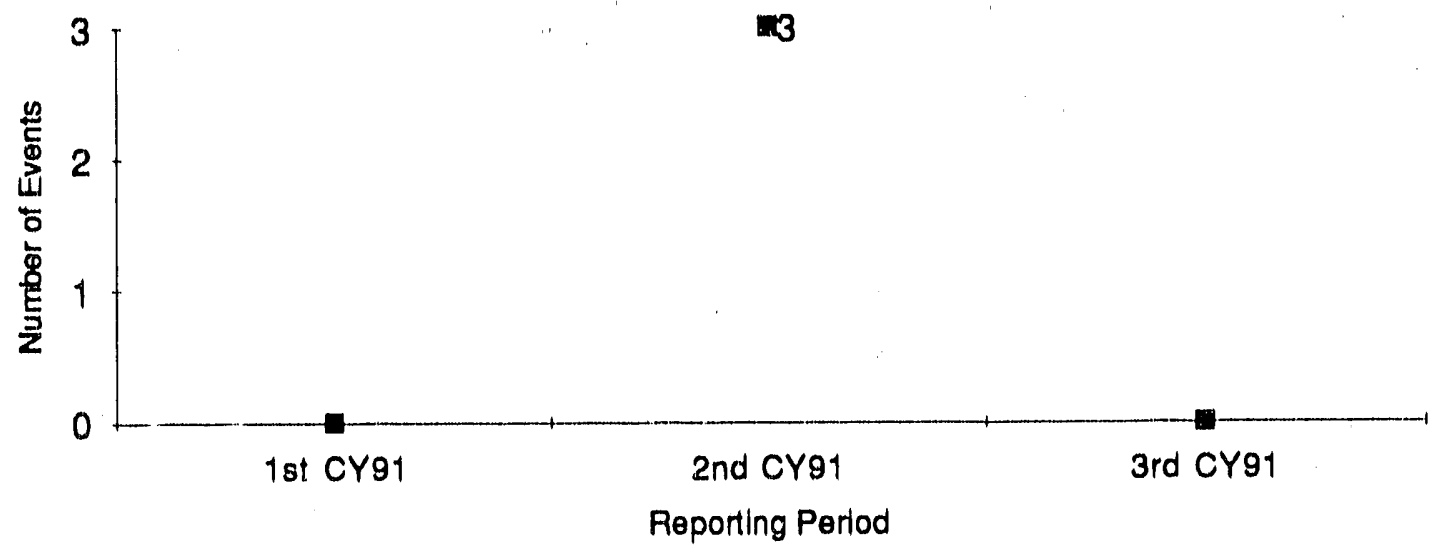

The second quarter data were prevlously reported as two (2) occurrences. There was, in fact, a third which occurred in the Material Science Division (see the MSD facility ohar below).

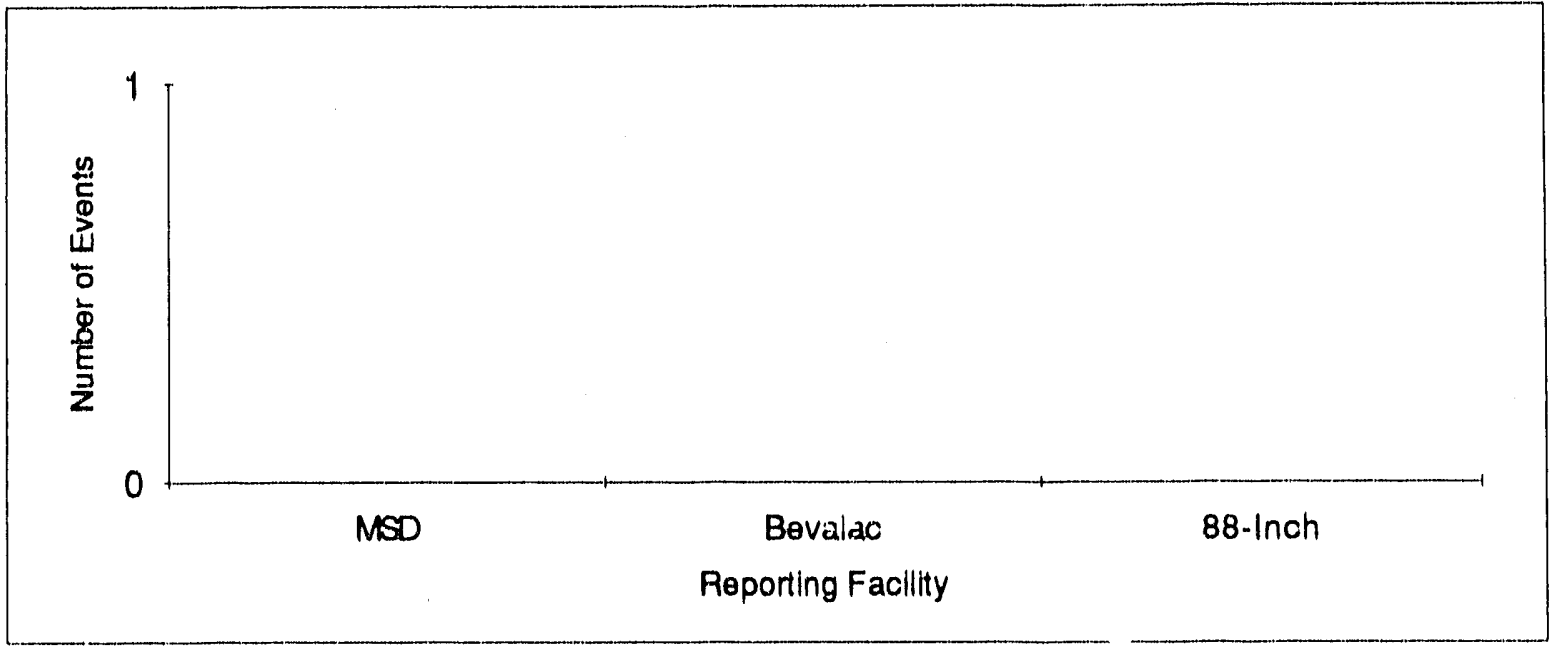

\section{Current Period Data}

No emergency or unusual occurrences during the current reporting period.

PI 2.6 
Root Cause of Occurrences

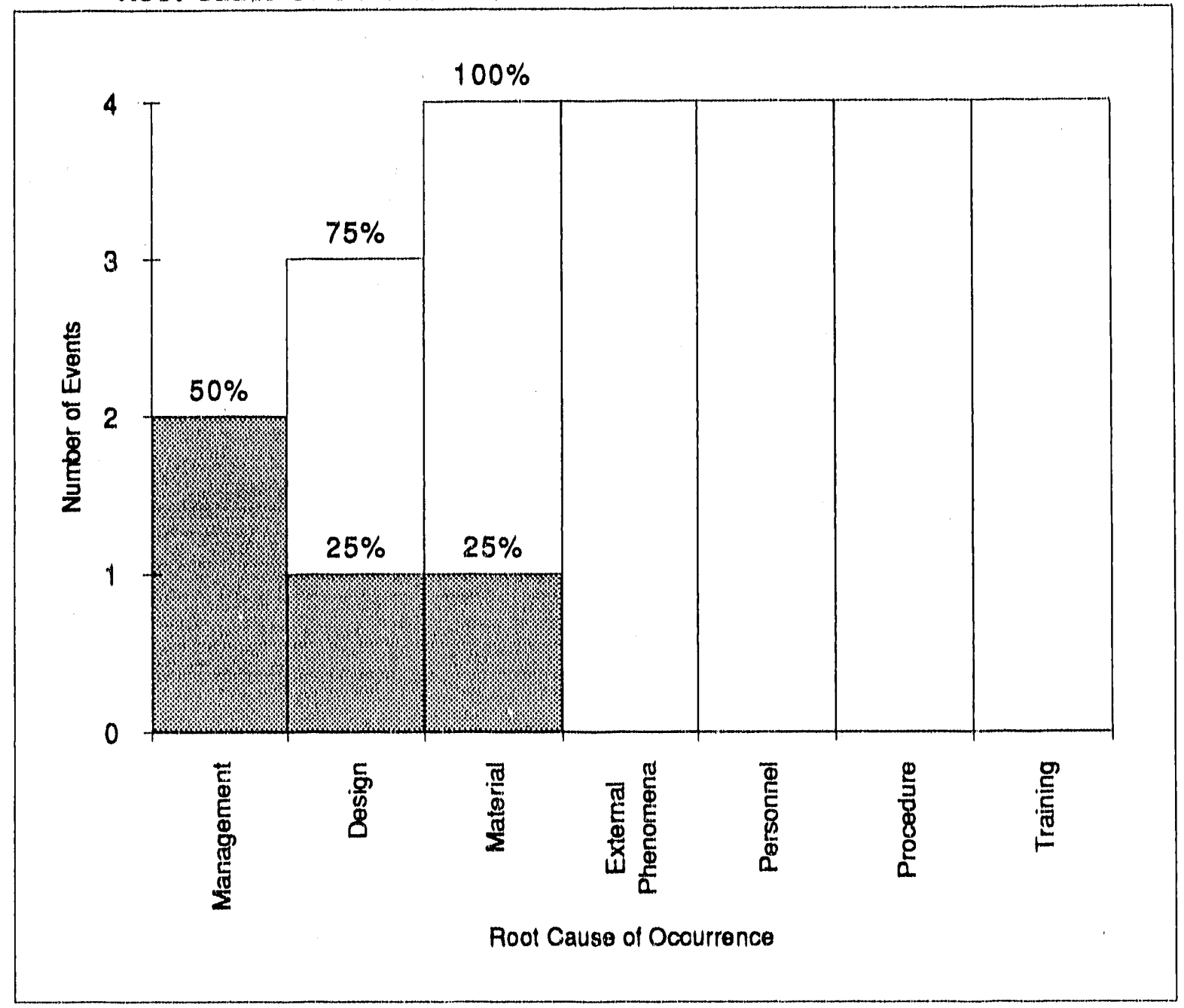

The chart shows the root causes of the following occurrences:

SAN-LBL-AFRD-1991-1001 (2nd qtr): Management

SAN-LBL-AFRD-1990-0028 (1990): Management

SAN-LBL-MSD-1991-1003 (1990): Design

SAN-LBL-MSD-1991-1004 (2nd qtr.): Material

The root cause of a fith unusual occurrence, which took place in the second quarter of 1991 (SAN-LBL-NSD-1991-1001), has yet to be determined.

PI 2.6 


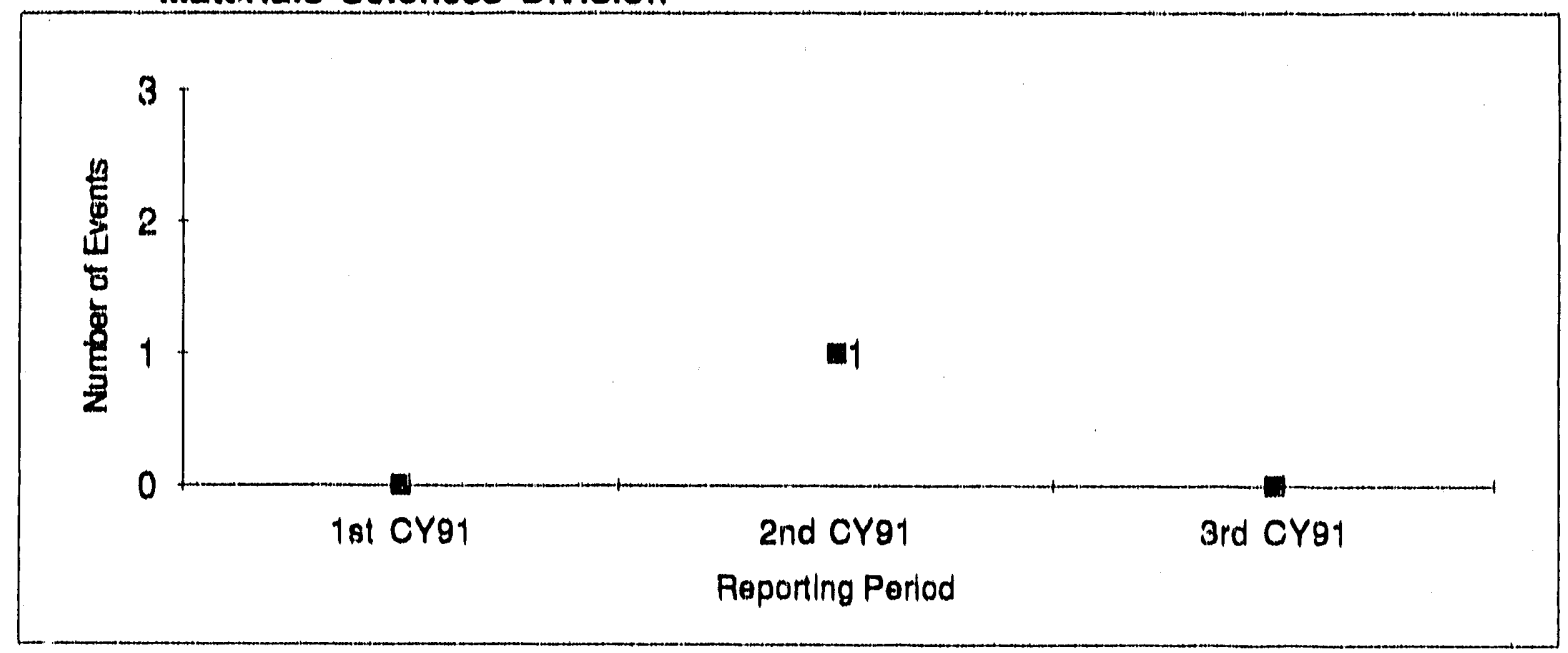

Although not reported in any prevlous PI report, nor on any errata sheet, there was, in fact, an unsual ocourrence in the MSD during the second quarter. It was reported in OR SAN-LBL-MSD-1991-1004.

\section{Bevalac}

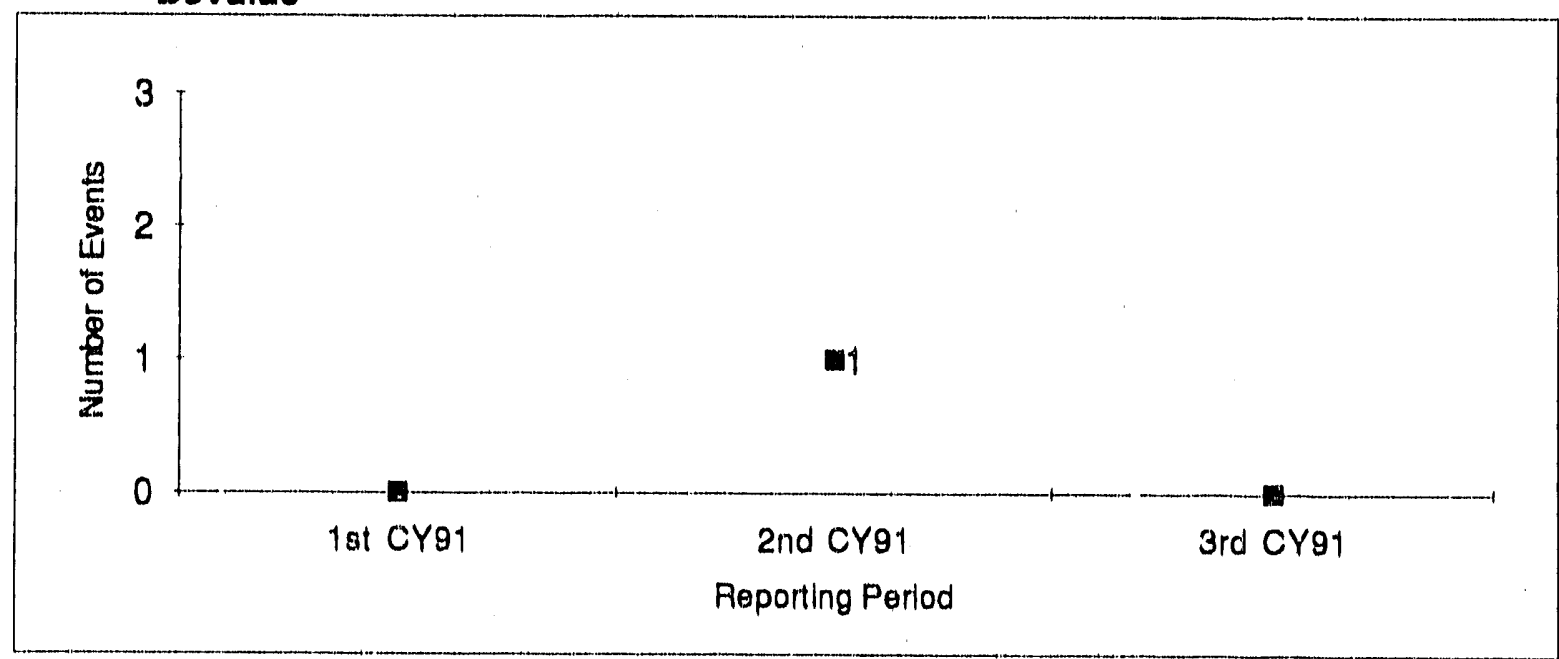

The above second quarter occurrenoe was reported in OR SAN-LEL-AFRD-1991-1001. 


\section{B8-Inch Cyalotron}

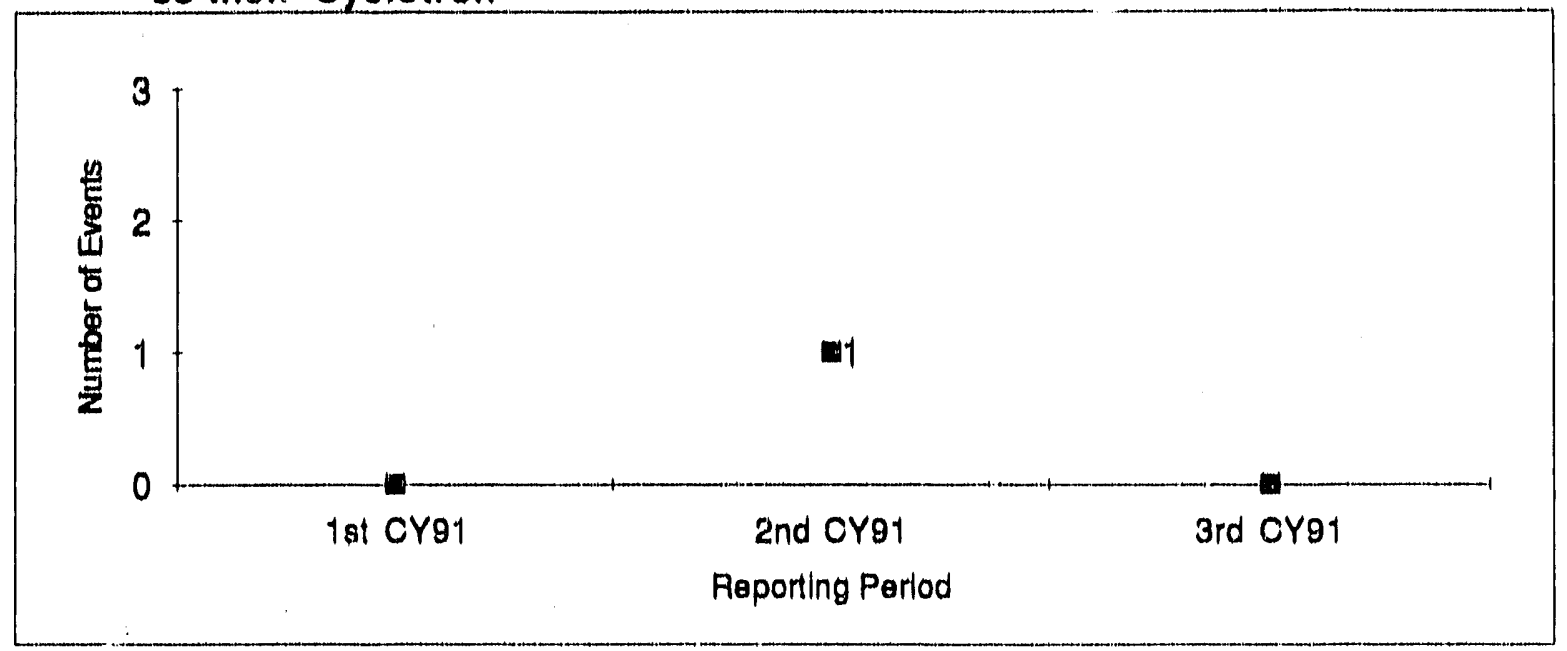

The above second quarter ocourrence was reported in OR SAN-LBL-NSD-1991-1001. 


\subsubsection{Radlonuclide Eifluent Releases (Alrberne)}

Alrborine releases to the environment, as measured at the point of release, for the following radionuolldes: plutonlurn, uranilum, nobel gases, partloulates (Including radioceslums and radiostrontlum, and activation products), radlolodine, tritlum, and other actinides.

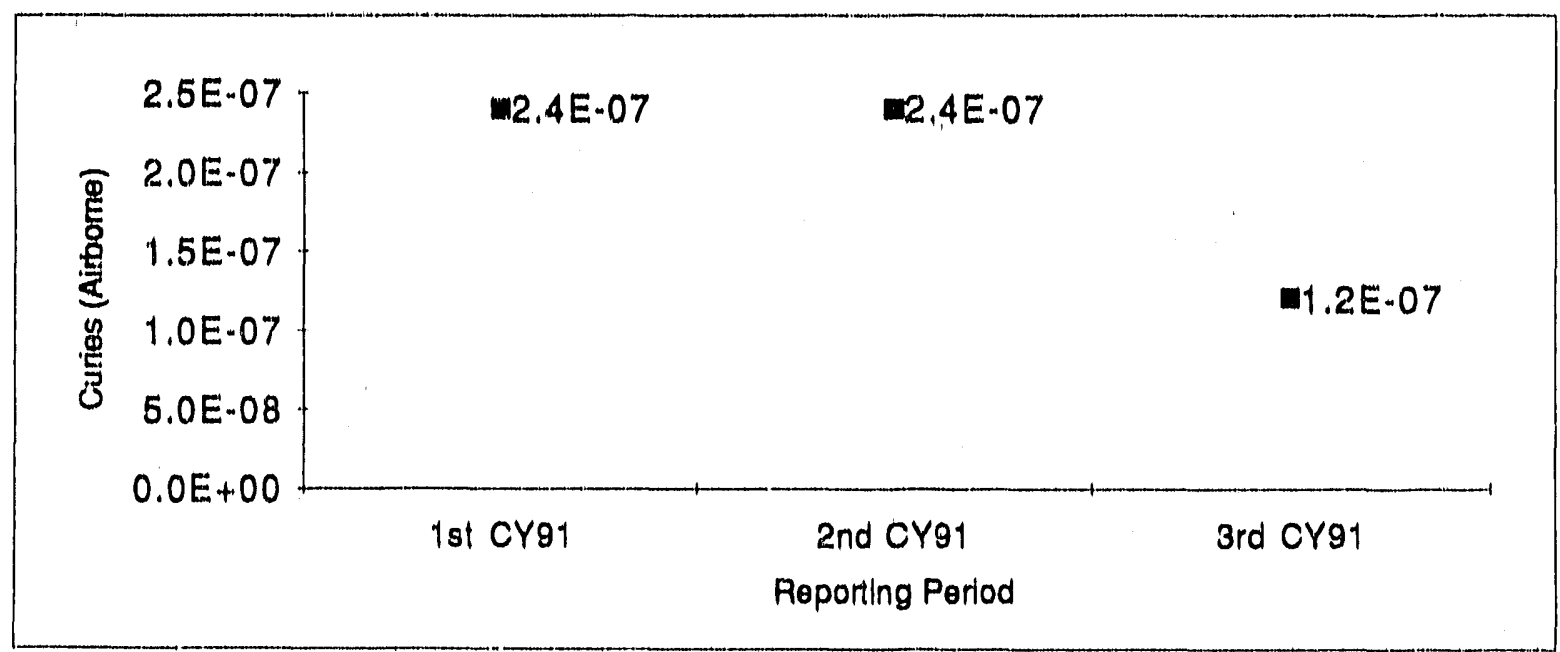

Note: The values in the chart deplat upper bounds on the amounts released.

To date, the amounts of alrborne radionuclide effluent releases from LBL have been statistioally Insignificant.

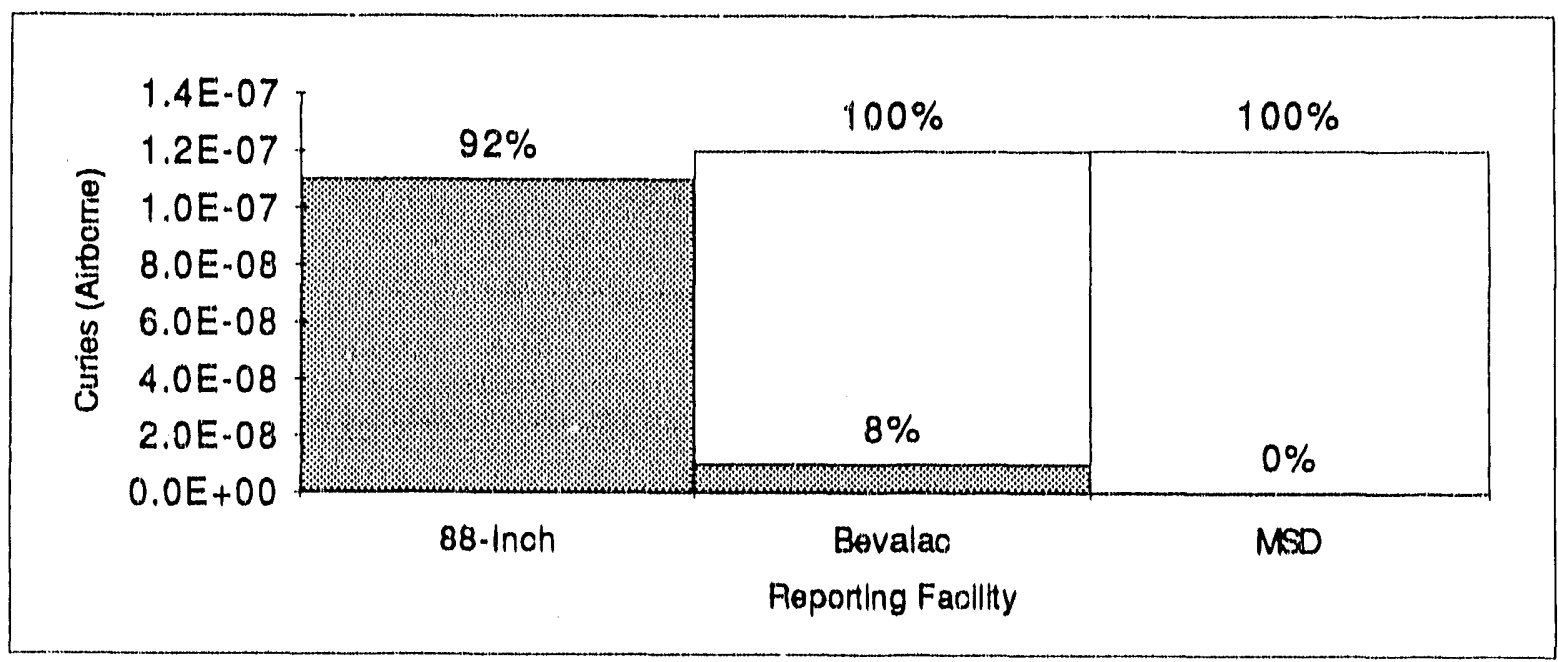

Current Period Data

Note: The values in the chart depict upper bounds on the amounts released.

Although the $88^{\prime \prime}$ facillty released more airborne radionuclide than the other two facillties by far, the actual amount released (less than 1.1E-07 Curles) is negligible. 


\section{Materials Sciences Division}

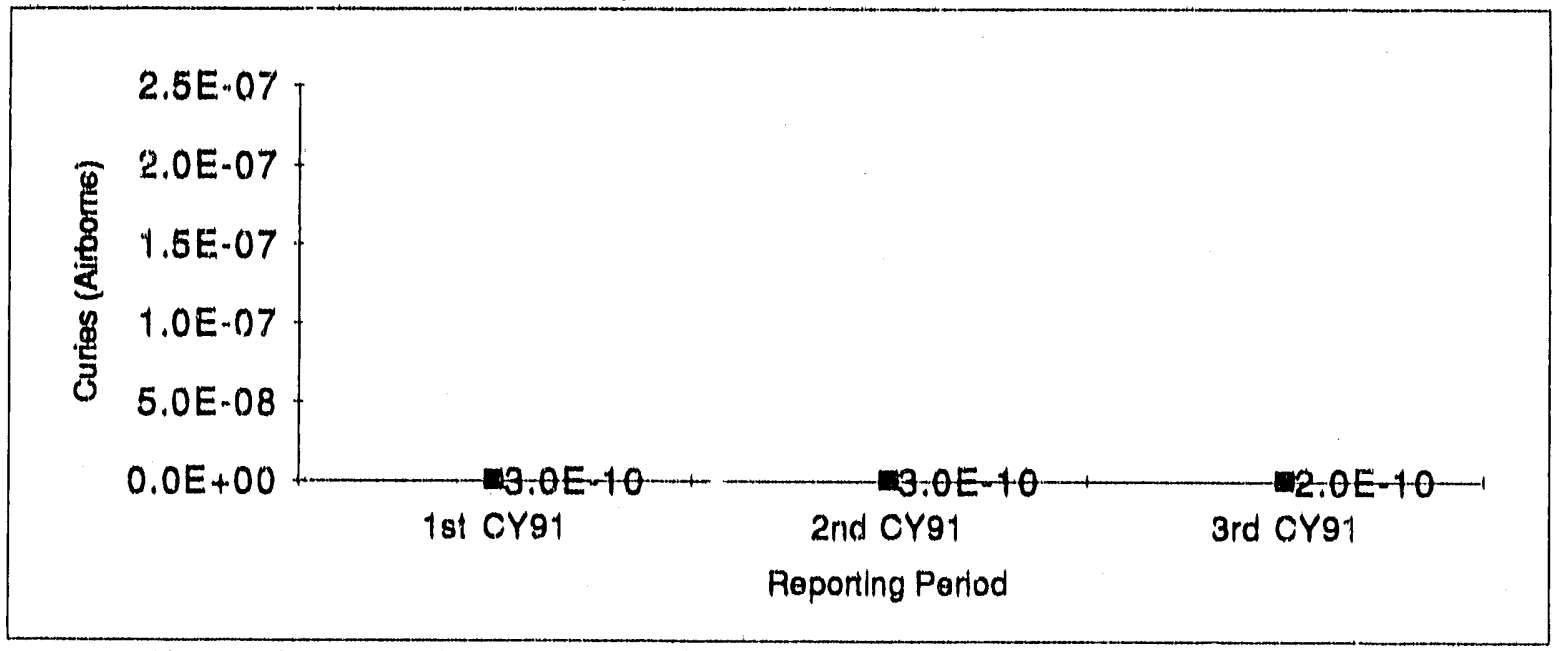

Note: The values in the chart deplat upper bounds on the amounts released.

Negligible to date.

\section{Bevalac}

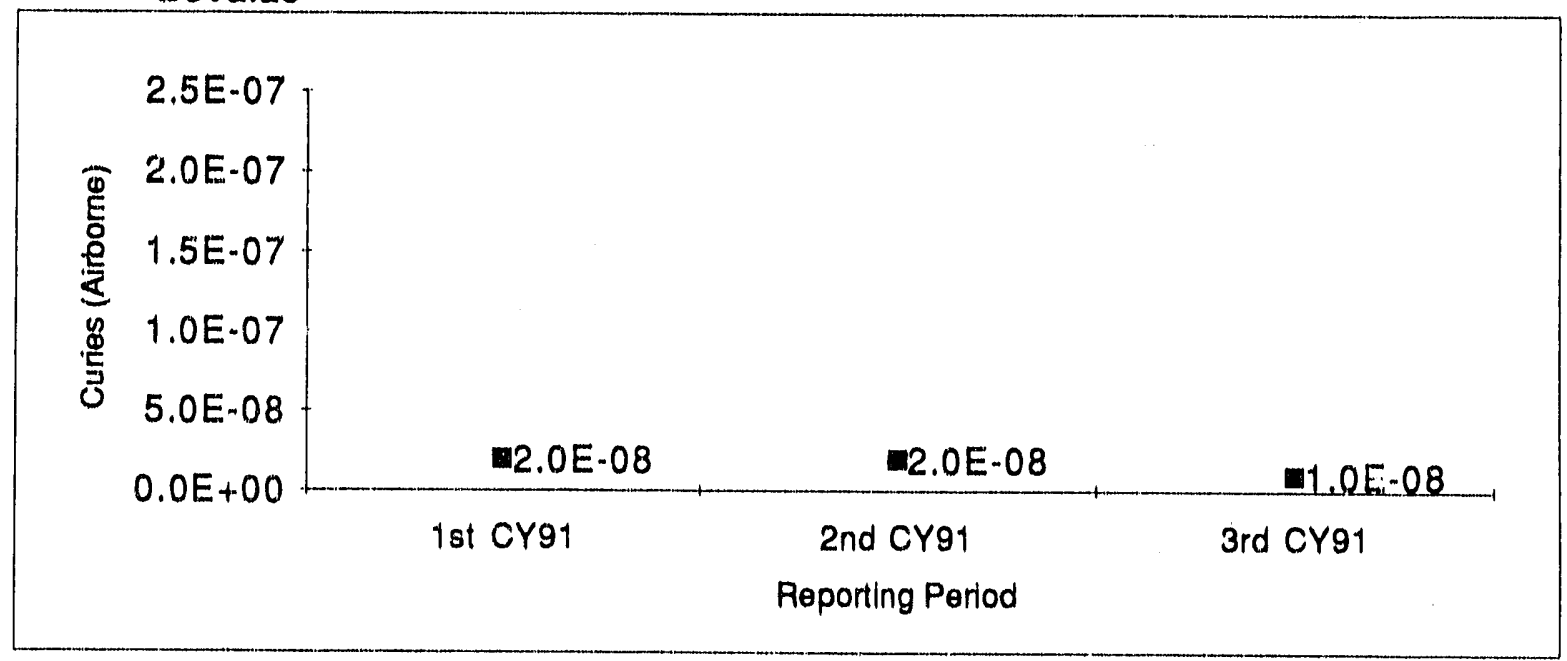

Note: The values in the chart deplct upper bounds on the amounts released.

Negligible to date.

P| 3.1 .1 


\section{8-Inch Cyclotron}

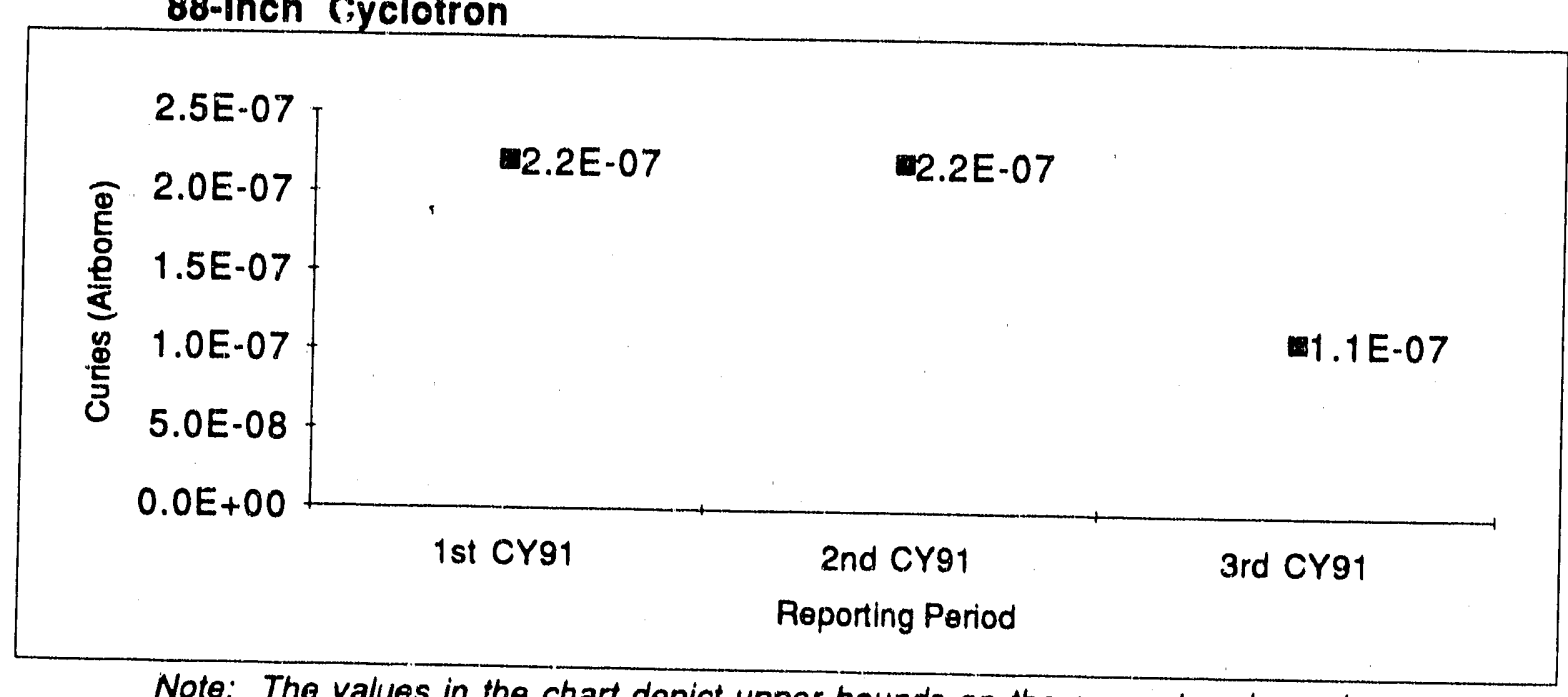

Note: The values in the chart depict upper bounds on the amounts released.

Negligible to date. 


\subsubsection{Radionuclide Effluent Releases (Liquid)}

Liquid releases to the environment, as measured at the point of release, for the following radionuclides: plutonium, uranium, nobel gases, particulates (including radiocesiums and radiostrontium, and activation products), radioiodine, tritium, and other actinides.

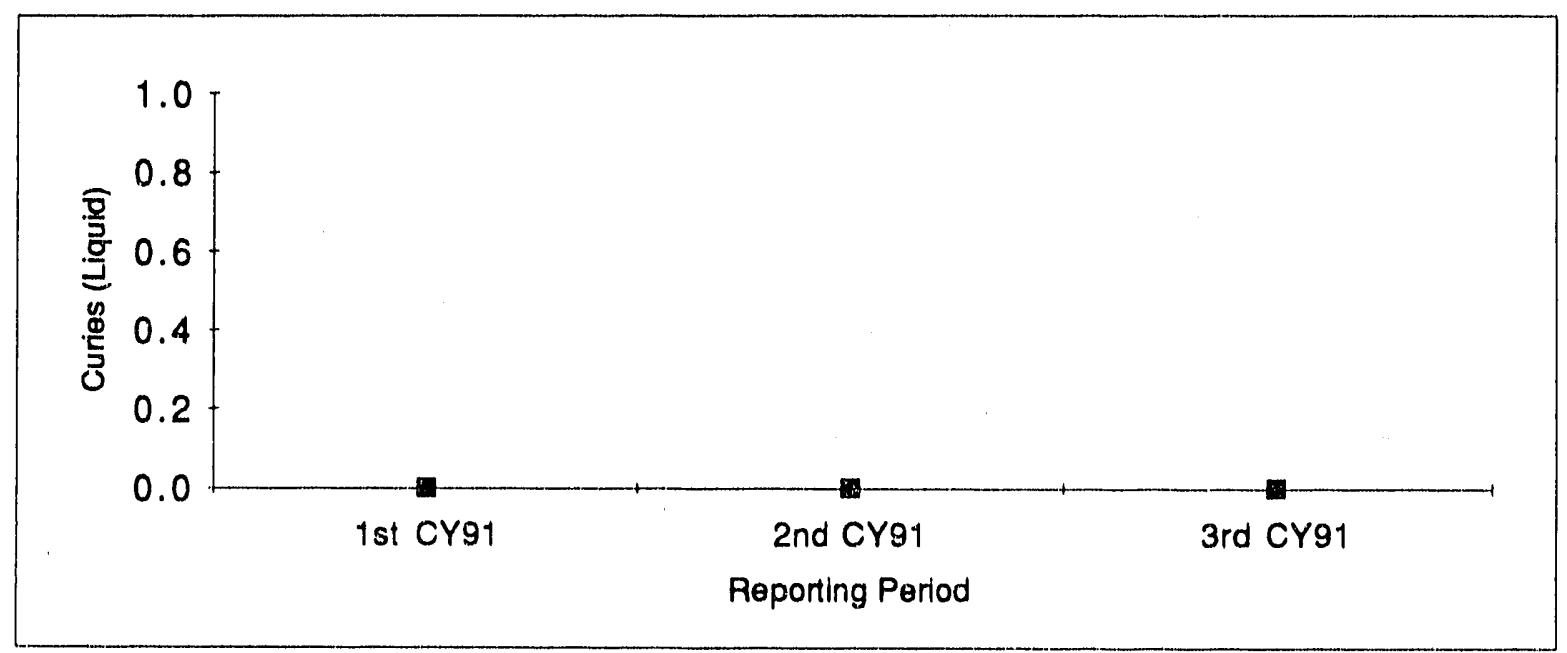

No liquid radionuclide effluent releases to date.

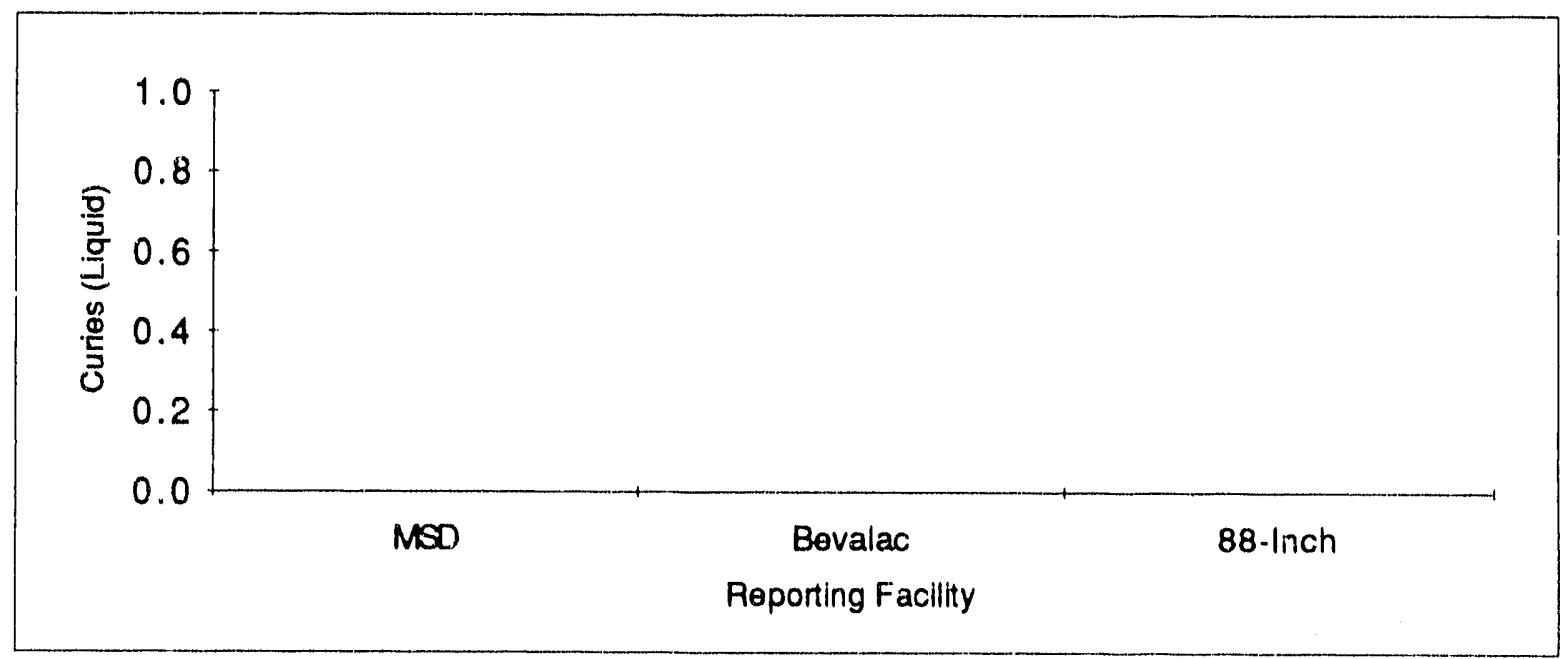

\section{Current Period Data}

No liquid radionuclide effluent releases during this reporting period.

PI 3.1 .2 


\section{Materials Scierices Division}

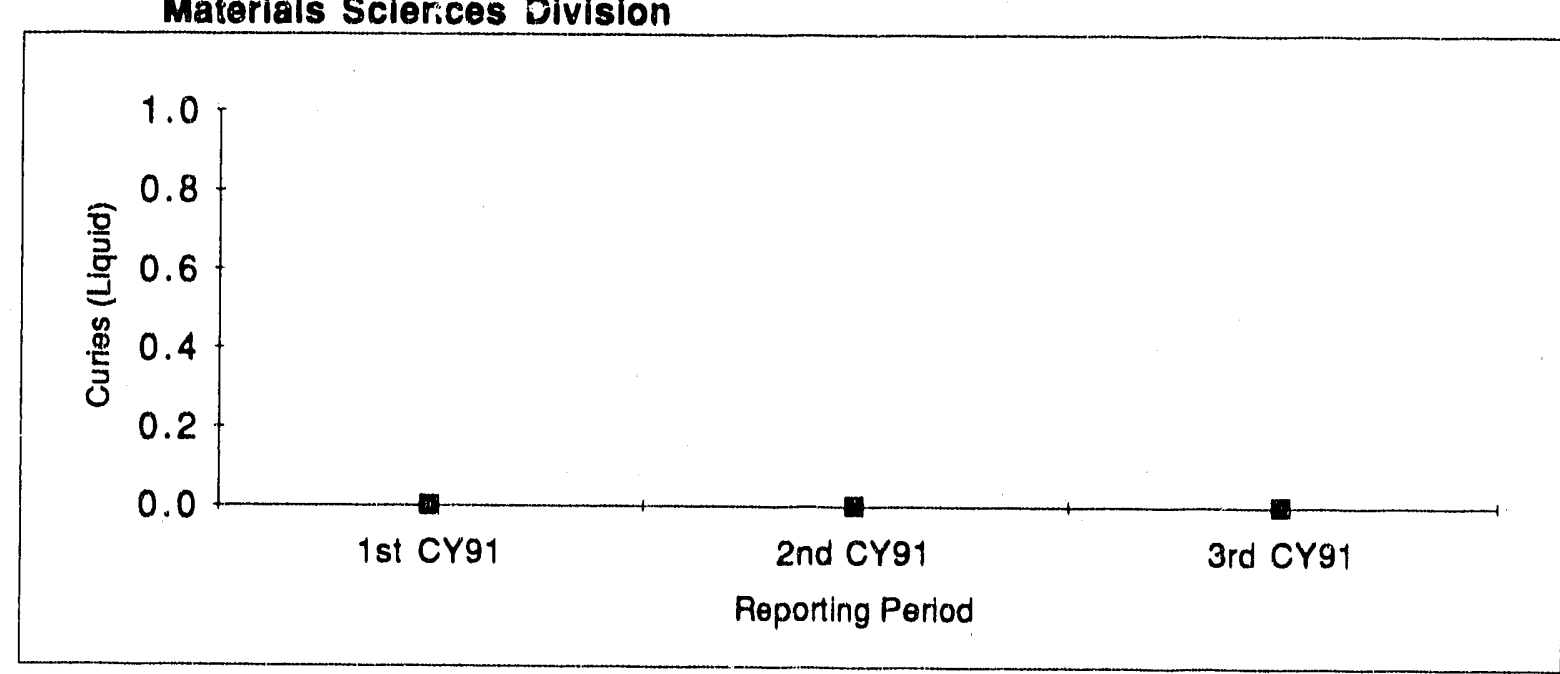

No liquid radionuclide effluent releases to date.

\section{Bevalac}

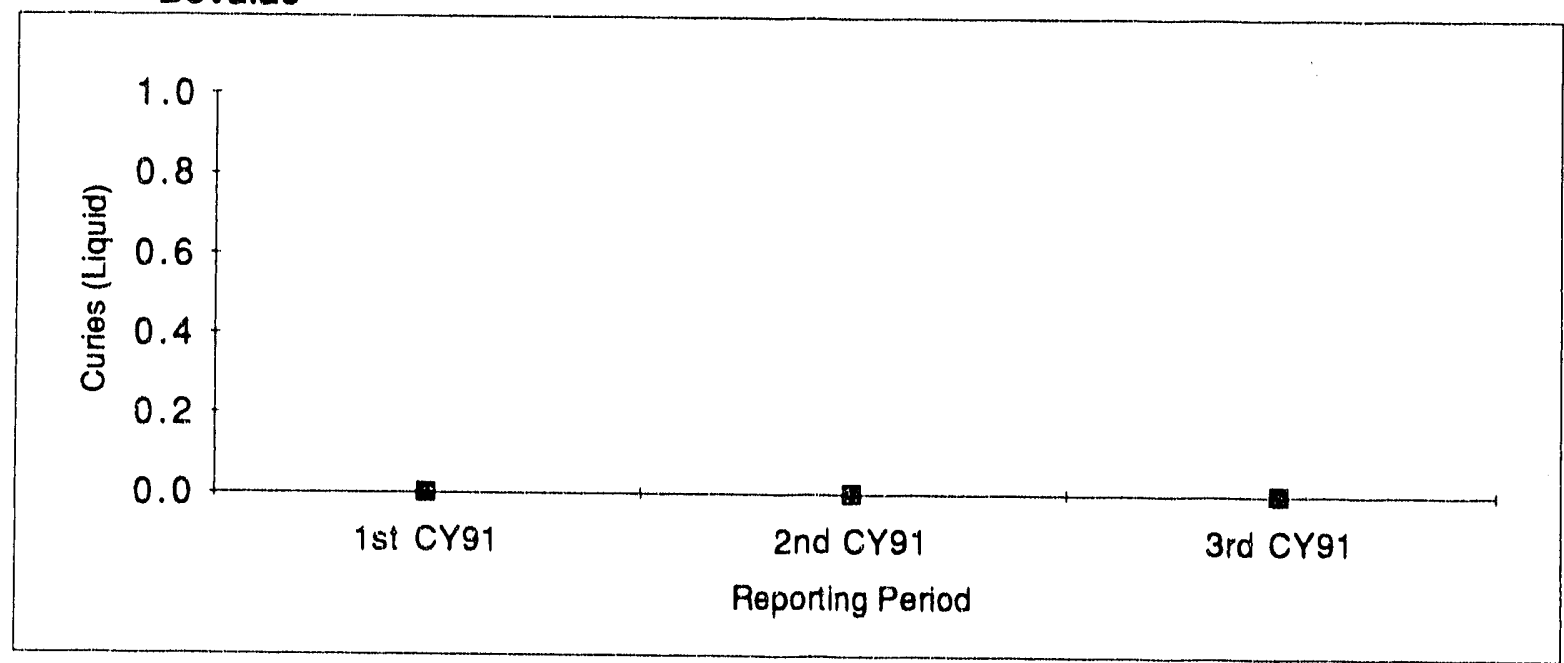

No liquid radionuclide effluent releases to ciate.

PI 3.1 .2 


\section{8-Inch Cyclotron}

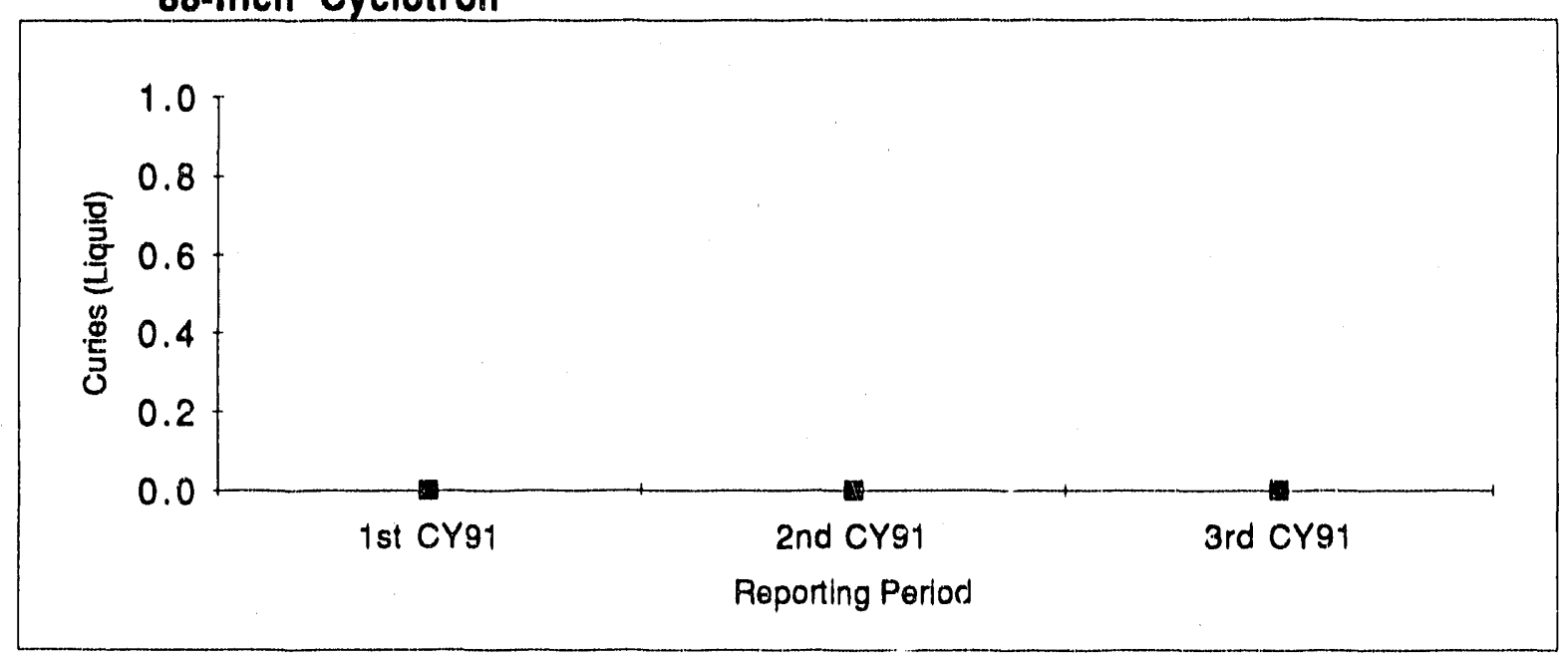

No liquid radionuclide effluent releases to date.

PI 3.1 .2 


\subsubsection{Hazardous Substance/Regulated Pollutant Etfluent Release (Airberne)}

The amount of "permitted" airborne non-radioactive releases. All hazardous substances and regulated pollutants that are listed in permits (e.g., Clean Air Act or NPDES permits) or otherwise reported to regulators (e.g., through SARA Title III, Section 313 reporting requirements) are included. Data shall be cumulative over the reporting period and reported in units of pounds.
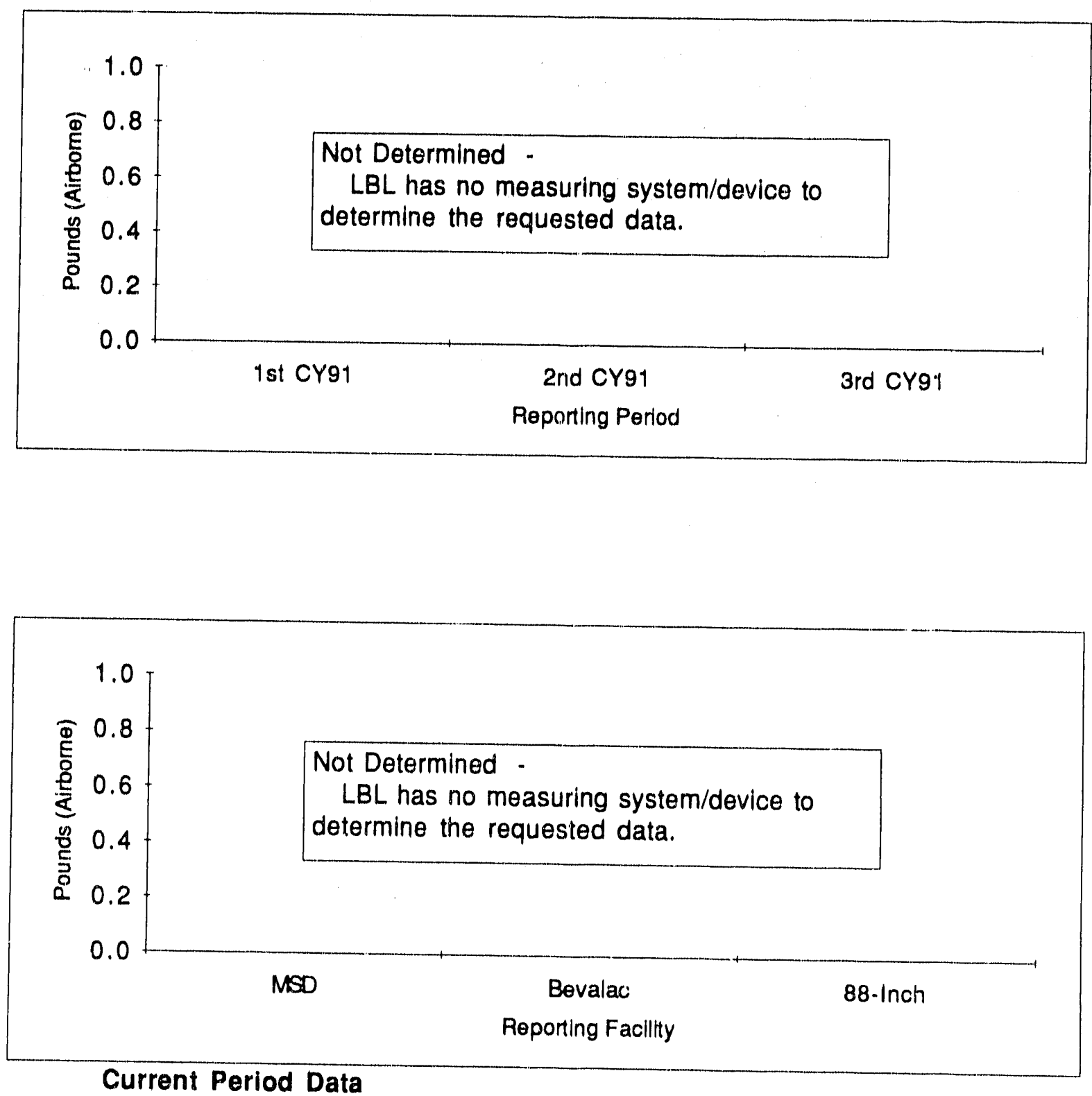
Materials Sciences Division

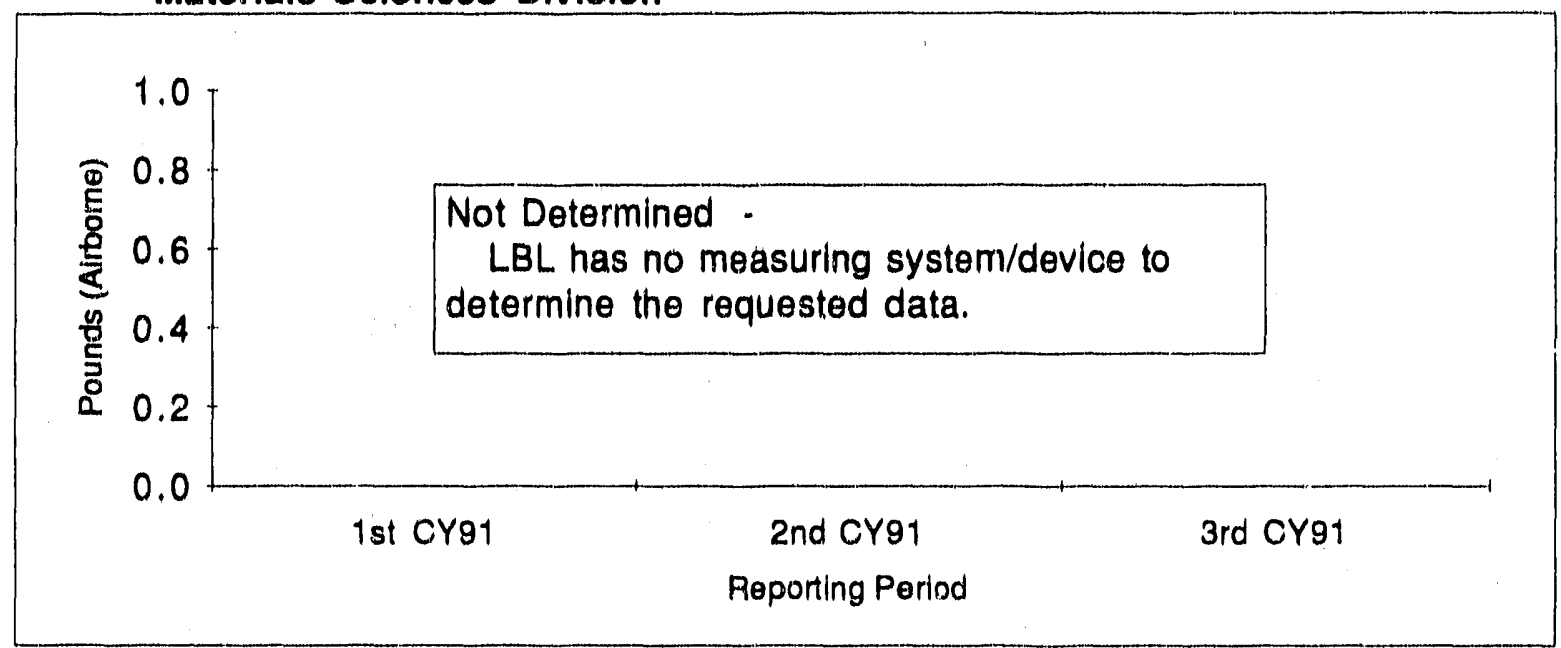

\section{Bevalac}

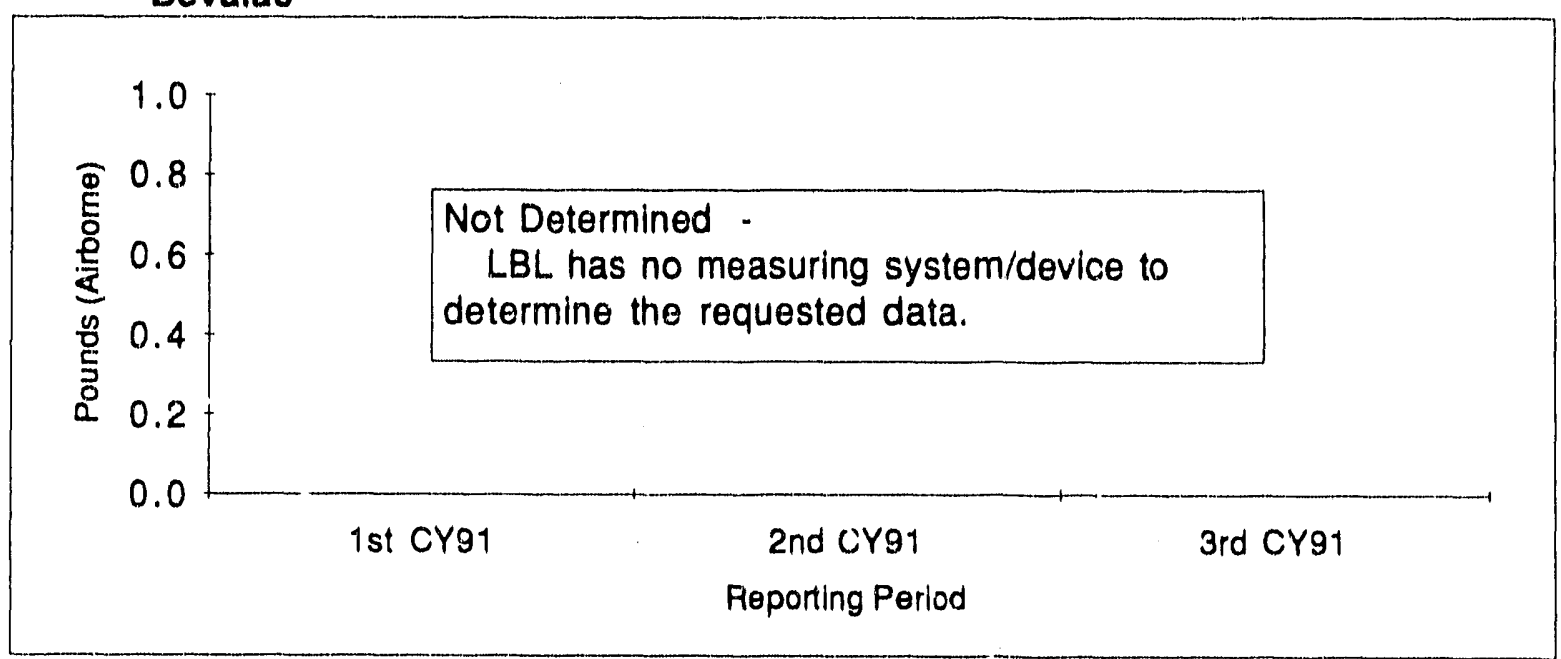




\section{8-Inch Cyclotron}

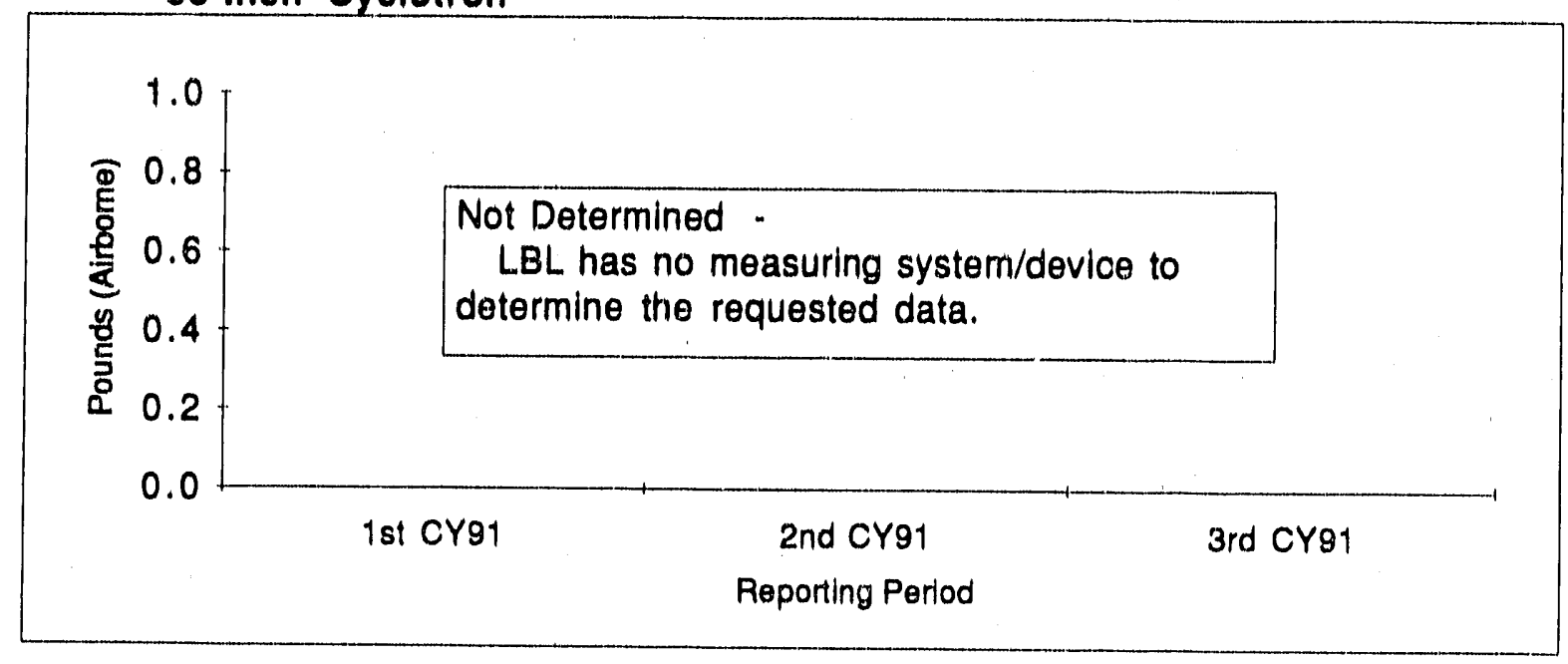




\subsubsection{Hazardous Substance/Requlated Pollutant Effluent Releases (Liquid)}

The amount of "permitted" liquid non-radioactive releases. All hazardous substances and regulated pollutants that are listed in permilts (e.g., Clean Air Act or NPDES permits) or otherwise reported to regulators (e.g., through SARA Title III, Section 313 reporting requirements) are included. Data shall be cumulative over the reporting period and reported in units of gallons.

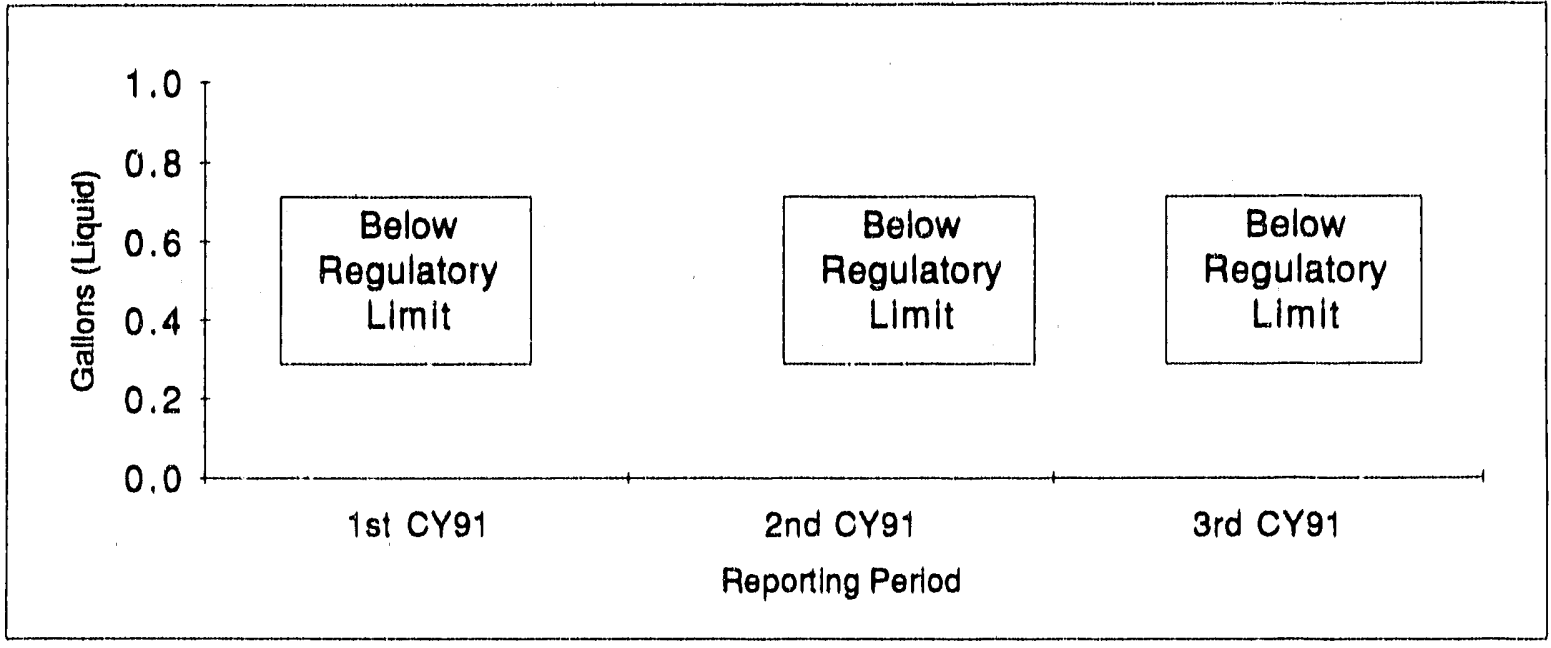

To date, the amounts of liquid hazardous substances and/or regulated pollutant effluent releases have been the below regulatory limit.

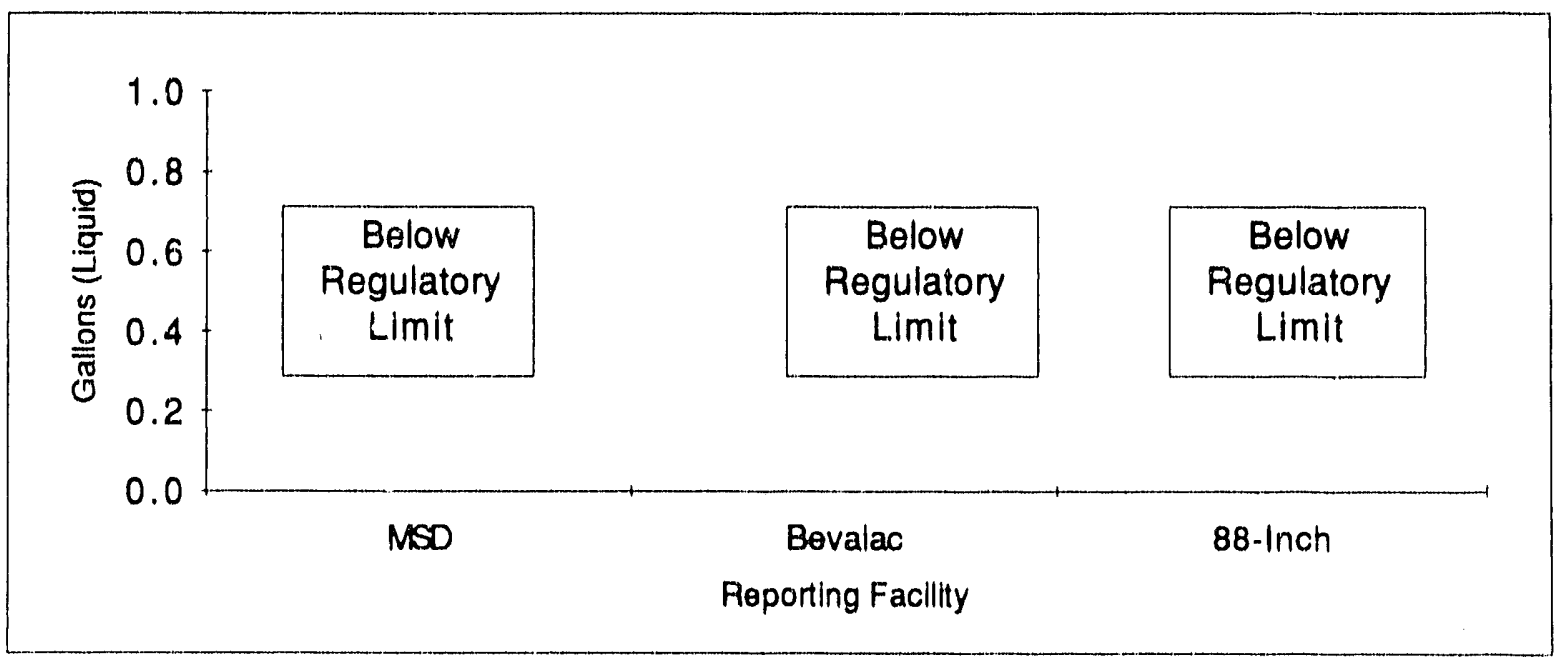

\section{Current Period Data}

The amounts of liquid hazardous substances and/or regulated pollutant effluent releases were below regulatory limit during this reporting period. 


\section{Materials Sciences Division}

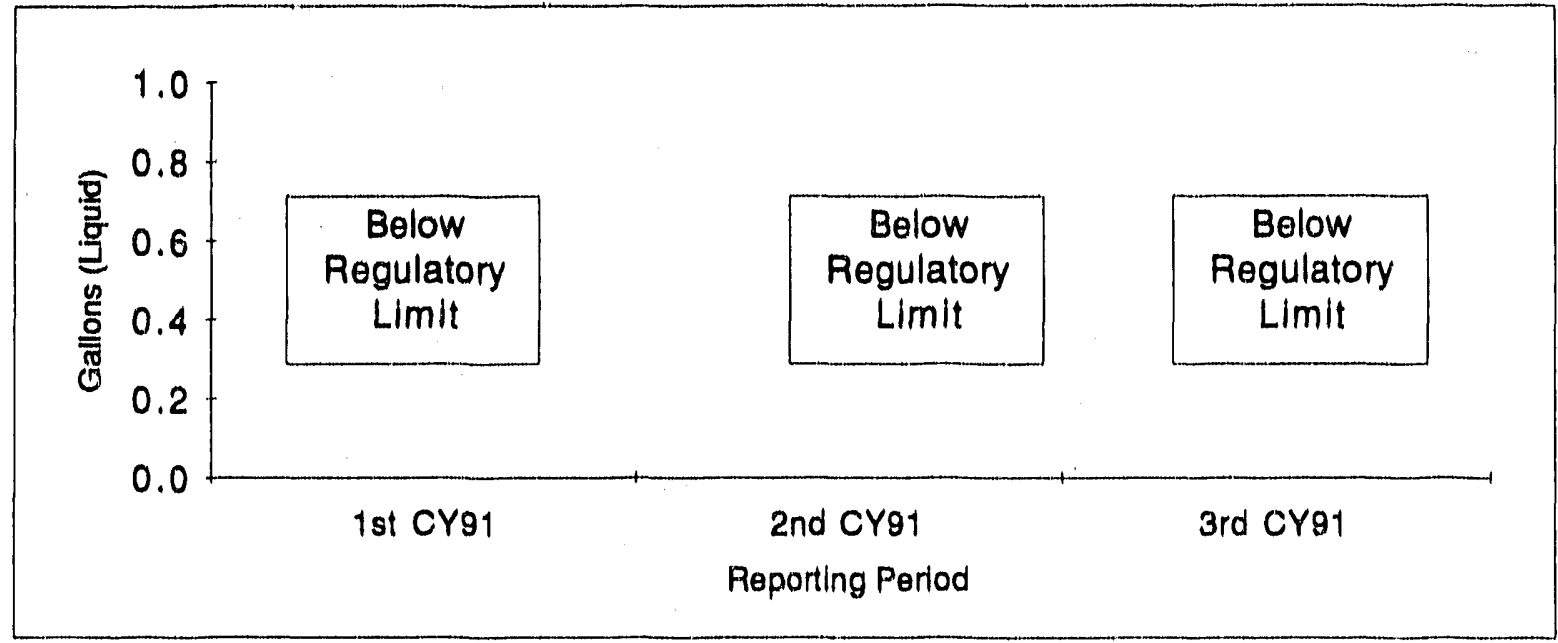

To date, the amounts of liquid hazardous substances and/or regulated pollutant effluent releases have been the below regulatory limit.

\section{Bevalac}

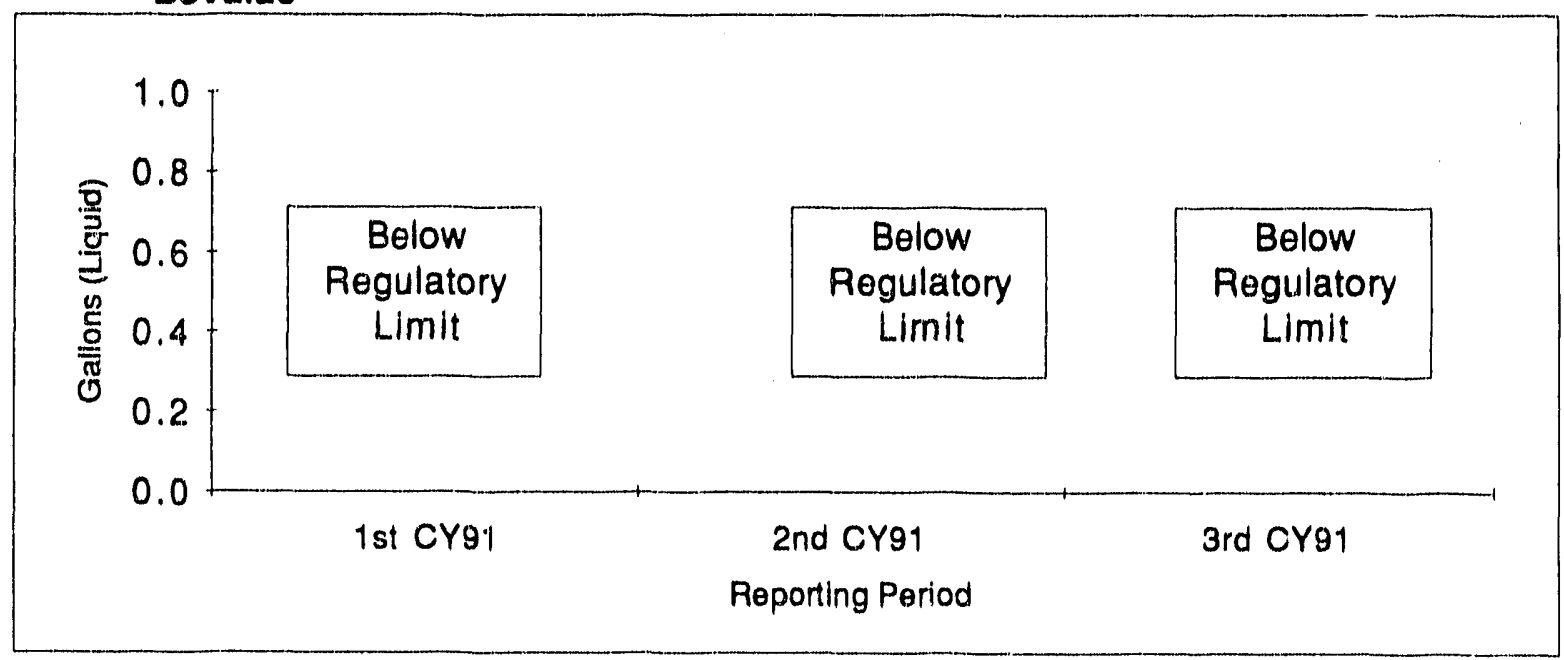

To date, the amounts of liquid hazardous substances and/or regulated pollutant effluent releases have been the below regulatory limit. 
88-Inch Cyclotron

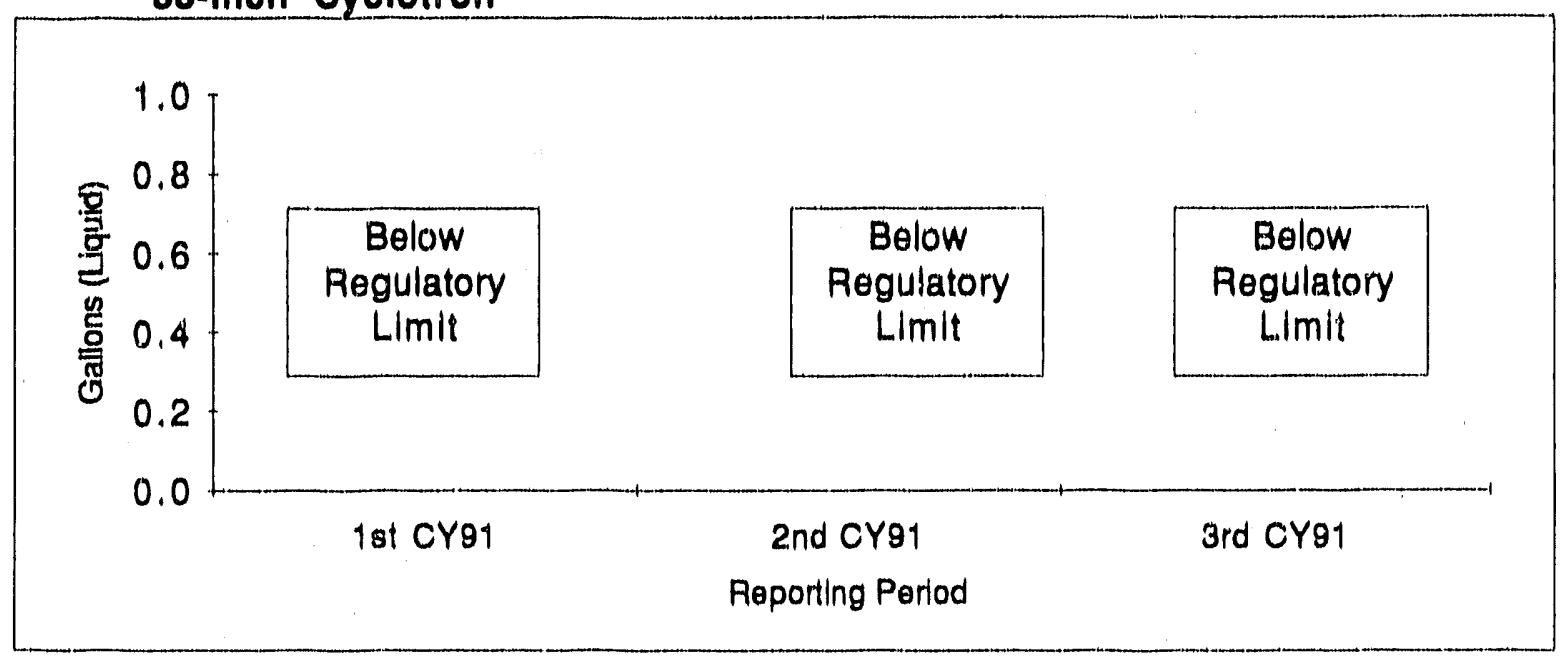

To date, the amounts of liquid hazardous substances and/or regulated pollutant effluent releases have been the below regulatory limit. 


\subsection{0pen DOE Audit lssues}

The total number of findings, Imeluding concerns and recommendatlons requiring correotive actlons, by oversight assessments and line program self-assessments for which contractor corrective actions have not been complated at the time of the report.
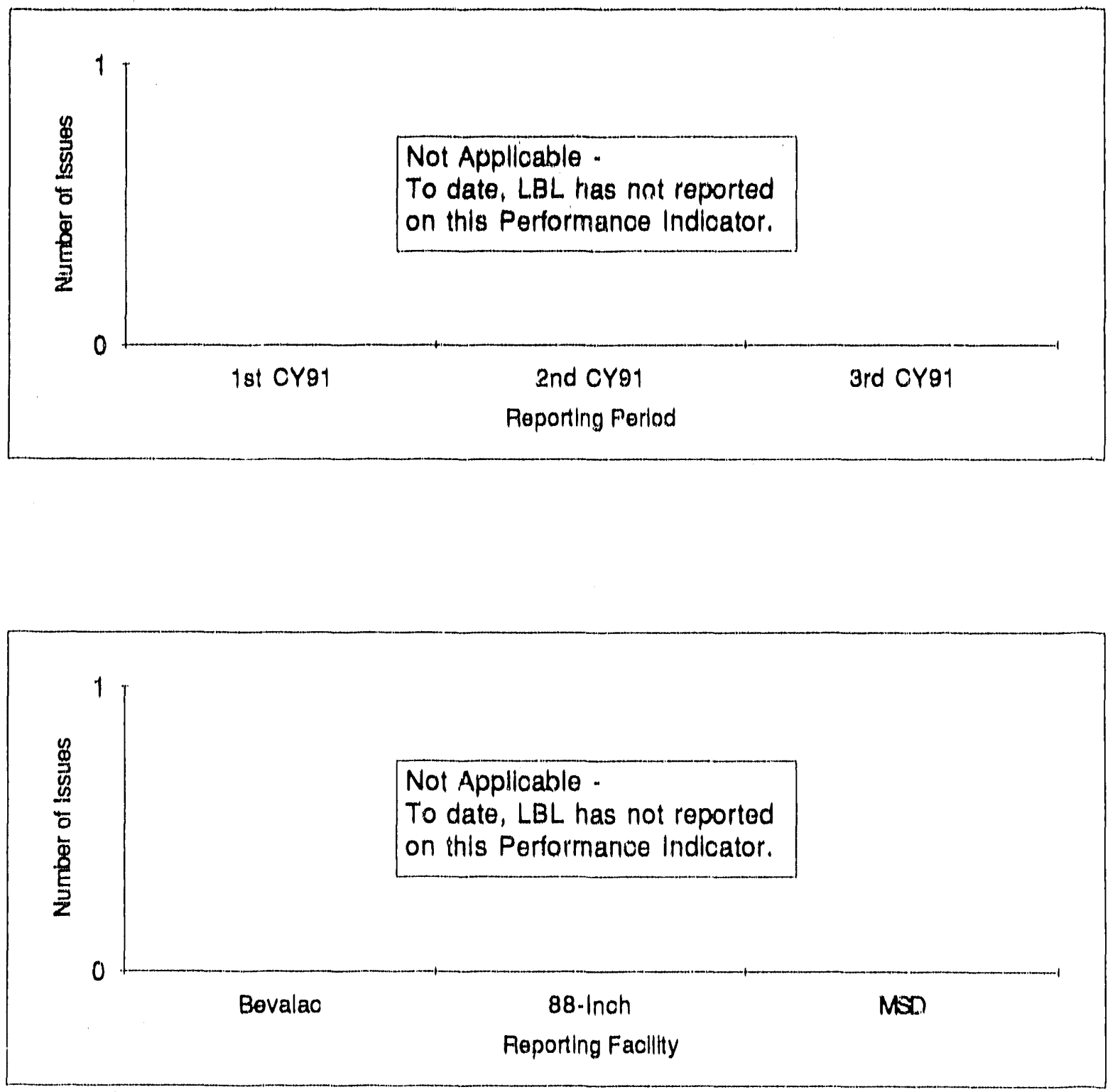

Current Period Data

PI 4.1 


\section{Materlals Sclences Division}

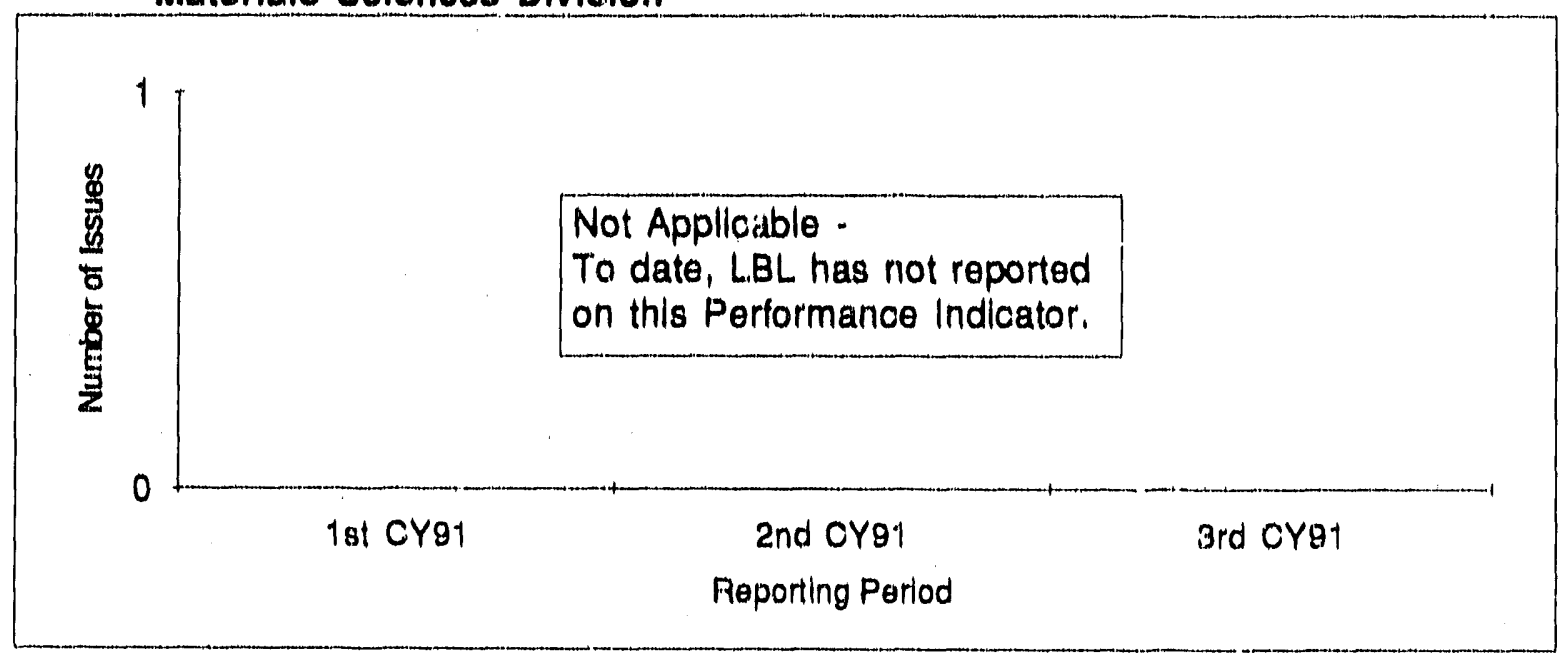

Bevalac

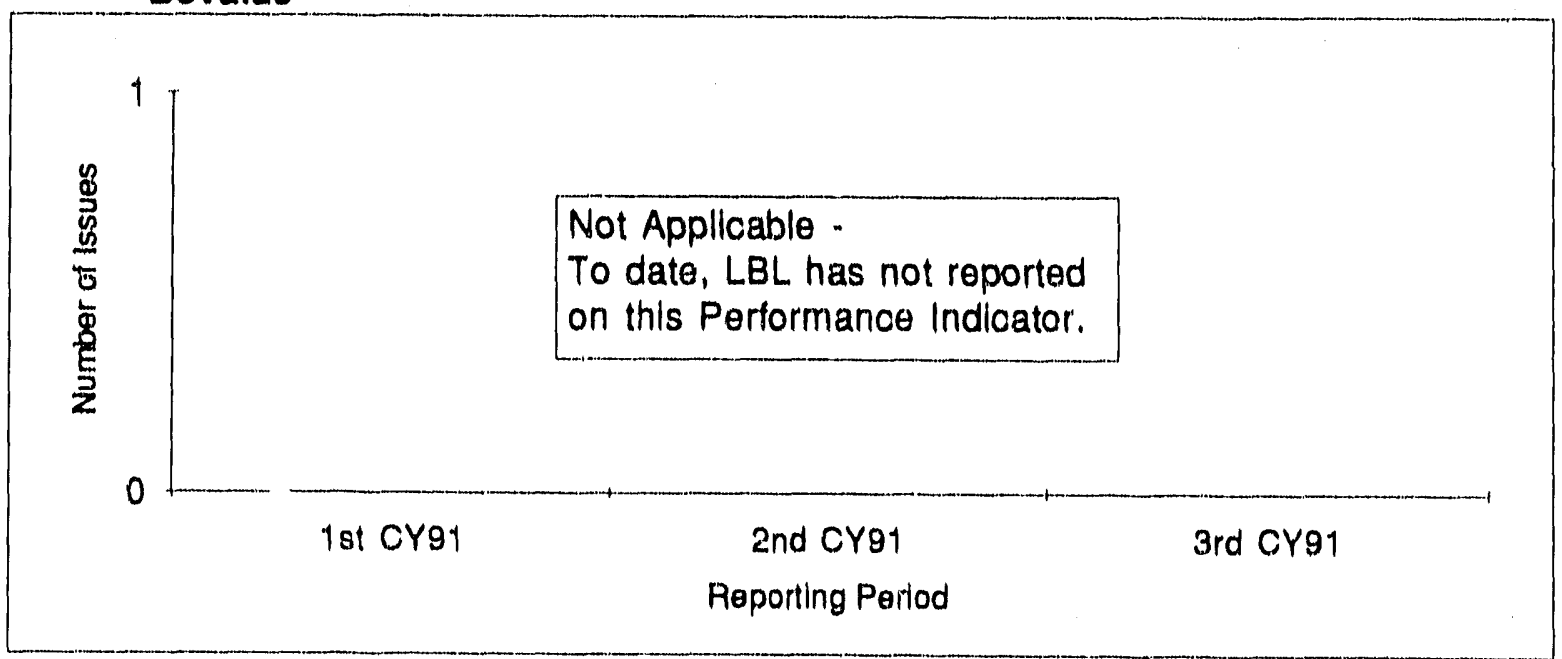




\section{8-Inch Cyclotron}

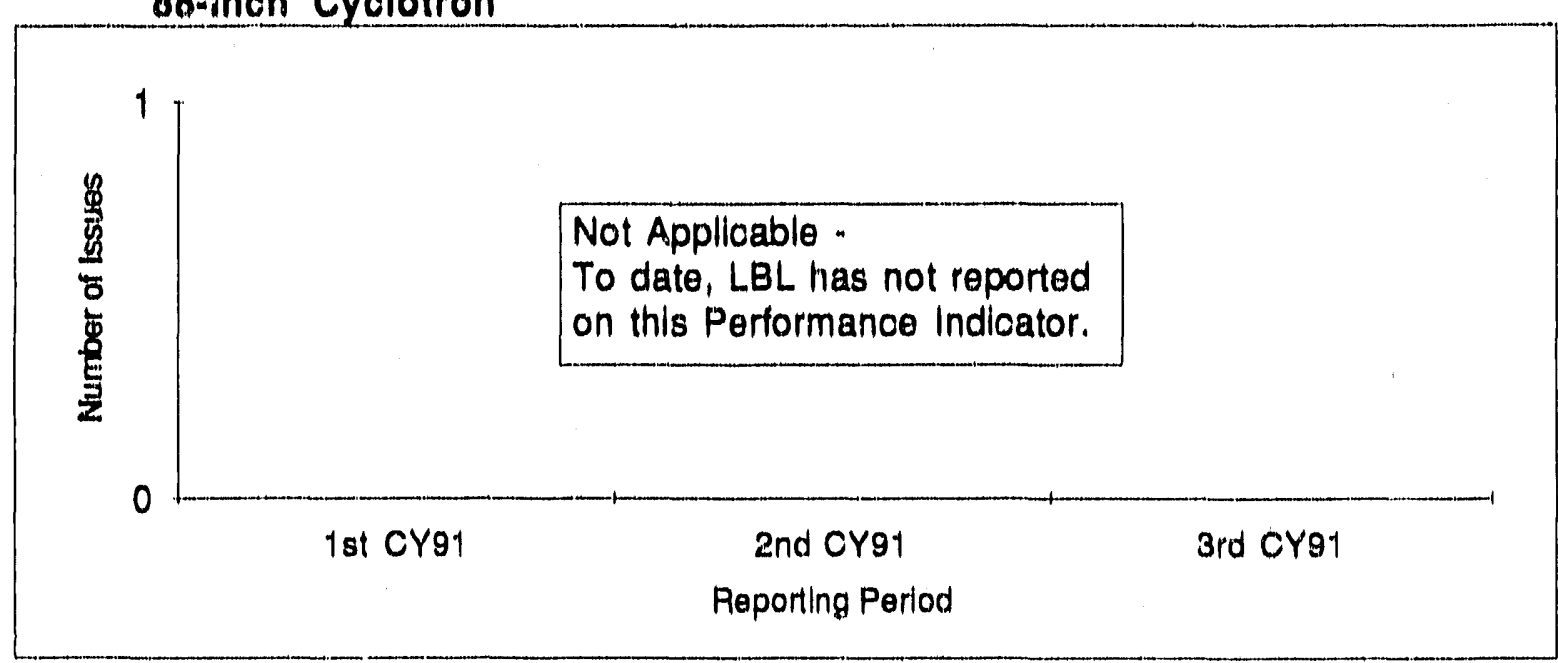

PI 4.1 


\subsection{Open External Oraanization Recemmendations}

The total number of recommendations by external orgarizations, such as the Advisory Committeo on Nuclear Facillty Safety, the Defense Nudear Facillty Safety Board, the National Academy of Sciences, etc., directed to speciflc contractors or thelr facillty operations, for which contractor corrective actions have not been completed at the time of the report.
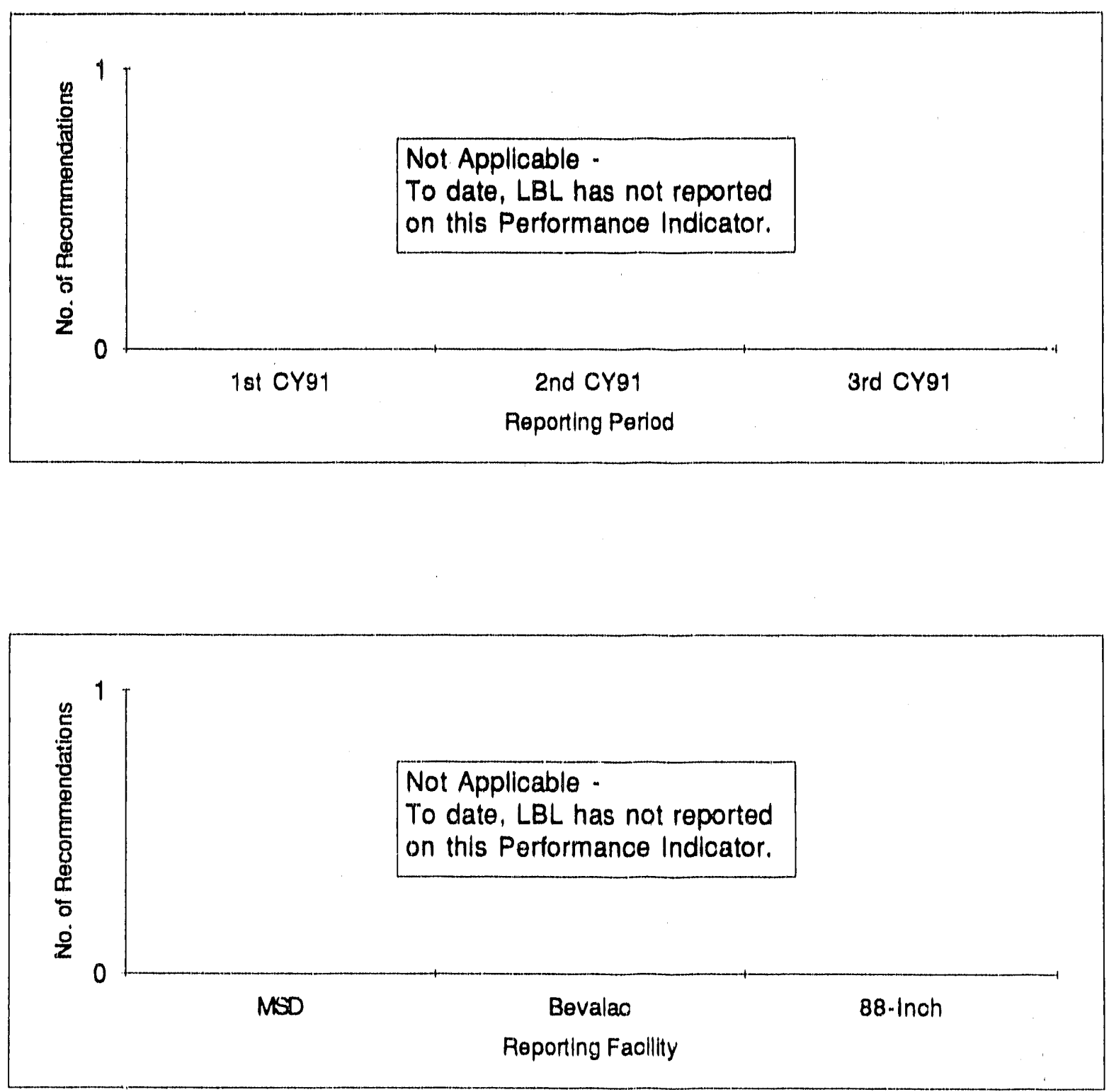

Current Period Data

$P \mid 4.2$ 
Materials Sciences Division

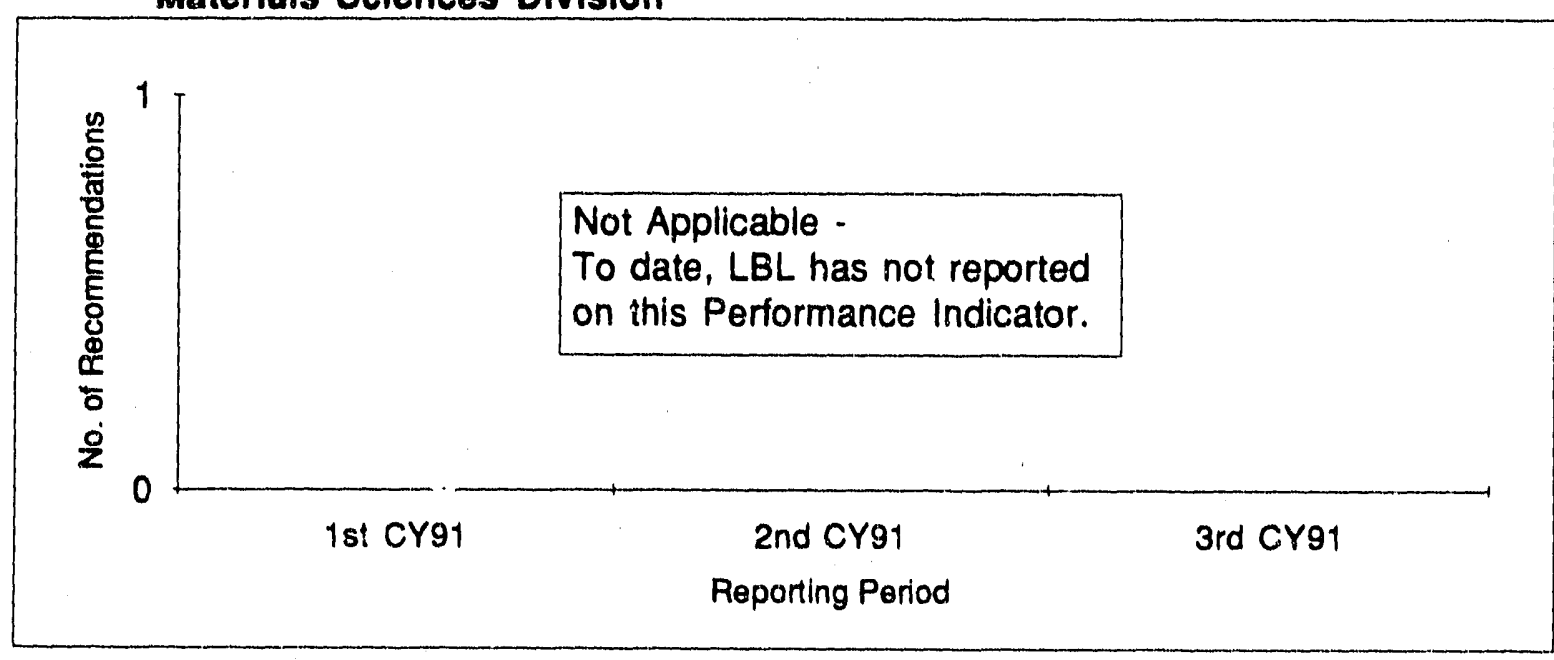

\section{Bevalac}

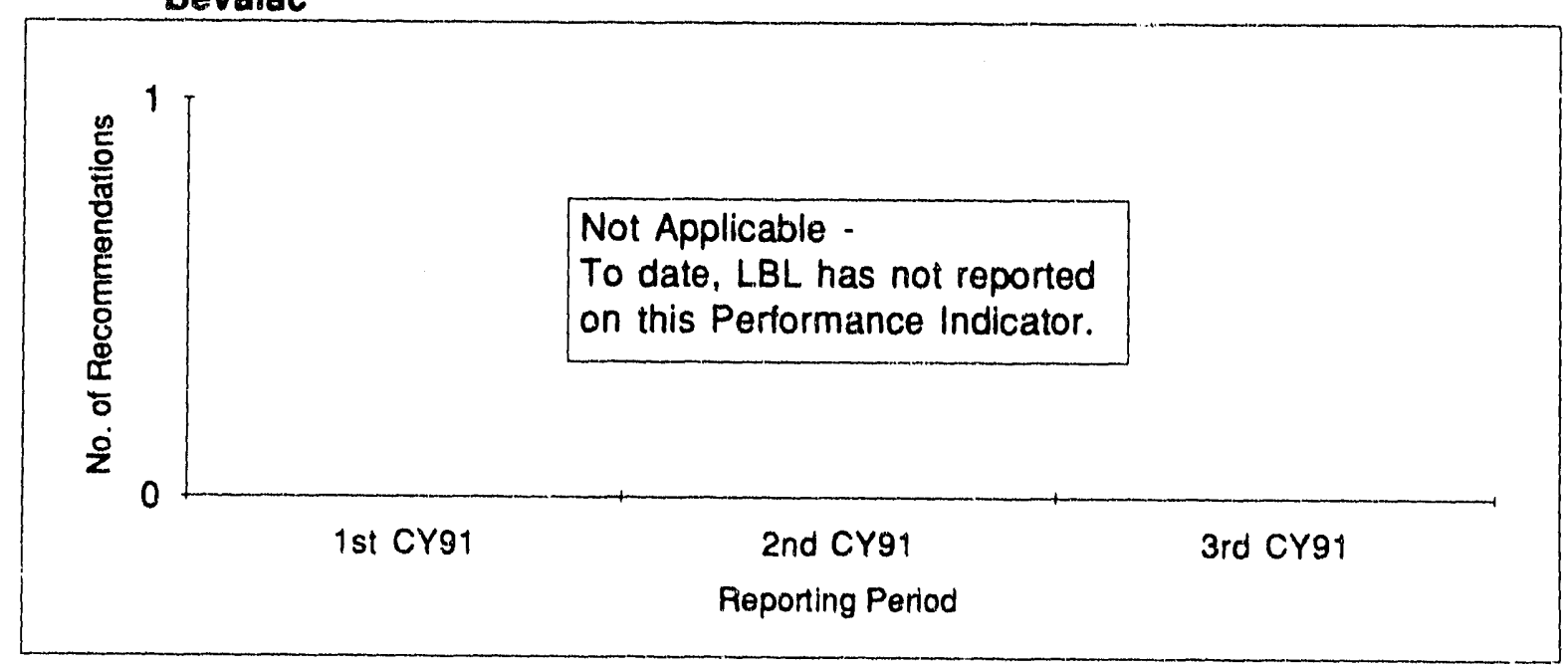


88-Inch Cyclotron

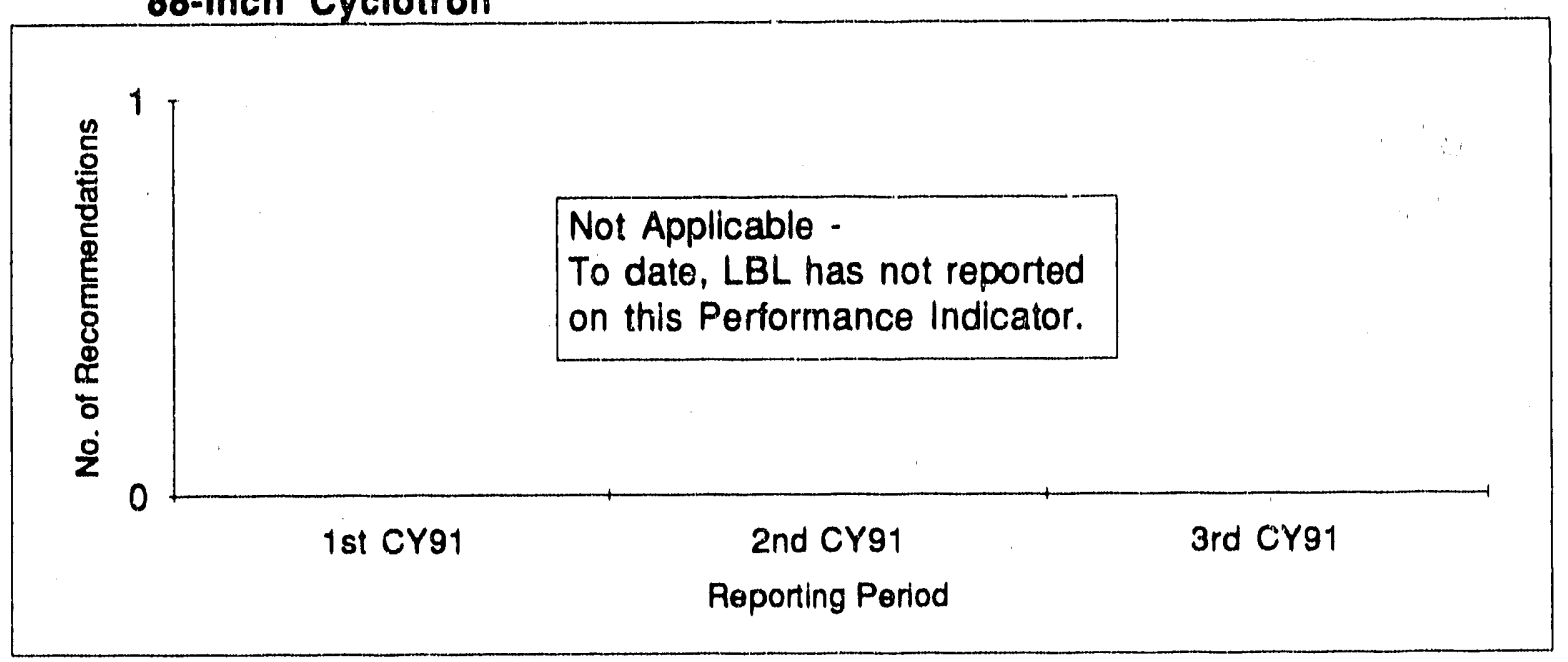

P| 4.2 


\subsection{0ccurrence Reports with Open Corrective Actions}

The number of Final Occurrence Reports for which all corrective actions have not been completed at the time of the report.

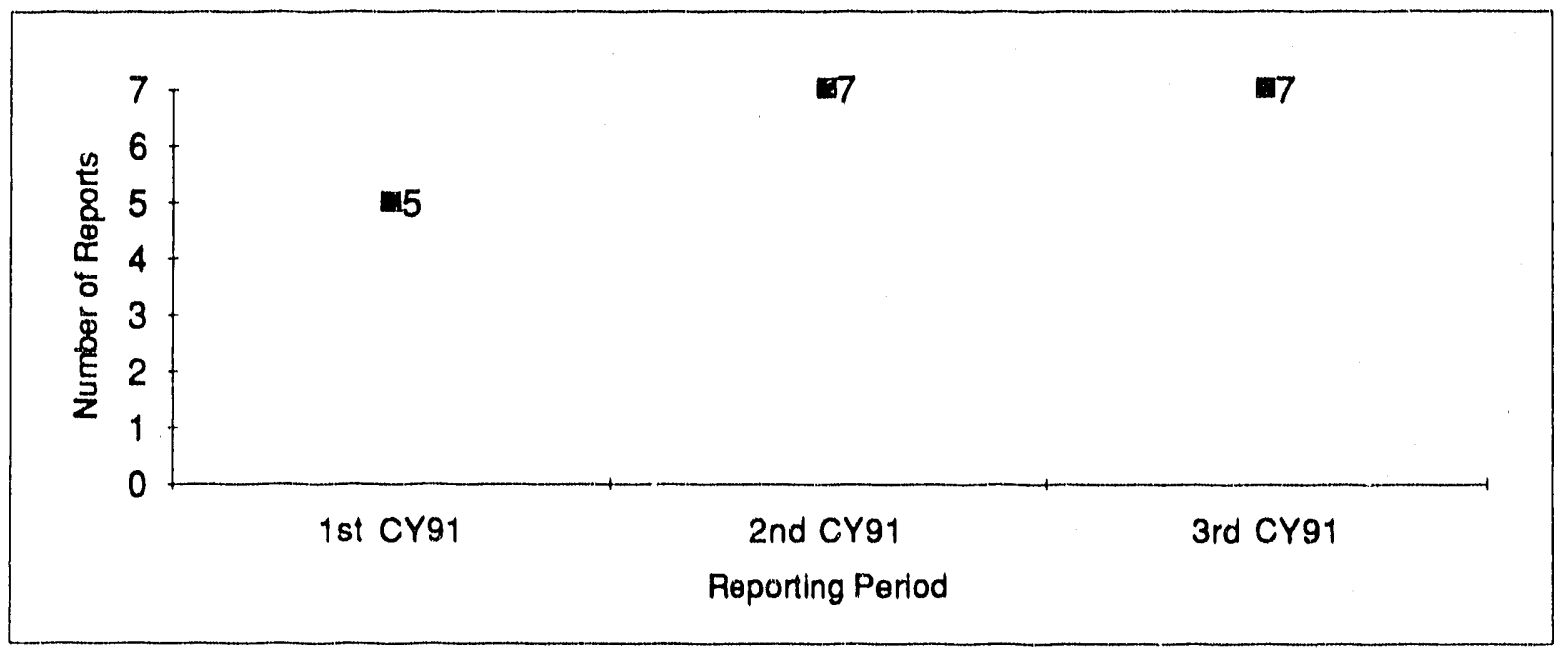

The above figures refleci corrections to the first and second quarter data which were reported on the errata sheets dated 11/27/91.

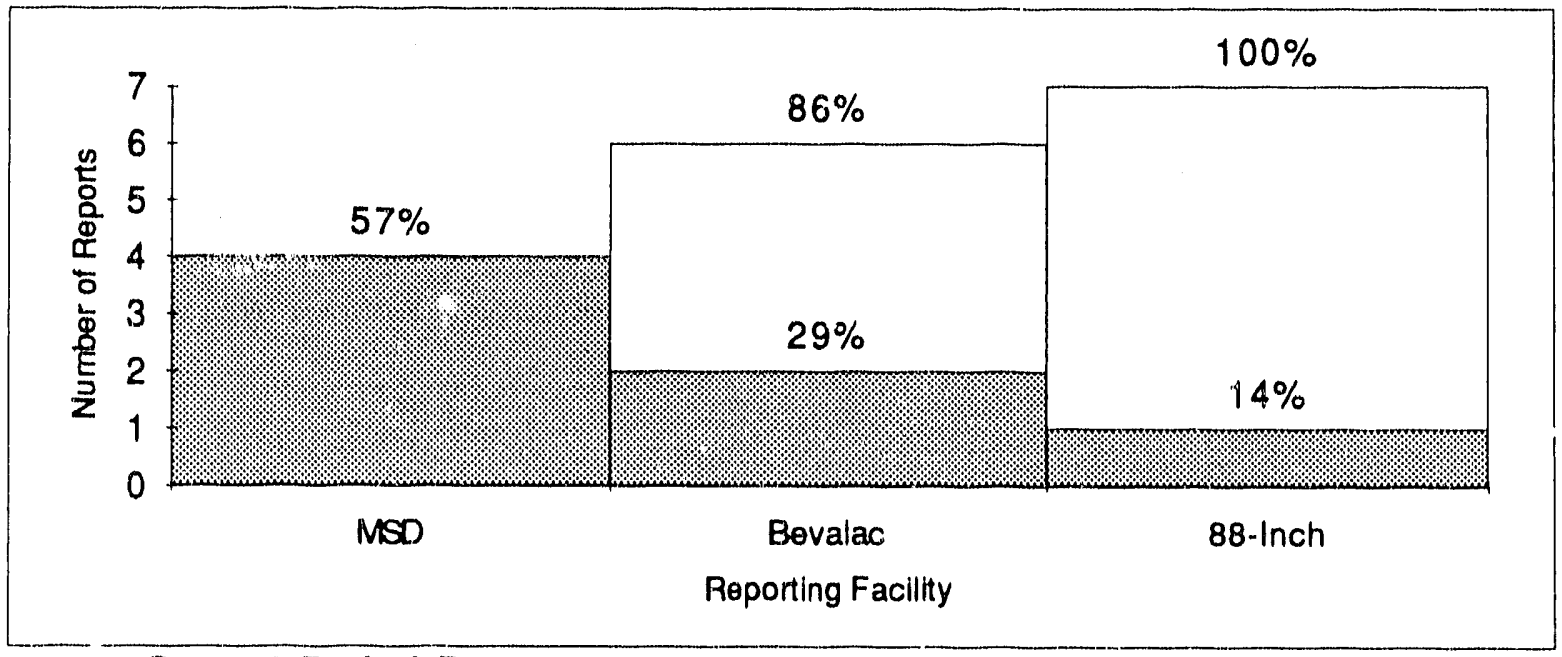

\section{Current Period Data}

Although the Materials Sciences Division has the largest number of Occurrence repnrts with oper, corrective actions, we note that it also has the largest number of personnel (2.00 as oppused to 150 for the Bevalac and 22 for the 88 " Cyclotron). 


\section{Materials Sciences Division}

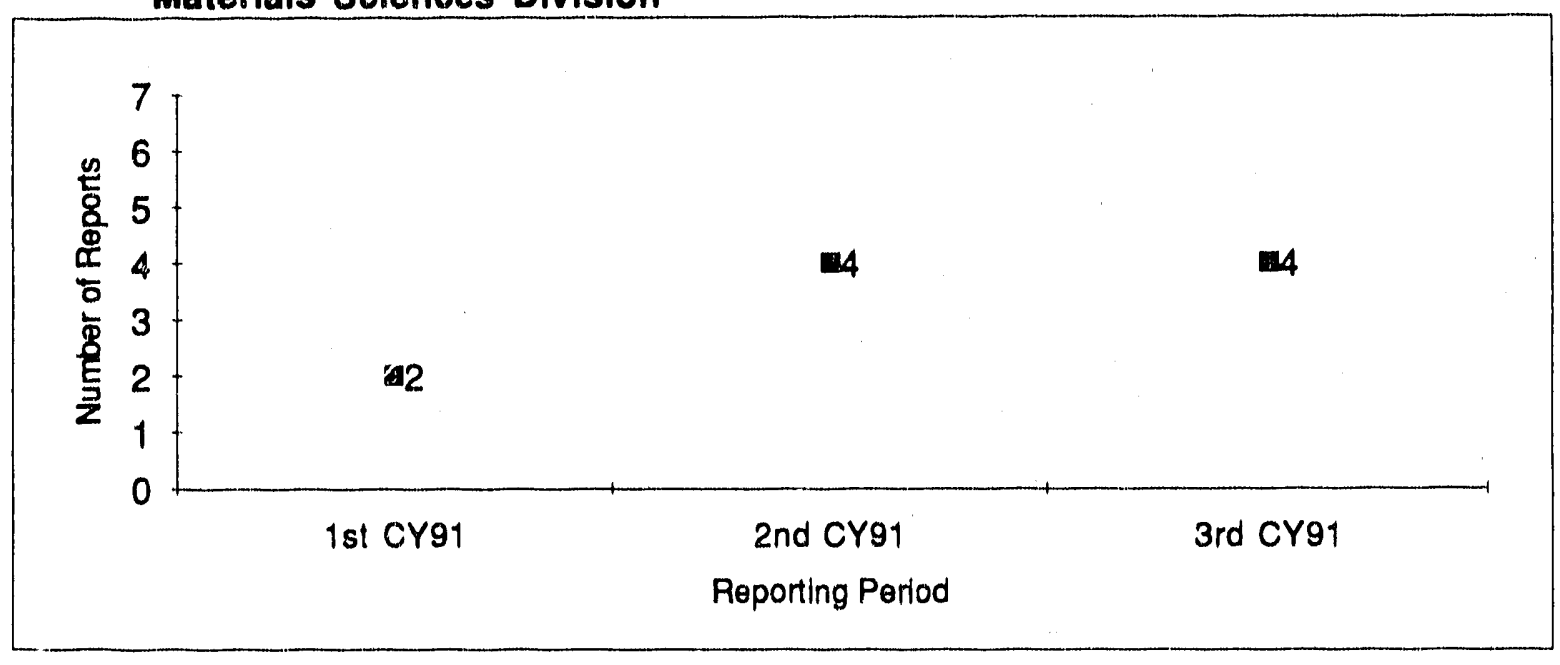

The first and second quarter data reflect corrections made on the errata sheets dated $11 / 27 / 91$.

\section{Bevalac}

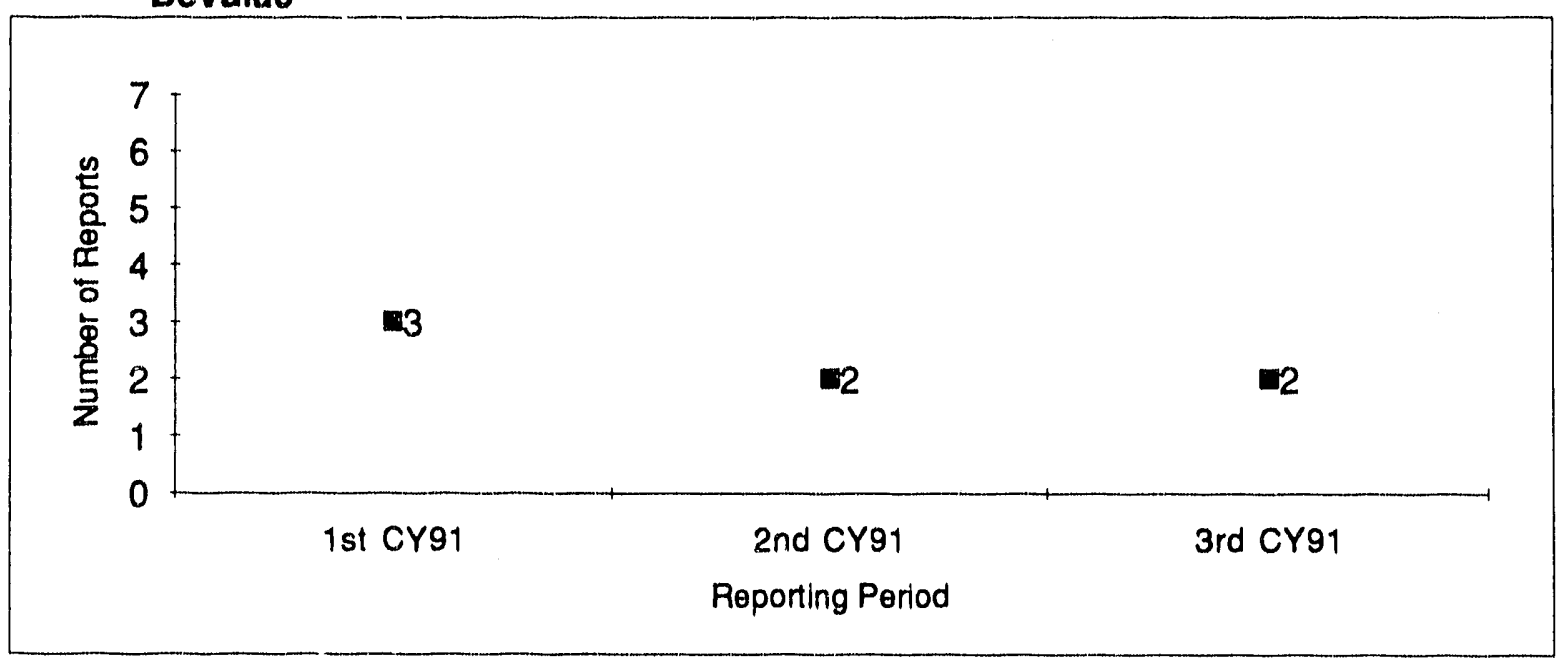

The first and second quarter data reflect corrections made on the errata sheets dated $11 / 27 / 91$.

PI 4.3 


\section{8-Inch Cyclotron}

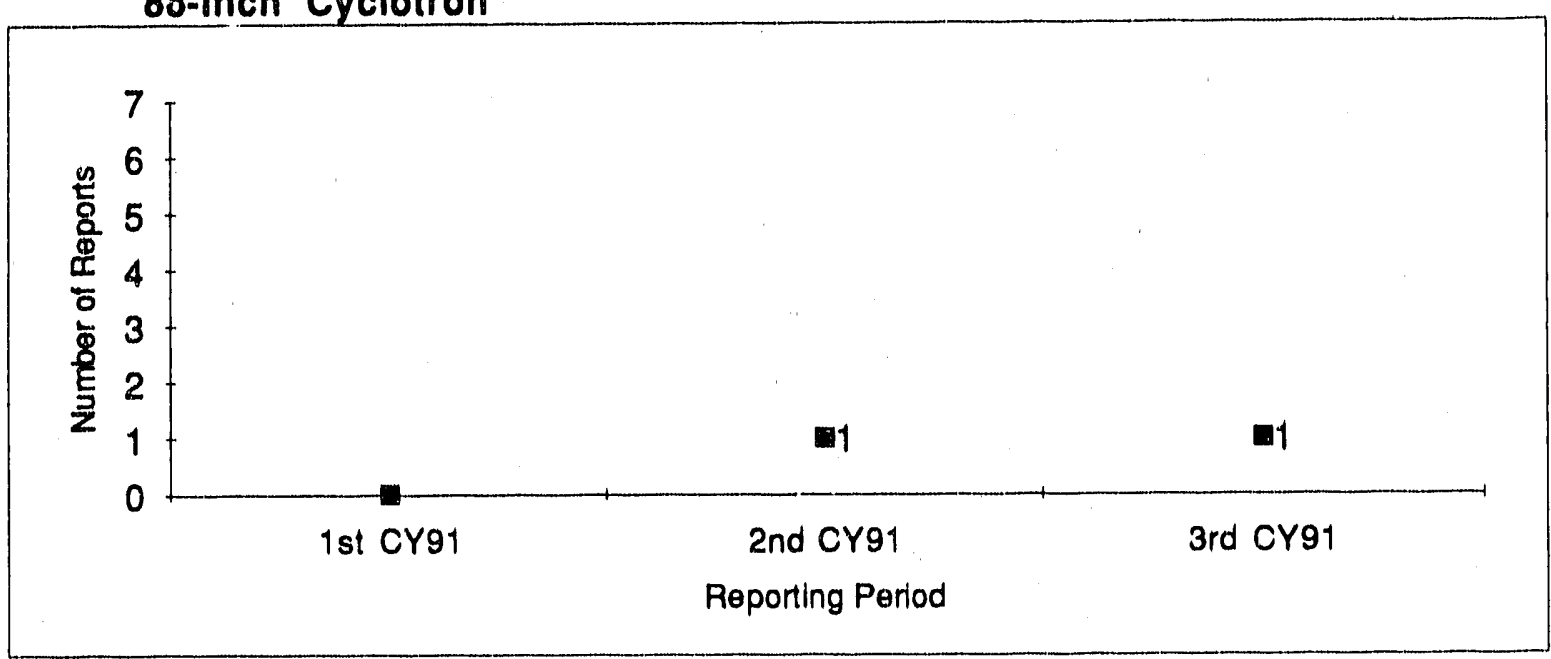

The second quarter data reflect corrections made on the errata sheets dated $11 / 27 / 91$.

PI 4.3 


\subsection{Corrective Maintenance Backloq}

The percentage of open corrective maintenance work requests, including those requiring facility or process shutdown, that are greater than three months old at the end of the reporting period. Corrective mainienance may include minor modifications if performed under a corrective maintenance work request.

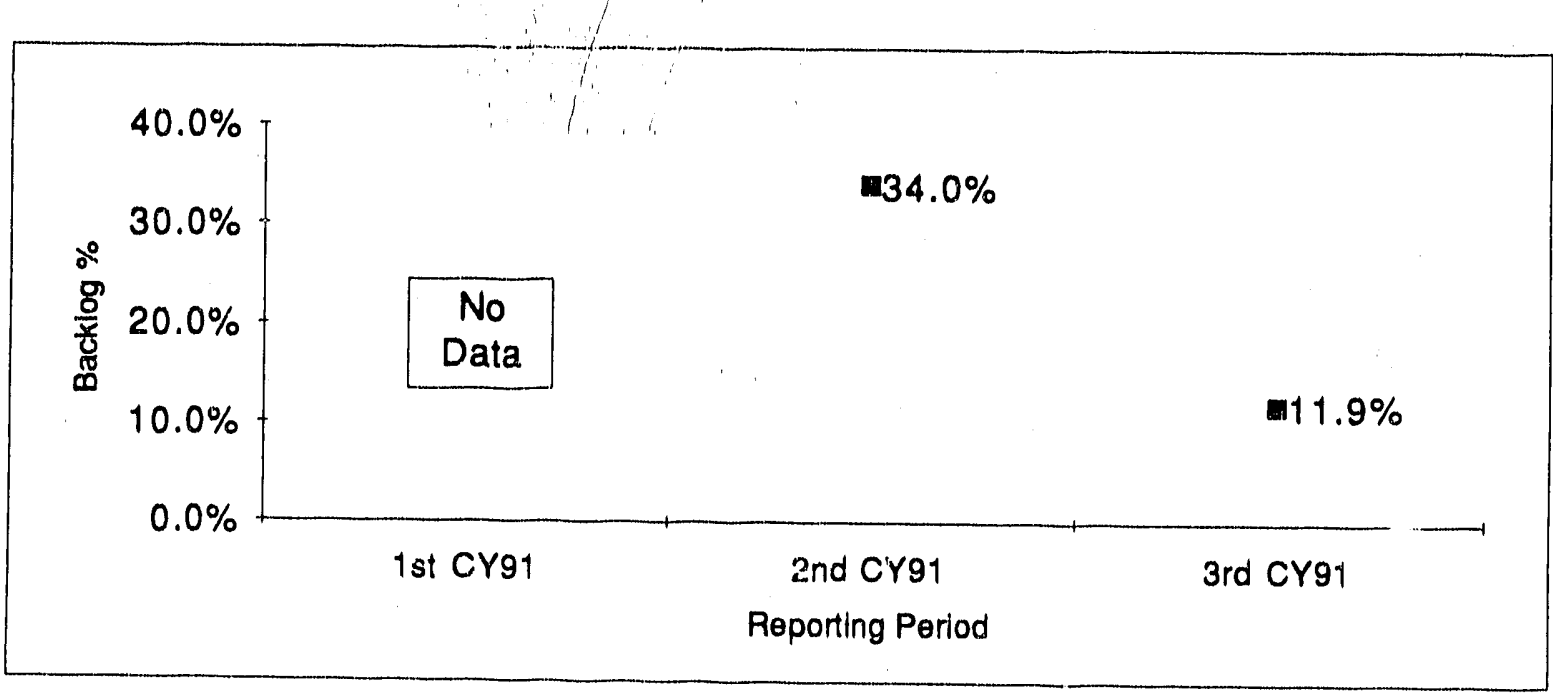

The corrective maintenance backlog has improved over the past quarter.

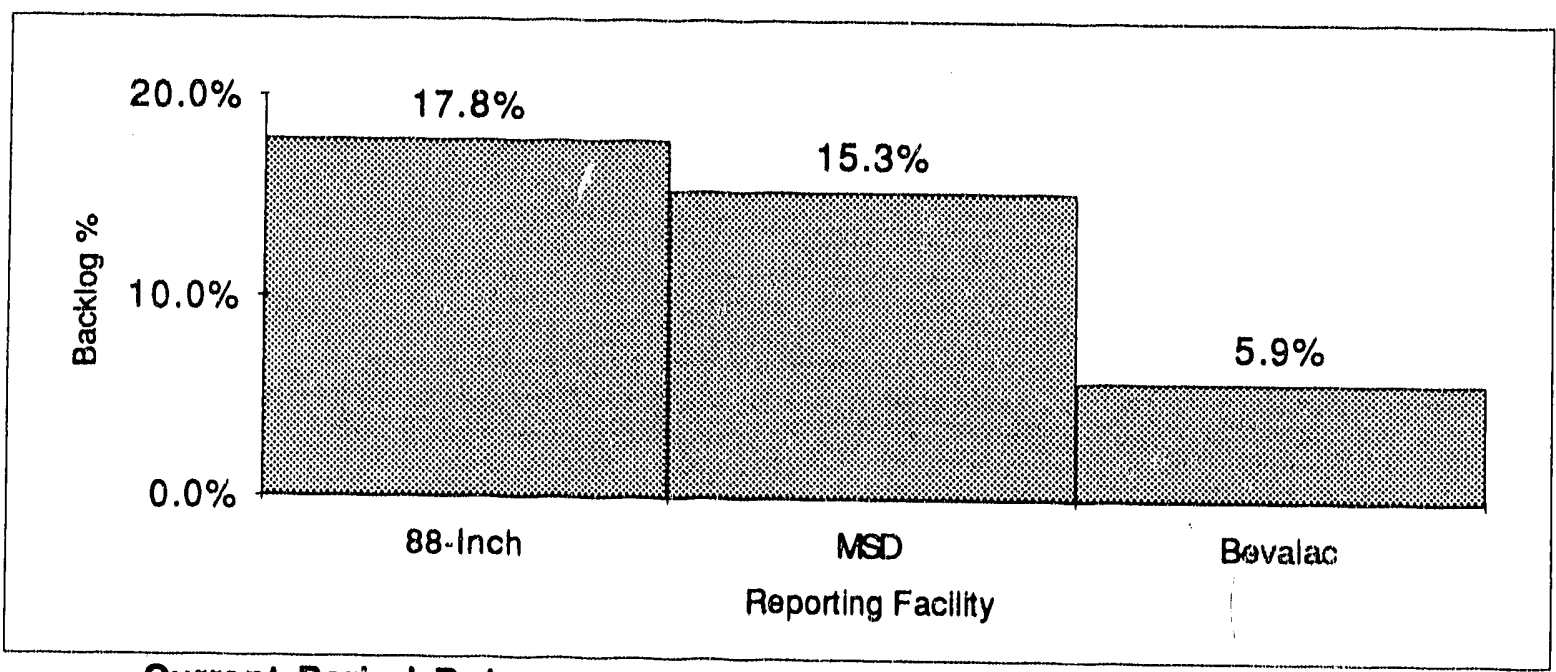

Current Period Data

Note: Because the sum of the facility rates does not accurately reflect the overall $L B L$ rate, the individual facility rates are given here. 
Materials Sciences Division

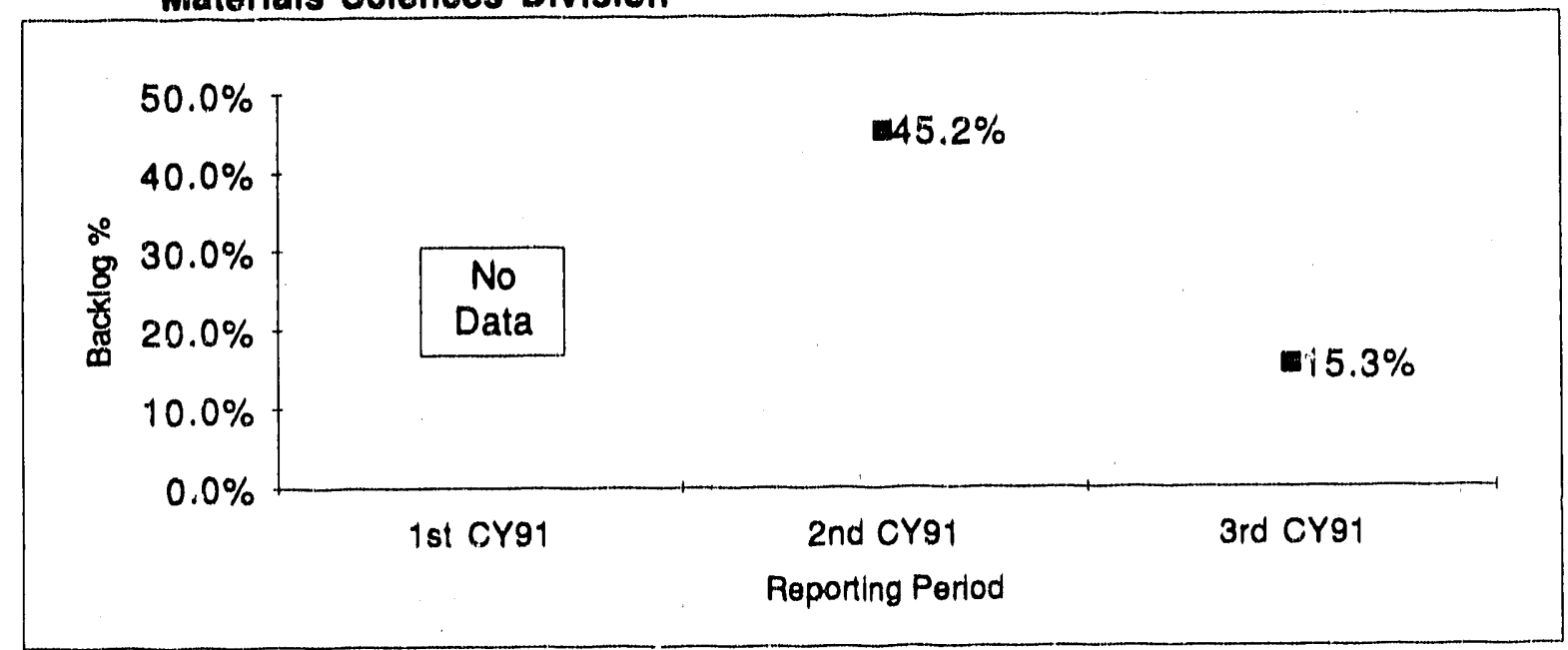

The corrective maintenance backlog was significantly reduced in the current reporting period from the second quarter high.

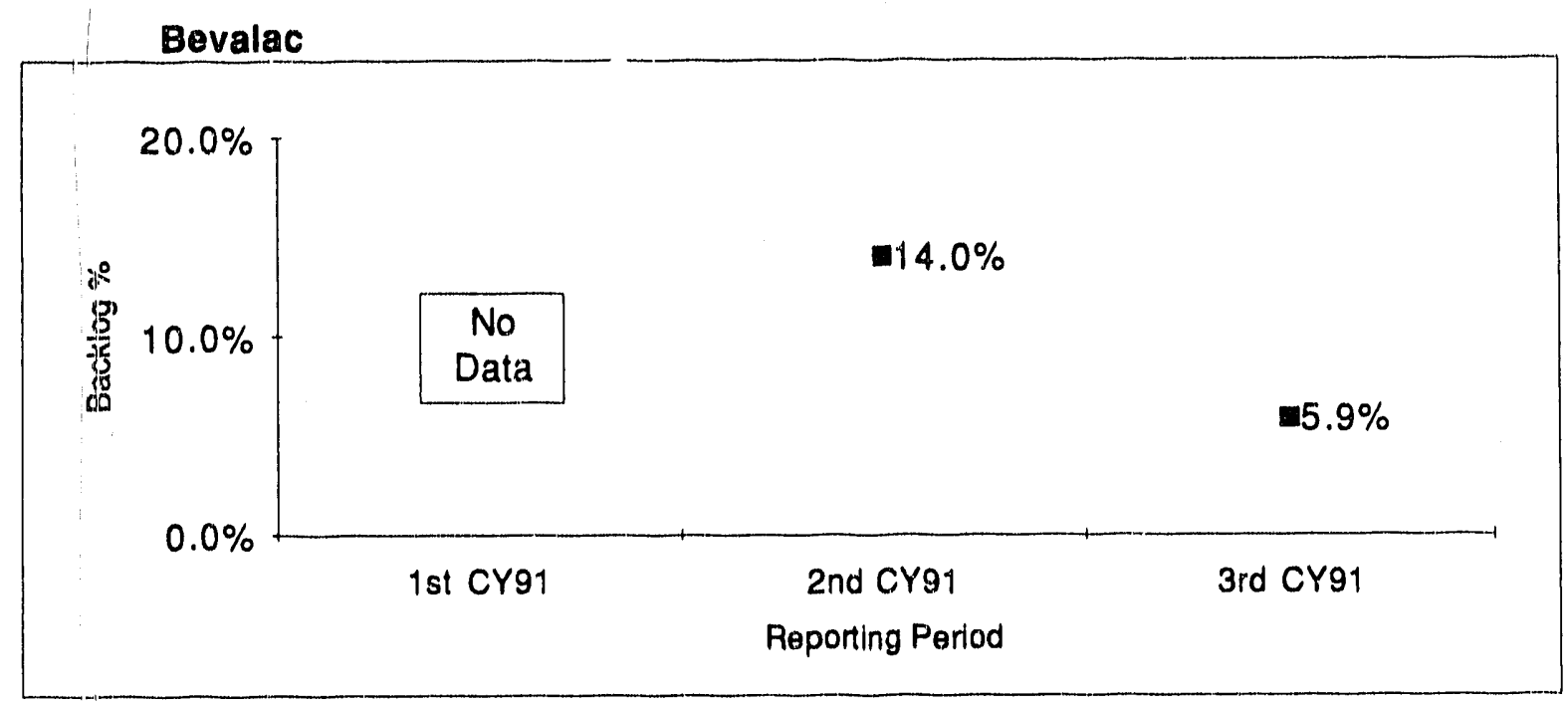

The corrective maintenance backlog was reduced in the current reporting period from the second quarter high.

PI 4.4 


\section{8-Inch Cyclotron}

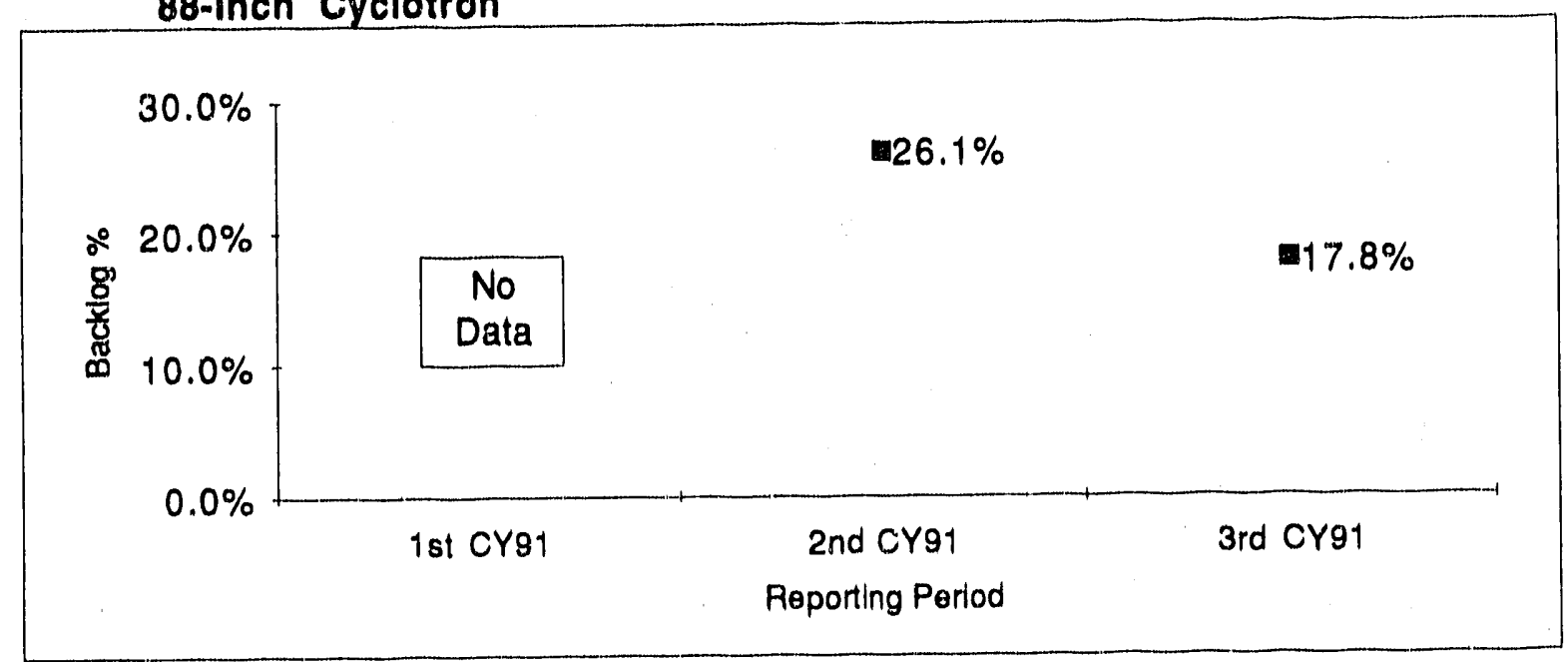

A decrease in the corrective maintenance backlog was evident during the third quarter. 


\subsection{Preventive Maintenance Overdue}

The percentage of preventive maintenance items that were not completed within the originally scheduled interval.

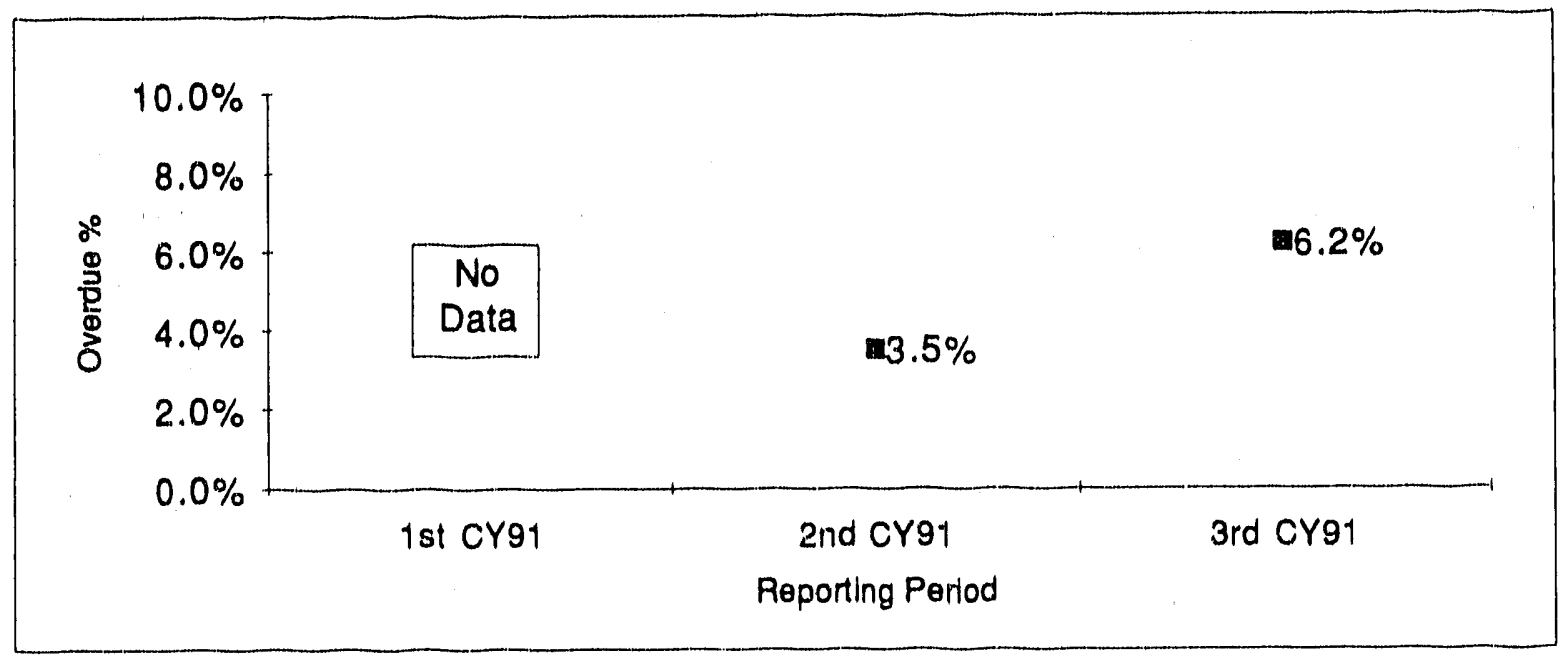

Overdue preventive maintenance has increased since the last quarter.

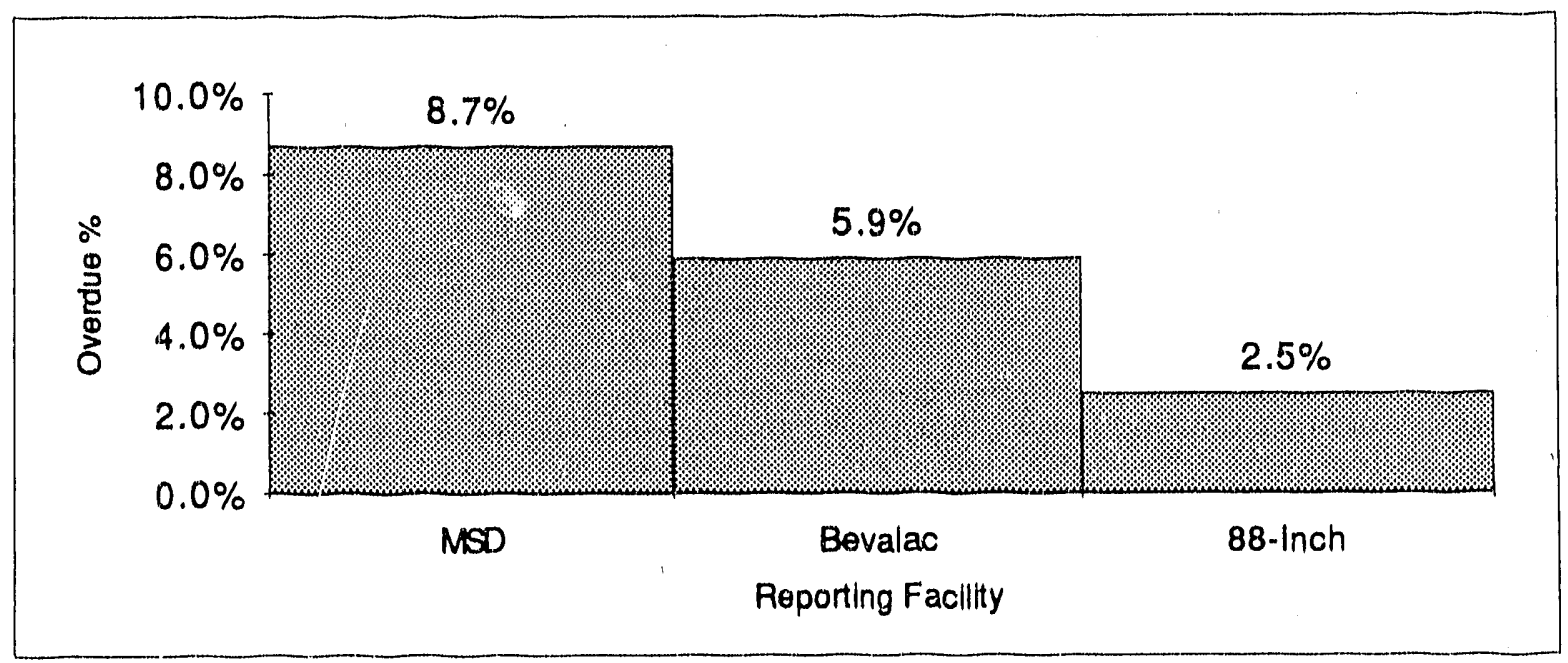

Current Period Data

Note: Because the sum of the facility rates does not accurately reflect the overall $L B L$ rate, the individual faclity rates are given here.

PI 4.5 


\section{Materials Sciences Division}

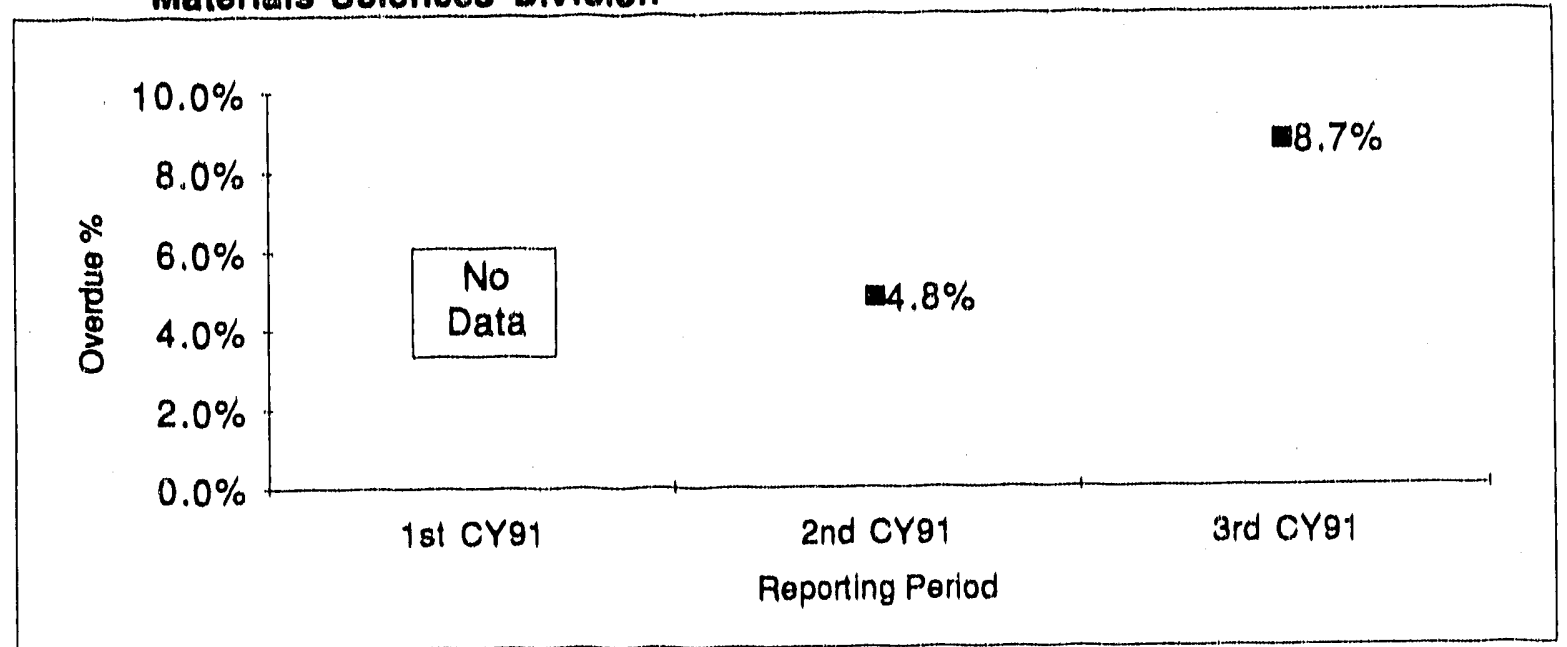

Overdue preventive maintenance is up since the last quarter.

Bevalac

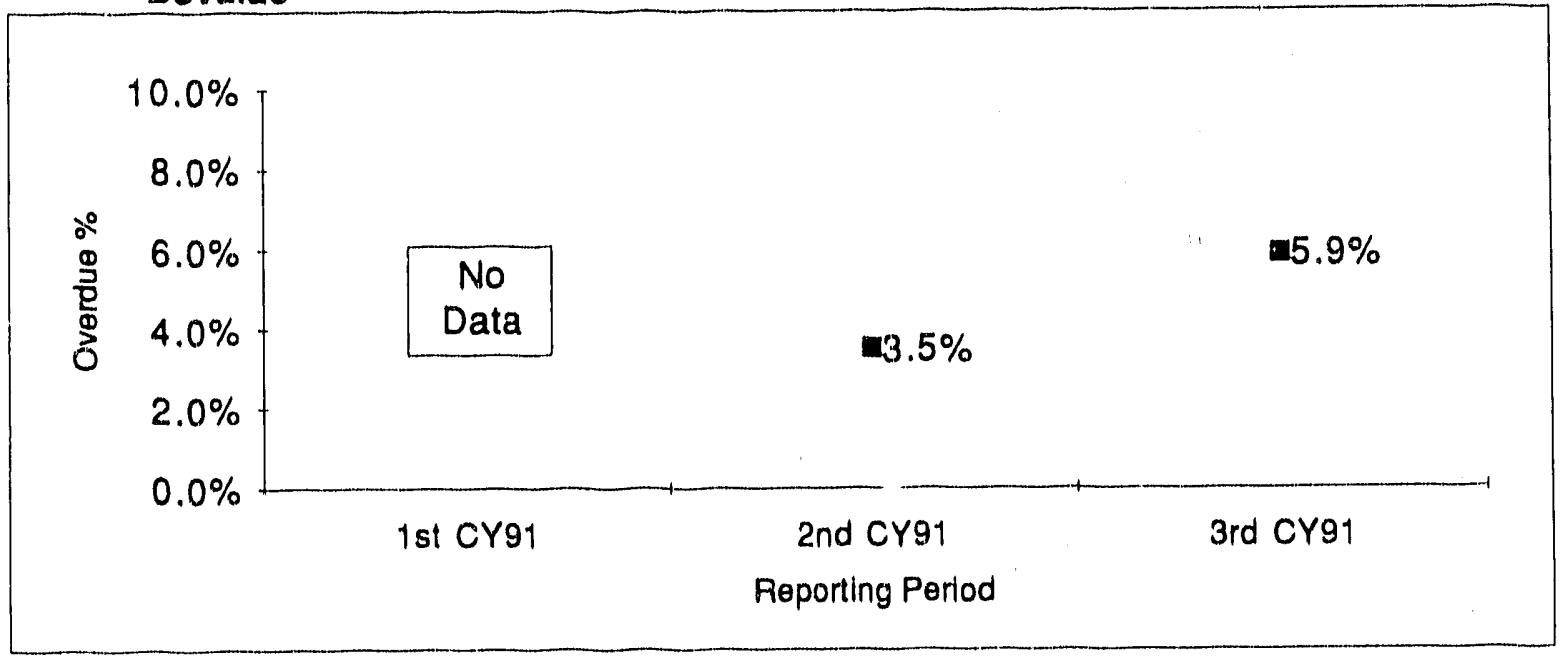

Overdue preventive maintenance is up since the last quarter.

Pl 4.5 


\section{8-Inch Cyolotron}

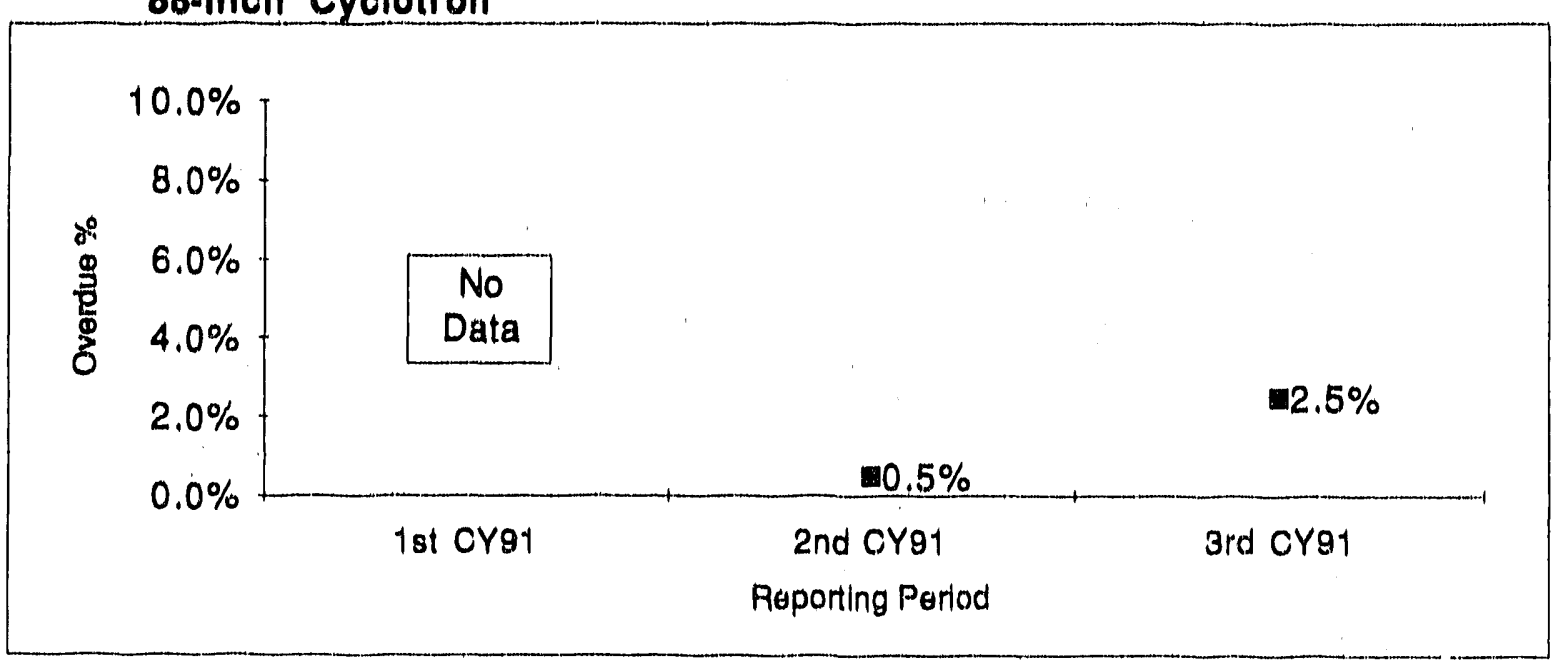

Overdue preventive maintenance is up since the last quarter.

P| 4.5 


\subsection{Substance Abuse Incidents}

The number of reportable ocourrences involving personnel use, possession or involvement ot/with controlled substances, e.g., drugs, alcohol, etc.

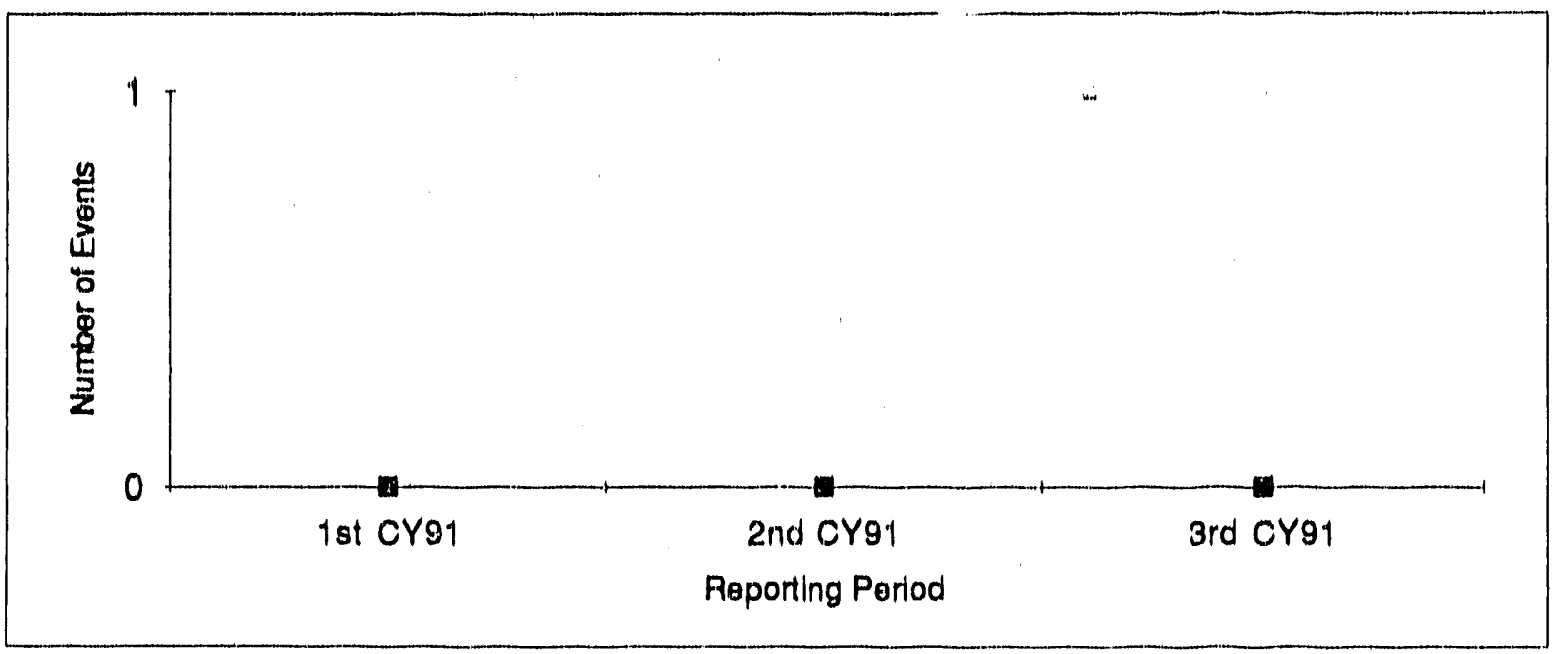

There have been no substance abuse incidents at LBL to date.

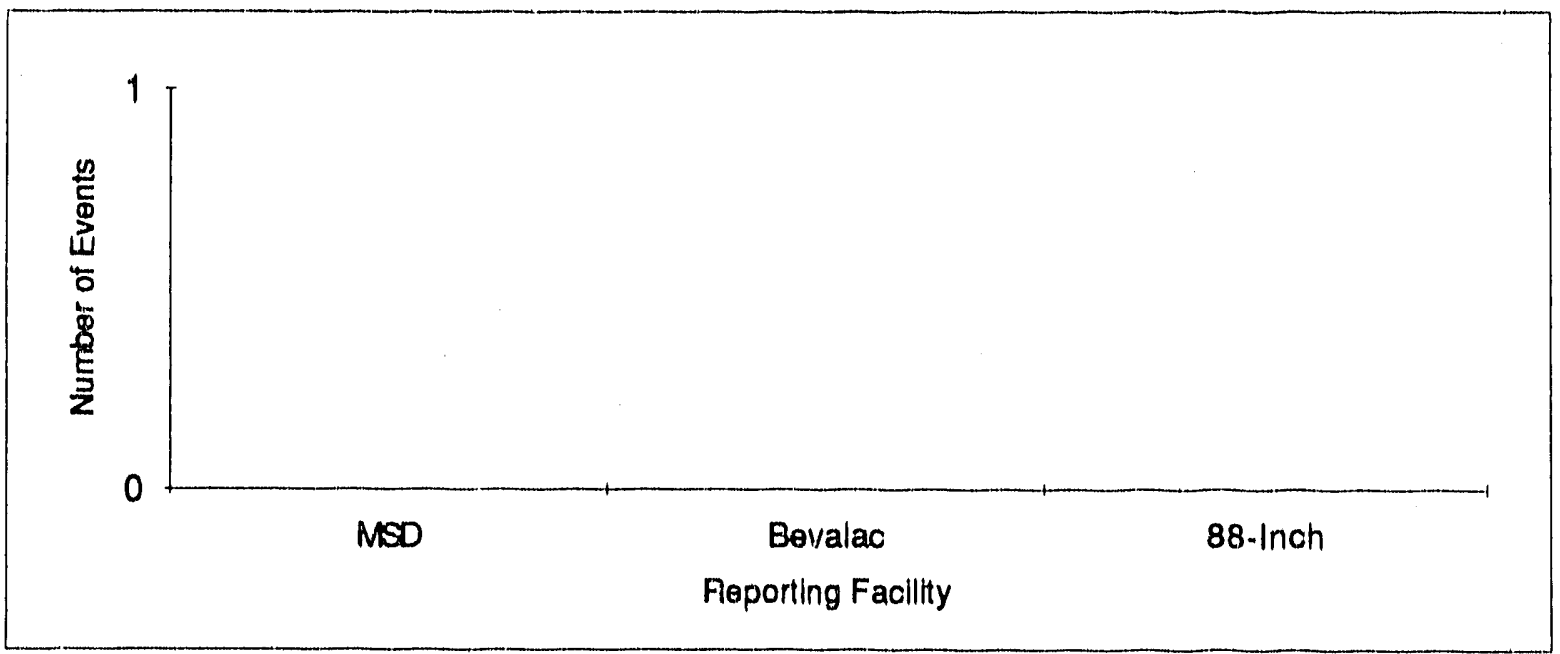

\section{Current Period Data}

There were no substance abuse incidents at LBL during the ourrent reporting period. 


\section{Root Cause of Occurrences}

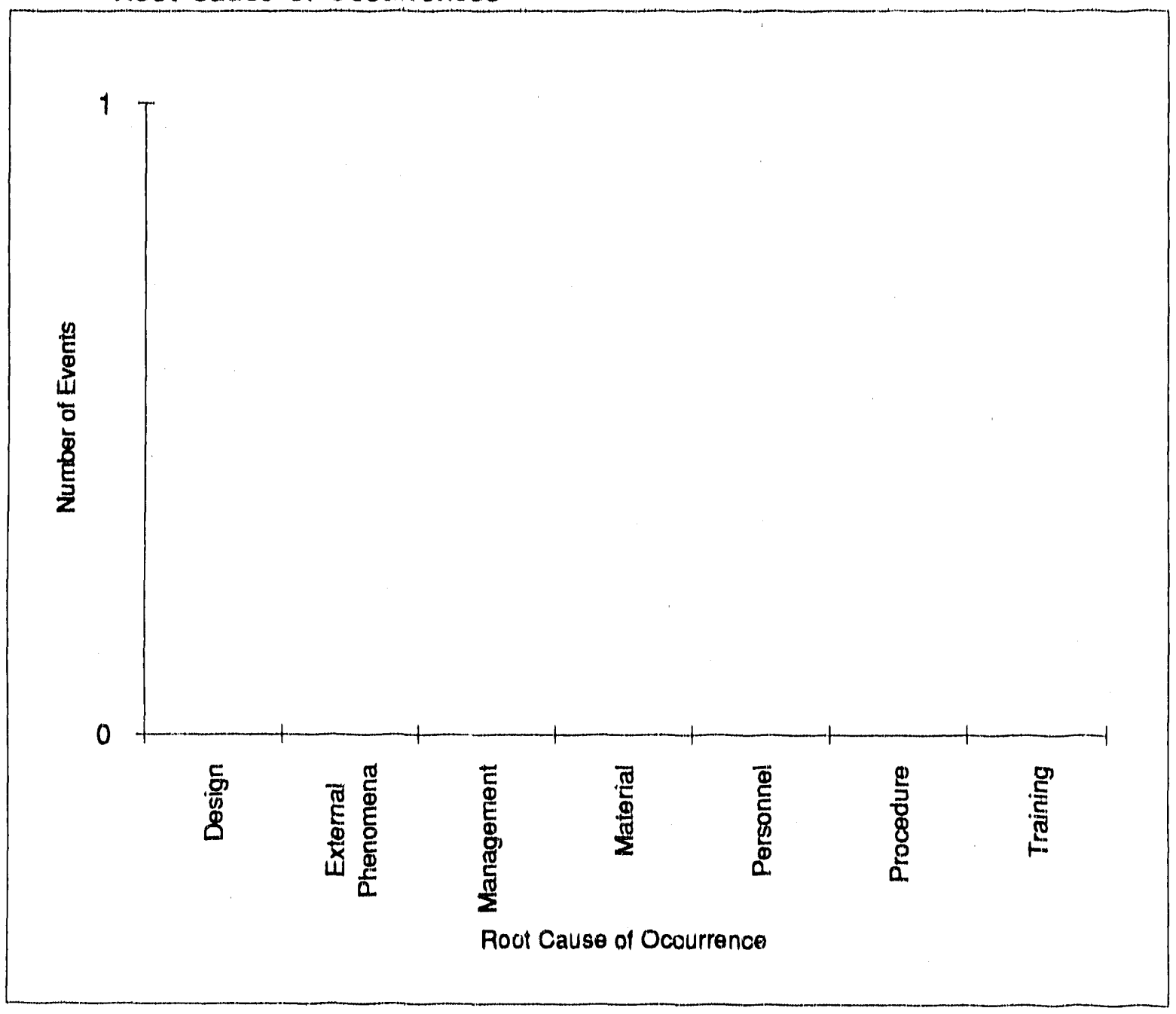

There have been no substance abuse incidents at LBL to date.

P| 4.6 


\section{Materials Sclences Division}

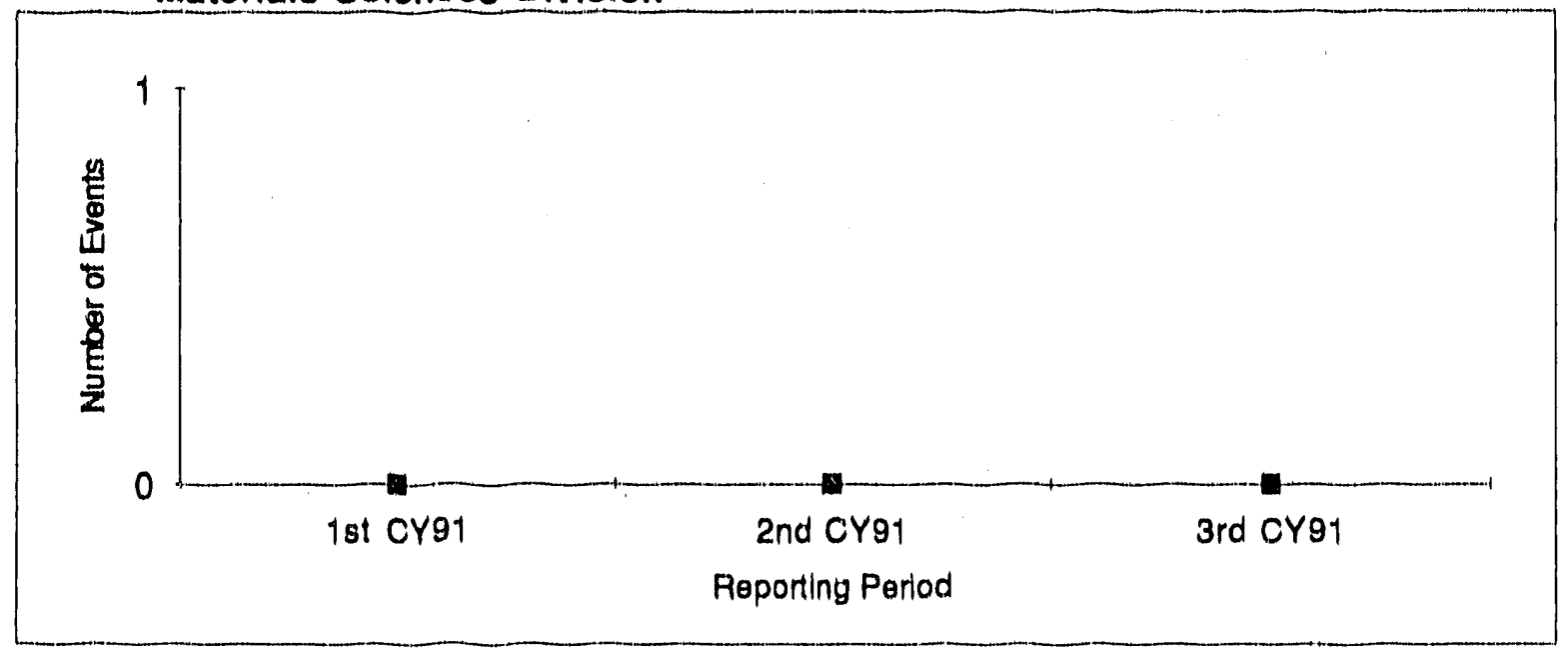

No substance abuse incidents to date.

\section{Bevalac}

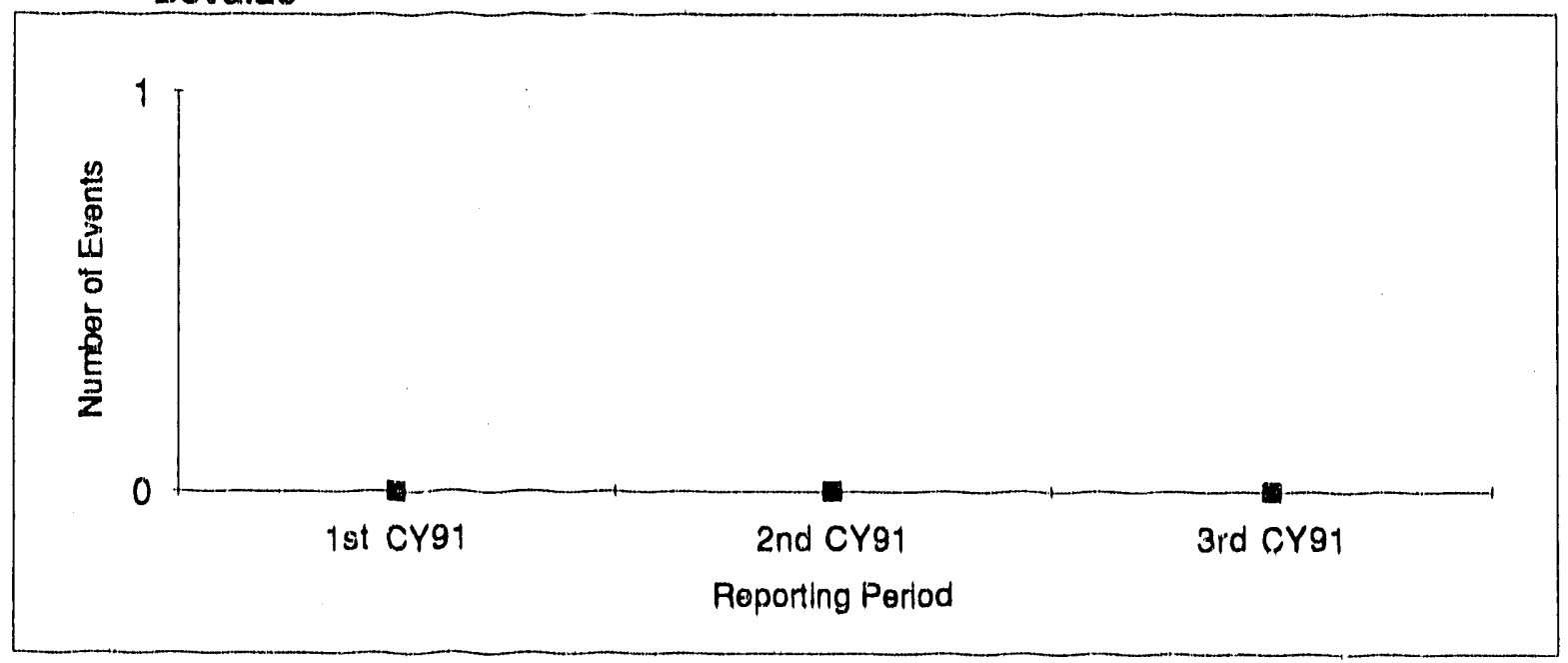

No substance abuse incidents to date. 


\section{8-Inch Cyclotron}

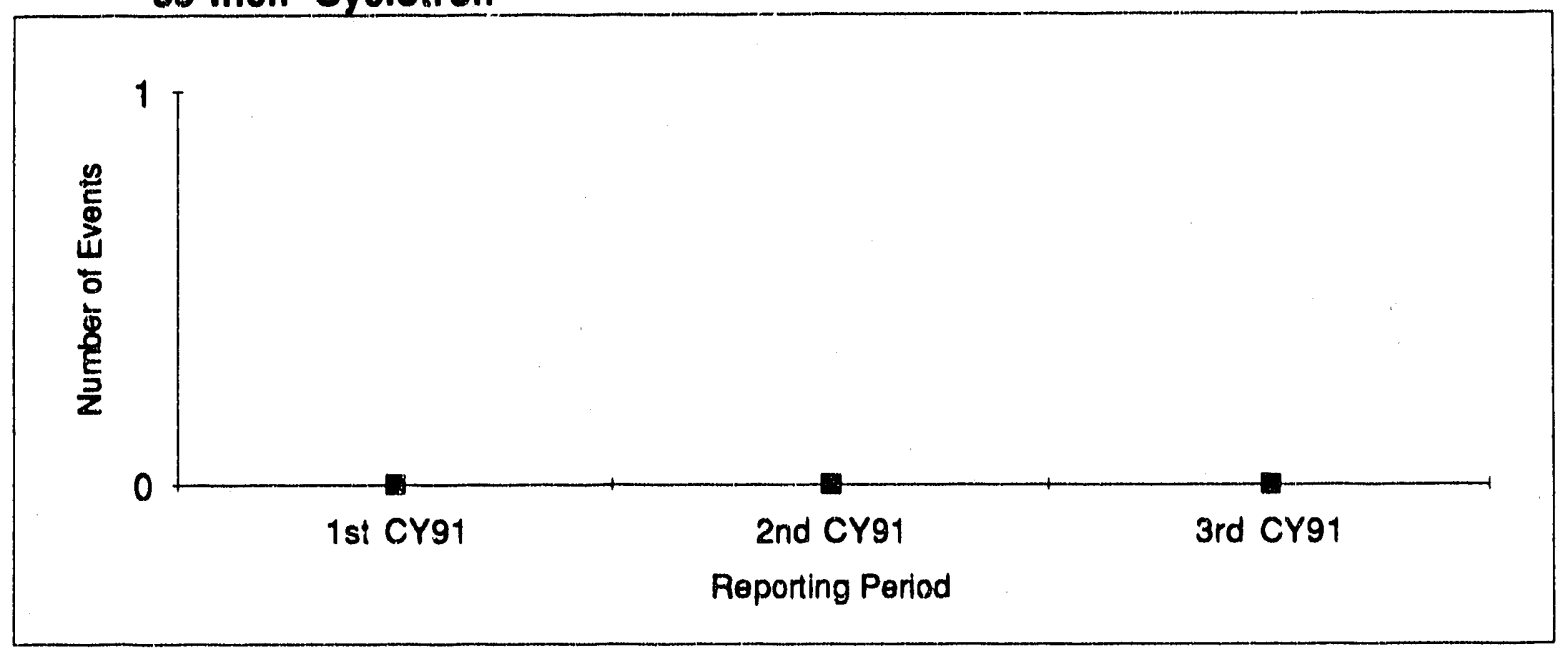

No substance abuse incidents to date.

P| 4.6 


\subsubsection{Solid Low Level Radioactive Waste - Generated}

The total volume, in cubic feet, of solid low level radioactive wasie generated during the reporting period.

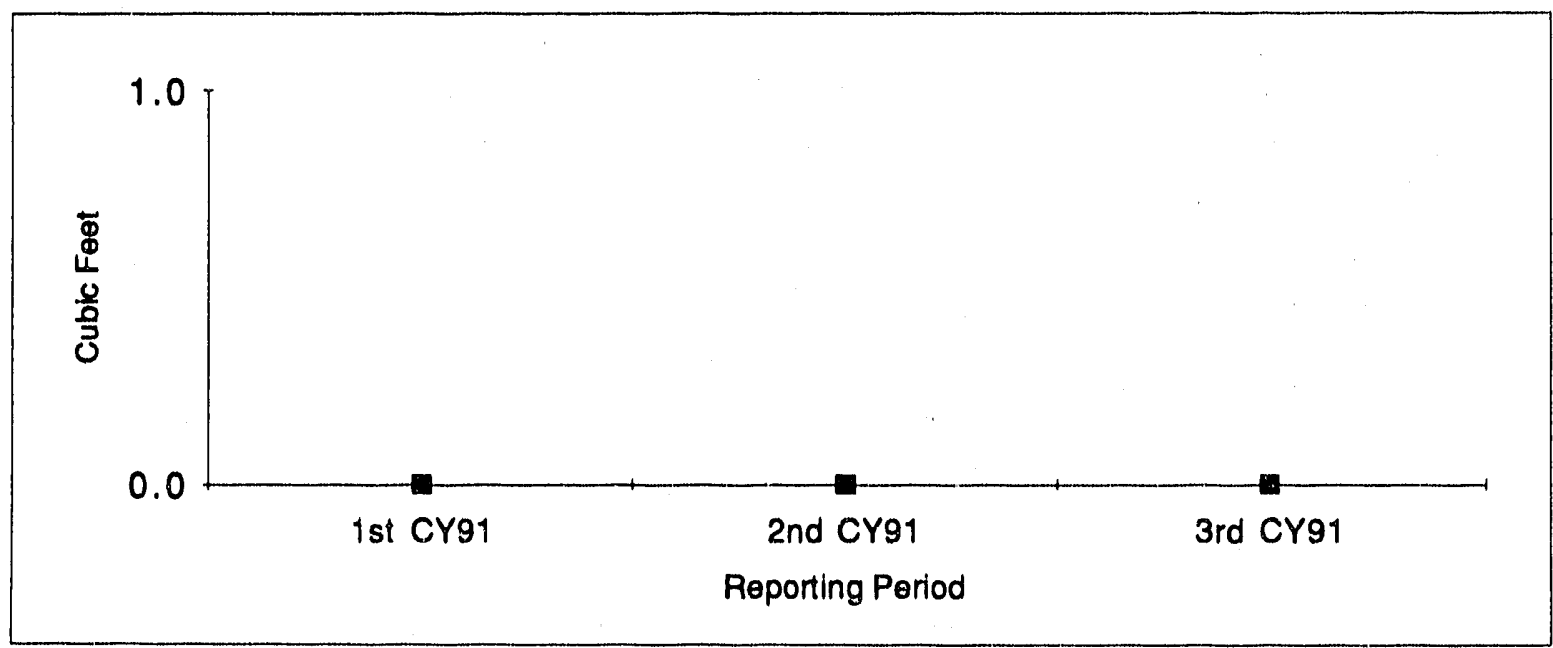

There has not been any low level radioactive waste has been generated at LBL to date.

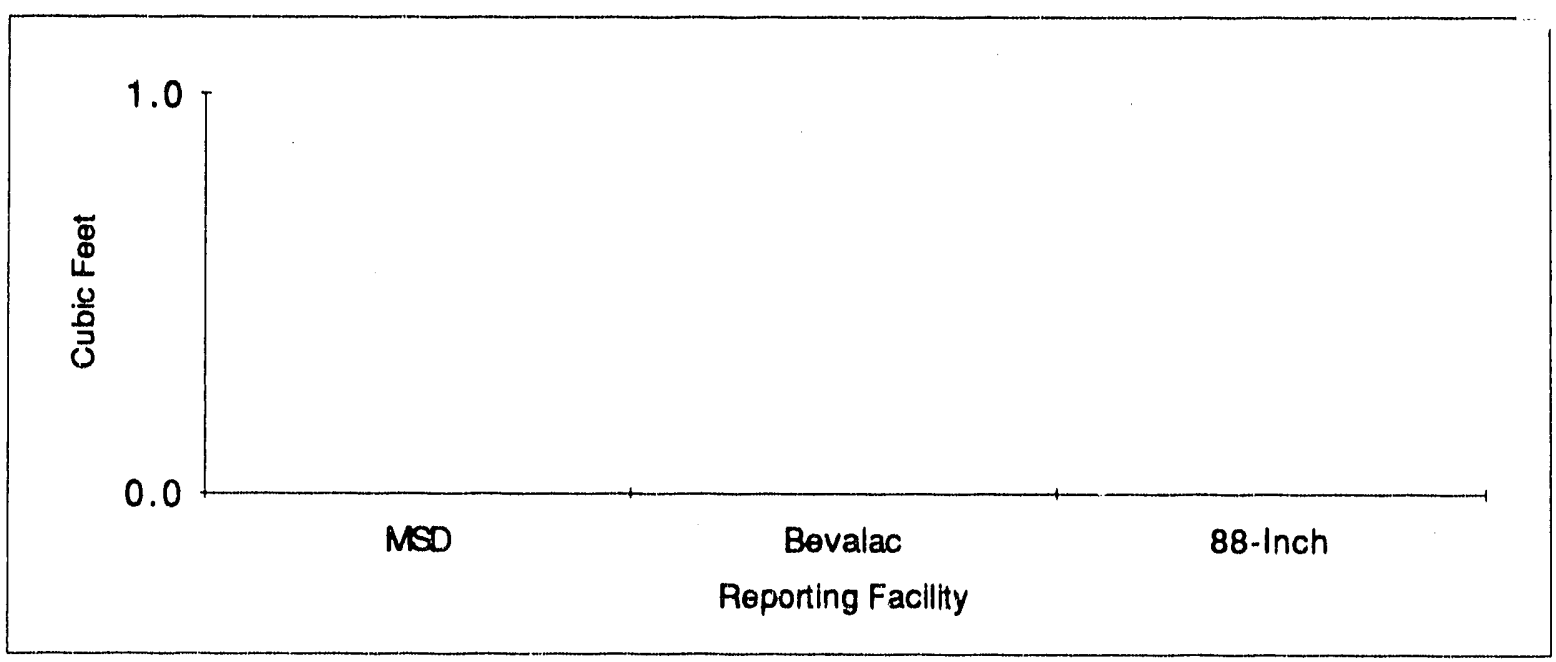

Current Period Data

There was no low level radioactive waste generated at LBL during the current reporting period.

PI 4.7.1.1 


\section{Materials Sciences Division}

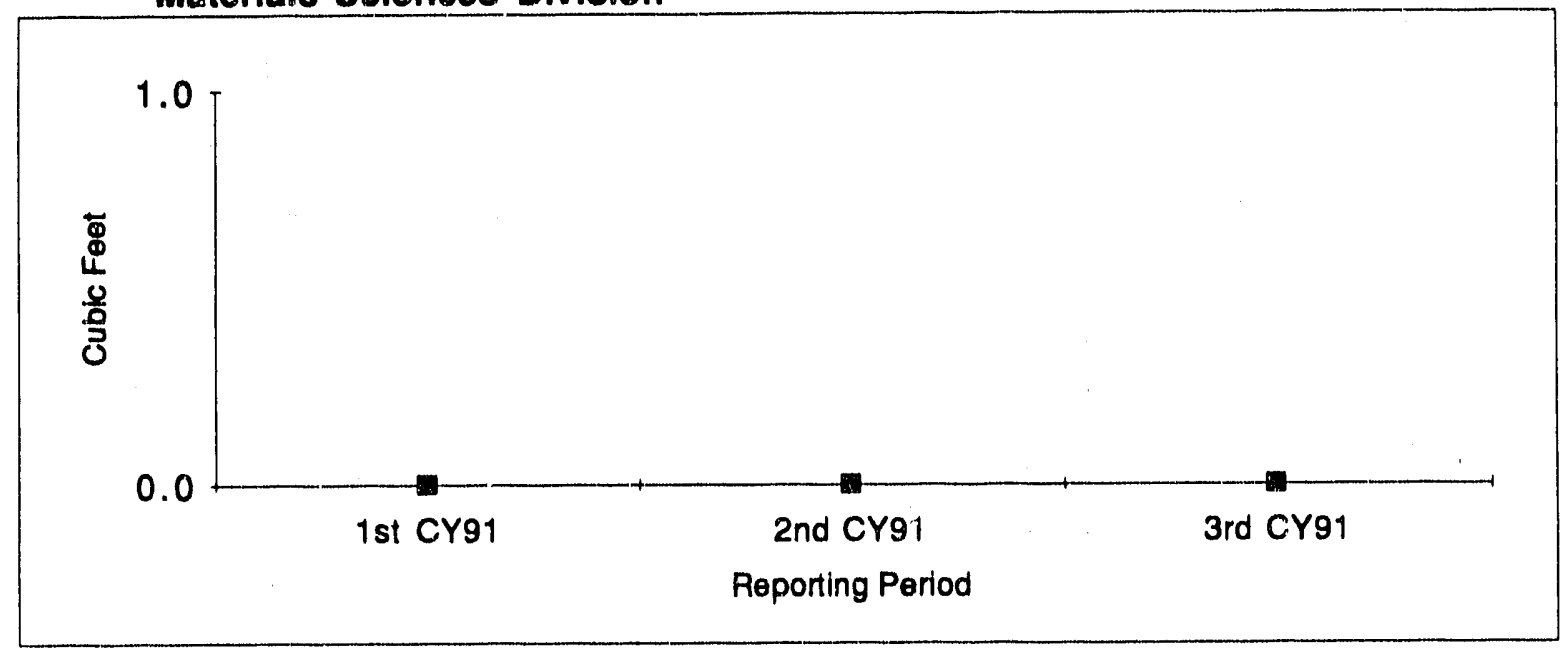

No low level radioactive waste generated to date.

\section{Bevalac}

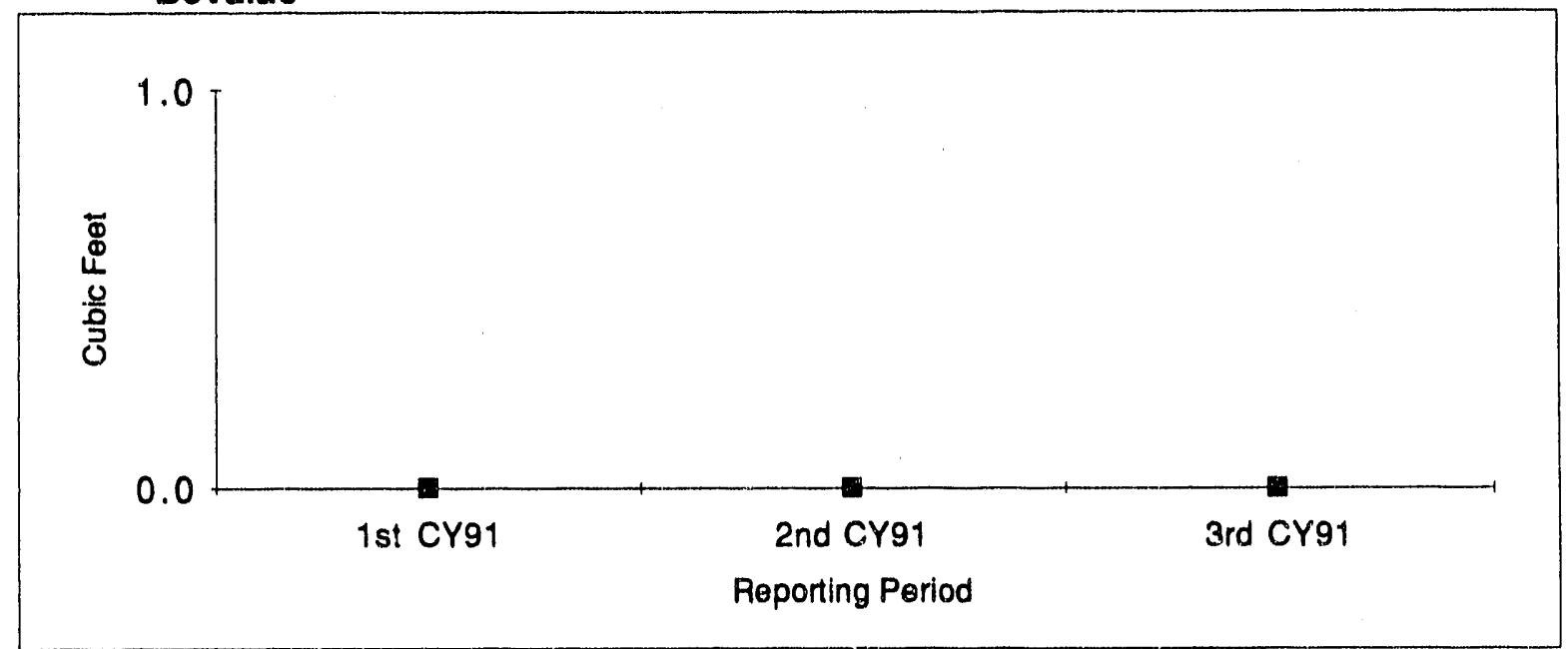

No low level radioactive waste generated to date.

PI 4.7.1.1 


\section{8-Inch Cyclotron}

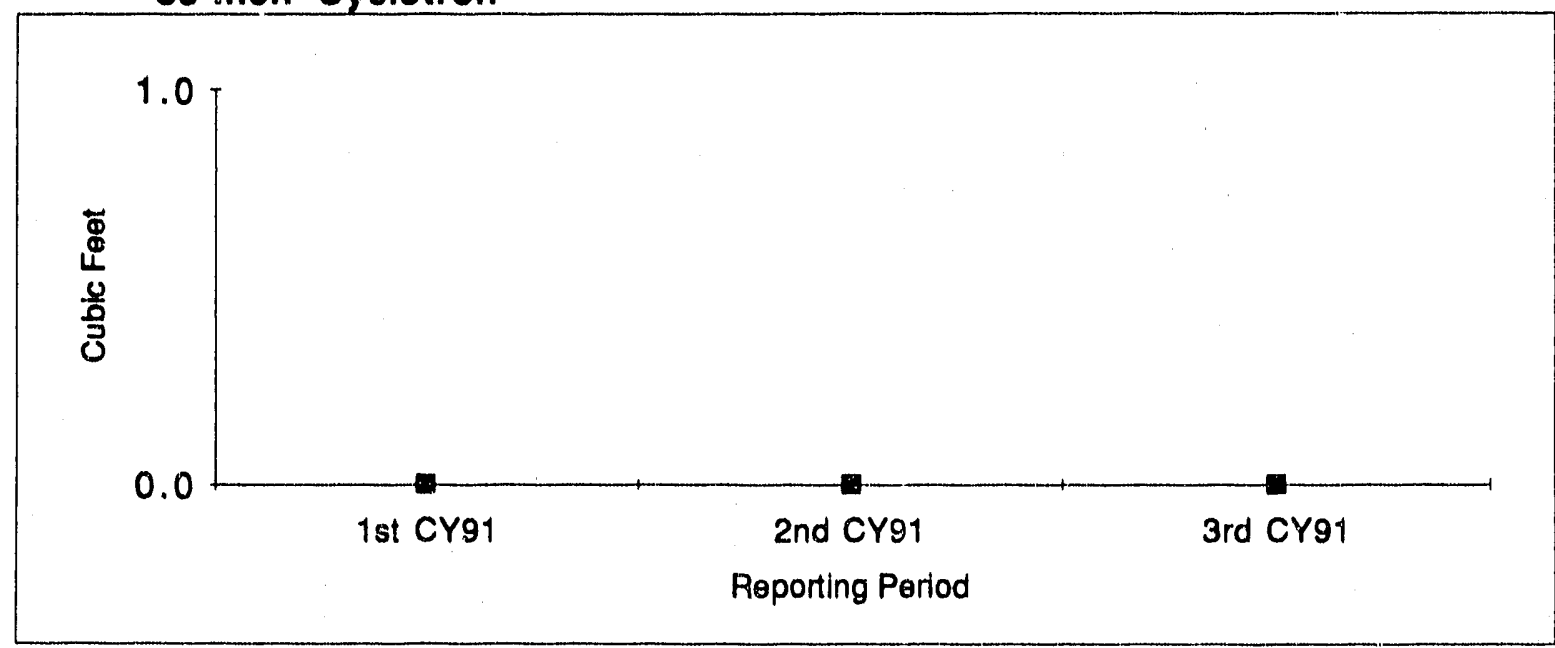

No low level radioactive waste generated to date.

PI 4.7.1.1 


\subsubsection{Solid Low Level Radioactive Waste - Ready to Shle}

The total volume, in cubic feet, of the final form (pending shipment) of solid low level radioactive waste generated during the reporting period.

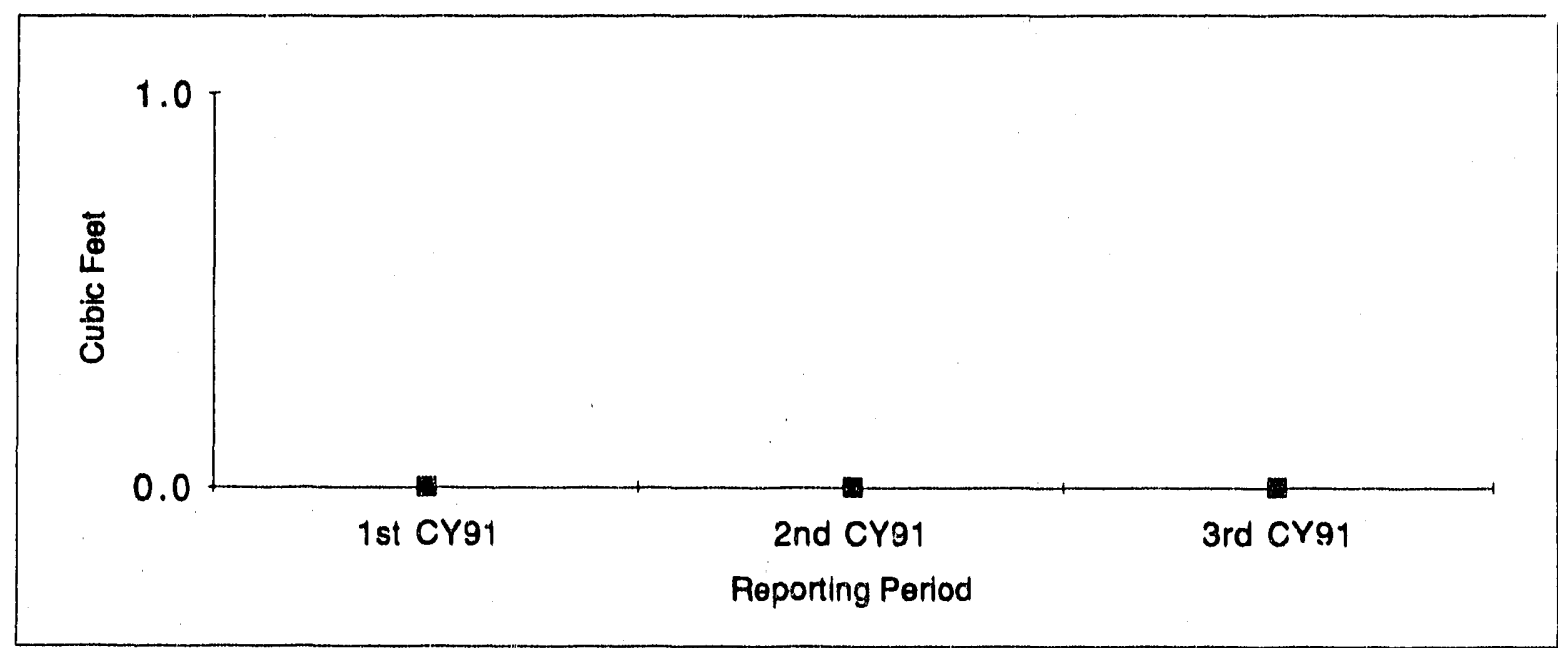

There has not been any low level radioactive waste has been generated at LBL to date.

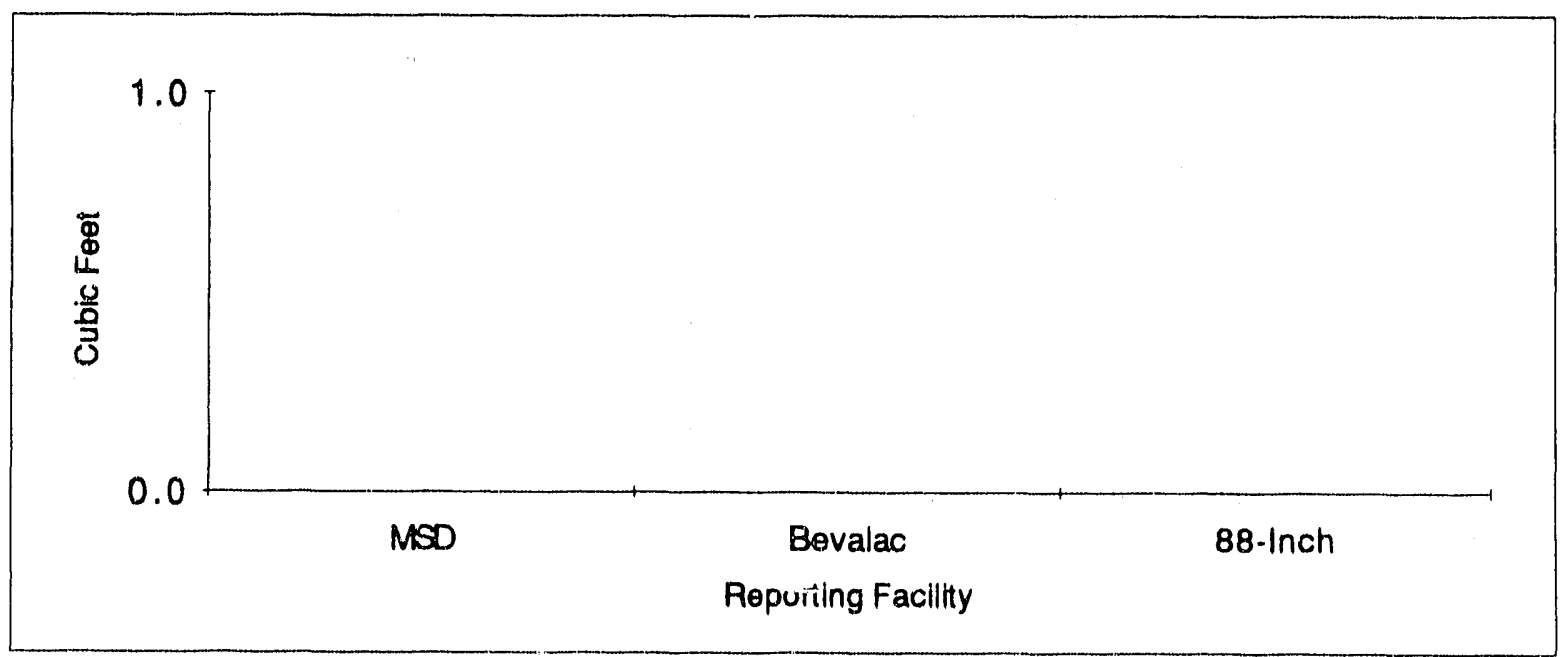

\section{Current Period Data}

There was no low level radioactive waste generated at LBL during the current reporting period. 


\section{Materials Sciences Dlvision}

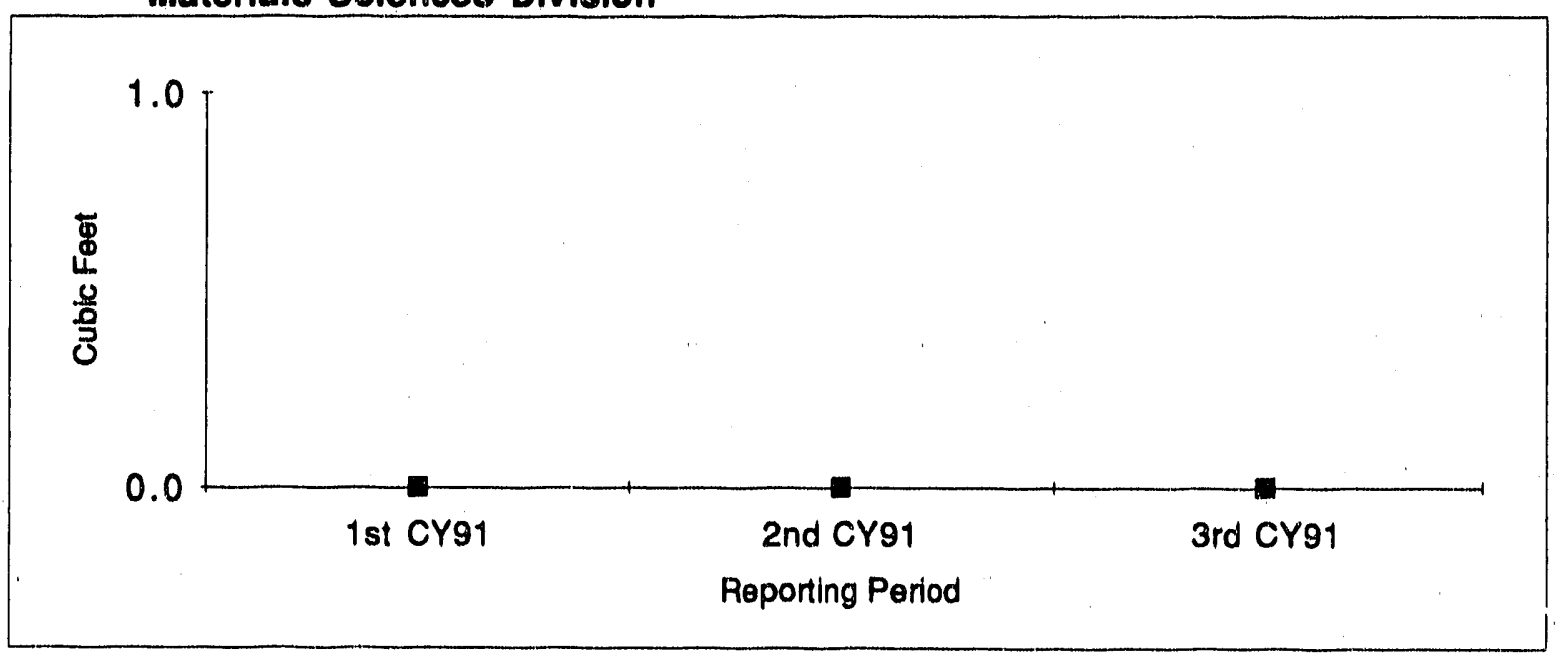

No low level radioactive waste generated to date.

Bevalac

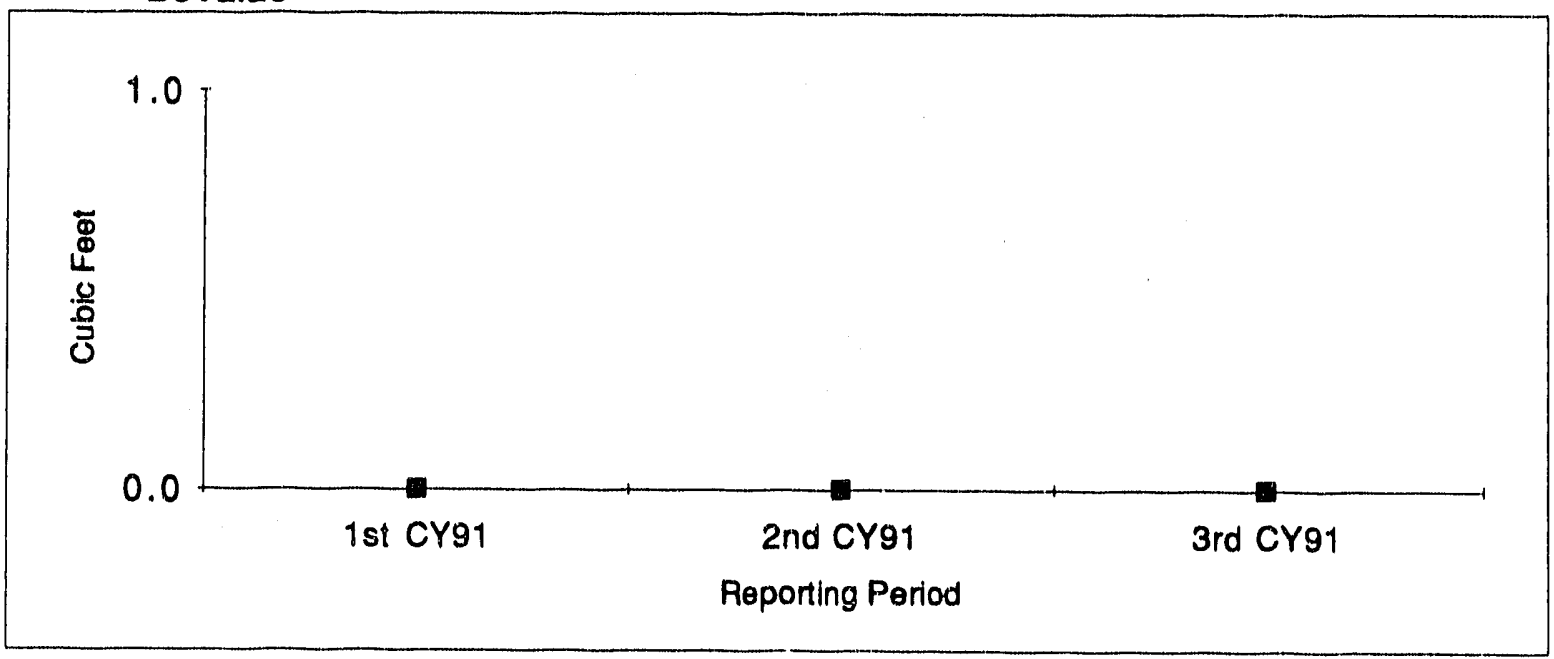

No low level radioactive waste generated to date.

PI 4.7.1.2 


\section{8-Inch Cyclotron}

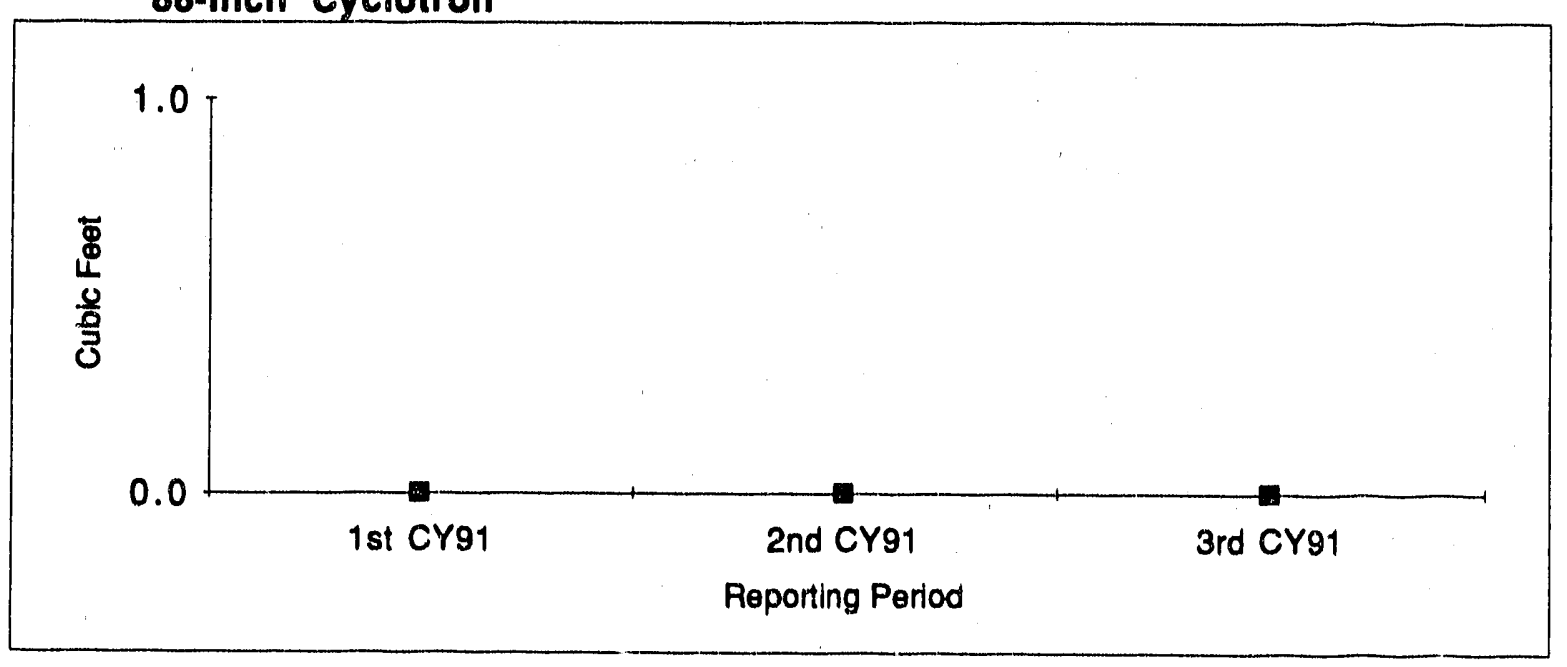

No low level radioactive waste generated to date.

PI 4.7.1.2 


\subsubsection{Solid Low Level Radioactive Waste - Shipped}

The total volume, in cubic feet, of solid low level radioactive waste shipped during the reporting poriod.

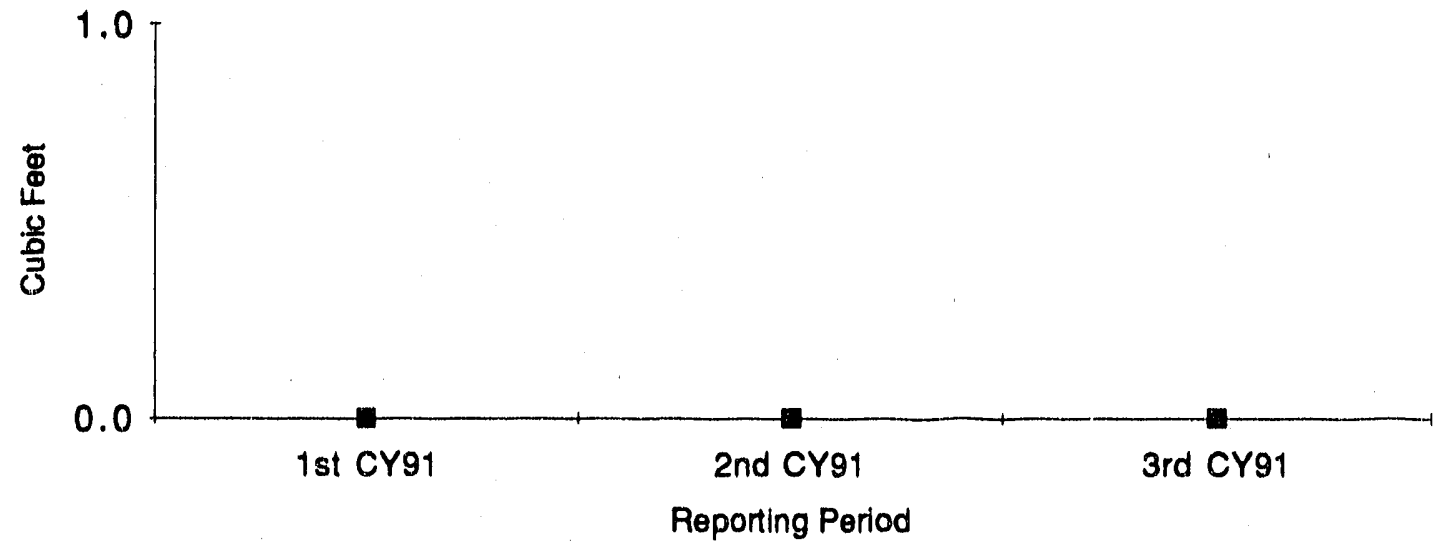

There has not been any low level radioactive waste has been generated at LBL to date.

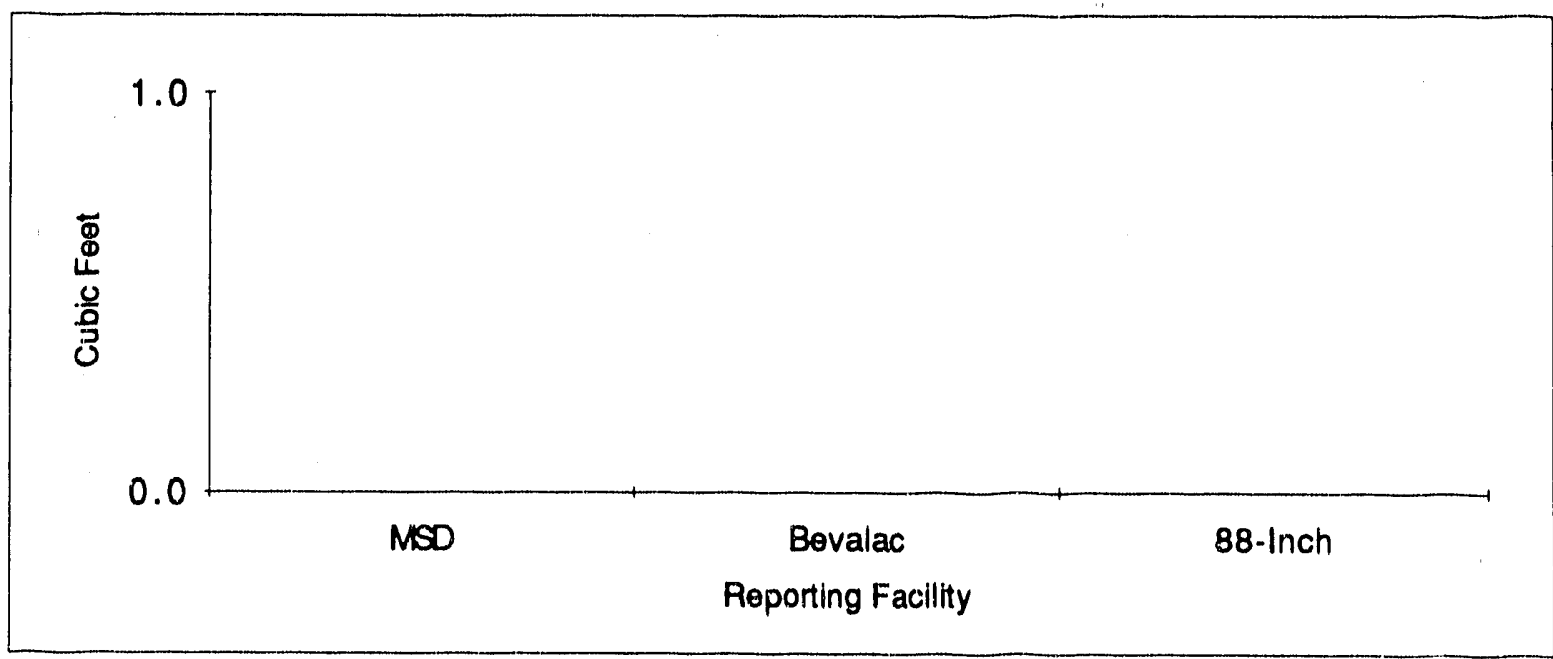

Current Period Data

There was no low level radioactive waste generated at LBL during the current reporting period.

PI 4.7.1.3 
Materials Sciences Division

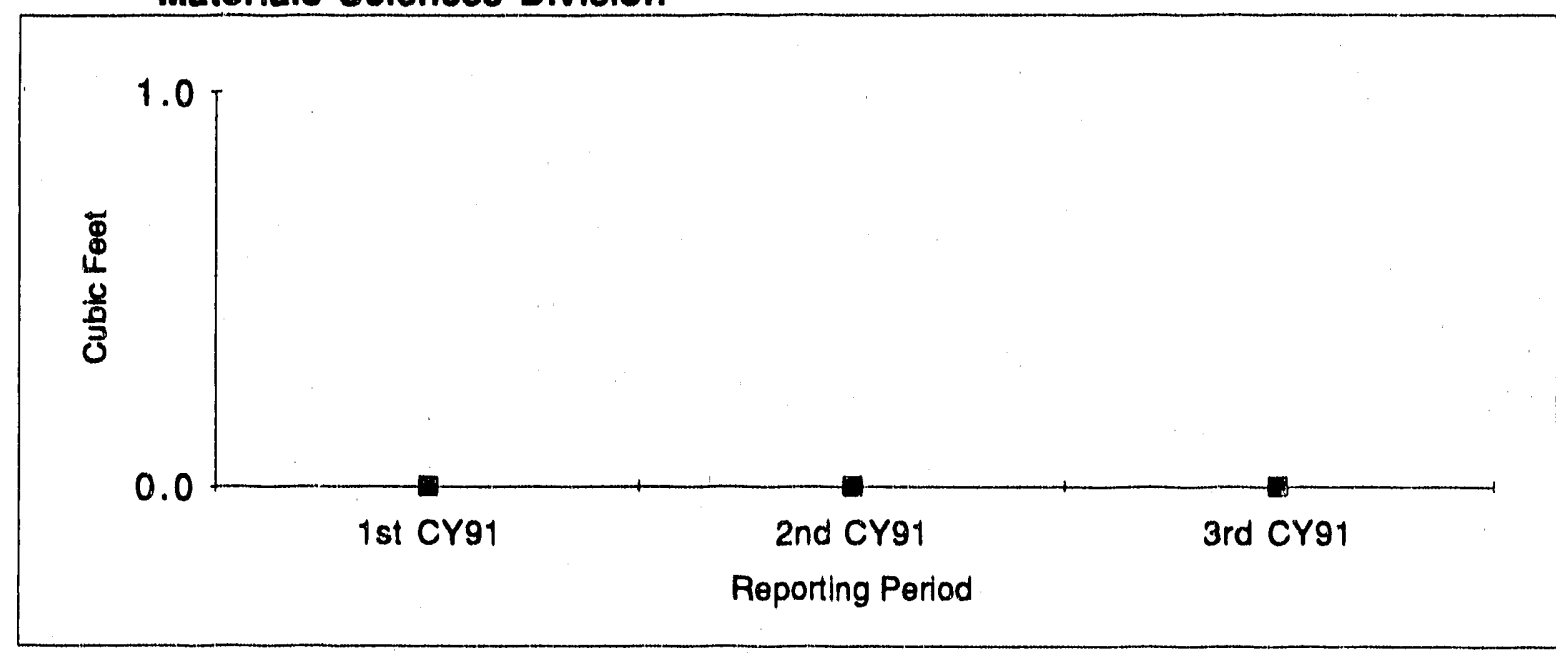

No low level radioactive waste generated to date.

\section{Bevalac}

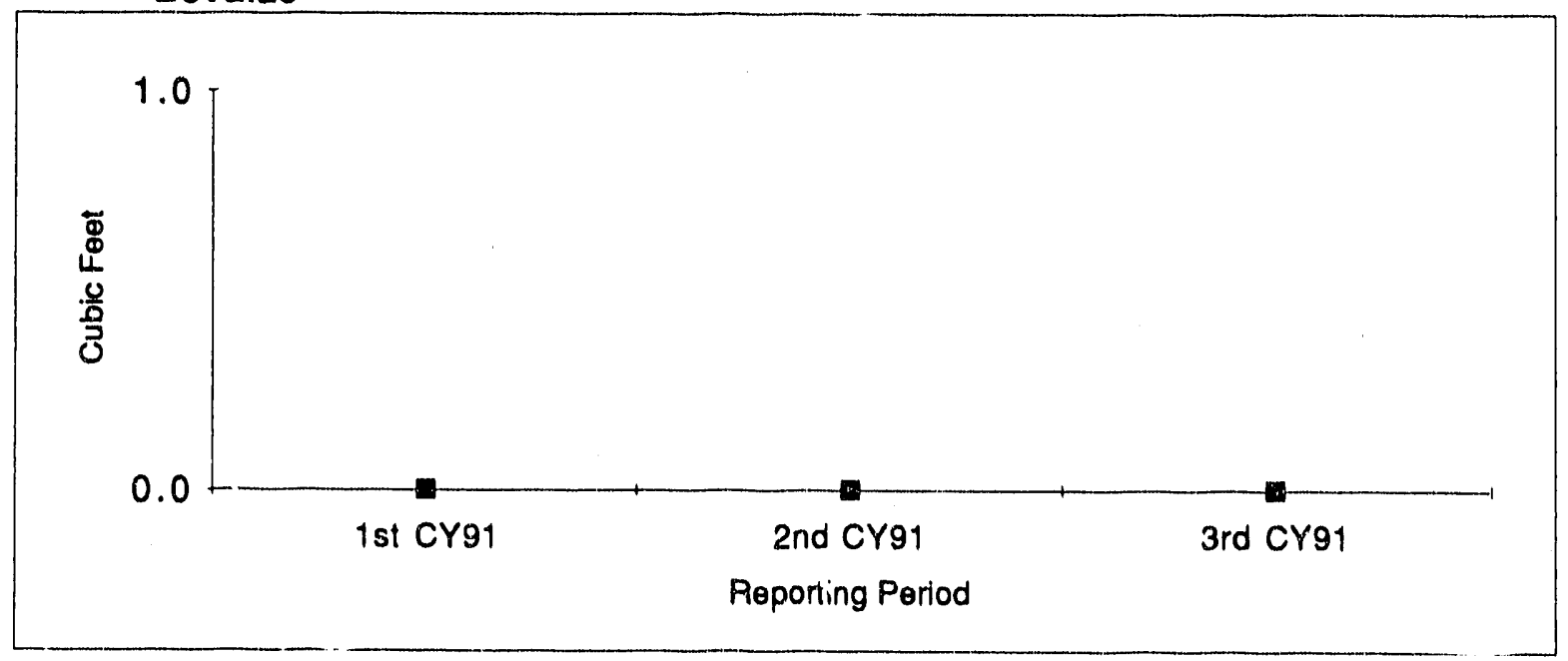

No low level radioactive waste generated to date.

P| 4.7.1.3 


\section{8-Inch Cyclotron}

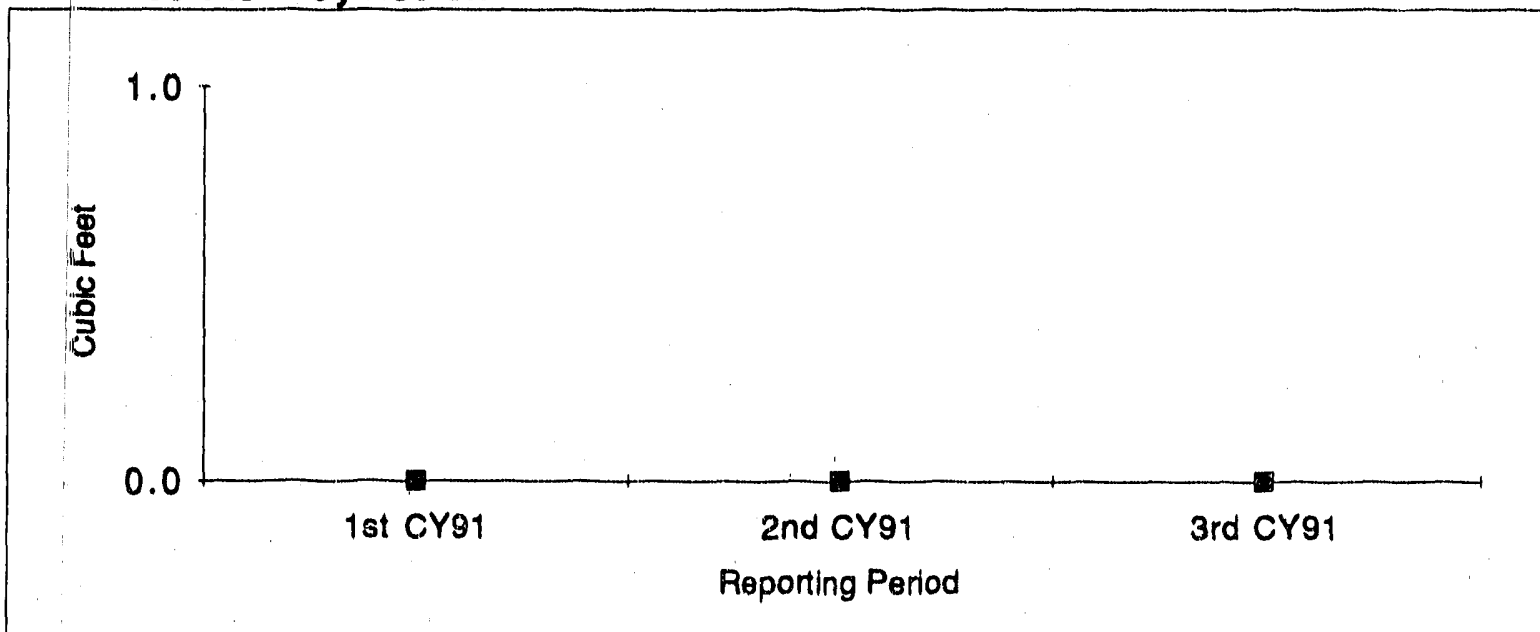

No low level radioactive waste generated to date.

PI 4.7.1.3 


\subsubsection{Solid Low Level Hazardous Waste - Generated}

The total volume, in cubic feet, of solid low level hazardous waste generated during the reporting period.

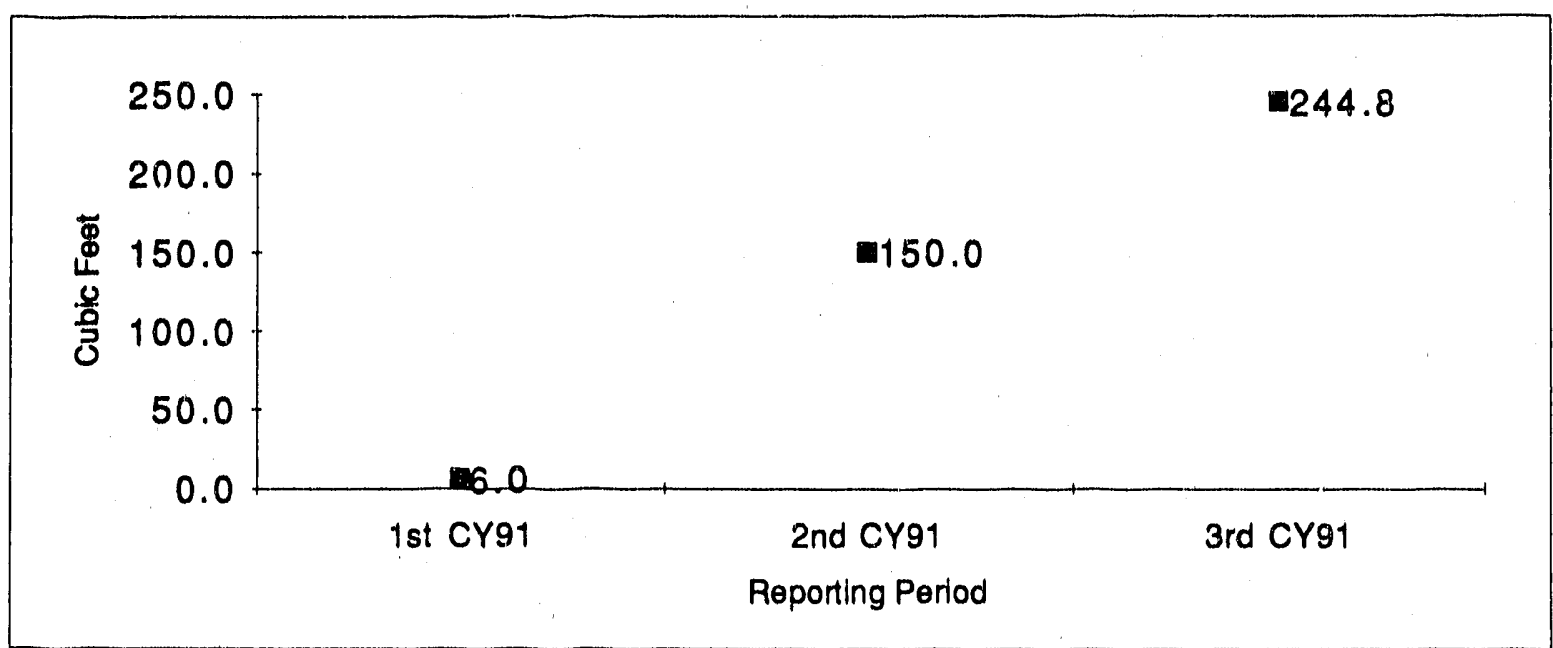

The amount of low-level hazardous waste generated has been increasing steadily over the past three quarters.

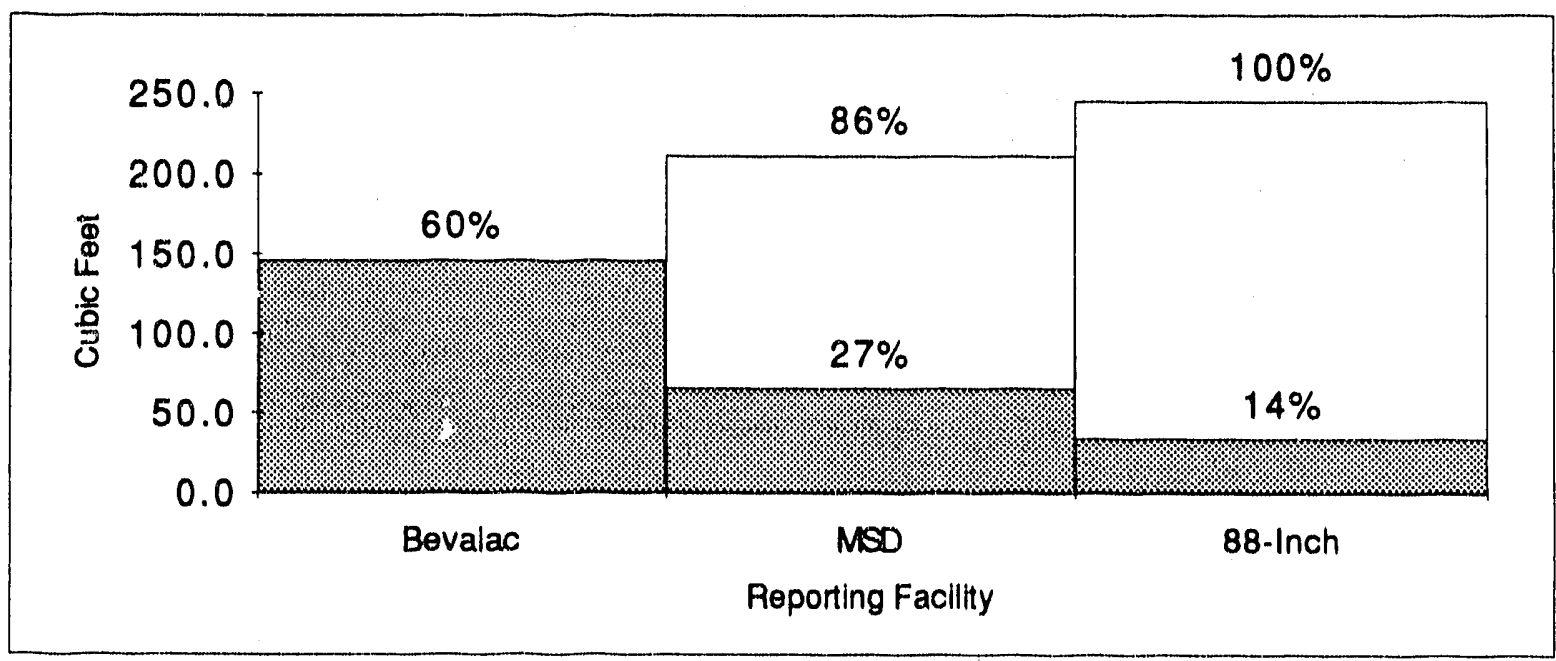

\section{Current Period Data}

PI 4.7.2.1 


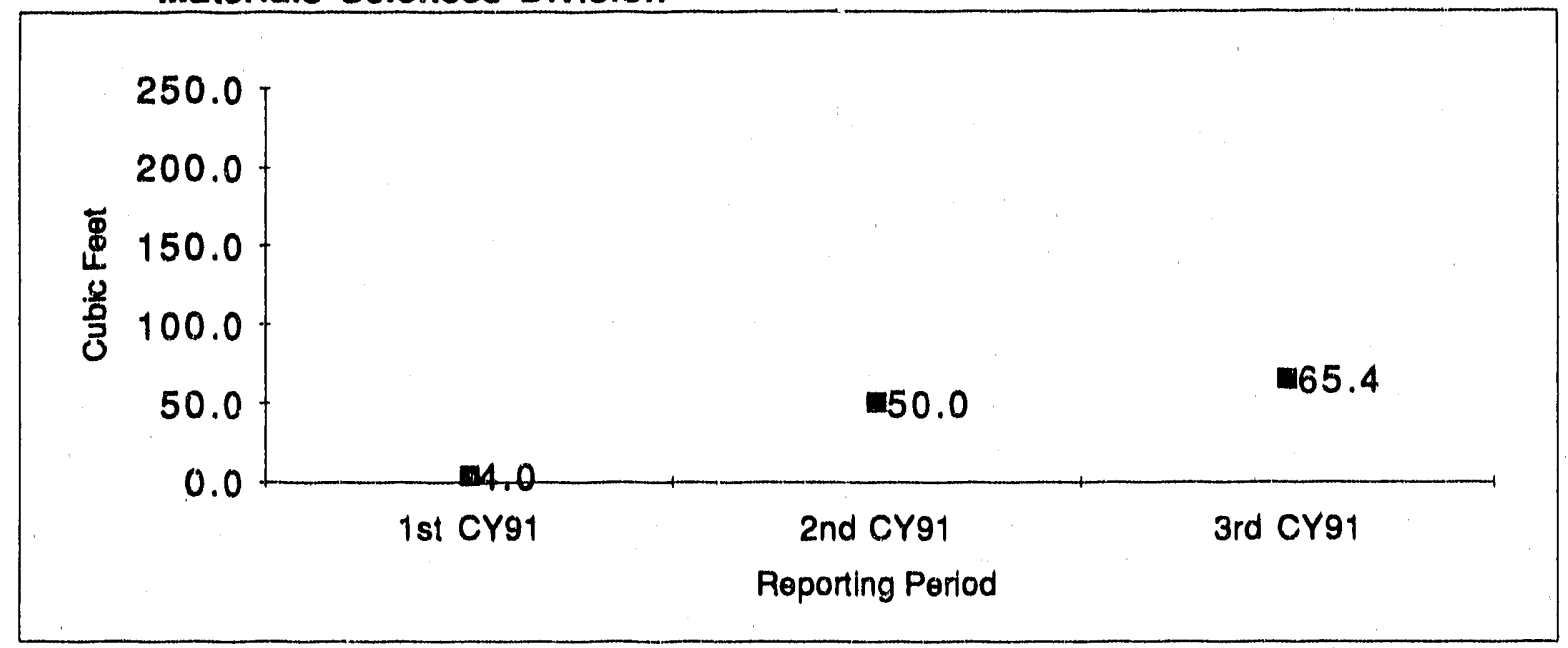

Solid low level hazardous waste generation has increased during the year.

\section{Bevalac}

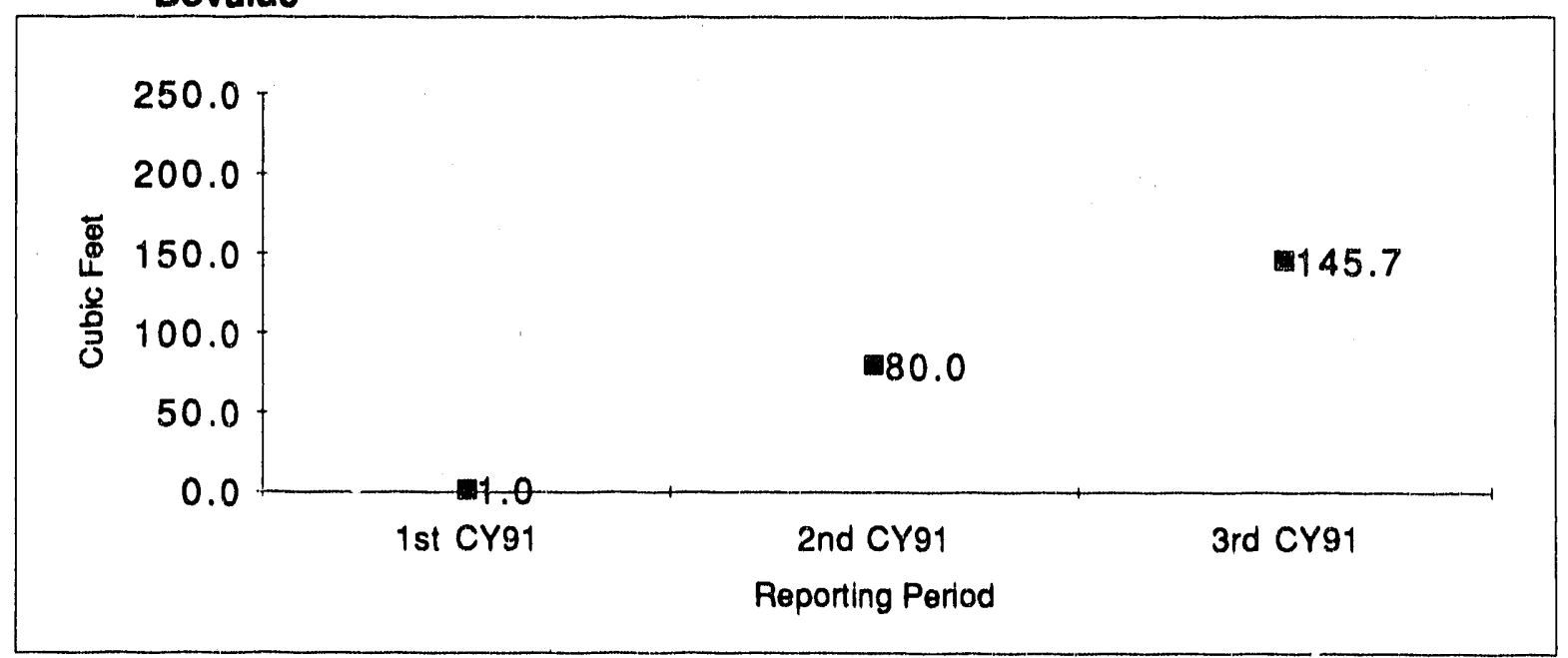

An increase in low level hazardous waste has been reported.

P| 4.7.2.1 


\section{8-inch Cyclotron}

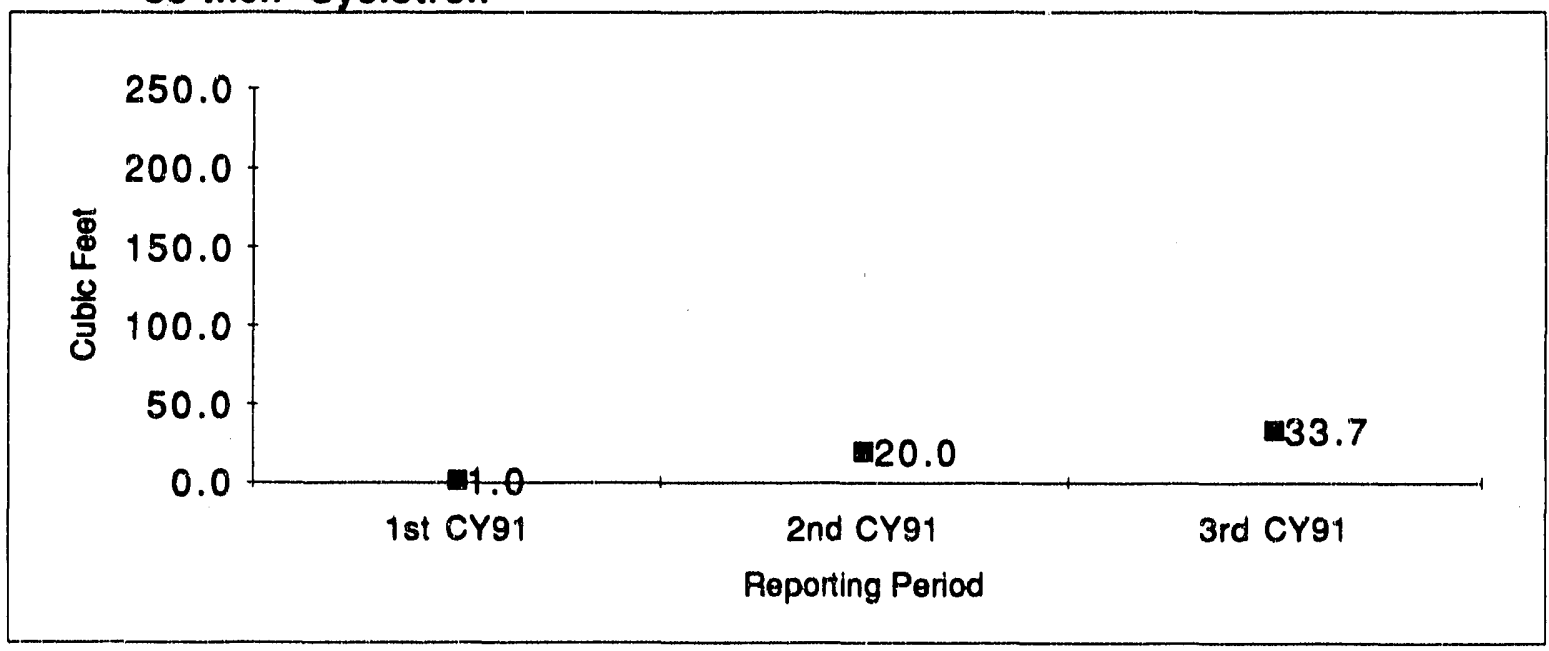

An increase in low level hazardous waste has been reported. 


\subsubsection{Solid Low Level Hazardous Waste - Ready to Shlp}

The total volume, in cubic ieet, of the final form (pending shipment) of low level hazardous waste generated during the reporting period.

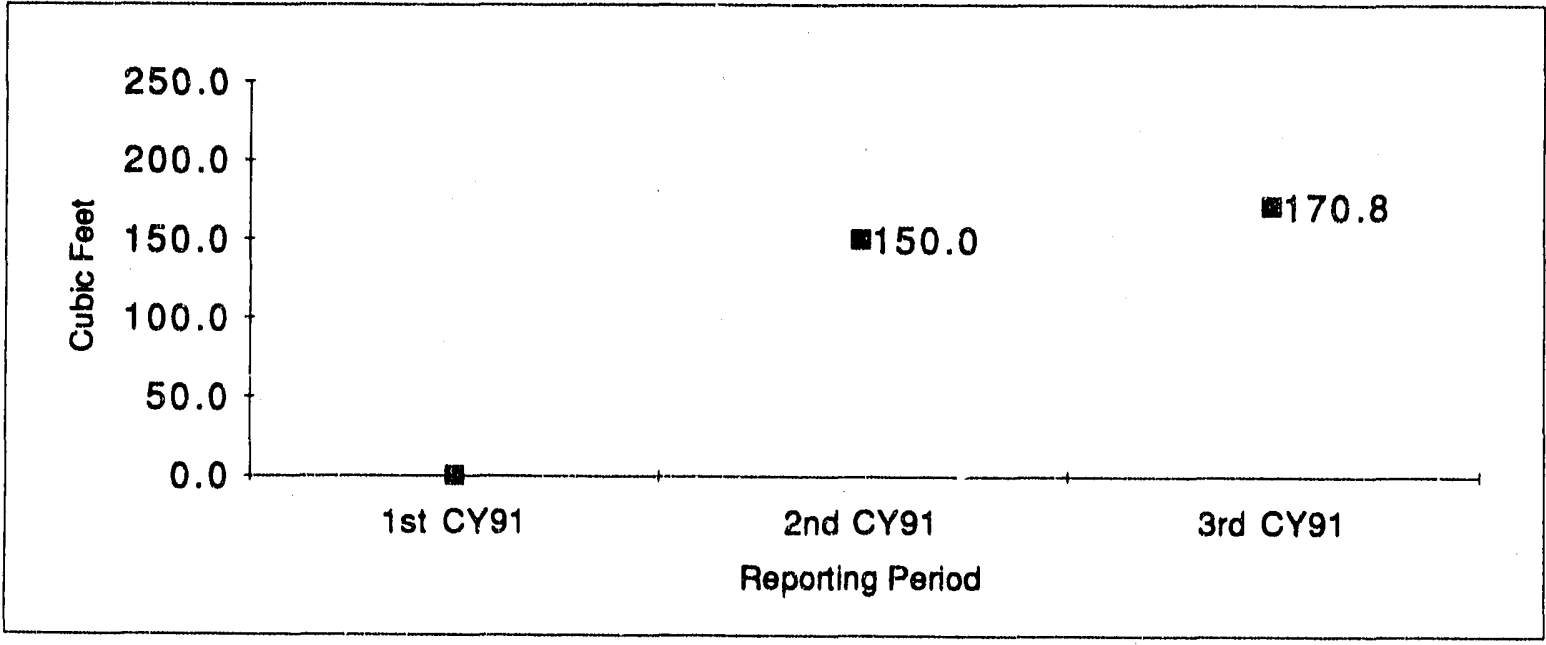

The amount of low-level hazardous waste prepared for shipment was up slightly over the second quarter.

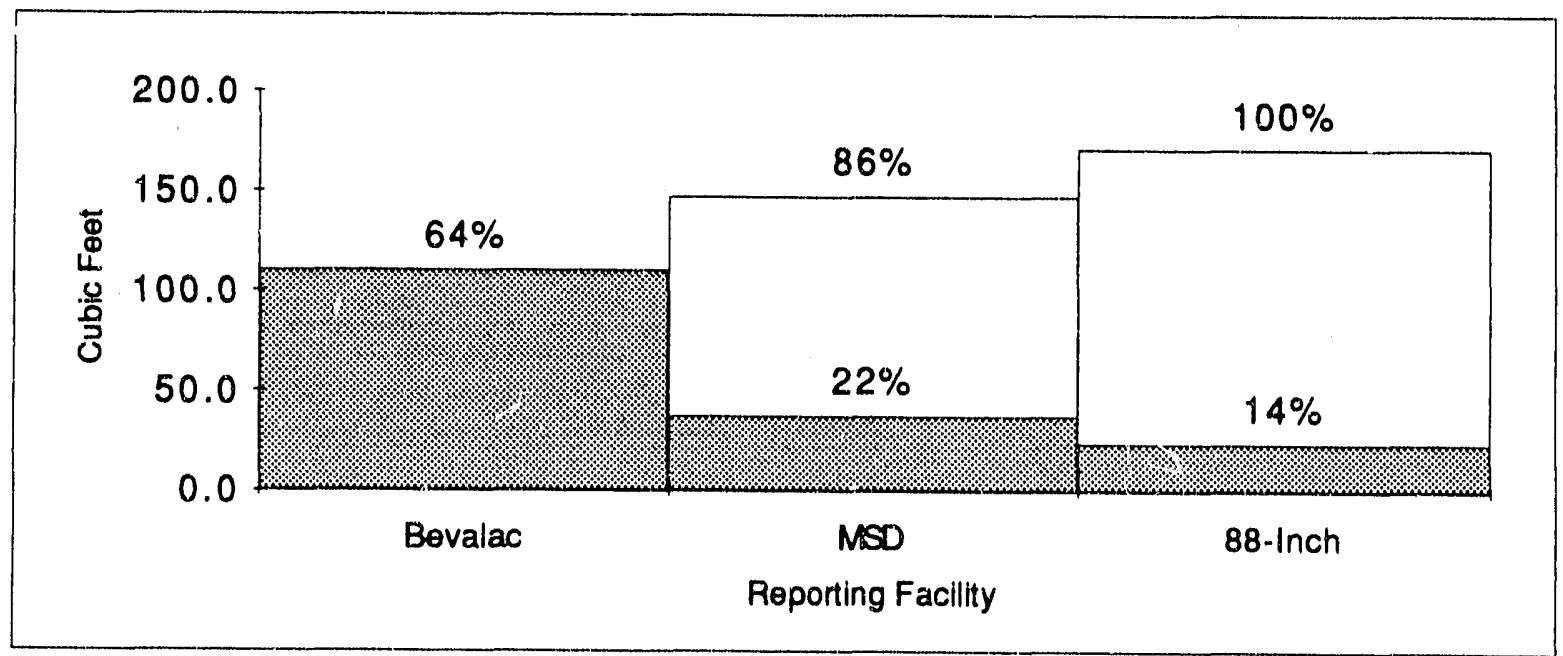

Current Period Data

PI 4.7.2.2 


\section{Materiais Sciences Division}

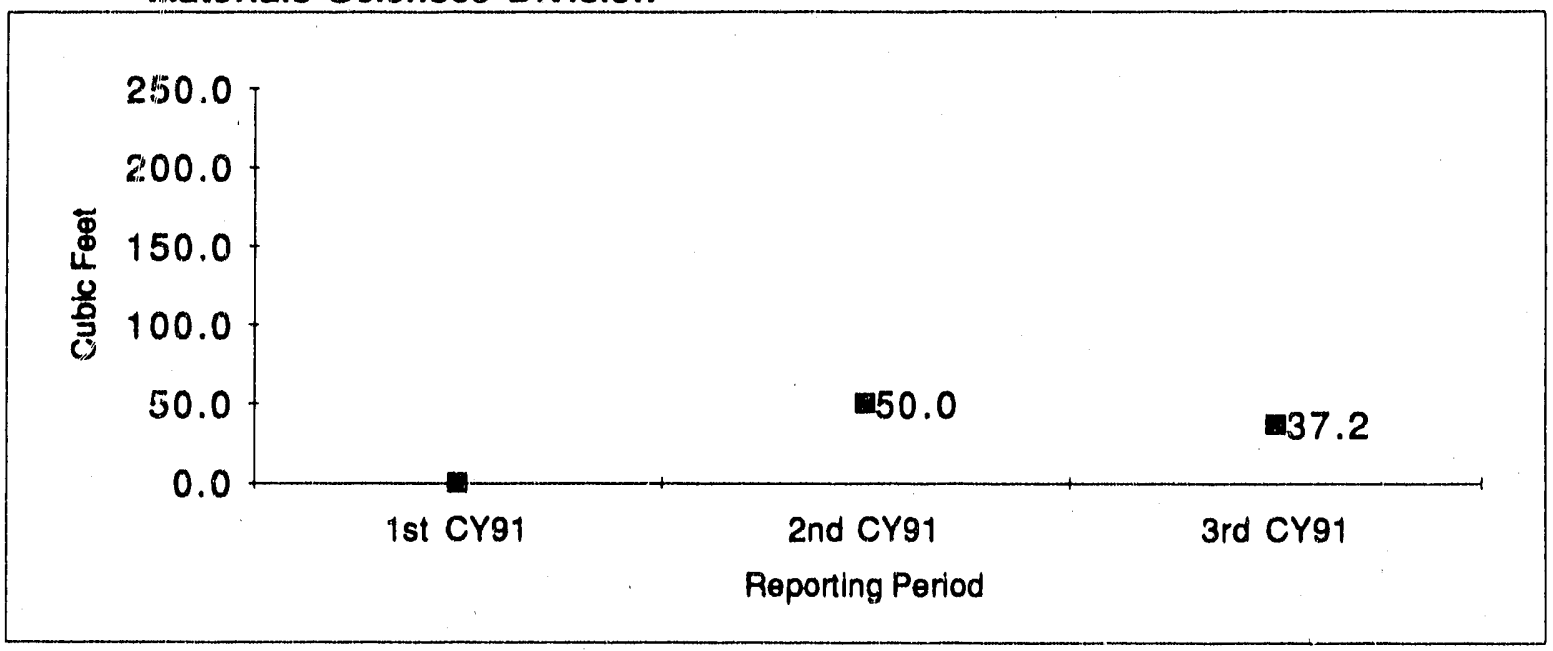

No trend noted.

Bevalac

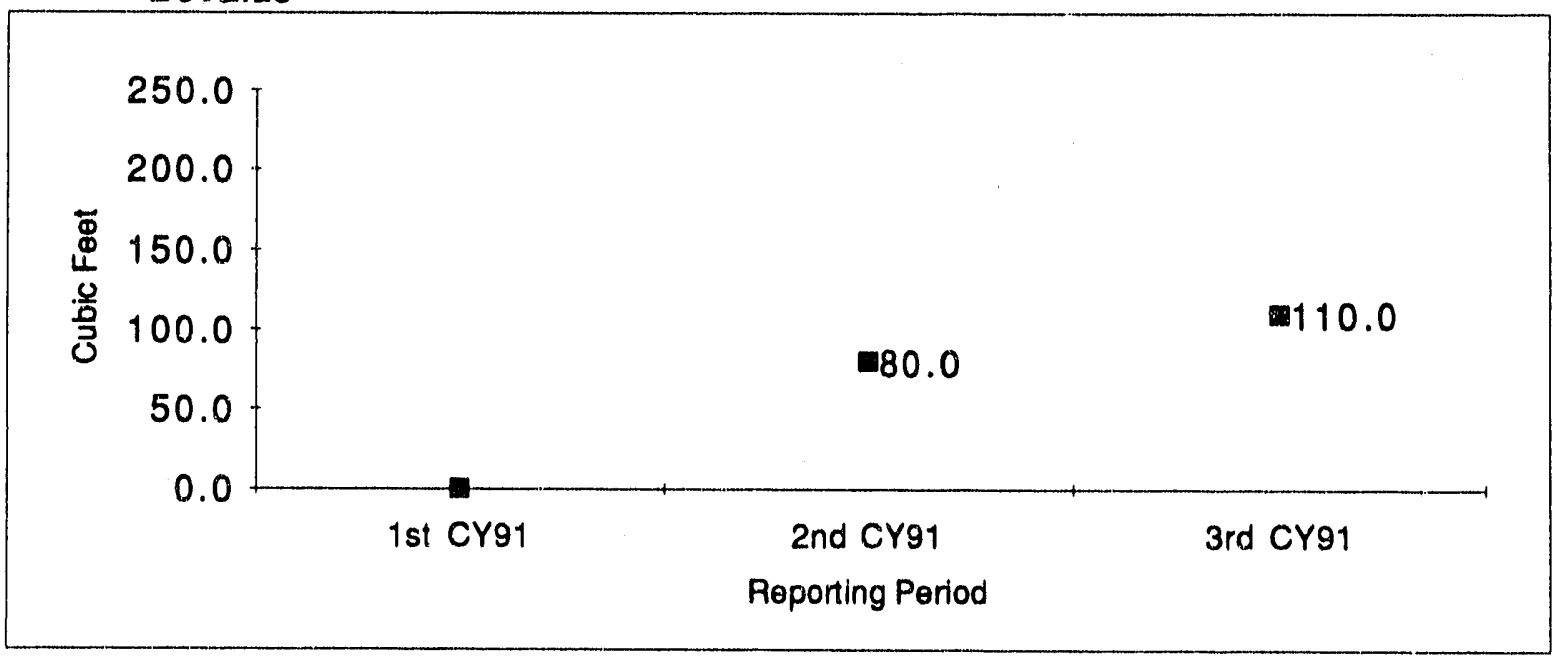

Quantity of low level hazardous waste ready iu ship has steadily increased since the first quarter. 
88-inch Cyclotron

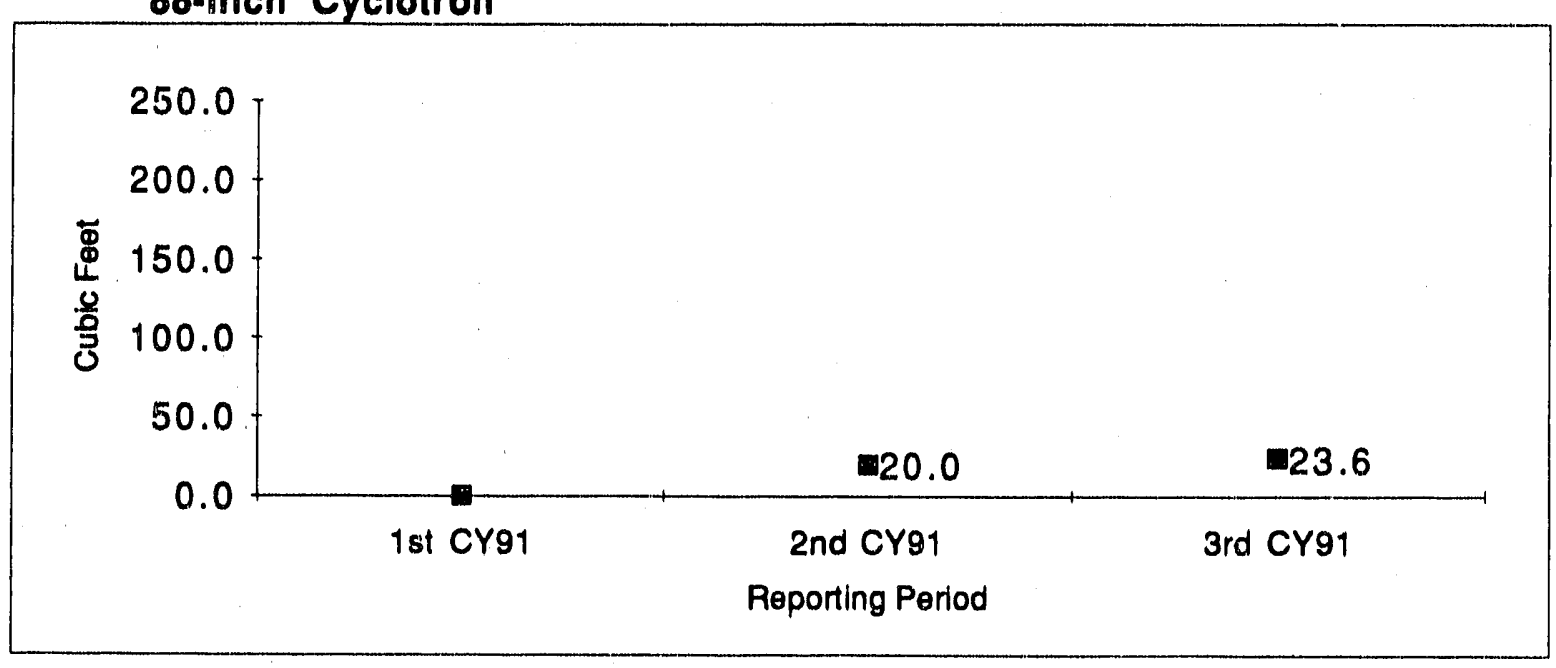

A slight increase in low level hazardous waste ready to ship was noted since the last reporting period. 


\subsubsection{Solid Low Level Hazardous Waste - Shlpped}

The total volume, in cubic foet, of low lovel hazardous waste shipped during the reporting period.

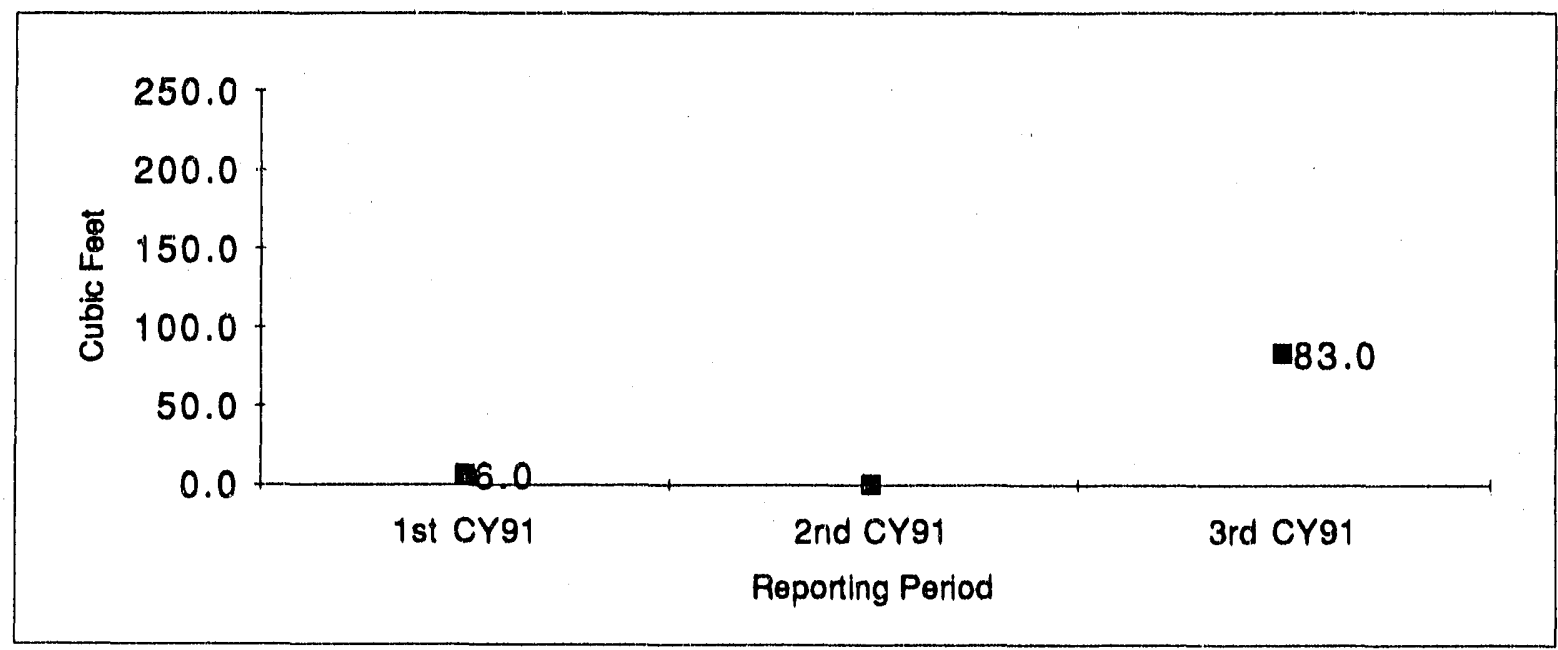

Shipment of low-level hazardous waste resumed during the third quarter. The amount shipped was the most to date.

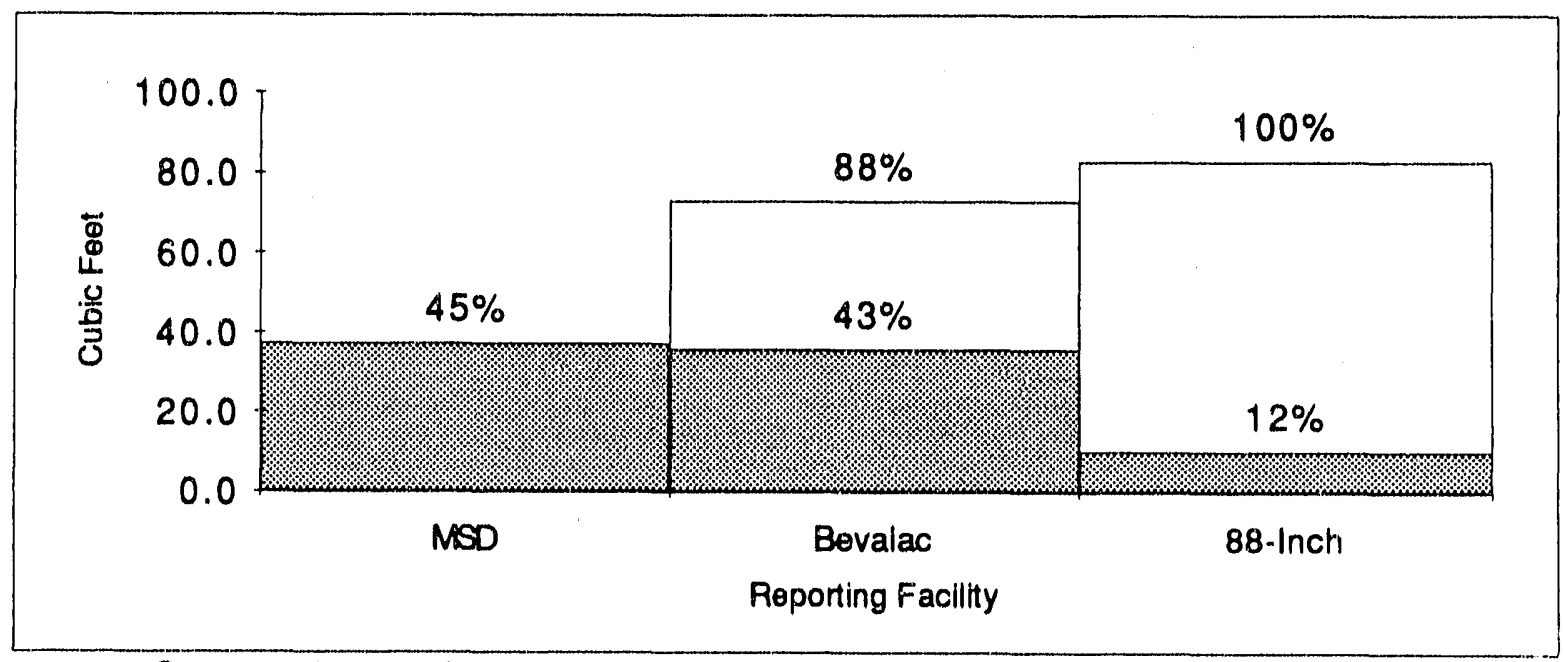

Current Period Data

P| 4.7.2.3 


\section{Materials Sciences Division}

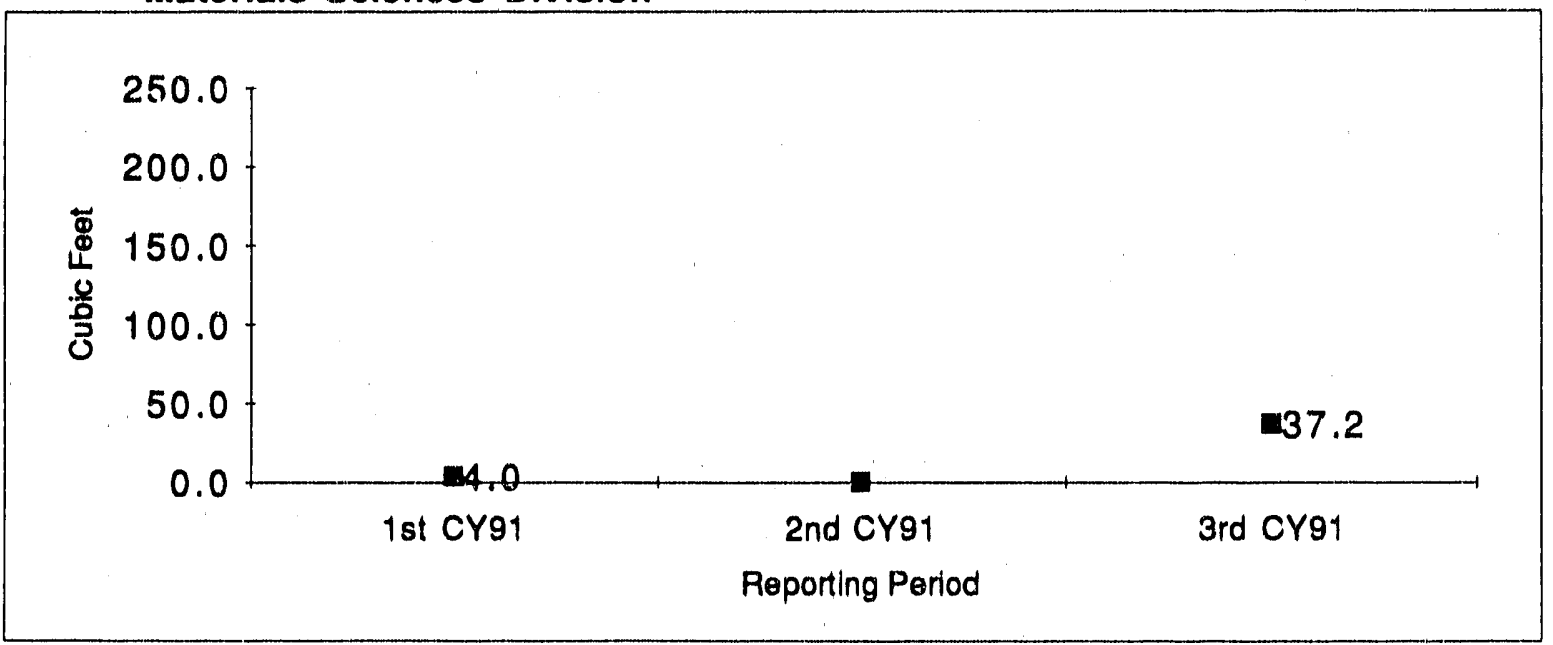

Shipments resumed in the third quarter of CY-1991.

\section{Bevalac}

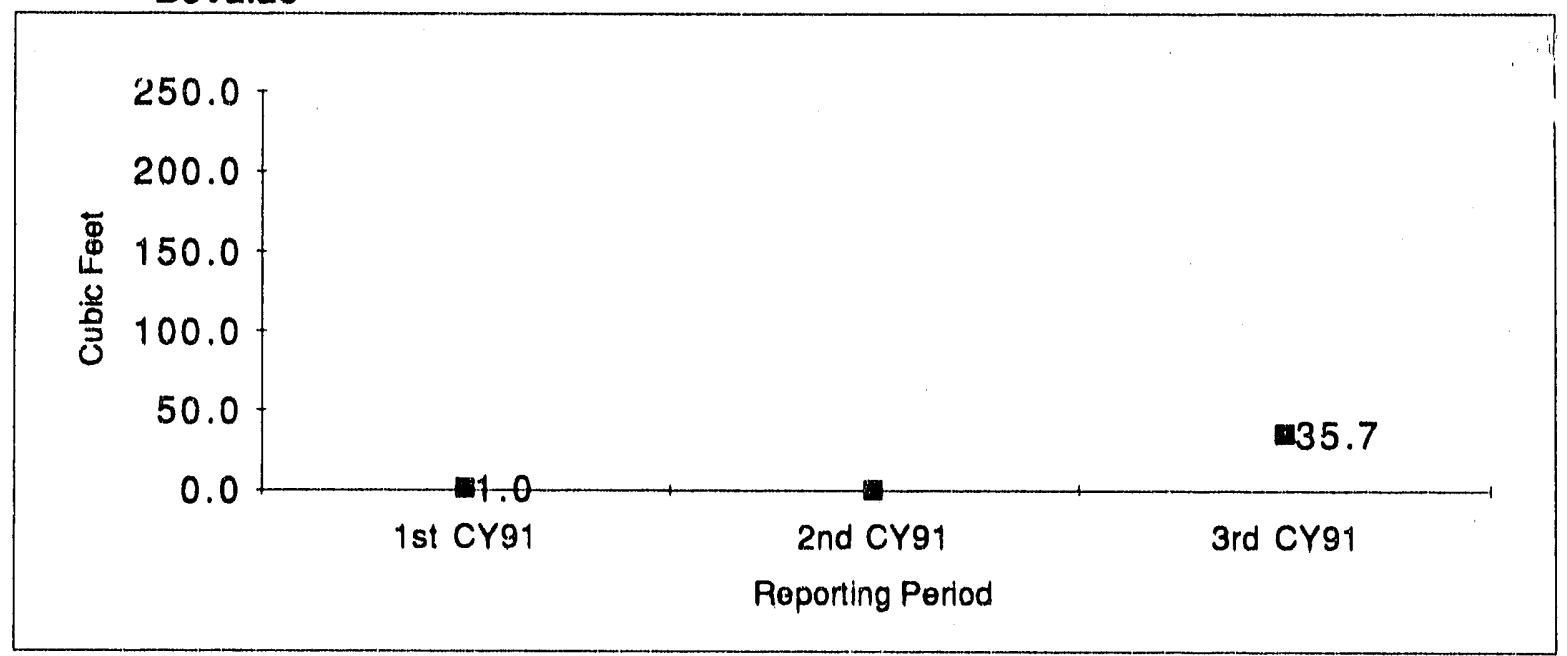

Shipments resumed in the third quarter of CY-1991.

P| 4.7.2.3 


\section{8-Inch Cyclotron}

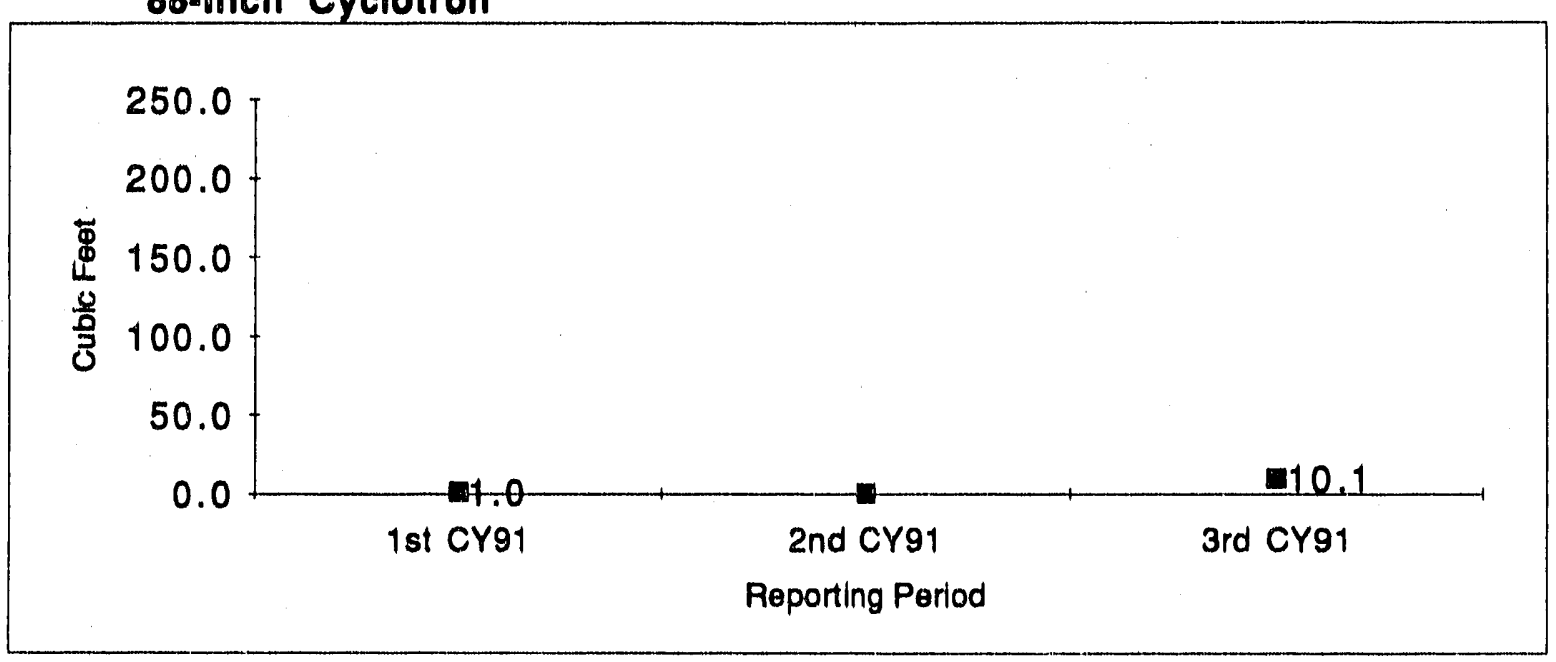

Shipments resumed in the third quarter of CY-1991. 


\subsubsection{Solld Low Level Mixed Waste - Generated}

The total volume, in cubic feet, of low level mixed waste generated during the reporting period.

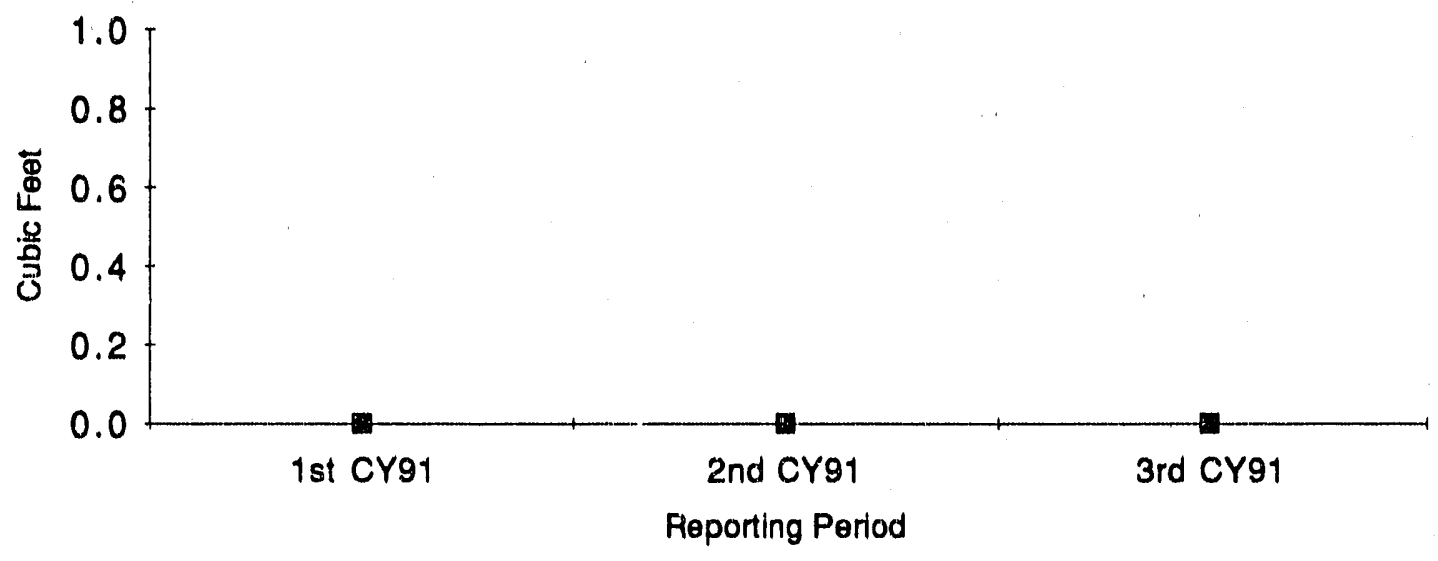

There has not been any low level mixed waste generated at LBL to date.

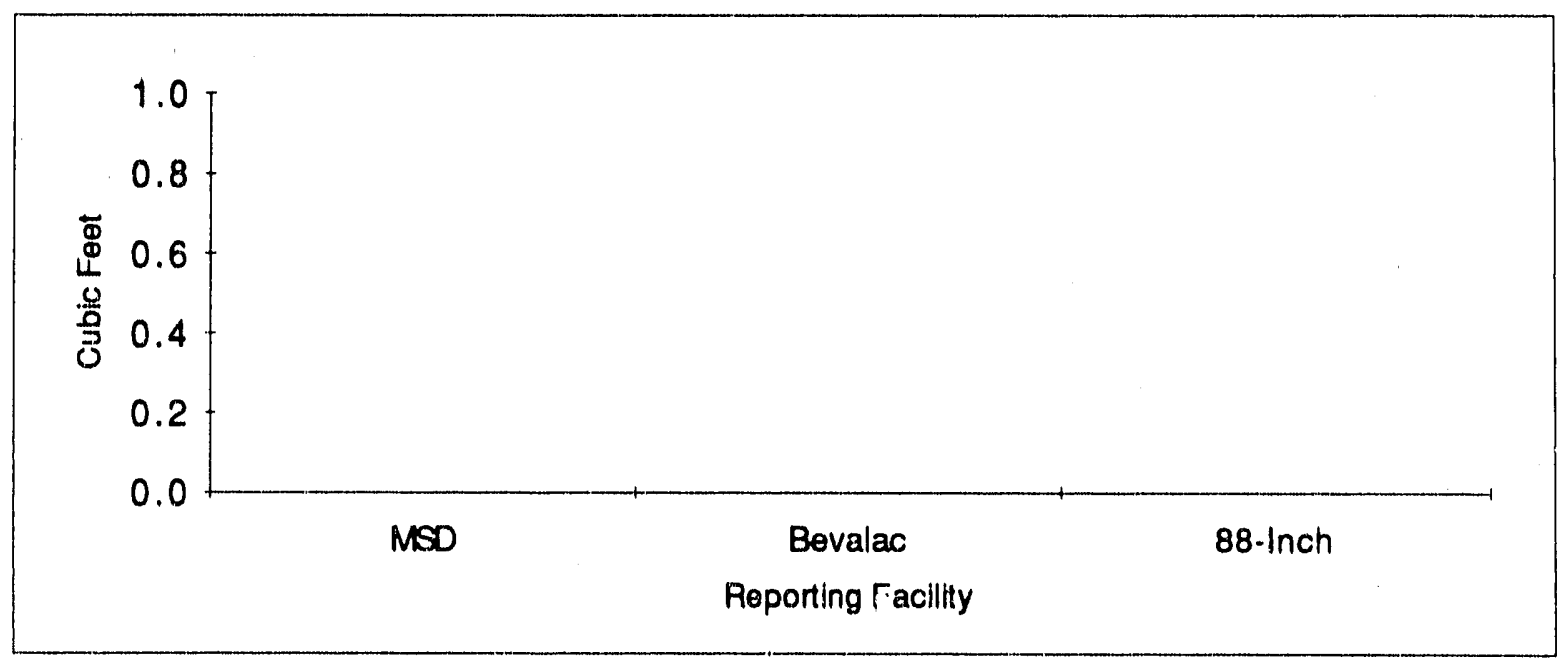

Current Period Data

There was no low level mixed waste generated at LBL during the current reporting period.

PI 4.7.3.1 


\section{Materials Sciences Division}

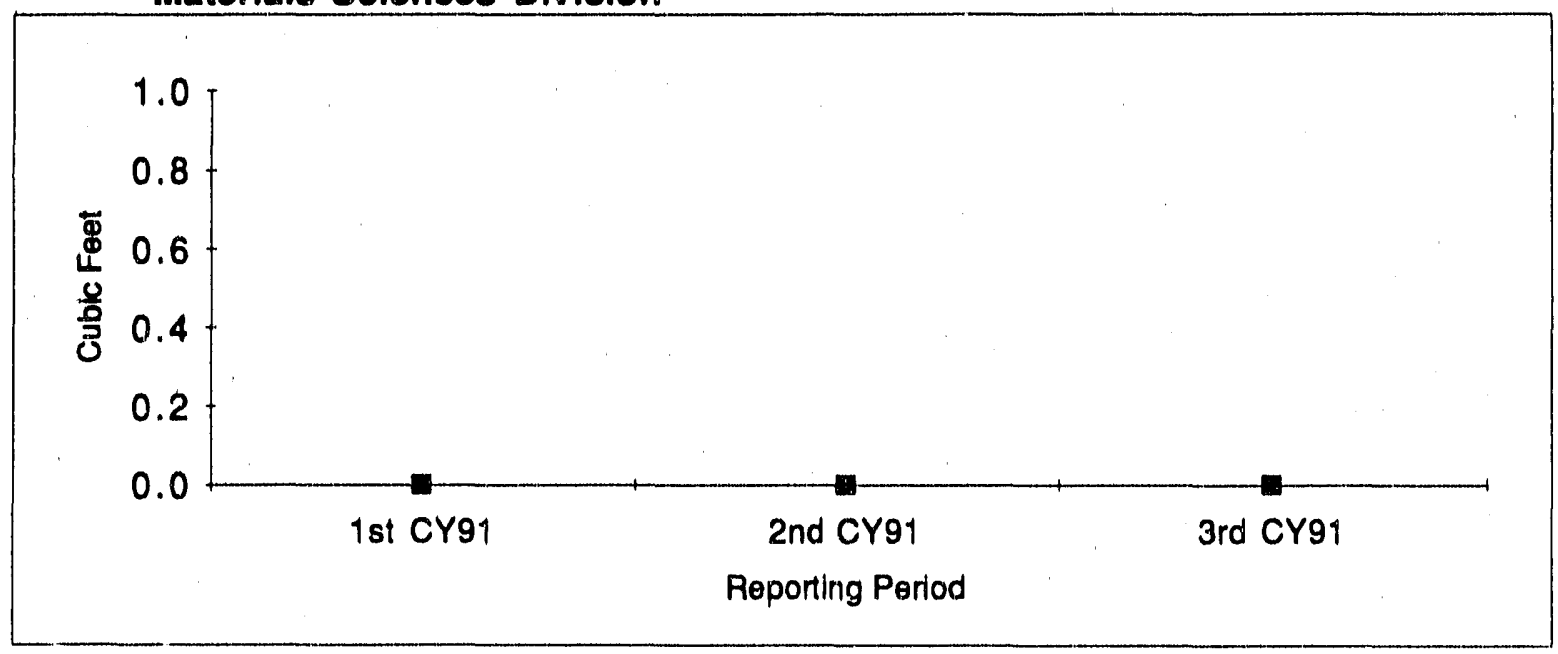

No low level mixed waste generated to date.

\section{Bevalac}

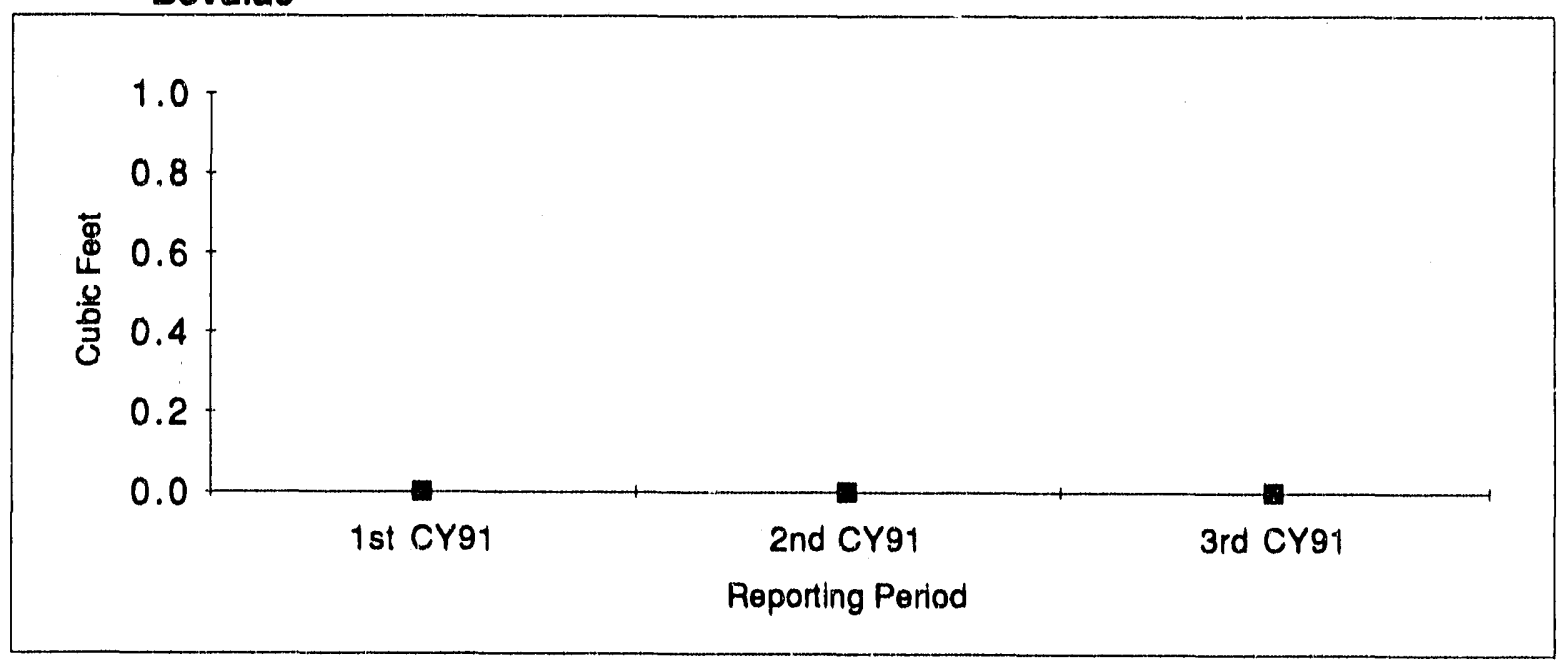

No low level mixed waste generated to date.

PI 4.7.3.1 
88-Inch Cyclotron

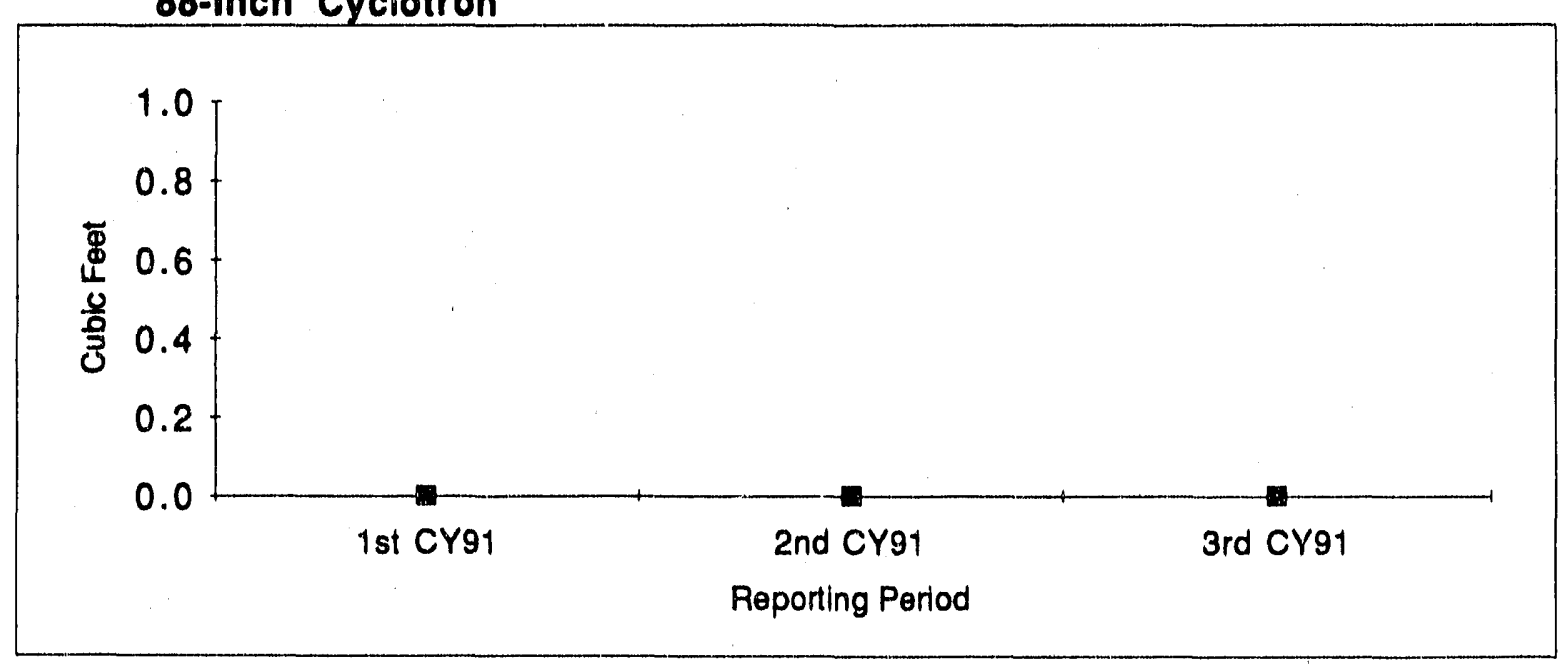

No low level mixed waste generated to date.

PI 4.7.3.1 


\subsubsection{Solld Low Level Mixed Waste - Ready to Ship}

The total volume, in cubic teet, of the final form (pending shipment) of low level mixed waste generated during the reporting period.

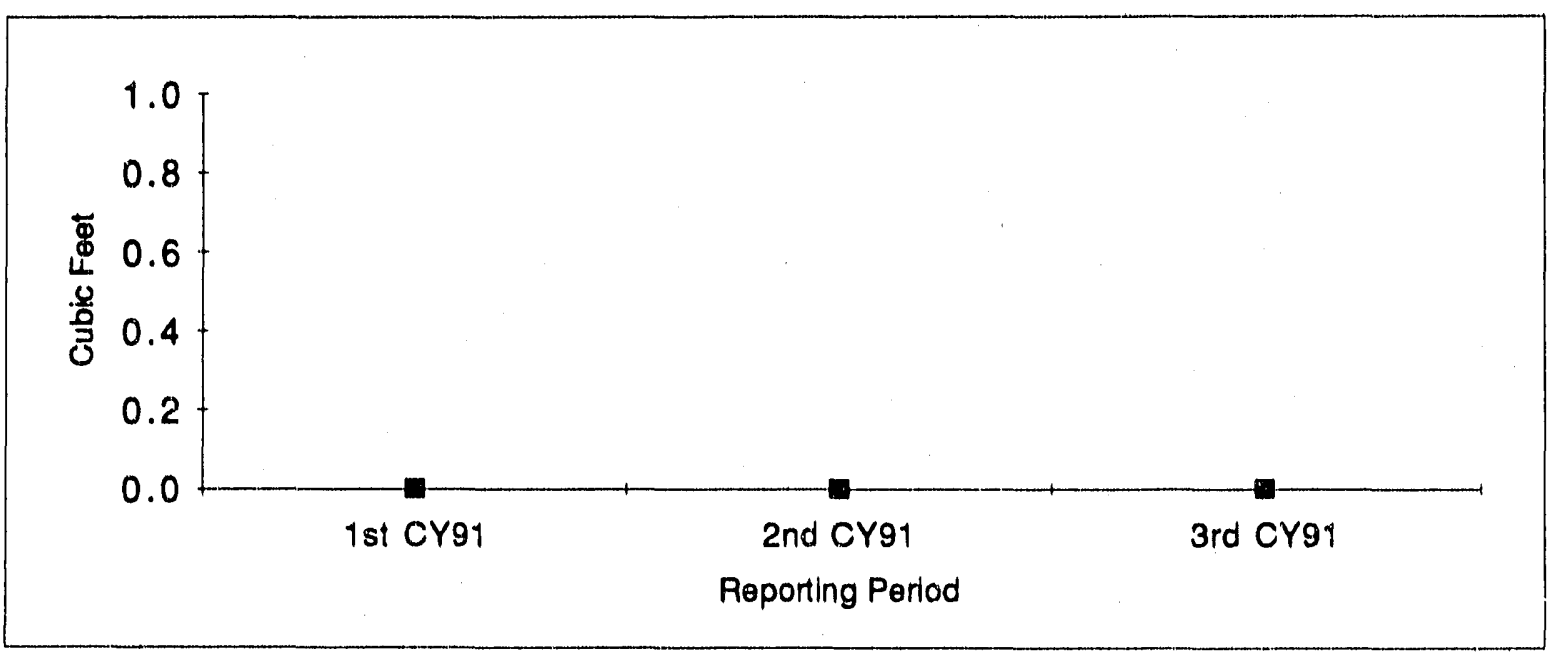

There has not been any low level mixed waste generated at LBL to date.

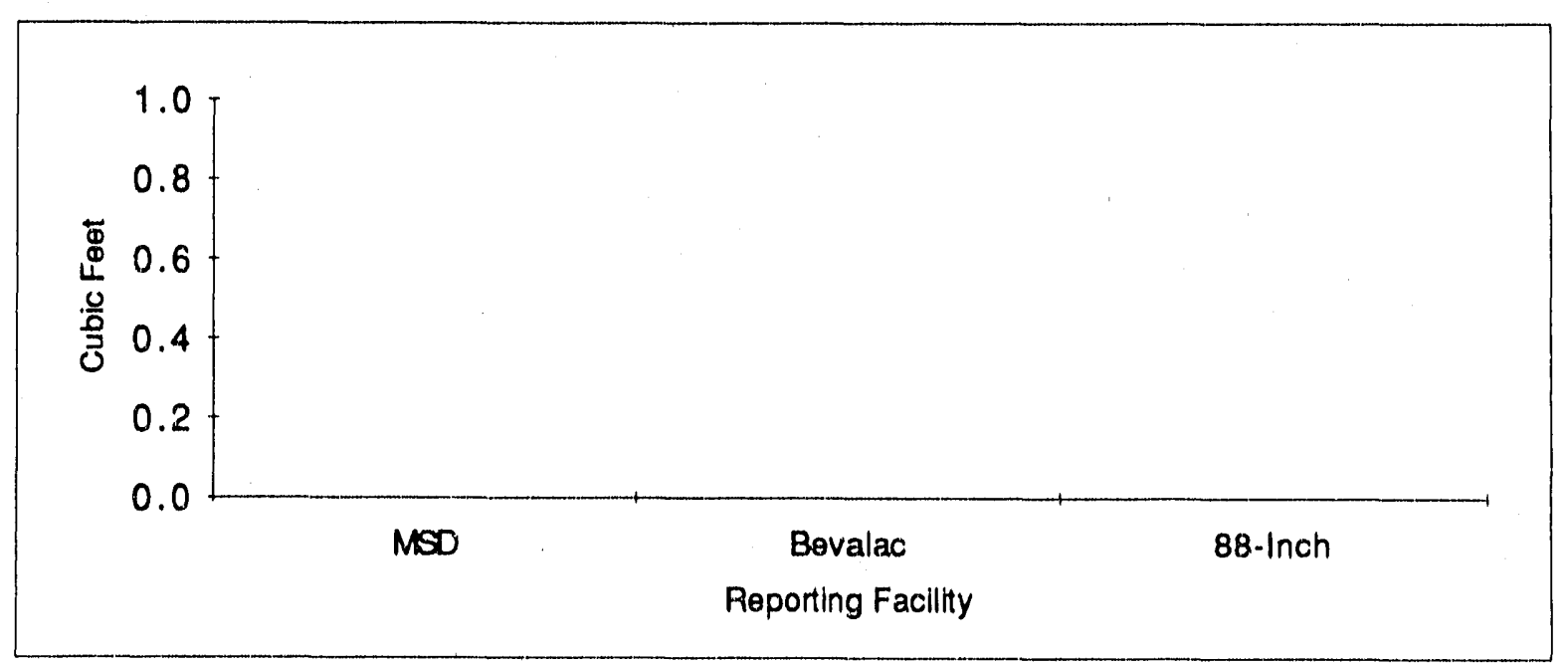

\section{Current Period Data}

There was no low level mixed waste generated at LBL during the current reporting period.

PI 4.7.3.2 
Materials Sciences Division

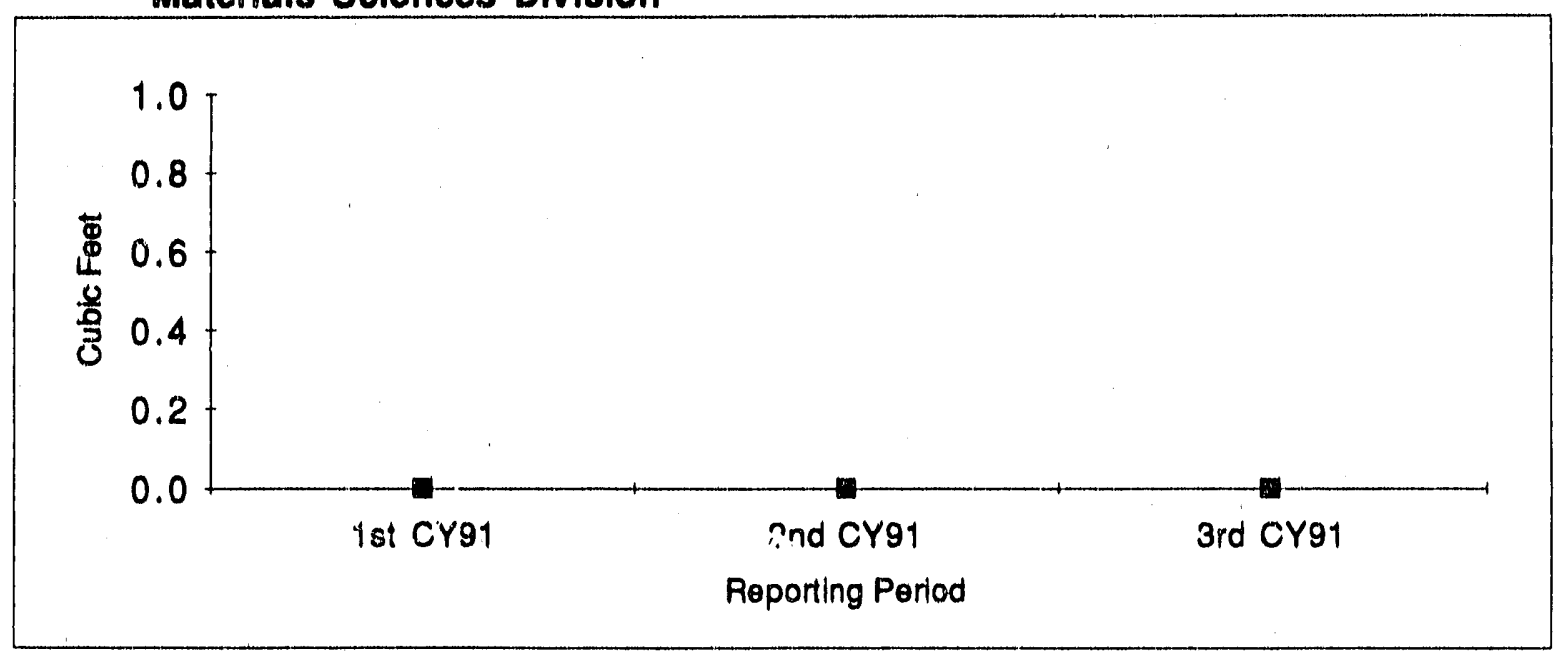

No low level mixed waste generated to date.

\section{Bevalac}

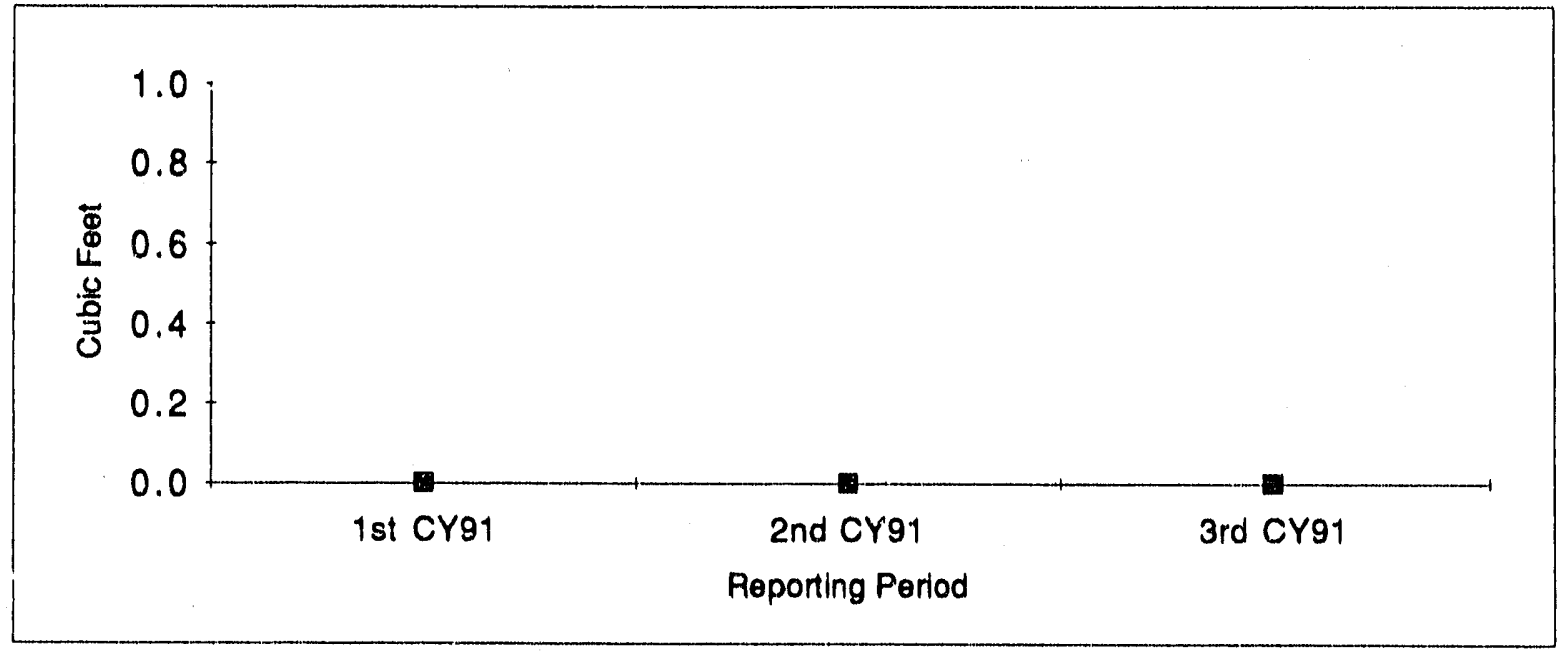

No low level mixed waste generated to date.

PI 4.7.3.2 


\section{8-Inch Cyclotron}

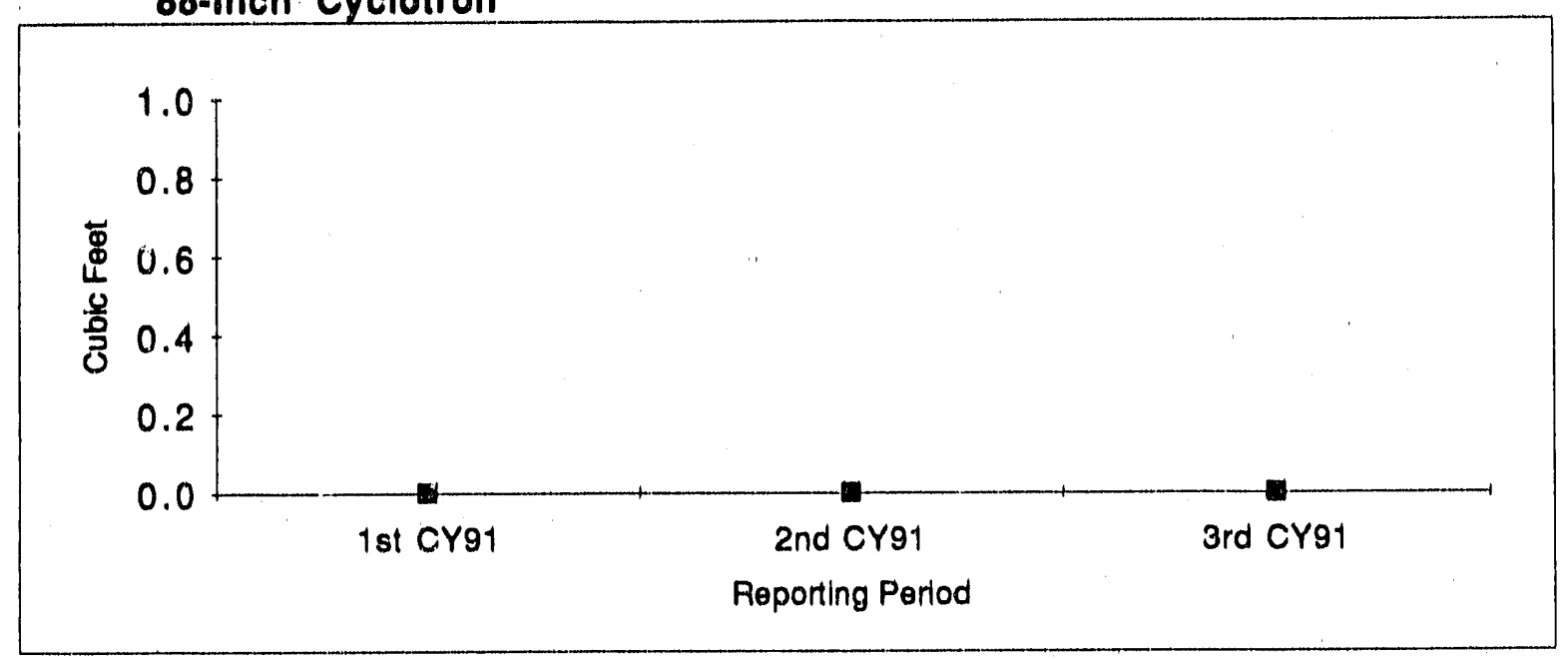

No low level mixed waste generated to date.

PI 4.7.3.2 


\subsubsection{Sollid Low Level Mixed Waste - Shipped}

The total volume, in cubic teet, of low level mixed waste shipped during the reporting period.

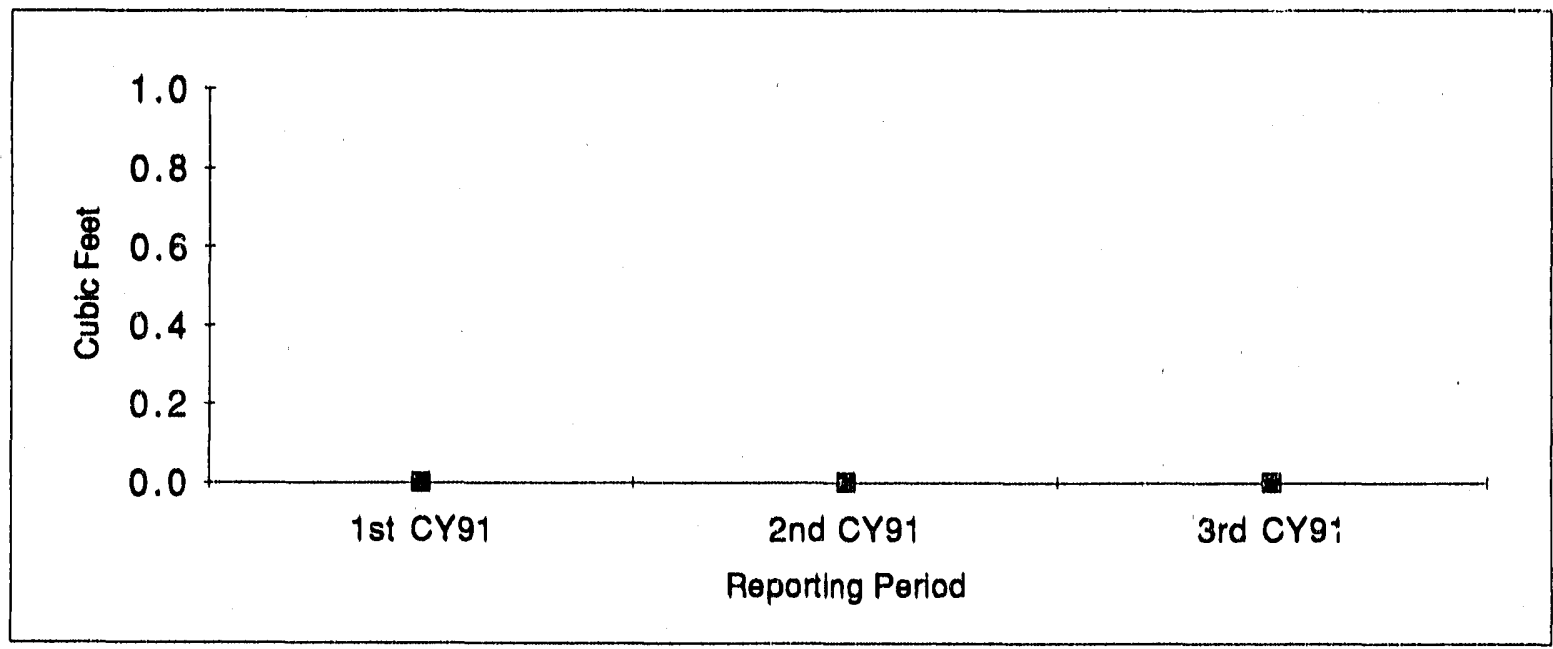

There has not been any low level mixed waste generated at $L B L$ to date.

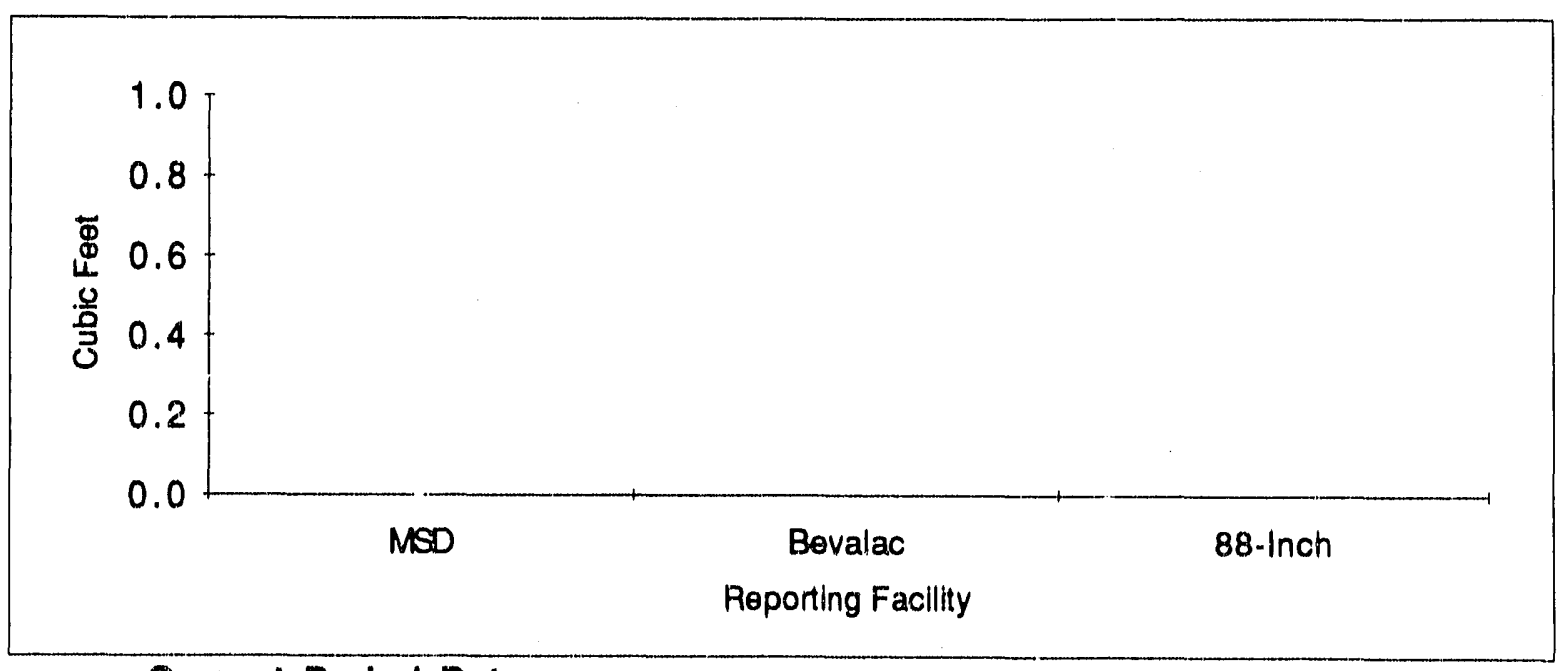

\section{Current Perlod Data}

There was no low level mixed waste generated at LBL during the current reporting period. 


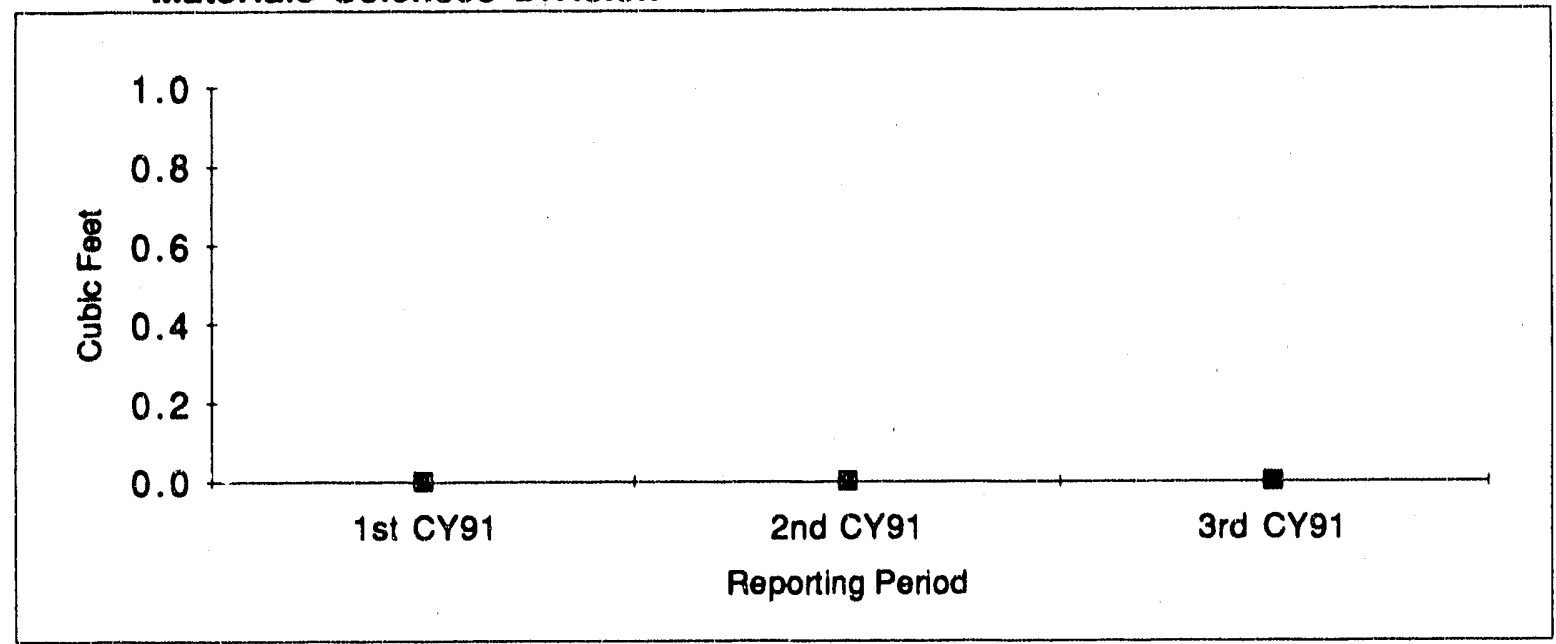

No low level mixed waste generated to date.

\section{Bevalac}

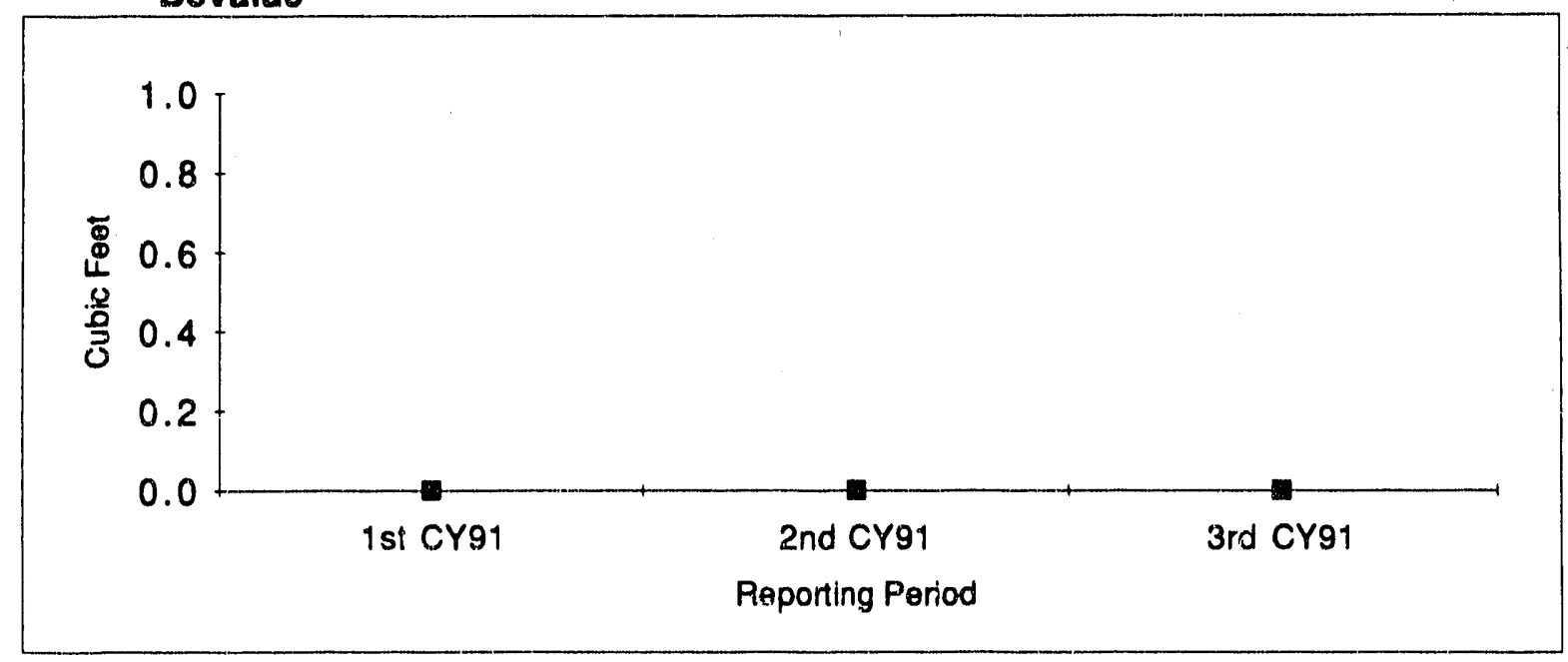

No low level mixed waste generated to date.

PI 4.7.3.3 


\section{8-Ineh Cyclotron}

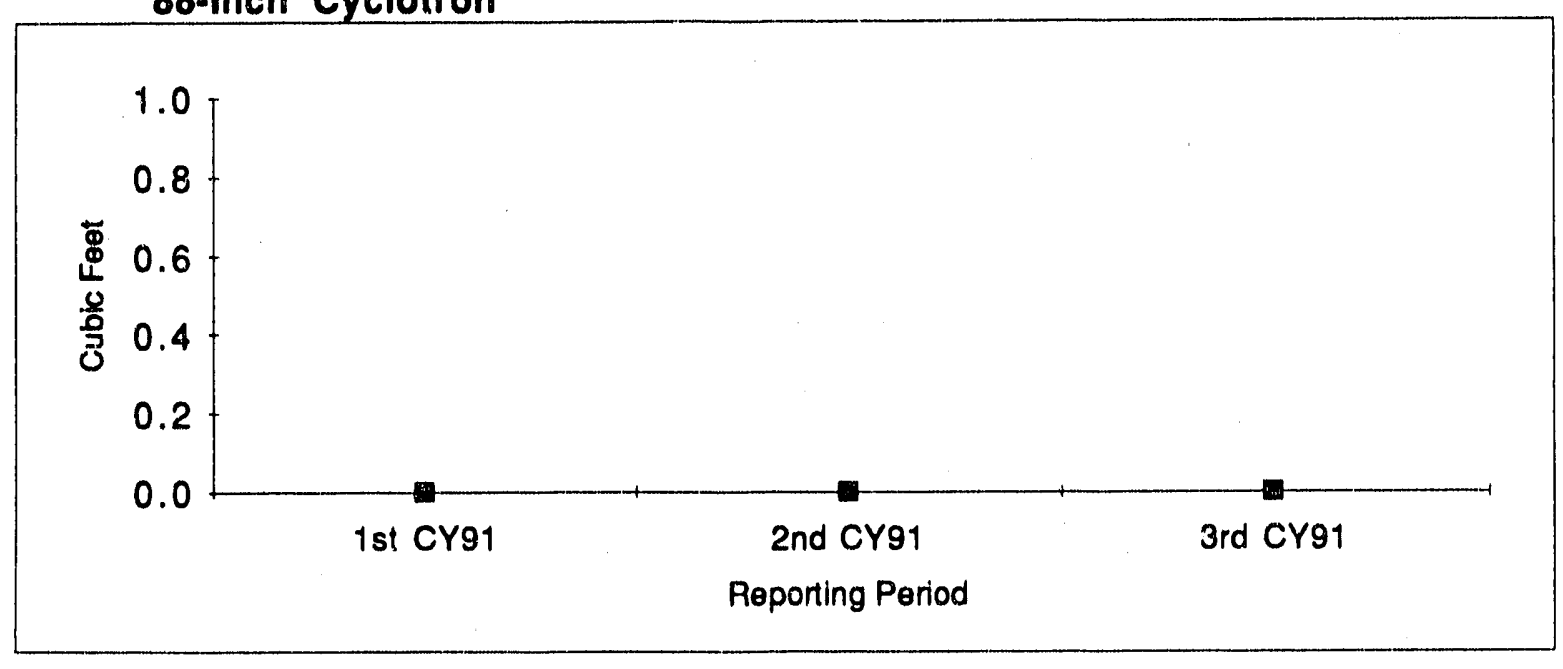

No low level mixed waste generated to date.

PI 4.7.3.3 


\section{Appendix 3: Performance Indicator Definitions}

This appendix provides descriptions of the 22 performance indicators of DOE facility performance. Comments on these definitions are anticipated from DOE contractors, Operations Office and Headquarters organizations. Based on the resolution of these comments, the performance indicator definitions may be revised with the numbering in SEN-29-91.

\subsection{Personnel Safety}

\subsection{Collective Radiation Dose}

Purpose: The purpose of this indicator is to measure the effectiveness of the facility radiation control program in maintaining facility personnel radiation exposures as low as reasonably achievable (ALARA).

Definition: The total external whole-body dose (deep and shallow) received by all facility personnel (including subcontractors and visitors) as measured by the primary dosimeter, i.e., thermoluminescent dosimeter (TLD), or film badge. Exposure measured by direct reading dosimeters should be included only for those periods or situations when more accurate data are not avallable. Collective radiation dose is reported in units of person-rem.

Notes: Data for this indicator are mainly collected quarterly by contractor. For reporting under this indicator, the data should be collected on a facility basis. It is recognized that the collective radiation dose for certain personnel (maintenance, health physicists, construction, etc.), due to their site-wide services, may be difficult to identify as resulting from exposure at a given facility. How these personnel are handled in each specific facility case should be discussed in the written descriptive statements that are provided with the data.

Data Needed: 1) Collective whole-body dose; by facility (units: person-rem)

\subsection{Skin Contaminations}

Purpese: The purpose of this indicator is to monitor progress in controlling radioactive contamination as a measure of the effectiveness of radiological work practices. A low number of contaminations indicates good radiological work practices, minimum contamination in areas intended to be free of contamination, and/or effective precautions for work in contaminated areas. This indicator is valuable for identifying adverse trends so that corrective actions can be taken.

Definition: The total number of confirmed skin and personal clothing contaminations for all facility personnel, including subcontractors and visitors. Skin or clothing contamination due to radioactive noble gases or naturally occurring radon gas are not included.

Data Needed: 1) Number of events, by facility 
Appendix 3: Performance Indlcator Definltions

\section{Internal Contaminations}

Pureese: The purpose of this indicator is to monitor the effectiveness of radiological control programs to limit the internal uptake and deposit of radiological materials by facility personnel.

Definition: The total number of confirmed intakes or radioactive material for all facility personnel, including subcontractors and visitors, occurring during the reporting period.

Data Needed: 1) Number of events, by facility.

\subsection{Radioactive or Hazardous Materials Overexposure}

Purpese: The purpose of this indicator is to measure the overall effectiveness of the facility radiation and hazardous material control programs that are established to ensure the prevention of overexposures.

Definition: The number of reportable occurrences resulting from a personnel exposure (for all facility personnel, including subcontractors and visitors) to radioactive or hazardous materials in excess of limits established in DOE Orders.

Data Needed: 1) Number of events, by facility

\subsection{Lost Work Day Cases (Lost Time Accident Rate)}

Purpese: The purpose of this indicator is to measure the progress in improving industrial safety performance for personnel permanently assigned to the facility. This indicator measures the number of accidents that are serious enough to require time off from work.

Definition: Number of incidents for all facility personnel involving days away from work per 200,000 person-hours worked (100 person-years)

Notes: The definition that was indicated at the January 10, 1991 meeting has been modified to clarify the intent. That is, it is intended that the number of lost work day cases be reported, rather than the number of days lost.

Rate $=(200,000$ hours $\times$ number of events $) /($ total hours worked $)$

Data Needed: 1) Number of events, 2) Total hours worked, by facility 


\subsection{Recordable Injurles/llinesses Rate}

Purpose: The purpose of this indicator is to measure thi progress in improving the industrial safety for personnel permanently assigned to the facility. By measuring all work-related injuries and illnesses meeting OSHA standards, this indicator measures all instances where work restrictions occur.

Deflnition: Total number of injuries or illness instances resulting from on-the-job activities that are recordable in accordance with OSHA standards, per 200,000 personhours worked.

Notes: The definition of this indicator has been modified since the January 10, 1991 meeting to normalize the data and thereby produce a recordable injury/iliness rate.

Rate $=(200,000$ hours $\times$ number of events $) /($ total hours worked $)$

Data Needed: 1) Number of events, 2) Total hours worked, by facillty

\subsection{Operational Incidents}

\subsection{Environmental Incidents}

Purpose: The purpose of this indicator is to measure the effectiveness of the facility programs and controls in place to minimize inadvertent releases of radioactive or hazardous materials to the environment.

Definition: The number of reportable occurrences, both on-site and off-site, involving an inadvertent radioactive or hazardous material spill or release.

Data_Needed: 1) Number of events, by facility

\subsection{Unplanned Safety Function Aciuations}

Purpose: The purpose of this indicator is to monitor progress in reducing the number of instances of significant abnormal facility conditions, requiring the actuation of facility safety functions (equipment/systems). In addition, this indicator monitors the unnecessary exercising of facility safety functions, due to spurious or inadvertent signals, which could result in those functions not being available when needed. Limiting the number of unplanned safety function actuations indicates that an adequate margin of safety is being maintained.

Definitions: The number of unplanned actuations of any safety function or facility safety systems that occur when an actuation setpoint for a safety function is reached or when a spurious or inadvertent signal is generated, and major equipment is actuated or demanded. Unplanned means that the actuation was not part of a planned test or evolution.

Notes: For the purpose of this program, a safety function or system shall be defined to be consistent with the DOE Order 5000.3A definition of "Class A equipment" - any active or passive safety device/system or any primary environmental monitors.

Data Needed: 1) Number of events, by facility. 


\subsection{Violations of Operating Procedures}

Purpose: The purpose of this indicator is to monitor the adequacy of faollity training programs which emphasize compliance with procedures that are intended to ensure safety and effective facility operations. This indicator is a measure of the effectiveness of the safety culture and discipline of the management and staff of the facility.

Definition: The number of instances where a failure of personnel to follow operation procedures resulted in a reportable occurrence.

Data Needed: 1) Number of events, by facility.

\subsection{OSHA Violations}

Eurpese: The purpose of this indicator is to monitor the adequacy of facility training programs which emphasize compllance with industrial safety standards, procedures and practices intended to ensure conduct of activities in a safe workplace. This indicator is a measure of the effectiveness of the safety culture and discipline of the management and staff of the facility.

Definition: The total number of times of noncompliance with OSHA standards.

Data Needed: 1) Number of events, by facility.

\subsection{Unplanned Shutdowns}

Purposes: The purpose of this indicator is to measure progress in minimizing unplanned shutdowns that result from equipment failures, persorinel errors and other causes. In the case of reactors, only automatic shutdowns are included. Manual shutdowns to protect equipment or mitigate consequences of a transient are not counted because operator initiated shutdowns and actions to protect equipment should be discouraged. This indicator reflects the effectiveness of facility programs that support operations and permit the facility to meet its intended mission. These facility programs include, but are not limited to, maintenance, training, and engineering support for correction of design problems. Experience has generally shown that facilities that operate with a high availability rate (i.e., minimal number of unplanned shutdowns) are usually well-maintained, are managed and staffed by personnel that are competent and follow good operating practices and can be expected to have a high margin of safety.

Definition: The number of unscheduled shutdowns of a facility, process or operation.

Data Needed: 1) Number of events, by facility. 


\subsection{Emergency and Unusual Occurrences}

Purpese: The purpose of this indicator is to provide an overall measure of the frequenoy of significant problems that arise at a facility. Reporting in accordance with DOE Order $5000.3 \mathrm{~A}$ provides the details of each occurrence. This indicator provides a measure of the safety culture existing at the facility and the degree of control being maintained over the activities being conducted. Repeated significant problems are an indication of potentially reduced margins of safeiy for facility operations.

Definition: The number of Emergency and Unusual Occurrences reported in accordance with DOE Order 5000.3A, "Occurrence Reporting and Processing of Operations Information."

Data Needed: 1) Number of events, by facility

\subsection{Environmental Releases (Normal Operations)}

\subsection{Radionuclide Effluent Releases}

Purpese: The purpose of this indicator is to measure the effectiveness of radiological effluent control programs in place to minimize radionuclide releases to the environment.

Definition: Separate reporting for airborne and liquid releases to the environment, as measured at the point of release, for the following radioniuclides: plutonium, uranium, noble gases, particulates (including radiocesiums and radiostrontium and activation products), radioiodine, tritium, and other actinides.

Data shall be cumulative over the reporting period and reported in units of curies.

Data Needed: 1) Airborne, curies (2) liquid, curies; by facillites.

\subsection{Hazardous Substances/Requlated Pollutant Effluent Releases}

Purpese: The purpose of this indicator is to measure the effectiveness of the facility programs in place to control and minimize releases to the environment of hazardous substances and regulated pollutants.

Definition: Separate reporting of the amounts of "permitted" airborne and liquid nonradioactive releases. All hazardous substances and regulated pollutants that are listed in permits (e.g., Clean Air Act or NPDES permits) or otherwise reported to regulators (e.g., through SARA Title III, Section 313 reporting requirements) are included. Data shall be cumulative over the reporting period and reported in units of pounds or gallons.]

Data Needed: 1) Airborne, cumulative pounds 2) Liquid: cumulative gallons; by facility. 


\subsection{Envilronmental Monltering Data}

Purnese: The purpose of this indloator is to measure the effectiveness of on-site programs to control radiological releases, and off-site programs to monitor radioactive materials in the environment from faollity activities.

Definition: DOE 5400 series orders and guidance specify parameters, conditions and frequencies for environmental monitoring. Environmental monitoring data shall be reported in accordance with applicable site reporting requirements. These data include but are not limited to that for water (surface and ground), air, sediment, food and vegetation, milk, solid and direct radiation levels.

Notes: This indicator is intended, conceptually, to provide DOE management with information regarding the Department's off-site monitoring programs. As discussed at the January 10, 1991 meeting, it is difficult to specifically define this indicator and it was requested that input be provided to ald in this effort. Therefore. until such time that further auldance is developed, ne data should be reponted for this indicator

Date Needed: As required by site specific monitoring requirements; by site.

\subsection{Management}

\subsection{Open DOE Audit Issues}

Purpese: The purpose of this indicator is to measure the responsibility of facility management and staff to findings, concerns and recommendations from oversight and line program assessments. This PI provides an indication of the management control and staff attitude toward improvements in the conduct of facility activities and openness to suggestions of outside DOE organizations.

Definltien: The total number of findings, including concerns and recommendations requiring corrective actions, by oversight assessments and line program self-assessments for which contractor corrective actions have not been completed at the time of this report.

Notes; It is intended that the total number of issues which require contractor corrective actions, for which all corrective actions have not been completed, be reported for this indicator rather than the total number of open corrective actions. In addition, it is the intent that the issues reported be limited to those dealing with environment, safety and health and exclude, so as not to be duplicative, the data reported under OSHA violations.

Data Needed: 1) Number of issues, by contractor 


\subsection{Open External Oraanizations Recommendations}

Purpese: The purpose of this indicator is to measure the responsiveness of DOE and facility management and staff to findings, concerns arid recommendations from external organizations. This $\mathrm{PI}$ provides an indication of the management control and staff attitude toward improvements in the conduct of facility activities and openness to suggestions of external organizations.

Definition: The total number of recommendations by external organizations, such as the Advisory Committee on Nuclear Facility Safety, the Defense Nuclear Facility Safety Board, the National Academy of Sclences, etc., directed to specific contractors or their facility operations, for which contractor corrective actlons have not been completed at the time of the report.

Netes: As for the previous indicator, it is intended that the total number of recommendations, with open corrective actions, be reported here, rather than the total number of open corrective actions.

Data Needed: 1) Number of recommendations, by contractor

\subsection{Occurrence Reperts with Open Corrective Actions}

Purpese: The purpose of this indicator is to measure the commitment of DOE line program management and facility management and staff to taking timely correctlve actions for improving facillty operation and safety margins. This $\mathrm{PI}$ is an indication of the safety culture of the facility personnel by demonstrating follow-up and applying lessons-learned from occurrences.

Definition: The number of Final Occurrence Reports for which all corrective actions have not been completed at the time of the report.

Data Needed: 1) Number of final reports with open corrective actions, by facillty. 


\subsection{Corrective Malntenance Backlog}

Purnose: The purpose of this indicator is to measure the effectiveness of the programs in place to ensure necessary and timely repairs are made to facility equipment. Maintaining a small backlog is an indication of management control and staff concern regarding the material and safety status of the facility. It is a measure of effective planning, scheduling, coordination and materlals management. Keeping long-standing deficiencles to a minimum enhances the ability to operate the facility and encourages facllity personnel to report deficiencies.

Definition: The percentage of open corrective maintenance work requests, including those requiring facility or process shutdown, that are greater than three months old at the end of the reporting period. Corrective maintenance may include minor modifications if performed under a corrective maintenance work request.

Netes: The definition corrective maintenance is as follows:

Cerrective (Repair) Malntenance: The repair of falled or malfunctioning equipment, system or facility to restore the intended function or design conditions. This maintenance does not result in a significant extension of the expected useful life.

Data Needed: 1) Number of open items $>3$ months old, 2) total number of open items; by facility.

\subsection{Preventive Maintenance Overdue}

Purpose: The purpose of this indicator is to monitor progress in the administration and execution of facility preventive maintenance programs. A small percentage of preventive maintenance items overdue indicates a management and staff commitment to the preventive maintenance program and an ability to plan, schedule and perform preventive maintenance tasks as programs require. A facility with a good preventive maintenance program should require less emergency maintenance, which may be reflected in improved safety and reliability and more efficient operation.

Definition: The percentage of preventive maintenance items that were not completed within the originally scheduled interval.

Notes: The definition of preventive maintenance is as follows:

Preventive Maintenance; All those systematically planned and scheduled actions performed for the purpose of preventing equipment, system or facility fallure.

In addition, it is the intent that, if a facility maintenarice program is such that the scheduled time interval includes a grace period (1.e., $\pm 25 \%$ of the frequency of the maintenance), the item would not be considered overdue until that grace period has expired.

Dota Needed: 1) Number of events, by facility 


\subsection{Substance Abuse Incidents}

Purpose: The purpose of this Indicator is to measure the effectiveness of DOE and facility specific fitness-for-duty programs. Individuals involved with controlled substances contribute to unsafe operating conditions and undermine efforts to accomplish the faolity mission.

Definition: The number of reportable occurrences involving personnel use, possession or involvement of/with controlled substances, e.g., drugs, alcohol, etc.

Data Needed: 1) Number of events, by facility

\subsection{Volume of Solld Waste Generated}

Purpese: The purpose of this indicator is to monitor progress toward reducing the volume of solid low-level radioactive, hazardous and/or mixed waste destined for disposal. Reducing the volume will decrease storage, transportation and disposal needs and will decrease the environmental impact of such operations.

Definition: The total volume, in cuble feet, of solid low level radioaotive and/or hazardous and/or mixed waste generated during the reporting perlod, separately reported, by facility.

Note: In response to comments and concerns raised during the meeting on January 10 , 1991, the category of mixed waste has been added to the definition of this indicator. The reporting units shall be cubic feet. It is understood that all hazardous waste, regardless of the form, is considered to be solid waste.

\section{Data_Needed: (by facility)}

Badioactlive waste:

1) Volume generated

2) Volume in final form, pending shipment

3) Volume shipped for disposal

Hazardous waste:

1) Volume generated

2) Volume in final form, pending shipment

3 ) Volume shipped for disposal

Mixed waste:

1) Volume generated

2) Volume in final form, pending shipment

3) Volume shipped for disposal 


\section{Appendix 4: Root Cause Narratives}

Following are brief descriptions by Periormance Indicator of those incidents which require the root cause to be reported. Included are the Occurrence Report riumber and title, the date of discovery, the rooi cause, and the description of cause.

\subsection{Skin Contaminations}

No incidents to date.

\subsection{Internal Contaminations}

No incidents to date.

\subsection{Badloactive/Hazardous Materlal Overexposures}

(1) OR number : SAN-LBL-AFRD-1990-0028 (Elevated Personal Dosimeter Reading)

Discovered : 12/19/1990 (4th qtr. CY-1990)

Root cause : Management (Policy not adequately defined, disseminated, or enforced)

Description of cause:

A warning chime was relocated at least 5 years ago. The relocation involved turning the chime on its side, which made It inaudible, although th checked out electrically. At the time, no procedure existed for modification approval of personnel protective systems. A contributing cause was the design of the push button inside the cave, which allowed it to be routinely bypassed. The root cause is Bevalac management's failure to define a policy requiring any modification of a personnel protective system to undergo review and approval, no matter how slight the intended modification. 


\subsection{Envilronmental Incidents}

(1) OR number : SAN-LBL-AFRD-1990-0007 (Possible PCB Contamination)

Discovered : 11/16/1990 (4th qtr. CY-1990)

Root cause : Management (Polloy not adequately defined, disseminated, or enforced)

Description of cause:

The drain system, designed in 1950, did not separate the bullding drain system from that needed to remove ground water. The design appears to ensure that all substance entering the building drains mix with ground water. No procedures were in place in 1971, when the PCB spill occurred, to ensure that hazardous materlal spills in the building would not enter the bullding drain systern, contributing to the cause. Management of the facility never looked into the design of the drain system with respect to ground water contamination. This fallure allowed a system potentially dangerous to the environment to exist, and should be considered to the root cause.

(2) OR number: SAN-LBL-AFRD-1991-1001 (Freon Spill)

Discovered : 04/04/1991 (2nd qtr. CY-1991)

Root cause : Management (Inadequate administrative control)

Description of cause:

An older type of compression fitting failed about 14 hours after an injector cooling system was turned on, releasing Freon. More comprehensive inspections of the systern after iurnon including use of a Freon leak detector, might have detected the failure in its early stages. Management should ensure that potentlally hazardous systems, such as those which contain large amounts of Freon, are routinely checked for leaks, especially following system turn-on. Management failure to define an inspection procedure as part of system turn-on shouid be considered the root cause. 


\subsection{Environmental Incidenis (cont.)}

(3) OR number : SAN-LBL-MSD-1991-1001 (Sanitary Sewer Overflow into a Storm Drain)

Discovered : 04/26/1991 (2nd qtr. CY-1991)

Root cause : Personnel error (Violation of requirement or procedure)

Description of cause:

Paper towels and sanitary napkins are being flushed down the tollets. This practice results in clogged drain pipes. Although there are informal signs in some of the restrooms advising employees of the proper disposal of these ltems, management has not stressed the importance of adhering to this notice. "Otficial" signs will be purchased and installed in each restroom addressing the proper disposal of these ltems.

\subsection{Violations of Operating Procedures}

(1) OR number : SAN-LBL-MSD-1991-1002 (Improper Storage of Methyl Chloromethyl Ether) Discovered : 02/01/1991 (1st qir. CY-1991)

Root cause : Procedure (Lack of Procedure)

Description of cause:

When the material was purchased, personnel were not immediately provided information relating to OSHA Lab Safety Standards. Laboratory personnel falled to read MSDS indicating improper training. UC Campus EH\&S was unaware MCME was in laboratory. A new action plan has been implemented to identify carcinogens when ordered and that appropriate handling and storage standards are in place.

(2) OR number : SAN-LBL-NSD-1991-1001

(Violation of Safety Requirements at the 88-Inch Cyclotron)

Discovered : 05/17/1991 (2nd qir. CY-1991)

Root cause : To Be Determined

Description of cause:

Incident under investigation. Causes are yet to be determined.

\subsection{Unplanned Shutdowns}

No incidents to date. 


\subsection{Emergencies and Unusual Occurrences}

(1) OR number : SAN-LBL-MSD-1991-1003

(Fire Presumed to be of Electrical or Chemical Origin)

Discovered : 04/25/1990 (2nd qtr. CY-1990)

Root cause : Design (Inadequate or defective design)

Description of cause:

Fire resulted from sparks coming from battery experiment into excessive combustible materials. Experiment was unattended and lacking proper safety devices.

(2) (i, number : SAN-LBL-AFRD-1990-0028 (Elevated Personal Dosimeter Reading)

Discovered : 12/19/1990 (4th qtr. CY-1990)

Root cause : Management (Policy not adequately defined, disseminated, or enforced)

Description of cause:

(See item \#1 under 1.4 Radioactive/Hazardous Material Overexposures above)

(3) OR number : SAN-LBL-AFRD-1991-1001 (Freon Spill)

Discovered : 04/04/1991 (2nd qtr. CY-1991)

Root cause : Management (Inadequate administrative control)

Description of cause:

(See item \#2 under 2.1 Environmental Incidents above)

(4) OR number: SAN-LBL-MSD-1991-1004 (Possible PCB Contamination)

Discovered : 05/16/1991 (2nd qtr. CY-1991)

Root cause : Equipment/Material (Defective or failed part)

Description of cause:

An oil filled capacitor, as a component of an isolation/constant voltage transformer, failed in service. This unit was PCB filled and over 20 years old. Under current regulations and conditions, this is not a preventable situation as this small quantity of PCB is "nonreportable" and not marked on either the capacitor or transformer. 


\subsection{Emergencies and Unusual Occurrences (cont.)}

(5) OR number : SAN-LBL-NSD-1991-1001

(Violation of Safety Requirements at the 88-Inch Cyclotron)

Discovered : 05/17/1991 (2nd qtr. CY-1991)

Root cause : To Be Determined

Description of cause:

(See item \#2 under 2.3 Violations of Operating Procedures above)

\subsection{Substance Abuse Incidents}

No incidents to date. 


\section{Appendix 5: Errata}

Following is the latest Performance Indicator data errata for the first, second, and third quarters of CY-1991. Although most of this was included in the third quarter errata report dated 11/27/91, a few more errors have come to light, namely, PI 2.3 (Violation of Operating Procedures) in the first quarter data, PI 2.6 (Unusual Occurrences) in the second quarter data, and PI 1.1 (Collective Radiation Dose) in the third quarter data.

\section{First Quarter CY-1991 Errata}

\subsection{Lost Work Day Cases (Lost Time Accident Rate) (1st Qtr. CY-1991)}

The total hours worked given for the three LBL facilities were for one month only.

- Correct daia

$\begin{array}{lrrrr} & \text { Total } & \text { MSD } & \text { Bevalac } & \text { 88" cycle } \\ \text { Number of Events } & 2 & 0 & 1 & 1 \\ \text { Total hours worked } & 170,920 & 96,000 & 65,000 & 9,920 \\ \text { Lost Time Accident Rate } & 2.34 & 0.00 & 3.08 & 20.16\end{array}$

\subsection{Violation of Operating Procedures (1st Qtr. CY-1991)}

Originally reported as zero for all facilities, zero total. In fact, there was one incident in the Materials Sciences Division (SAN-LBL-MSD-1991-1002). The root cause for this occurrence was "lack of procedure".

- Correct data: one for MSD, zero for Bevalac, zero for 88" Cyclotron, one total.

\subsection{Occurrence Reports with Open Corrective Actions (1st Qtr. CY-1991)}

Originally the number of reports was given as two for the Bevalac, two total. Upon reexamination, we find that there were in fact two for the MSD (Nos. SAN-LBL-MSD-19911002, -1003) and three for the Bevalac (Nos. SAN-LBL.AFRD-1991-0028, -1001, 1007), five total.

- Correct data: two for MSD, three for Bevalac, zero for 88 " Cyclotron, five total.

\section{Second Quarter CY-1991 Errata}

\subsection{Radioactive/Hazardous Materials Overexposures (2nd Qtr. CY-1991)} Originally reported as one event for the Bevalac (LBL-90-28-51-8), one total. The event reported for the Bevalac occurred in 1990 and should not have been reported.

- Correct data: zero for all facilities, zero total. 


\subsection{Environmental Incidents (2nd Qtr. CY-1991)}

Originally reported as one event for the MSD (LBL-MSD-1991-1001) and two for the Bevalac (LBL-AFRD-1990-0007 and LBL-AFRD-1991-1001), three total. LBL-AFRD-1990-0007 occurred in 1990 and should not have been reported.

- Correct data: one for MSD, one for Bevalac, zero for 88" Cyclotron, two total.

\subsection{Violations of Operating Procedures (2nd Qtr. CY-1991)}

Originally reported as one event for the Bevalac (LBL-90-28-51-8) and one for the $88^{\text {" }}$ Cyclotron (LBL-NSD-1991-1001), two total. The violation at the Bevalac should not have been reported (see 1.4 above).

- Correct data: zero for MSD, zero for Bevalac, one for 88" Cyclotron, one total.

\subsection{Emergency and Unusual Occurrences (2nd Qtr. CY-1991)}

Originally reported as one for the Bevalac (SAN-LBL-AFRD-1991-1001), and one for the 88" Cyclotron (SAN-LBL-NSD-1991-1001), two total. There was also and unusual occurrence in the MSD (SAN-LBL-MSD-1991-1004), which had "material" as its root cause.

- Correct data: one for MSD, one for Bevalac, one for 88" Cyclotron, three total.

\subsection{Occurrence Reports with Open Corrective Actions (2nd Qtr. CY-1991)}

Originally reported as zero entries for all facilities due to a misinterpretation. Actually there were four for the MSD (Nos. SAN-LBL-MSD-1991-1001, -1002, -1003, -1004), iwo for the Bevalac (Nos. SAN-LBL-AFRD-1991-0028, -1007), and one for the 88" Cyclotron (SANLBL-NSD-1991-1001). Seven total.

- Correct data: four for MSD, two for Bevalac, one for 88" Cyclotron., seven total.

\section{Ihird Quarter CY-1991 Errata}

\subsection{Collective Radiation Dose (3rd Qtr. CY-1991)}

On the Third Quarter data sheet submitted on 11/27/91, the collective radiation dose data was reported as 0.089 person-rem for the MSD, 0.180 for the Bevalac, and 0.296 for the $88^{\prime \prime}$ Cyclotron, 0.565 person-rem total. These figures are in error. The correct figures follow:

- Correct data (in person-rem): 0.049 for the MSD, 0.099 for the Bevalac, 0.168 for the 88" Cycloiron, 0.316 total. 


\section{DISCLAIMER}

This document was prepared as an account of work sponsored by the United States Government. Neither the Unuted States Government nor any agency thereof, nor The Regents of the University of Callfornia, nor any of their employees, makes any warrenty, express or im. plied, or assumes any legal liability or responsibility for the accuracy, completeness, or usefulness of any information, apparatus, product, or procese disclosed, or represents that its use would not infringe privately owned rights. Reference herein to any specific commercial product, process, or service by lts trade name, trademark, manufacturer, or otherwise, does not necessarlly constitute or imply its endorsement, recommendation, or favoring by the United States Government or any agency thereof, or The Regents of the University of Calfornia. The views and opintons of authors expressed herein do not necessarily state or reflect those of the United States Covernment or any agency thereof or The Regents of the University of California and shall not be used for advertlsing or product endorsement purposes.

Lawrence Berkeley Laboratory is an equal opportunity employer. 

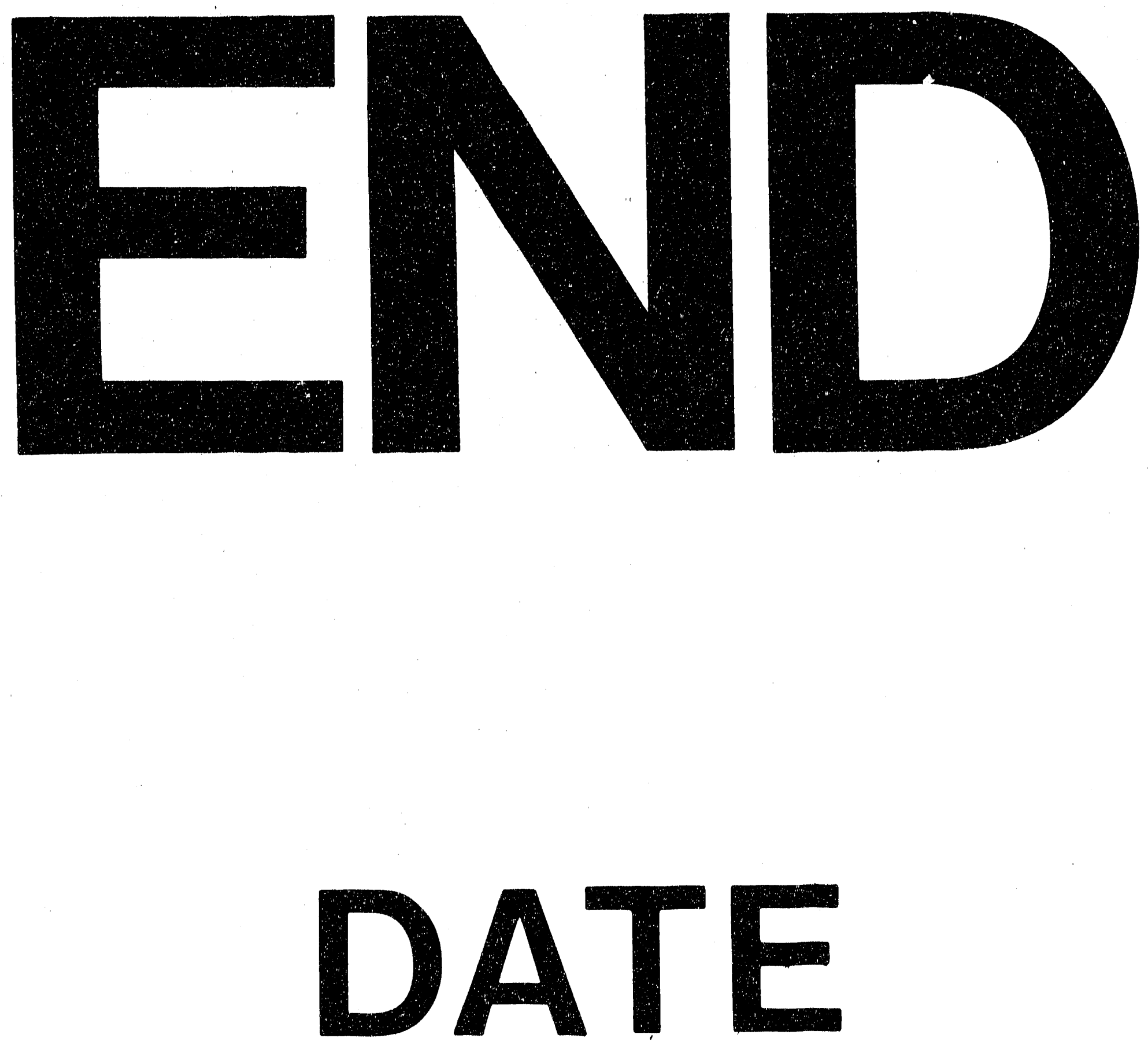

4
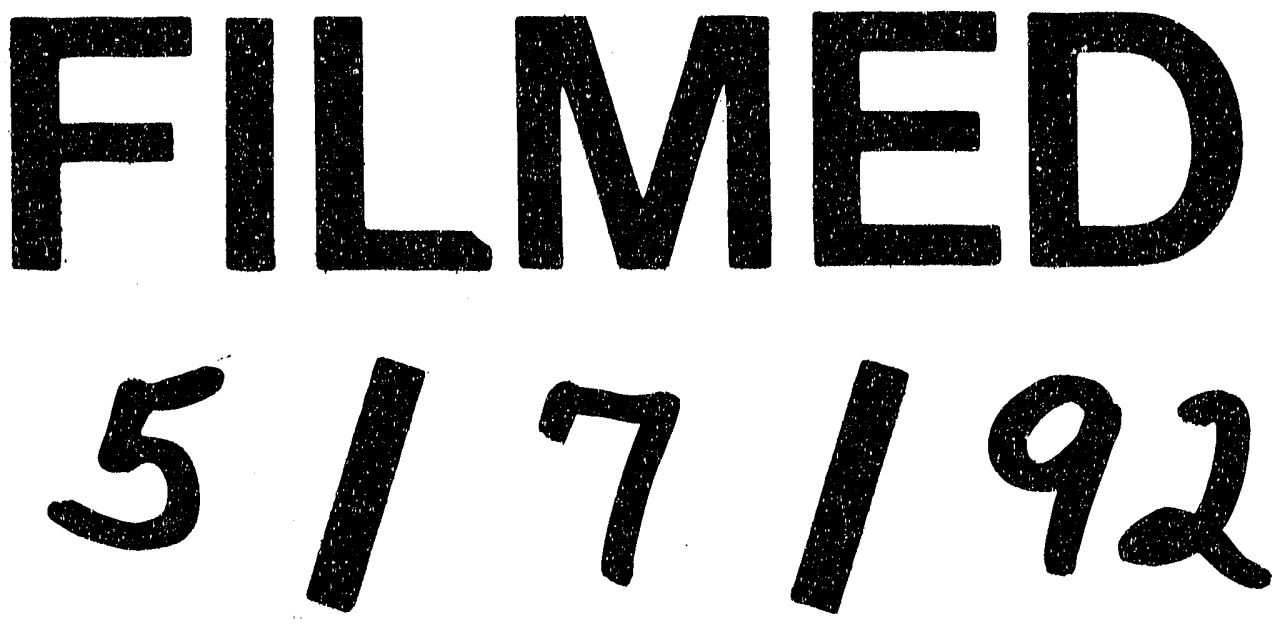

1 
